\title{
Alice Baldissera
}

\section{ESTUDO EXPERIMENTAL DE UMA LIGAÇÃO VIGA- PILAR DE CONCRETO PRÉ-MOLDADO PARCIALMENTE RESISTENTE A MOMENTO FLETOR}

Dissertação apresentada à Escola de Engenharia de São Carlos, da Universidade de São Paulo, como parte dos requisitos para obtenção do Título de Mestre em Estruturas.

Orientador: Prof. Assoc. Mounir Khalil El Debs

São Carlos 
Ao professor Mounir Khalil El Debs pela orientação, dedicação e amizade.

Aos meus pais Suzana e Vilmar e minha irmã Catarina pela educação dada, o carinho e apoio incondicional.

A toda a minha família que me ajudou incentivando e torcendo para que tudo desse certo.

Ao meu noivo Jose Edival pela paciência, amor e as conversas quando à distância de casa apertava.

Aos amigos que fiz em São Carlos, em especial a Danusa, Thais, Tati, Karenina, Gláucia, Lívia, Daniela, Danilo, Ricardo, Marlos, Codá, Gustavo, Eduardo, Eimair e a Sandra.

A Tati e Edson pela paciência em ensinar o ANSYS.

As minhas grandes amigas de Recife, Mirella e Izabela, pela amizade e apoio onde quer que esteja.

Aos professores do Departamento de Engenharia de Estruturas de EESC-USP.

Aos funcionários do Departamento de Estruturas da EESC-USP, em especial a Rosi Rodrigues e Nadir Minatel.

A toda a equipe do laboratório de estruturas EESC-USP, em especial Amaury e Luiz Vareda.

A todos que de uma forma ou de outra contribuíram não só para a conclusão de mais uma etapa, como tornaram estes dois anos inesquecíveis. 


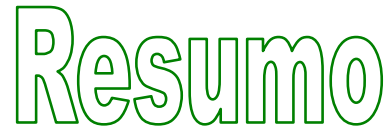

BALDISSERA, A. (2006). Estudo experimental de uma ligação viga-pilar de concreto pré-moldado parcialmente resistente a momento fletor. Dissertação (Mestrado) - Escola de engenharia de São Carlos, Universidade de São Paulo, São Carlos. 2006.

Neste trabalho estudou-se o comportamento de uma ligação viga-pilar de estrutura prémoldada parcialmente resistente a momento fletor quando submetida a momentos negativos e positivos. A ligação estudada é composta por dois chumbadores inclinados presos à viga através de chapas metálicas, porcas e arruelas e uma capa de concreto com armadura longitudinal passando por dentro do pilar. No programa experimental foram elaborados dois modelos submetidos a carregamentos alternados, em ciclos e de curta duração. Em seguida foi desenvolvido um modelo analítico para cálculo dos momentos resistentes e feita uma simulação numérica para avaliar a influência da semi-rigidez da ligação em estruturas típicas de concreto pré-moldado. Os resultados experimentais indicaram que a ligação apresenta uma boa capacidade de transmissão a momento fletor negativo e a momento fletor positivo com um comportamento bastante dúctil. Sem a necessidade de grandes alterações de custos e de execução a ligação proposta promoveu uma redução significativa dos momentos na base dos pilares (aproximadamente $50 \%$ ) quando comparado à ligação articulada. Quando comparada à ligação similar, porém com os chumbadores retilíneos, há um aumento superior a 2,5 vezes no momento de plastificação e de 2 vezes na rigidez no sentido do momento fletor positivo.

Palavra-chave: estruturas de concreto, concreto pré-moldado, ligação viga-pilar, ligação semi-rígida, ligação viga-pilar parcialmente resistente a momento fletor. 
BALDISSERA, A. (2006). Experimental study of a partial moment resistant beam-tocolumn connection in precast concrete. Dissertation - Escola de engenharia de São Carlos, Universidade de São Paulo, São Carlos. 2006.

In this research the behavior of a partial moment resistant beam-to-column connection in precast concrete subjected to negative and positive moments was studied. This connection has two inclined dowels fixed to the beam with steel plate, washer and nut and a concrete cap with longitudinal reinforced bars passing trough the column. In the experimental program two prototypes was made and subjected to an alternative cyclic e short duration load. Afterwards it was develop an analytical model and a numerical simulation to analyze the influence of the semi-rigid connection in a typical precast structure. The experimental results shown that the connection has a good capacity of transmitte the bending moments and has a ductile behave. Without any significative difference of cost and manufacture the connection studied promoted a reduction on the column base bending moment (approximately $50 \%$ ) when compared to pinned connection. When compared to similar structures but with a vertical dowel, the connection presents a moment resistance over 2.5 times and over 2 times the stiffens for positive moments.

Key-words: concrete structures, precast concrete, beam-to-column connection, semirigid connection, partial moment resistance beam-to-column connection. 


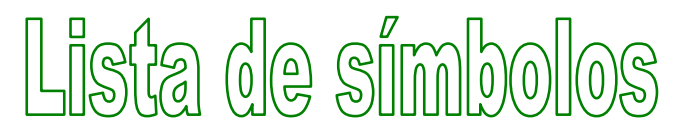

$$
\begin{array}{ll}
\phi & \text { - Rotação } \\
M & \text { - Momento atuante } \\
S_{j} & \text { - Rigidez da ligação } \\
M_{j, E d} & \text { - Momento solicitante de projeto na ligação } \\
M_{j . R d} & \text { - Momento resistente de projeto da ligação } \\
\eta & \text { - Fator redutor da rigidez da ligação } \\
E & \text { - Módulo de elasticidade } \\
I_{b} & \text { - Momento de inércia da viga } \\
I_{c} & \text { - momento de inércia do pilar } \\
L_{b} & \text { - Vão da viga } \\
L_{c} & \text { - Altura do pilar } \\
K_{b} & \text { - Razão entre } I_{b} \text { e } L_{b} \\
K_{c} & \text { - Razão entre } I_{c} \text { e } L_{c} \\
d & \text { - Profundidade da viga } \\
b_{j} & \text { - Largura do pilar } \\
M_{p l, R d} & \text { - Momento de plastificação de projeto da viga conectada } \\
M_{b . p l, R d} & \text { - Momento de plastificação de projeto da viga } \\
M_{c, p l, R d} & \text { - Momento de plastificação de projeto do pilar } \\
F_{i} & \text { - Força na mola i } \\
\Delta_{i} & \text { - Deslocamento na mola i } \\
K_{i} & \text { - Rigidez da mola i } \\
F_{R d} & \text { - Força de projeto } \\
\tau_{b} & \text { - Braço de alavanca } \\
T_{\text {maxima de aderência }} & \text { - Tensão de aderência }
\end{array}
$$




\begin{tabular}{|c|c|}
\hline$S$ & - Deslizamento \\
\hline$f_{c k}$ & - Resistência à compressão do concreto \\
\hline$\tau_{y}$ & - Tensão de aderência no escoamento da barra \\
\hline$w_{u}$ & - Abertura de fissura em uma única interface \\
\hline$w_{u i}$ & - Abertura de fissura em duas interfaces \\
\hline$F_{y}$ & - Força correspondente ao escoamento da armadura tracionada \\
\hline$F_{u}$ & - Força última na armadura tracionada \\
\hline$\phi_{d}$ & - Diâmetro da armadura \\
\hline$f_{y}$ & - Tensão de escoamento do aço \\
\hline$E_{s}$ & - Módulo de elasticidade do aço \\
\hline$F_{p}$ & - Força responsável pela formação da segunda rótula plástica no chumbador \\
\hline$\phi_{c h}$ & - Diâmetro do chumbador \\
\hline$c_{1}$ & - Coeficiente para consideração do efeito de compressão tri-axial \\
\hline$f_{c c, \text { max }}$ & $\begin{array}{l}\text { - Maior valor de resistência à compressão dentre os elementos que envolvem } \\
\text { o chumbador }\end{array}$ \\
\hline$M_{y, \text { red }}$ & - Momento de plastificação do chumbador no ponto de fixação \\
\hline$M_{y}$ & - Momento de plastificação do chumbador \\
\hline$\alpha_{c r i t}$ & - Deformação angular crítica \\
\hline$h_{a}$ & - Altura livre entre os elementos de concreto que envolve o chumbador \\
\hline$\mu_{s}$ & - Coeficiente de atrito na interface \\
\hline$\sigma_{n}$ & - Tensão atuante no chumbador quando há a formação da rótula plástica \\
\hline$D_{j}$ & - Deformabilidade da junta \\
\hline$f_{c j}$ & - Resistência à compressão dos corpos-de-prova na data j \\
\hline$N$ & - Carga de ruptura à compressão \\
\hline$A$ & - Área da seção do corpo-de-prova \\
\hline$f_{c t, s p}$ & - Resistência à tração por compressão diametral \\
\hline$F$ & - Forma máxima aplicada no corpo-de-prova \\
\hline$d$ & - Diâmetro do corpo-de-prova \\
\hline$h$ & - Altura do corpo-de-prova \\
\hline$f_{u}$ & - Tensão de ruína das barras de aço \\
\hline$M_{y p}$ & - Momento de plastificação da ligação no sentido do momento fletor positivo \\
\hline
\end{tabular}


$M_{y n} \quad$ - Momento de plastificação da ligação no sentido do momento fletor negativo

$\phi_{y p} \quad$ - Rotação correspondente ao momento de plastificação no sentido do momento fletor positivo

$\phi_{y n} \quad$ - Rotação correspondente ao momento de plastificação no sentido do momento fletor negativo

$\varepsilon_{\text {concreto }}$ - Deformação por compressão do concreto pré-moldado

$L_{1} \quad$ - Comprimento do relógio comparador

$\sigma_{\text {concreto }}$ - Tensão de compressão no concreto pré-moldado

$E_{\text {concreto }} \quad$ - Módulo de elasticidade do concreto pré-moldado

$x \quad$ - Linha neutra

I $\quad$ - Momento de inércia

$\Delta l_{r e l} \quad$ - Leitura do relógio comparador

$\varepsilon_{\text {capa }} \quad$ - Deformação por tração do concreto da capa

$\sigma_{\text {capa }} \quad$ - Tensão de tração no concreto da capa

$E_{\text {capa }} \quad$ - Módulo de elasticidade do concreto da capa

$x_{1} \quad$ - Linha neutra no estádio I

$I_{1} \quad$ - Momento de inércia no estádio I

F $\quad$ - Força aplicada na viga

$F_{a l} \quad$ - Força de compressão na almofada de apoio

$F_{s} \quad$ - Força de tração na armadura da capa de concreto

$F_{g} \quad$ - Força de compressão do graute entre a viga e o pilar

$f_{c, a l} \quad$ - Resistência à compressão da almofada de apoio

$l_{c} \quad$ - Comprimento do consolo

b - Largura do consolo

$f_{c g} \quad$ - Resistência à compressão do graute de preenchimento entre a viga e o pilar

$A_{s n} \quad$ - Área da armadura da capa de concreto

$z_{n} \quad$ - Braço de alavanca para momento fletor negativo

$l_{c n} \quad$ - Comprimento entre o ponto de aplicação da carga ao ponto C

$l_{e} \quad$ - Comprimento entre o ponto de aplicação da carga e o eixo do pilar 


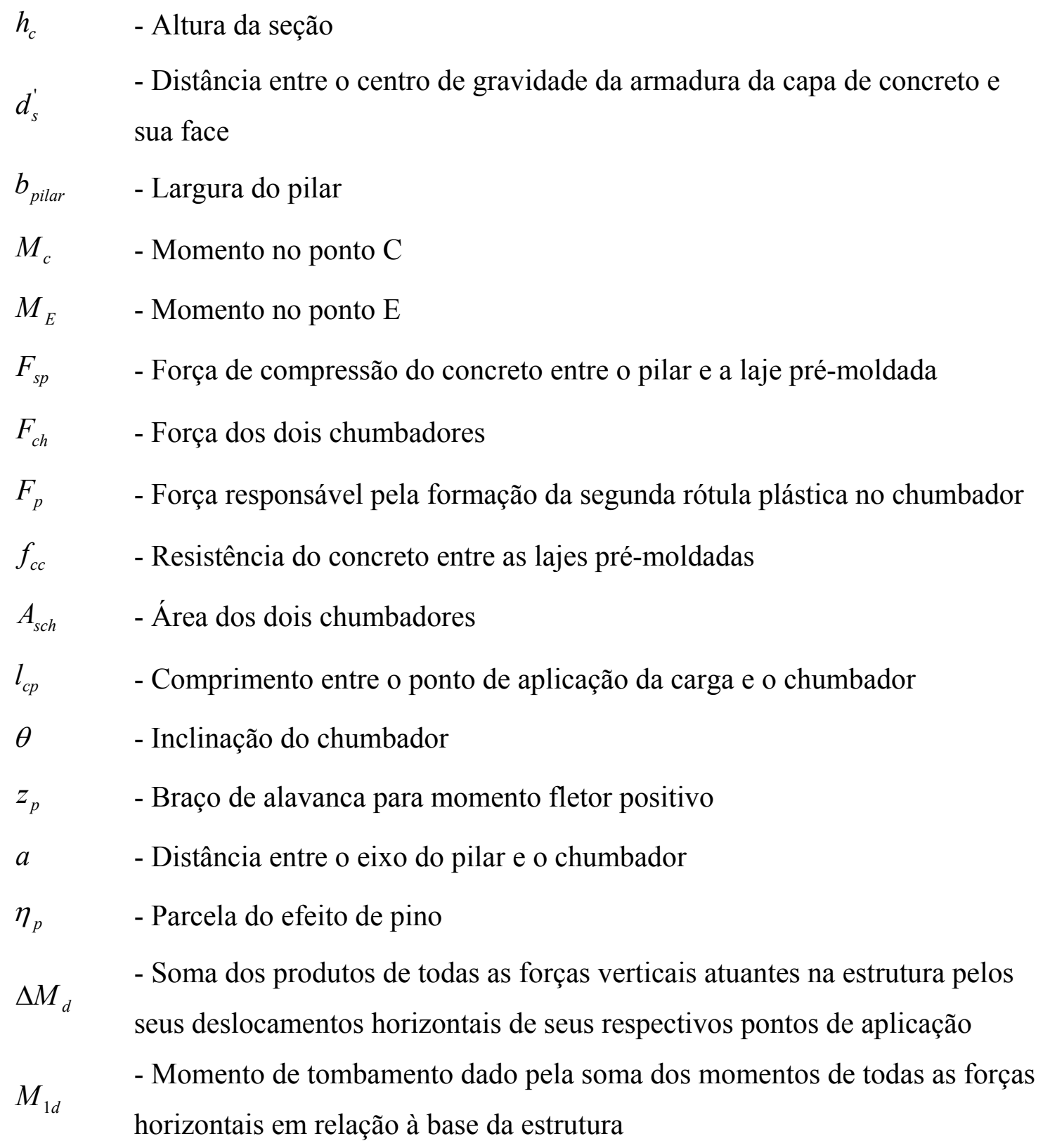




\section{SUMÁRIO}

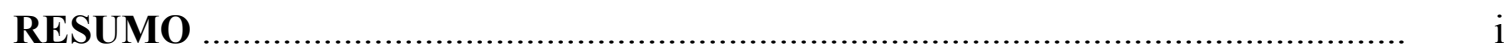

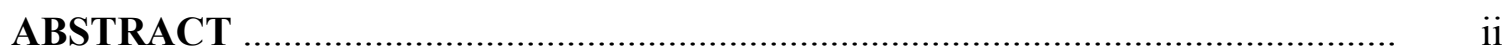

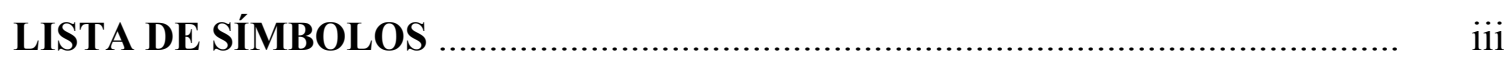

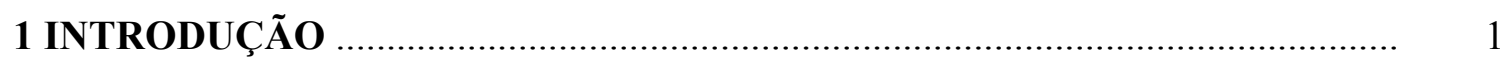

1.1 Considerações iniciais ...................................................................................... 1

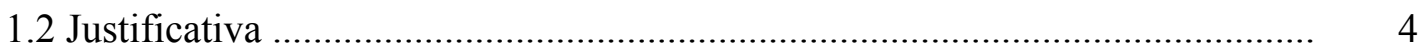

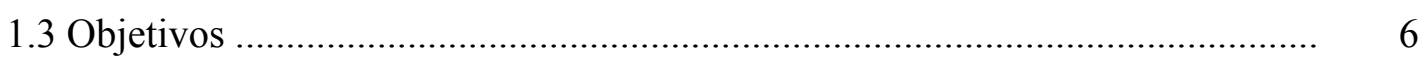

1.4 Apresentação do trabalho .................................................................................... 6

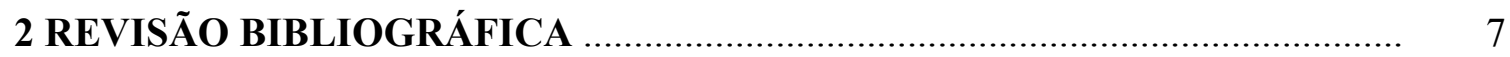

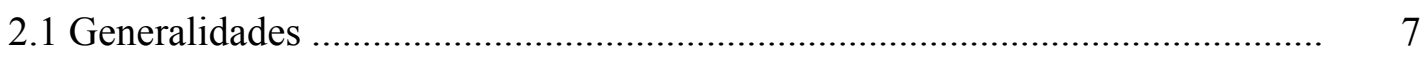

2.2 Classificação das ligações .............................................................................. 10

2.2.1 Classificação quanto à rigidez ......................................................... 11

2.2.2 Classificação quanto à resistência ..................................................... 13

2.3 Determinação do comportamento de ligações semi-rígidas ............................. 15

2.3.1 Procedimentos gerais ..................................................................... 15

2.3.2 Mecanismos básicos de deformação ..................................................... 18

2.3.2.1 Transferência de forças de tração ............................................. 19

2.3.2.2 Transferência de forças de cisalhamento ................................. 23

2.3.2.3 Transferência de forças de compressão .................................... 27

2.4 Principais estudos realizados ....................................................................... 28

3 PROGRAMA EXPERIMENTAL _.............................................................. 46

3.1 Considerações iniciais ................................................................................. 46

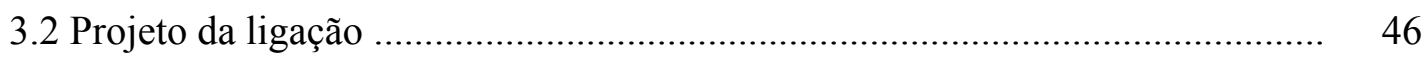

3.2.1 Especificação do concreto ............................................................... 48

3.2.2 Armadura de projeto …................................................................. 48

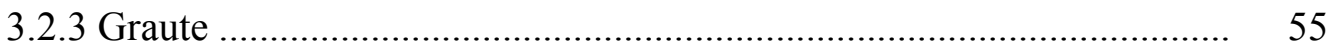

3.2.4 Almofada de apoio ................................................................ 55 
3.3 Confecção dos elementos ........................................................................... 55

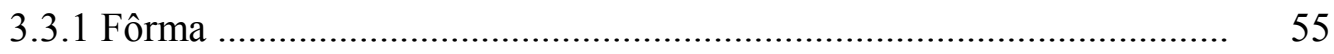

3.3.2 Armação dos elementos pré-moldados ............................................. 56

3.3.3 Concretagem dos elementos pré-moldados ...................................... 57

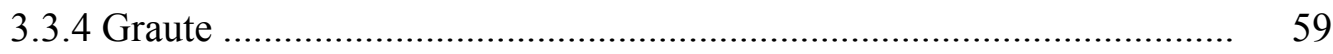

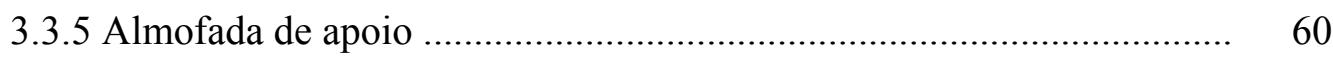

3.4 Montagem dos modelos ......................................................................... 61

3.5 Propriedades mecânicas dos materiais ................................................................ 64

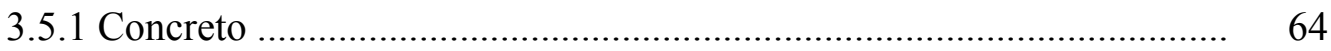

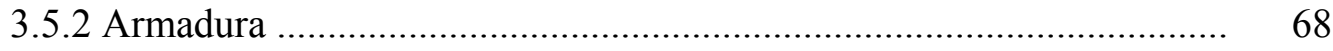

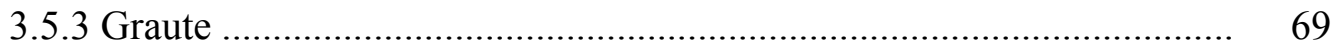

3.5.4 Almofada de apoio .................................................................. 71

3.6 Equipamentos e instrumentação ................................................................. 73

3.6.1 Instrumentação interna .................................................................. 73

3.6.2 Instrumentação externa .................................................................. 79

3.7 Procedimento de ensaio ......................................................................... 80

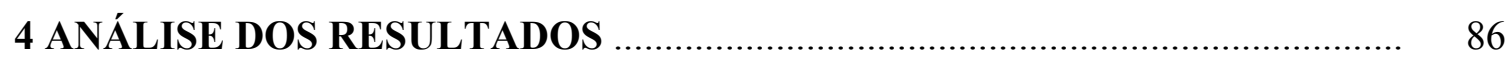

4.1 Considerações iniciais ............................................................................. 86

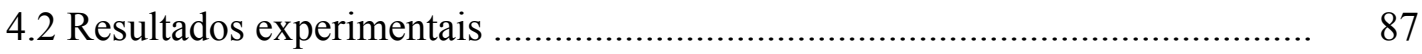

4.2.1 Determinação da curva momento fletor-rotação ................................ 89

4.2.1.1 Curva momento-rotação do modelo I ....................................... 92

4.2.1.2 Curva momento-rotação do modelo E ....................................... 99

4.3 Modelo analítico ................................................................................. 115

4.3.1 Momento fletor negativo .............................................................. 115

4.3.2 Momento fletor positivo ......................................................... 118

4.3.3 Comparação do modelo analítico com os resultados experimentais .... 121

4.4 Simulação numérica de uma estrutura típica de concreto pré-moldado ........... 123

5 CONSIDERAÇÕES FINAIS E CONCLUSÕES …...................................... 142 
5.1 Considerações iniciais ............................................................................. 142

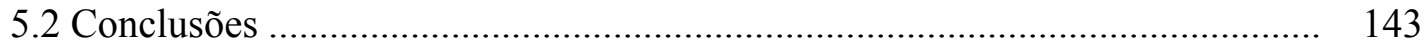

5.3 Sugestões para pesquisas futuras ........................................................... 144

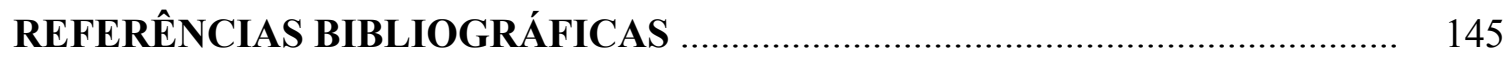



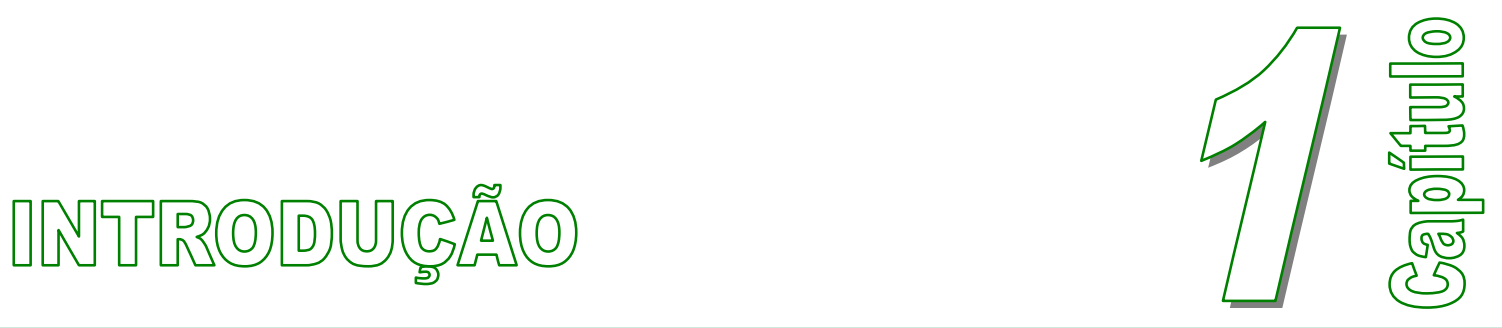

\subsection{CONSIDERAÇÕES INICIAIS}

A construção civil tem sido considerada atrasada quando comparada a outros ramos industriais por apresentar baixos índices de produtividade e qualidade, grandes desperdícios de materiais e morosidade. Uma alternativa em busca da redução desse atraso é a utilização da pré-moldagem.

Ainda em evolução, a indústria da pré-moldagem enfrenta algumas limitações para sua viabilização plena. Estas limitações são decorrentes da necessidade de equipamentos para transporte, colocação dos elementos nos seus locais definitivos de utilização e principalmente da necessidade de promover ligações entre os vários elementos que compõem a estrutura.

Segundo a Associação Brasileira de Normas Técnicas - Projeto e Execução de Estruturas de Concreto Pré-Moldado (NBR 9062/85) "ligações são dispositivos utilizados para compor um conjunto estrutural a partir de seus elementos, com a finalidade de transmitir os esforços solicitantes em todas as fases de utilização, dentro das condições de projeto".

Portanto a forma da ligação entre elementos é de fundamental importância. É a modelagem do comportamento das ligações que permite saber os esforços atuantes e garantir a estabilidade global da estrutura.

No concreto pré-moldado as ligações tendem a ter um comportamento variado, podendo apresentar-se como rígida, articulada ou semi-rígidas, comportamento este intermediário a nós rígidos e articulados podendo aproximar-se de um deles. 
Ao se projetar ligações em estruturas de concreto pré-moldado deve-se atentar a requisitos múltiplos, tais como, ductilidade (capacidade da ligação de apresentar deformações elasto-plásticas acentuadas antes de atingir a ruptura), durabilidade, resistência aos esforços solicitantes e ao fogo e construtibilidade. Contudo determinar tais parâmetros tem sido um desafio devido à falta de dados sobre o comportamento das ligações.

Cheok e Lew (1991) comentam que pela falta de dados sobre as ligações vigapilar as estruturas pré-moldadas tendem a ser presumida como menos dúcteis e estáveis que estruturas monolíticas.

Os estudos sobre o comportamento das ligações entre elementos de concreto prémoldados tornaram-se mais abrangentes e expressivos no início da década de 60 e tinham por objetivo aumentar o banco de dados, compreender e sistematizar os projetos de ligações de concreto pré-moldado. Neste âmbito destacou-se o programa de pesquisas desenvolvido pela Portalnd Cement Association (PCA) como o estudo da continuidade em elementos pré-moldados em duplo T para pisos de Rostasy (1962), o estudo de resistência do apoio no topo de pilar para vigas de concreto pré-moldado de Kris e Raths (1963) dentre outros.

Em 1986 foi lançado o programa PCI Specially Funded Research and Development Program 1 and 4 (PCI-SFRAD) com o objetivo de compreender o comportamento das ligações mais utilizadas nos Estados Unidos da América. Os resultados do projeto foram publicados na revista PCI Journal Prestressed Concrete Institute e intitulados "Moment Resistant Connections and Simple Connections".

Em 1990 o Centre d'Etudes et de Recherches de l'industrie du Béton (CERIB) propôs o programa intitulado Investigation of Behavior of Semi-rigid Connections com o objetivo principal de estudar o comportamento de ligações semi-rígidas dos diversos tipos de ligações (viga-pilar, viga-viga) dando ênfase a ligações presentes nas estruturas em esqueleto.

Também em 1990 inicia-se o programa Precast Seismic Structural Systems (PRESS), formado por universidades dos Estados Unidos da América e do Japão, com o âmbito de analisar o comportamento de diversas ligações em concreto pré-moldado quando submetidas a sismos. Este estudo foi dividido em 3 fases, ficando a fase 1 responsável pela classificação e avaliação das ligações, desenvolvendo critérios de projeto e modelos analíticos, a fase 2 a escolha e realização de testes individuais e a fase 
3 a realização de 5 ensaios experimentais em estruturas de concreto pré-moldado e análises de projetos.

Em 1991 iniciou-se o programa COST C1 "Control of the Semi-rigid Behavior of Civil Engineering Structural Connections" com o objetivo de ampliar os conhecimentos das ligações presentes na engenharia civil de forma a se ter à possibilidade de obter benefícios sobre o custo das estruturas e abrir a oportunidade de se ter novos conceitos na preparação das normas. Durante os sete anos de duração do programa COST C1 participaram 23 países e foram publicados mais de 125 projetos sobre estruturas de concreto, aço, estruturas mistas, madeira, formação de base de dados, projetos sísmicos, simulações numéricas e matérias compostas por polímeros.

No Brasil estudos sobre o comportamento das ligações, em especial semirígidas, ainda são bastante incipientes, contudo a EESC-USP tem prestado grandes contribuições nesta área.

Ballarin (1993) iniciou as pesquisas em ligações de elementos pré-moldados elaborando um estudo da arte. Nele são estabelecidos sistemas de classificação tipológica e uma avaliação crítica do estado da arte através de análises sistemáticas do desempenho das ligações.

Ferreira (1993) realizou um estudo sobre a associação analítica de mecanismos básicos de deformação das ligações, desenvolvendo modelos para o cálculo das deformabilidades em vários tipos de ligações de elementos pré-moldados.

Dando continuidade a seu trabalho Ferreira (1999) ensaiou duas ligações vigapilar submetidas a cisalhamento, flexão e torção, sendo a primeira ligação viga-pilar com almofada de apoio de elastômero e chumbador e a segunda ligação viga-pilar com chapas soldadas. Baseado nestes estudos experimentais consolidou-se a proposta metodológica para o cálculo da deformabilidade em ligações de estruturas pré-moldadas iniciado em Ferreira (1993).

Soares (1998) promoveu uma avaliação teórica-experimental do comportamento, dando ênfase na deformabilidade, de uma ligação viga-pilar em um sistema estrutural de pórticos para telhados de duas águas. Sua dissertação também traz recomendações de projeto tendo em vista os resultados obtidos em estudos anteriores.

Barboza (2001) realizou análises do comportamento de juntas horizontais de argamassa solicitadas à compressão na ligação entre elementos pré-moldados de forma a obter recomendações que caracterizem sua deformabilidade e resistência e auxilie o seu projeto. 
Miotto (2002) estudou o comportamento de duas ligações viga-pilar em concreto pré-moldado com ênfase na deformabilidade a momento fletor. A primeira ligação, dando continuidade ao trabalho de Soares (1998), foi executada sobre consolo com chumbadores. A segunda ligação representou uma estrutura aporticada utilizando almofada de apoio, chumbador e capa de concreto moldado no local.

\subsection{JUSTIFICATIVA}

As ligações semi-rígidas entre elementos pré-moldados muitas vezes são concebidas como ligações articuladas ou rígidas, desconsiderando a influência da rigidez real da ligação.

Este procedimento decorre da dificuldade de se propor modelos analíticos simplificados que representem o comportamento da ligação semi-rígida, uma vez que é necessário atribuir valores experimentais de deformabilidade e resistência para calibração destes.

Uma vez que o desempenho do sistema estrutural depende do comportamento da ligação, este procedimento também faz com que os esforços atuantes na estrutura sejam diferentes dos calculados gerando assim seções menos otimizadas ou até insatisfatórias.

Dando continuidade à linha de pesquisa desenvolvida sobre ligações semirígidas no Departamento de Estruturas da Escola de Engenharia de São Carlos, em particular a tese de doutorado de Miotto (2002), o presente trabalho apresenta o estudo experimental do comportamento a momento fletor da ligação viga-pilar semi-rígida mostrada nas Figuras 1.1 e um modelo analítico para os momentos resistentes que a represente de forma a auxiliar os projetistas na consideração da sua semi-rigidez.

A Figura 1.2 mostra a ligação estudada por Miotto (2002). Observa-se que a ligação proposta neste trabalho e em Miotto (2002) são bastante similares, tendo como principal diferença mudança do chumbador retilíneo para um chumbador inclinado presos à viga através de porcas e arruelas. 


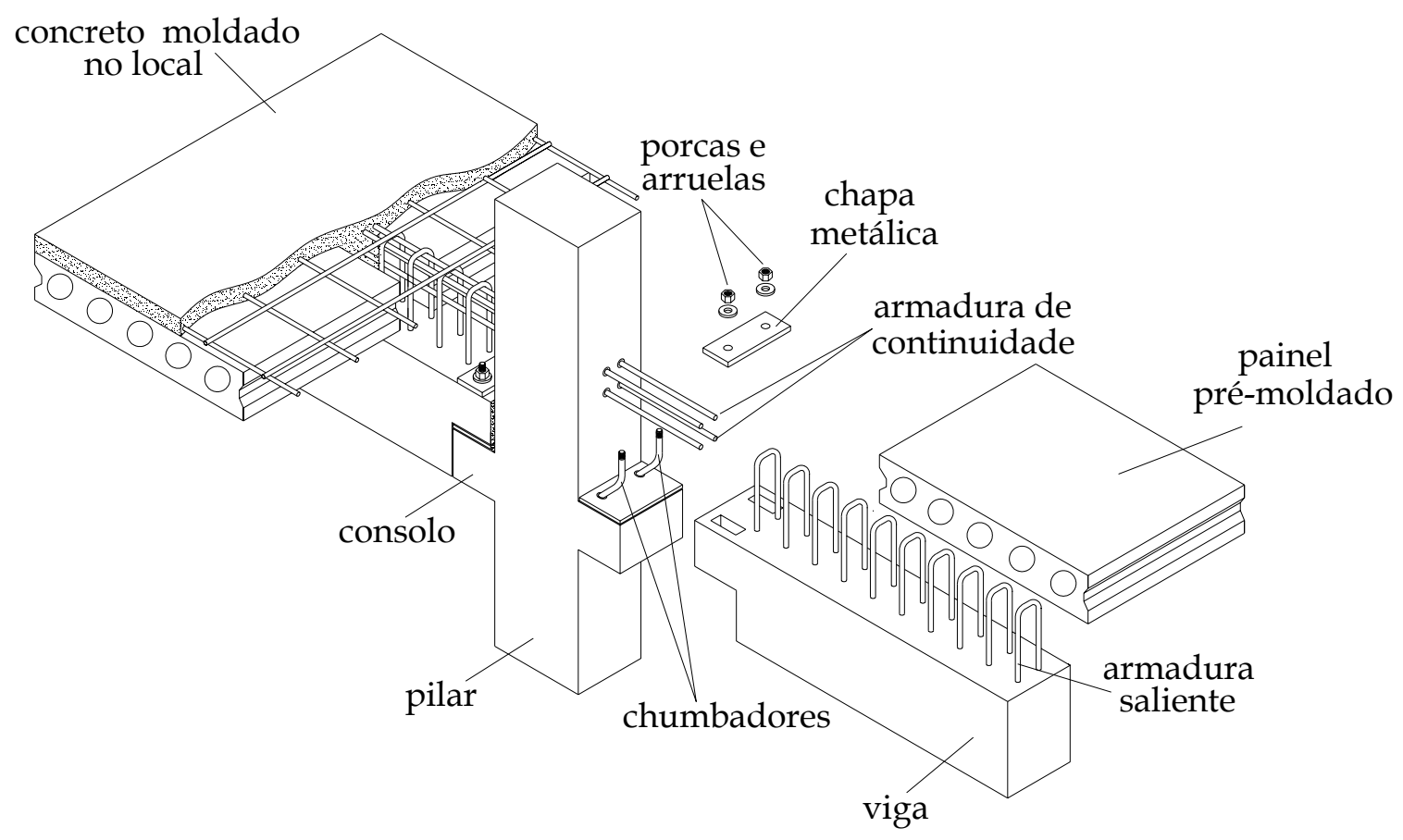

Figura 1.1 - Ligação viga-pilar estudada

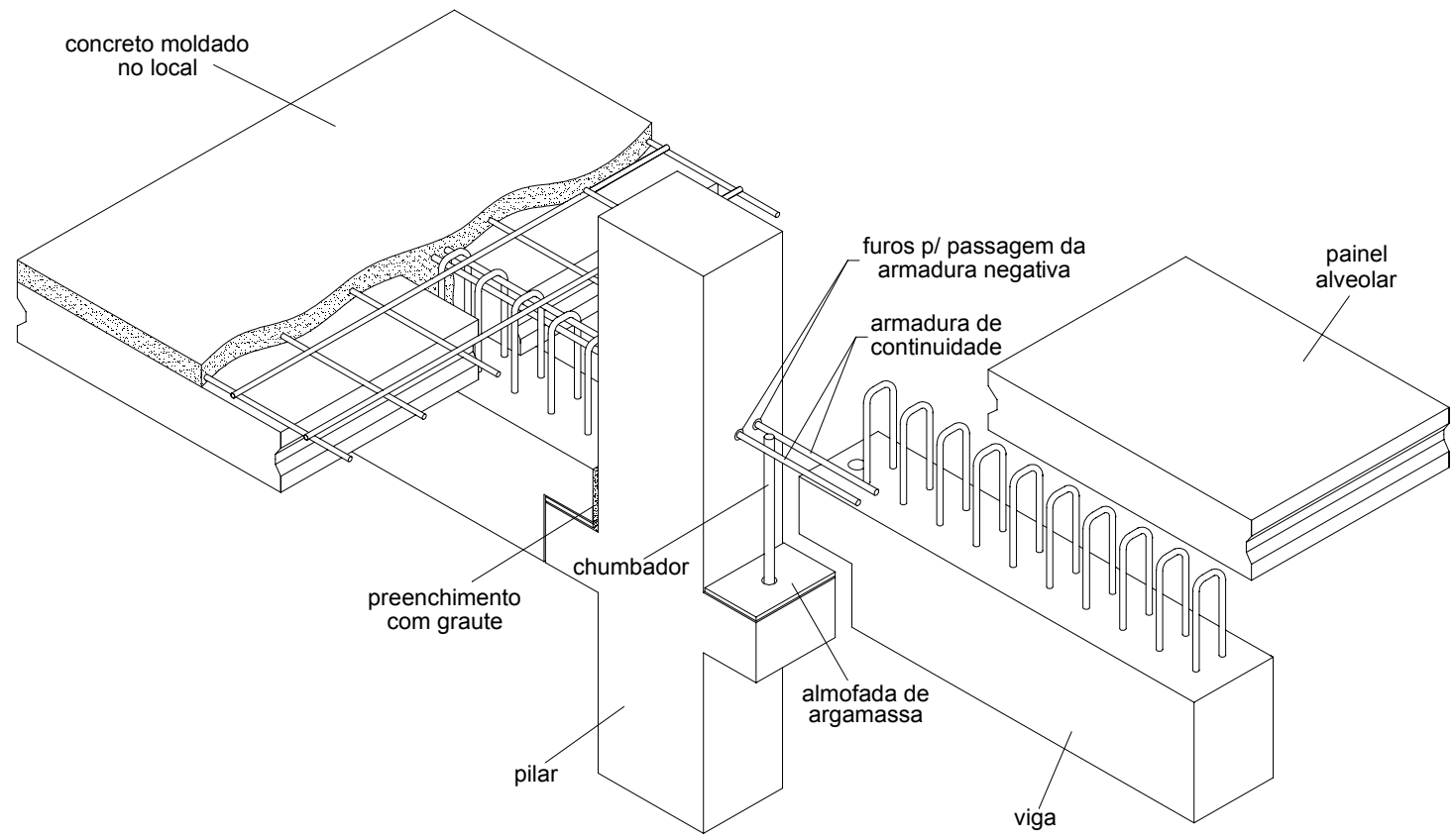

Figura 1.2 - Ligação estudada por Miotto (2002)

Esta mudança no posicionamento do chumbador teve por objetivo aumentar a rigidez e momento de plastificação a momento positivo da ligação, uma vez que o 
chumbador comportara-se como uma barra inclinada cujo principal esforço atuante é o de tração ou compressão.

\subsection{OBJETIVOS}

O objetivo geral do presente trabalho consiste em fazer uma análise experimental de uma ligação viga-pilar pré-moldada parcialmente resistente a momento fletor.

Entre os objetivos específicos estão:

$\checkmark$ Determinar as rigidezes a momento negativo e positivo da ligação.

$\checkmark$ Determinar os momentos negativos e positivos resistentes da ligação.

$\checkmark$ Avaliar os benefícios da ligação estudada, em particular a ligação estudada por Miotto (2002).

\subsection{APRESENTAÇÃO DO TRABALHO}

No capítulo 1 é feita uma abordagem sobre ligações em elementos pré-moldados e uma explanação da ligação estudada, listando os objetivos e justificativas deste trabalho.

No capítulo 2 é realizada uma revisão bibliográfica sobre ligações semi-rígidas em estruturas de concreto pré-moldado, apresentando formas de classificação e determinação do comportamento semi-rígido. Por fim são apresentados os principais estudos encontrados na literatura.

No capitulo 3 apresenta-se o programa experimental realizado, onde são detalhados os modelos e forma de ensaio.

No capítulo 4 apresenta-se a análise dos resultados experimentais e propõem-se uma formulação para determinação dos momentos resistentes comparando-os com os dados experimentais. Para avaliar a influência da ligação em estruturas típicas de concreto pré-moldado foram realizadas simulações numéricas, através do programa ANSYS 8.0, levando-se em consideração as diversas etapas de carregamento.

No capitulo 5 são apresentadas as considerações finais, conclusões e sugestões para trabalhos futuros. 

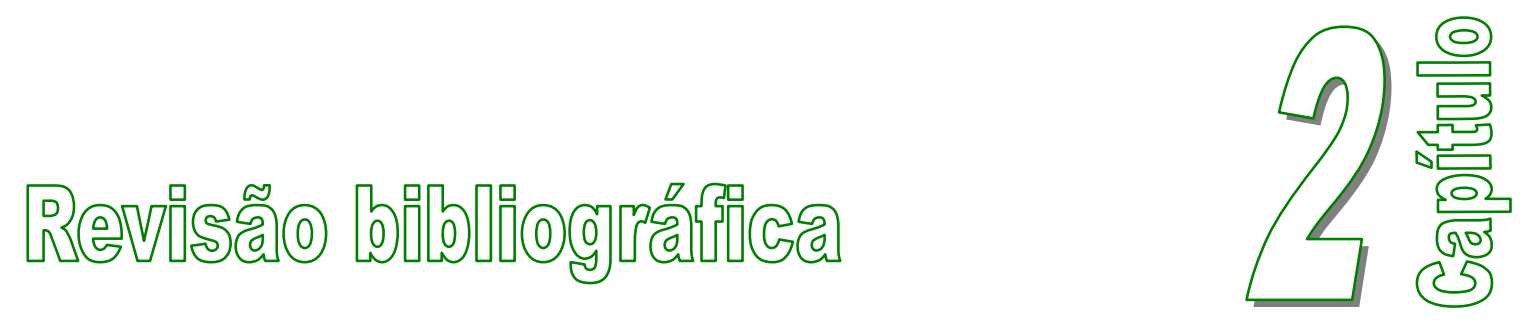

\subsection{GENERALIDADES}

As ligações entre elementos de concreto pré-moldado, em geral, não se comportam da forma em que são concebidas nas análises estruturais (rígidas ou articulada) em vista de simplificações de cálculo, porém tais ligações podem apresentar um comportamento semi-rígido, ou seja, são capazes de transmitir esforços e possuírem certa rigidez.

Com o objetivo de incorporar o comportamento semi-rígido das ligações em projetos, diversos procedimentos, simplificados ou através de programas computacionais sofisticados, foram desenvolvidos.

Segundo Leon (1998) no início da década de 50 as ligações semi-rígidas ou de resistência parcial eram incorporadas a projetos através do método simplificado permitidos pelas normas AISC conhecido por "ligações inteligentes", uma vez que as ligações eram capazes de diferenciar os momentos provocados por carregamentos gravitacionais e laterais.

Neste modelo, as ligações eram supostas articuladas sobre carregamento gravitacional e supostas rígidas ou de resistência total quando submetidas a carregamentos laterais (vento). Para análise em serviços as ligações eram consideradas rígidas.

Estudos comparando o método simplificado das ligações inteligentes com procedimentos rigorosos de análise estrutural para estado limite de serviço e estado 
limite últimos comprovaram que tal método apresenta resultados perfeitamente satisfatórios.

Outros métodos para incorporação do comportamento semi-rígido foram desenvolvidos, contudo a forma mais usual para levar em consideração o comportamento semi-rígido é utilizando os parâmetros de deformabilidade ou rigidez e resistência última das ligações extraídas de curvas forças-deslocamento.

A deformabilidade de uma ligação é relação entre o deslocamento relativo dos elementos adjacentes à ligação e o esforço aplicado na direção do deslocamento.

No caso em estudo de ligação viga-pilar submetida a momento fletor, a curva utilizada para obtenção dos parâmetros de deformabilidade e resistência última é a curva momento fletor-rotação ou simplesmente momento-rotação. $\mathrm{O}$ conceito de deformabilidade passa a ser a rotação relativa da viga com o pilar ao ser aplicado um momento fletor.

A Figura 2.1 mostra a curva momento rotação característica para as situações de ligação perfeitamente articulada, perfeitamente rígida e semi-rígida.
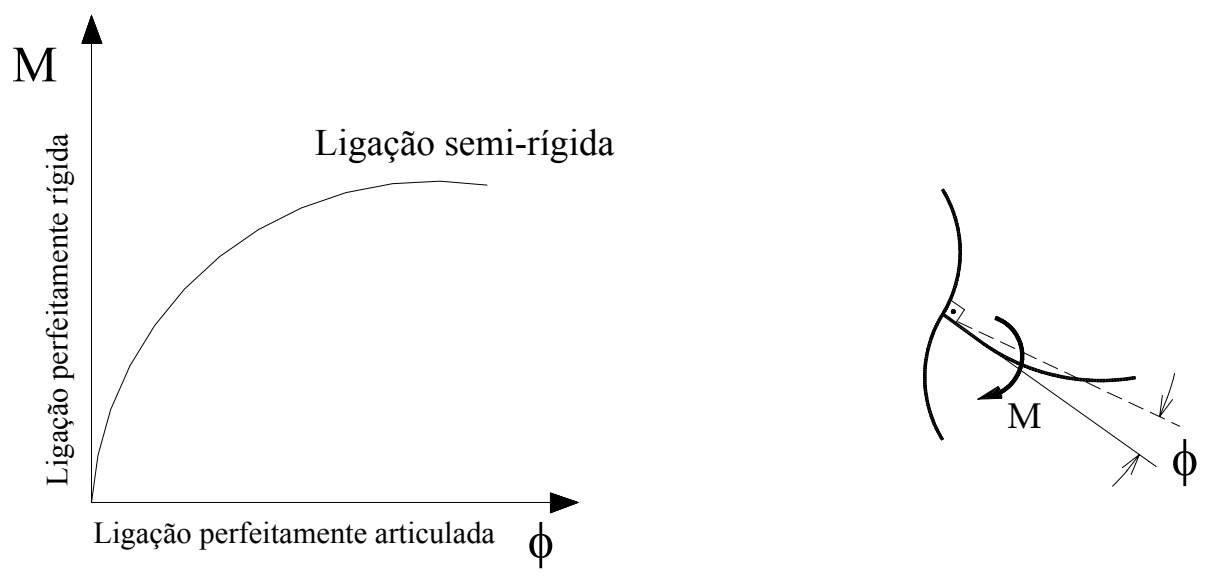

Figura 2.1 - Curva momento fletor rotação para os três tipos de ligação [MIOTTO (2002)]

A deformabilidade é dada por:

$\lambda=\frac{\phi}{M}$

A rigidez é o inverso da deformabilidade e, portanto pode ser definida como:

$K_{m}=\frac{M}{\phi}$ 
A resistência última é a resistência máxima suportada pela ligação que em projeto caracteriza-se por ser o momento em que ocorre a plastificação da ligação.

As ligações semi-rígidas, na sua maioria, apresentam um comportamento não linear, sendo que sua configuração dependerá da geometria, resistência dos materiais e capacidade rotacional.

Estudos realizados pelo departamento de engenharia civil da Universidade de Nottingham descritos em Elliot (1998) indicam que a rigidez inicial da ligação seja em função da geometria desta, em particular pela maneira pela qual foi construída e as tolerâncias admitidas. A resistência última seria devida principalmente à resistência dos materiais que compõem a ligação e a capacidade rotacional em função da ductilidade, sendo que a geometria também influenciaria.

No trabalho de Chefdebien (1998) sobre ligação viga-pilar com diferentes materiais para almofada de apoio e preenchimento do espaço dos chumbadores mostram que quando a almofada e o preenchimento vertical são rígidos as curvas momento fletor-rotação apresentam-se quase bi-linear e para as ligações com almofadas ou preenchimentos de materiais mais flexíveis às curvas tem um comportamento não linear.

Com o objetivo de simplificação dos cálculos, ao se projetar estruturas de concreto pré-moldado é comum promover uma linearização da Figura 2.1, tornando as bi ou tri-linear como mostra a Figura 2.2.
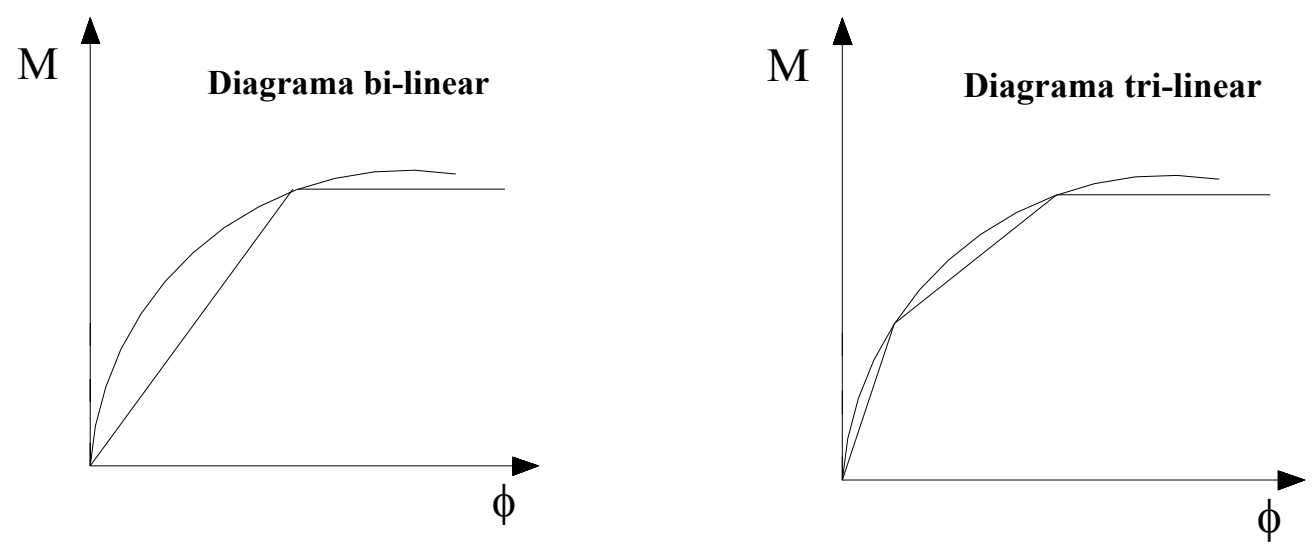

Figura 2.2 - Linearização das curvas momento fletor - rotação 
O Eurocode 3 (2002) determina, para o caso linearização de curvas momentorotação, que a rigidez da ligação $\left(\mathrm{S}_{\mathrm{j}}\right)$ seja similar à rigidez inicial da curva momentorotação não linear caso o momento solicitante de projeto $\left(\mathrm{M}_{\mathrm{j}, \mathrm{Ed}}\right)$ seja inferior a $2 / 3$ do momento resistente de projeto $\left(\mathrm{M}_{\mathrm{j}, \mathrm{Rd}}\right)$. Caso este valor ultrapasse os $2 / 3$ do momento resistente de projeto a rigidez fictícia é dada pela rigidez inicial dividida por um fator $\eta$ que depende do tipo de ligação (viga-pilar,viga-viga..) e dos componentes utilizados para a ligação (parafusos, soldas).

A Figura 2.3 demonstra o procedimento descrito acima.
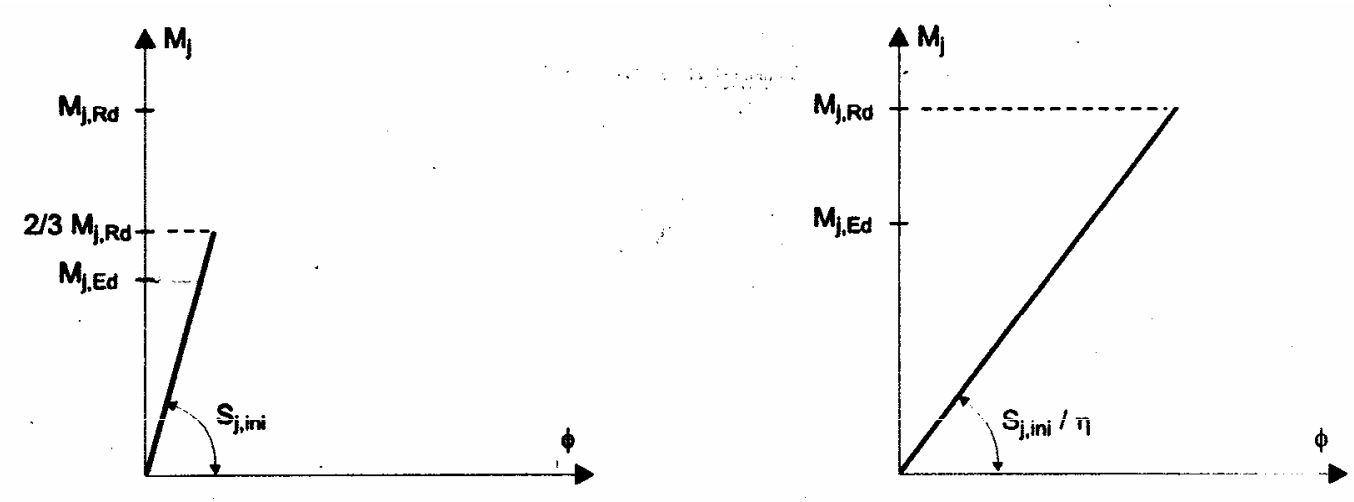

Figura 2.3 - Rigidez a ser considerada em projeto [EUROCODE 3 (2002)]

\subsection{CLASSIFICAÇÃO DAS LIGAÇÕES}

O estudo do comportamento das ligações em estruturas metálicas e mistas encontra-se consolidados e bem difundidos através de normas, publicações em revistas e congressos especializados quando comparado a estudos sobre o comportamento das ligações em estruturas de concreto pré-moldado.

Com o objetivo de fornecer uma direção na escolha do tipo de ligação mais adequado e econômico e indicar o método mais apropriado de análise estrutural (por exemplo, no caso de análises elásticas a rigidez é o fator primordial para a classificação enquanto que para as análises plásticas do comportamento da ligação o fator primordial é a resistência e a capacidade rotacional) as ligações de concreto pré-moldado serão classificadas tendo por base as classificações presentes em normas de estruturas metálicas. 
Atualmente existem dois tipos de classificação para as ligações; quanto a sua rigidez (rígida, articulada ou semi-rígida) e quanto a sua resistência (articulada, de resistência parcial ou de resistência total).

\title{
2.2.1 Classificação quanto à rigidez
}

As ligações são classificadas em articuladas, rígidas ou semi-rígidas comparando sua rigidez com os limites estabelecidos descritos abaixo.

As ligações articuladas caracterizam-se por serem capazes de transmitir esforços internos sem, contudo resistirem a momentos fletores significantes.

As ligações rígidas caracterizam-se por não influenciarem na distribuição de esforços internos, momentos fletores e nem deformações totais da estrutura.

As ligações semi-rígidas caracterizam-se por permitirem certa interação entre os elementos a ela adjacentes, transmitindo parcialmente os momentos fletores.

Tanto o Eurocode 3 (2002) como o texto base da norma brasileira NBR 8800 (2003) trazem como limite para ligações rotuladas $\mathrm{S}_{\mathrm{j}}<0,5 \mathrm{E} \cdot \mathrm{I}_{\mathrm{b}} / \mathrm{L}_{\mathrm{b}}$ e para ligações rígidas $\mathrm{S}_{\mathrm{j}}>\mathrm{K}_{\mathrm{b}} \mathrm{EI}_{\mathrm{b}} / \mathrm{L}_{\mathrm{b}}$, sendo $\mathrm{K}_{\mathrm{b}}=8$ para o caso de estruturas indeslocáveis e $\mathrm{K}_{\mathrm{b}}=25$ no caso de estruturas com $\mathrm{K}_{\mathrm{b}} / \mathrm{K}_{\mathrm{c}}>0,1$. Quando a estrutura tiver $\mathrm{K}_{\mathrm{b}} / \mathrm{K}_{\mathrm{c}}<0,1$ a ligação devera ser classificada como semi-rígida.

A Figura 2.4 delimita as zonas para as quais as ligações são consideradas rígidas, semi-rígidas e articuladas.

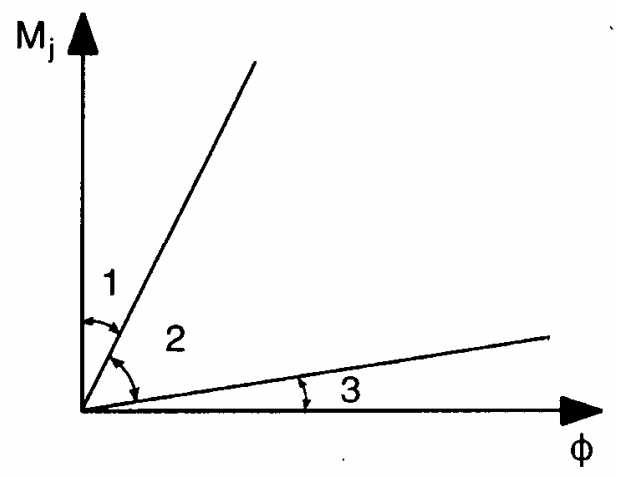

\author{
Zona 1 - Rígida $\mathrm{S}_{\mathrm{j}}>\mathrm{K}_{\mathrm{b}} \mathrm{EI}_{\mathrm{b}} / \mathrm{L}_{\mathrm{b}}$ \\ Zona 2 - Semi-rígida \\ Zona 3 - Articulada $\mathrm{S}_{\mathrm{j}}<0,5 \mathrm{EI}_{\mathrm{b}} / \mathrm{L}_{\mathrm{b}}$
}

Figura 2.4 - Classificação das ligações quanto à rigidez [EUROCODE 3 (2002)] 
As fixações destes limites ainda não são consenso geral. Trabalhos divulgados no programa COST C1 de 1998 revelaram existir diferentes valores para os limites entre ligação rígida e semi-rígida. A título de curiosidade a Tabela 2.1 apresenta algumas das formulações para classificação de ligações rígidas e seus respectivos autores.

Tabela 2.1 - Valores limites de classificação quanto à rigidez [GOMES et al (1998)]

\begin{tabular}{|l|l|}
\hline \multicolumn{1}{|c|}{ AUTORES } & LIMITES PARA CLASSIFICAÇÃO RÍGIDA \\
\hline Bjorhovde, Colson, Brozzetti & $\mathrm{EI}_{\mathrm{b}} / 2 \mathrm{~d}$ \\
\hline Bijlaard, Steenhuis & $\mathrm{EI}_{\mathrm{b}} / \mathrm{d} \quad$ (Pórticos deslocáveis) \\
& $\mathrm{EI}_{\mathrm{b}} / 2,5 \mathrm{~d} \quad$ (Pórticos indeslocáveis) \\
\hline Tschemmernegg, Hunter & $3 \mathrm{EI}_{\mathrm{b}} / 4 \mathrm{~d}$ \\
\hline Mazzolani, De Matteis, Mandara & $\mathrm{EI}_{\mathrm{b}} / \mathrm{d}$ \\
\hline Tschemmernegg, Huber & $\mathrm{EI}_{\mathrm{b}} / \mathrm{b}_{\mathrm{j}} \quad$ (Pórticos deslocáveis) \\
\hline
\end{tabular}

$\mathrm{d}$ : Profundidade da viga; $\mathrm{b}_{\mathrm{j}}$ : Largura do pilar; $\mathrm{I}_{\mathrm{b}}=$ Momento de inércia da viga.

A norma americana AISC-ASD (1989) ao classificar as ligações além de relacionar com a capacidade de distribuição de esforços e transmissão de momento explicita o percentual de rotação admissível entre os elementos.

As ligações do tipo 1 - Ligações rígidas, o ângulo original entre os elementos conectados é mantido praticamente inalterado após solicitação, admitindo-se rotações relativas não superiores a $10 \%$ da correspondente a situação de perfeitamente articulada.

As ligações do tipo 2 - Ligação articulada, a rotação relativa entre os elementos deve ser superior a $80 \%$ da correspondente a situação de ligação perfeitamente articulada.

As ligações do tipo 3 - Ligações semi-rígidas, há uma restrição parcial a rotação, com rotações relativas entre elementos de 10 a $80 \%$ da correspondente a situação de perfeitamente articulada.

A Tabela 2.2 resume os valores limites de classificação quanto à rigidez estabelecidos pelas normas Eurocode 3 (2002), texto base da NBR 8800 (2003) e o AISC-ASD (1989). 
Tabela 2.2 - Resumo dos limites de classificação à rigidez estabelecida por normas

\begin{tabular}{|c|c|c|c|}
\hline Norma & Articulada & Semi-rígida & Rígida \\
\hline Eurocode 3 & $\mathrm{S}_{\mathrm{j}}<0,5 \mathrm{EI}_{\mathrm{b}} / \mathrm{L}_{\mathrm{b}}$ & $0,5 \mathrm{~K}_{\mathrm{b}} \mathrm{EI}_{\mathrm{b}} / \mathrm{L}_{\mathrm{b}}<\mathrm{S}_{\mathrm{j}}<\mathrm{K}_{\mathrm{b}} \mathrm{EI}_{\mathrm{b}} / \mathrm{L}_{\mathrm{b}}$ & $\mathrm{S}_{\mathrm{j}}>\mathrm{K}_{\mathrm{b}} \mathrm{EI}_{\mathrm{b}} / \mathrm{L}_{\mathrm{b}}$ \\
\hline $\mathrm{NBR} 8800$ & $\mathrm{~S}_{\mathrm{j}}<0,5 \mathrm{EI}_{\mathrm{b}} / \mathrm{L}_{\mathrm{b}}$ & $0,5 \mathrm{k}_{\mathrm{b}} \mathrm{EI}_{\mathrm{b}} / \mathrm{L}_{\mathrm{b}}<\mathrm{S}_{\mathrm{j}}<\mathrm{K}_{\mathrm{b}} \mathrm{EI}_{\mathrm{b}} / \mathrm{L}_{\mathrm{b}}$ & $\mathrm{S}_{\mathrm{j}}>\mathrm{K}_{\mathrm{b}} \mathrm{EI}_{\mathrm{b}} / \mathrm{L}_{\mathrm{b}}$ \\
\hline AISC-ASD & $\begin{array}{c}\phi 80 \% \text { da ligação } \\
\text { perfeitamente } \\
\text { articulada }\end{array}$ & $\begin{array}{c}10 \%<\phi<80 \% \text { da ligação } \\
\text { perfeitamente articulada }\end{array}$ & $\begin{array}{c}\phi<10 \% \text { da ligação } \\
\text { perfeitamente } \\
\text { articulada }\end{array}$ \\
\hline
\end{tabular}

$\mathrm{S}_{\mathrm{j}}$ : rigidez da ligação

\subsubsection{Classificação quanto à resistência}

O Eurocode 3 (2002) define que as ligações podem ser classificadas em ligação articulada, de resistência parcial e resistência total comparando seu momento resistente com o momento resistente dos elementos que compõem a ligação.

Ligação articulada tem conceituação similar à da classificação a rigidez. Ligações com resistência parcial apresentam resistência inferior à resistência dos elementos a ela conectados e a ligação com resistência total apresenta resistência igual ou superior à resistência dos elementos conectados.

A Figura 2.5 mostra os limites para cada tipo de ligação segundo o Eurocode 3 (2002) e Tschemmernegg (1998). Observa-se que assim como ocorreu na classificação quanto à rigidez, há uma divergência nos limites. O Eurocode (2002) define um momento de 0,25 $\mathrm{M}_{\mathrm{pl}, \mathrm{Rd}}$ (momento de plastificação de projeto da viga conectada) e Tcchemmernegg (1998) um momento de $0,1 \mathrm{M}_{\mathrm{pl}, \mathrm{Rd}}$.

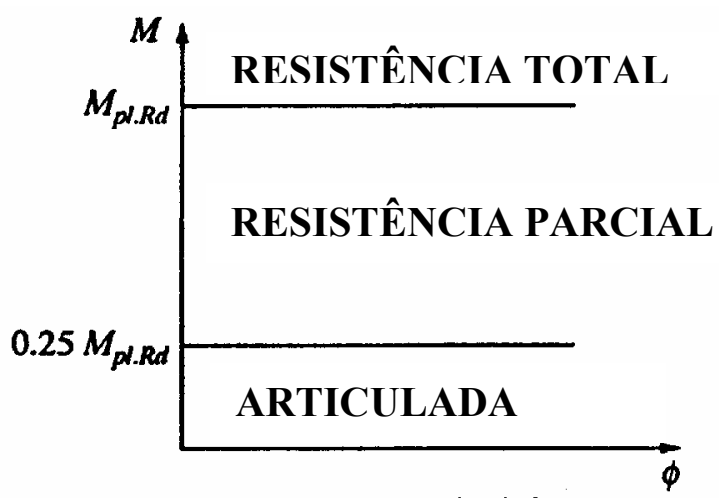

EUROCODE 3

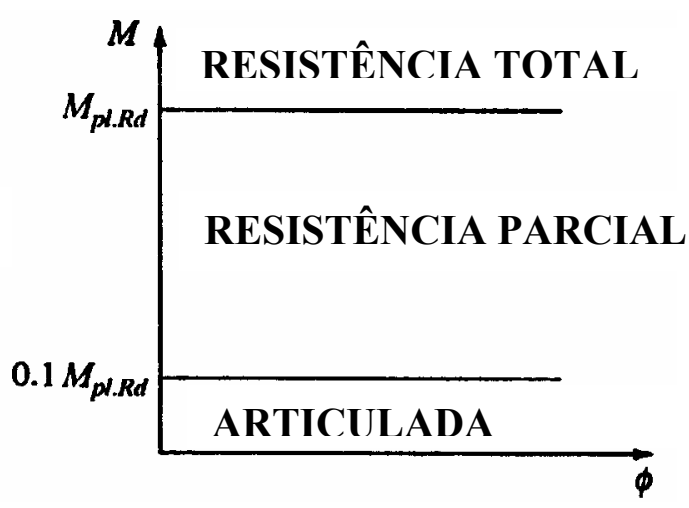

TCCHEMMERNEGG

Figura 2.5 - Classificação das ligações quanto à resistência [GOMES et al (1998)] 
Para ligações de resistência total o Eurocode 3 (2002) determina os momentos mostrados na Figura 2.6.

$$
\begin{aligned}
& \mathrm{M}_{\mathrm{j}, \mathrm{Sd}} \\
& \mathrm{M}_{\mathrm{J}, \mathrm{Rd}}>\mathrm{M}_{\mathrm{b}, \mathrm{pl}, \mathrm{Rd}} \\
& \mathrm{M}_{\mathrm{J}, \mathrm{Rd}}>\mathrm{M}_{\mathrm{c}, \mathrm{pl}, \mathrm{Rd}}
\end{aligned}
$$

Figura 2.6 - Limite quanto à resistência total dado pelo Eurocode [EUROCODE 3 (2002)]

Sendo:

$\mathrm{M}_{\mathrm{J}, \mathrm{Rd}}=$ Momento resistente de projeto da ligação

$\mathrm{M}_{\mathrm{b}, \mathrm{pl}, \mathrm{Rd}}=$ Momento de plastificação de projeto da viga

$\mathrm{M}_{\mathrm{c}, \mathrm{pl}, \mathrm{Rd}}=$ Momento de plastificação de projeto do pilar

A norma brasileira NBR 8800 é omissa quanto a este tipo de classificação.

Na Figura 2.7 ilustra a classificação das ligações quanta à rigidez e resistência.

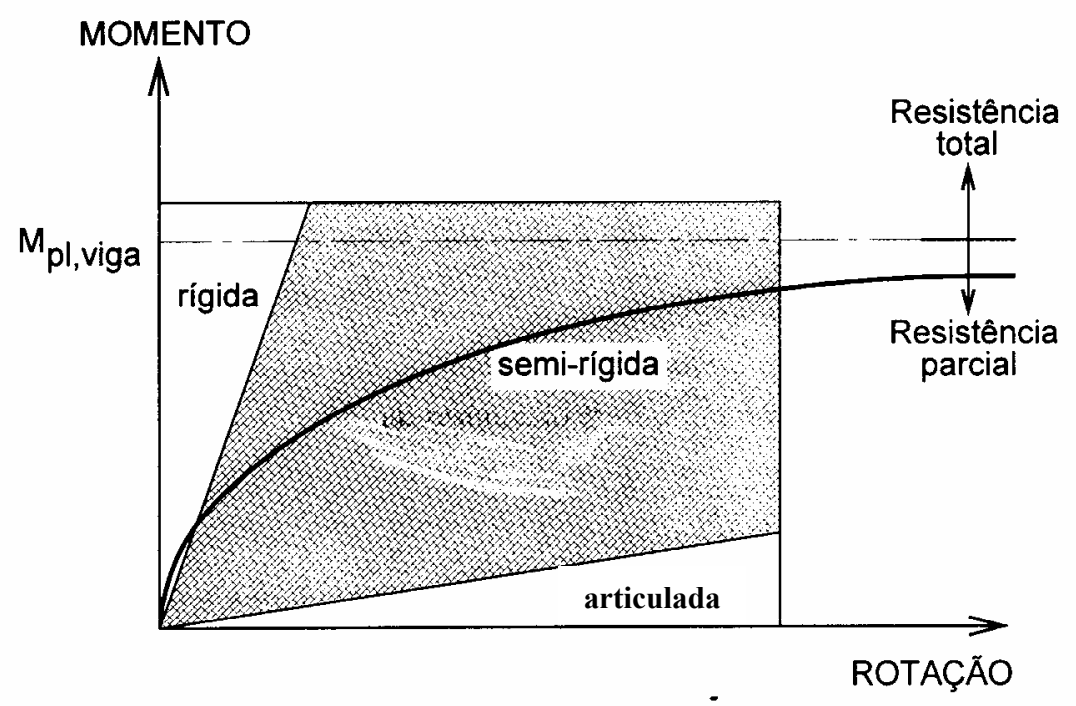

Figura 2.7 - Classificação das ligações quanto à rigidez e resistência [Adaptada de LEON et al (1996) apud MALITE (2003)] 
A Tabela 2.3 apresenta o resumo dos limites de classificação quanto à rigidez definida pelo Eurocode (2002) e o Tschemmernegg (1998).

Tabela 2.3 - Resumo dos limites de classificação quanto à resistência

\begin{tabular}{|c|c|c|}
\hline Norma & $\begin{array}{c}\text { Limite Resistência total/ } \\
\text { resistência parcial }\end{array}$ & $\begin{array}{c}\text { Limite Resistência parcial/ } \\
\text { rotulada }\end{array}$ \\
\hline Eurocode 3 & $\mathrm{M}_{\mathrm{pl}, \mathrm{Rd}}$ & $0,25 \mathrm{M}_{\mathrm{pl}, \mathrm{Rd}}$ \\
\hline Tschemmernegg & $\mathrm{M}_{\mathrm{pl}, \mathrm{Rd}}$ & $0,1 \mathrm{M}_{\mathrm{pl}, \mathrm{Rd}}$ \\
\hline
\end{tabular}

\subsection{DETERMINAÇÃO DO COMPORTAMENTO DE LIGAÇÕES SEMI-RÍGIDAS}

\subsubsection{Procedimentos gerais}

A determinação do comportamento de ligações semi-rígidas pode ser feita por ensaios experimentais, simulações numéricas ou modelos analíticos.

O emprego de ensaios experimentais em laboratório é uma das formas disponíveis para a obtenção do comportamento da ligação, porém o alto custo e tempo gasto tornam-na basicamente restritos a atividades científicas, impraticáveis nos escritórios de cálculo.

$\mathrm{Na}$ simulação numérica, o uso de programas computacionais sofisticados baseados no método dos elementos finitos (MEF), tem permitido determinar o comportamento semi-rígido das ligações levando-se em conta a não linearidade do material, efeitos de esmagamento do concreto, de contato e de atrito, contudo os problemas inerentes ao desenvolvimento dos modelos ainda não foram totalmente solucionados.

Diversas universidades vêm desenvolvendo programas para contabilizar o comportamento semi-rígido, a citar: Institute Nacional dês Science Appliquees the Lyon realizou simulações numéricas baseados no método dos elementos finitos em ligações viga-viga e viga-pilar submetidas a carregamentos estáticos e cíclicos, Technical University of Madrid que simulou o comportamento de pontes com ligações semirígidas submetidas a sismo atualizando o programa TRIGRA que permitia considerar o comportamento linear ou não linear das ligações, a Univeritat Kaiserslautern que 
simulou estruturas mistas utilizando o programa FEMAS-VERBUND, a University of Nottingham utilizou o programa SWANSA que permitia analisar pórticos em 3D e a não linearidade dos materiais.

O método analítico consiste no equacionamento do comportamento em conjunto dos mecanismos básicos de deformação, e é chamado de método dos componentes.

Ou seja, a idéia do método dos componentes é idealizar a posição deformada da ligação e a partir dessa associar os mecanismos básicos da sua deformação.

Segundo o programa COST C1 (1996) as etapas a serem realizados para determinação do comportamento da ligação pelo método dos componentes são:

- Listagem dos componentes ativos, ou seja, componentes da ligação que promovem contribuição para as propriedades da estrutura.

- Promover uma avaliação das características de deformação e resistência de cada componente individual.

- Promover uma associação dos componentes individuais para representar a ligação como um todo.

Para representar o comportamento da ligação, nos nós são aplicadas molas para simular a rigidez de cada componente.

Uma vez conhecidas todas as características dos componentes, obtidos experimentalmente, através de simulações numéricas ou analíticas dependendo do grau de sofisticação desejado, as molas podem ser adicionadas para configurar o comportamento da ligação como um todo.

A Figura 2.8 ilustra a ligação viga-pilar de estrutura metálica submetida a momento fletor e a configuração da ligação através de molas pelo método dos componentes.

As molas podem ser somadas em série ou em paralelo diminuindo assim a complexibilidade do modelo, como mostra a Figura 2.8 b e c. No caso da Figura 2.8 c, $\mathrm{K}_{1}, \mathrm{~K}_{\mathrm{eq}}$ e $\mathrm{K}_{11}$ representam respectivamente a alma do pilar submetido ao cisalhamento, armadura longitudinal tracionada na parte superior da ligação e a alma do pilar submetido à compressão em conjunto com a chapa de contato. 

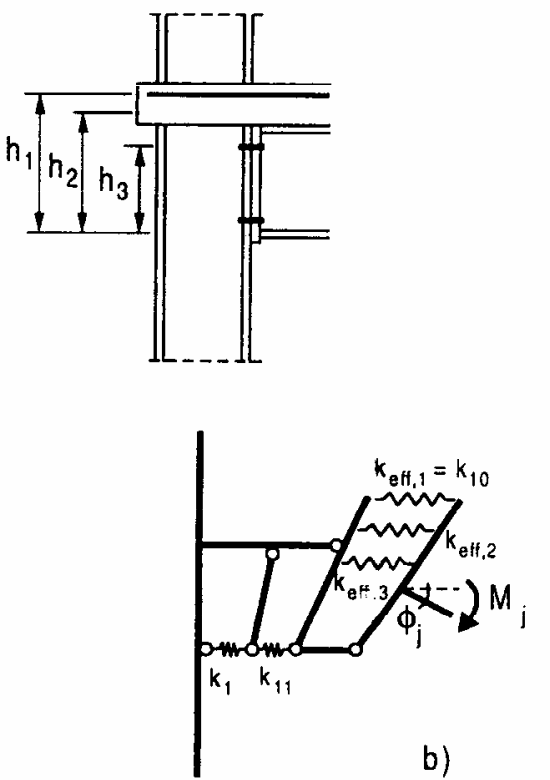

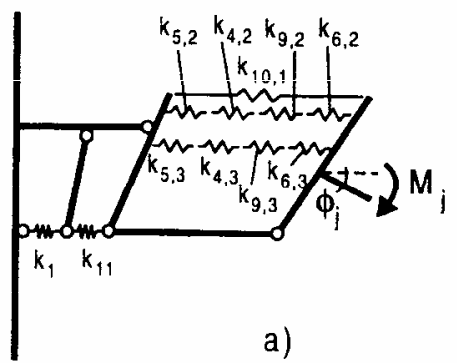

a)

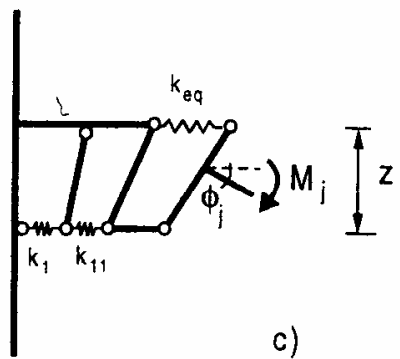

Figura 2.8 - Simplificação do modelo de molas através da soma de molas em série e paralelo [COST C1 (1996)]

Utilizar curvas não lineares para caracterização dos componentes da ligação é incompatível com a prática de projetos. Para simplificá-las consideramos a curva momento-rotação linear para análise no estado limite de serviço (ELS) e bi-linear para o estado limite último (ELU) como mostrado na seção 2.1.

A linearização do comportamento da ligação, no regime elástico, permite que a rigidez inicial de cada componente seja representada pela relação força-deformação dada por:

$$
F_{i}=K_{i} \cdot E \cdot \Delta_{i}
$$

$\mathrm{O}$ momento $\mathrm{M}_{\mathrm{j}}$ que atua sobre a ligação pode ser escrito como F.z, sendo z à distância entre o ponto central de tração e o de compressão. A rotação $\phi_{j}$ da ligação passa a ser:

$\phi_{j}=\frac{\Delta_{1}+\Delta_{10}+\Delta_{11}}{z}$

Portanto: 


$$
S_{j}=\frac{M_{j}}{\phi_{j}}=\frac{F \cdot z}{\frac{\Delta_{1}}{z}+\frac{\Delta_{10}}{z}+\frac{\Delta_{11}}{z}}=\frac{F \cdot z^{2}}{\frac{F}{E} \cdot\left(\frac{1}{K_{1}}+\frac{1}{K_{10}}+\frac{1}{K_{11}}\right)}=\frac{E \cdot z^{2}}{\sum_{i} \frac{1}{K_{i}}}
$$

Para a analise da resistência da ligação, o momento resistente de projeto da ligação $\mathrm{M}_{\mathrm{j}, \mathrm{Rd}}$ é relacionado à força de projeto $\mathrm{F}_{\mathrm{Rd}}$ do componente mais frágil. A figura 2.9 mostra o equilíbrio de forças.

$$
M_{j, R d}=F_{R d} \cdot z
$$

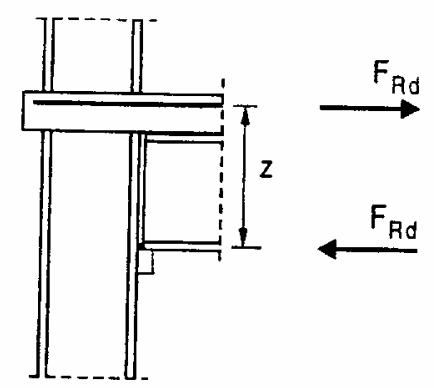

Figura 2.9 - Equilíbrio de forças [COST C1 (1996)]

Vê-se, portanto que o método dos componentes é suficientemente geral para permitir várias técnicas de determinação das características dos componentes e da junção destes para gerar o comportamento da ligação como um todo.

A boa representação do modelo, facilidade de cálculo e a possibilidade de representar inúmeras ligações devido à variedade de combinações dos componentes dos elementos torna o método dos componentes viável para utilização do dia-a-dia. Porém em ligações mais complexas essa avaliação pode ser mais difícil e em geral com maior grau de aproximação.

\subsubsection{Mecanismos básicos de deformação}

Nesta seção é promovida uma sucinta análise dos mecanismos de deformação para os quais a ligação a ser estudada estará submetida, possibilitando assim propor, mais adiante, a formulação de um modelo analítico que represente o comportamento da ligação a momento fletor. 


\subsubsection{Transferência de forças de tração}

A transferência de forças de tração em barras envoltas em concreto é dada ao longo da interface concreto/aço através de tensões de aderência que não são uniformemente distribuídas, devido ao escorregamento em pontos da barra, mas que para efeito de cálculo são consideradas uniformes. A Figura 2.10 apresenta a curva simplificada das tensões de aderência ao longo da barra.

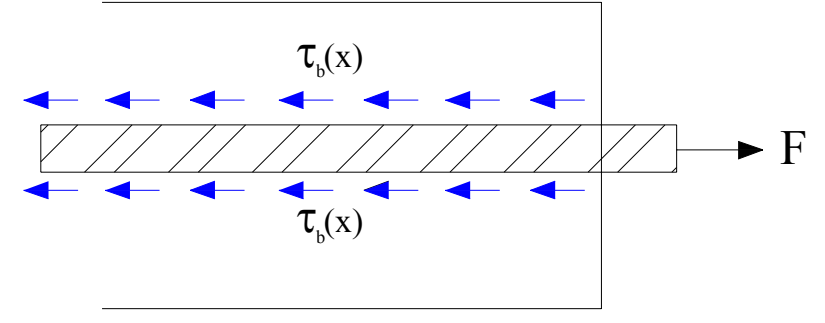

$\tau_{\mathrm{b}}(\mathrm{x})$

Figura 2.10 - Distribuição simplificada das tensões de aderência de barras tracionadas envoltas em concreto

Baseado em ensaios experimentais de arrancamento o CEB/FIP (1990) definiu a seguinte relação tensão de aderência x deslizamento indicado na Figura 2.11.

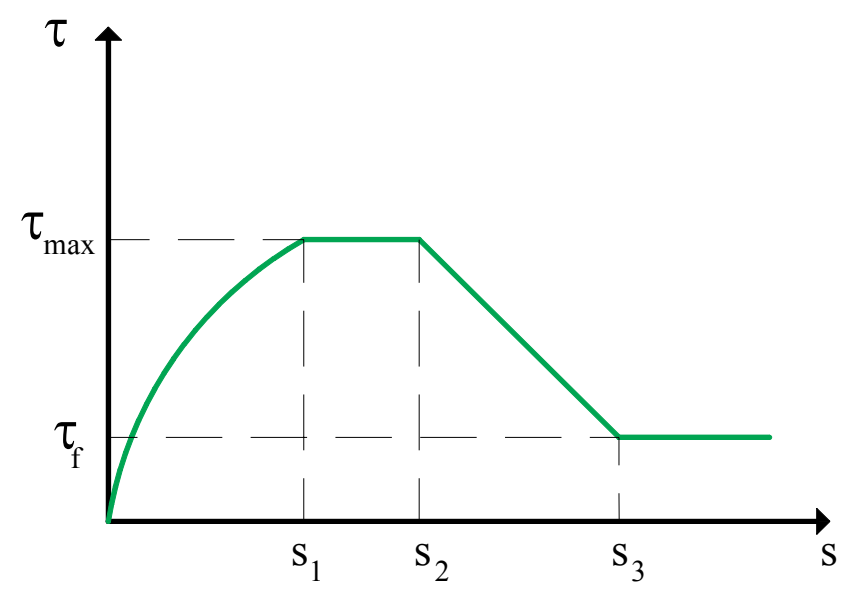

Figura 2.11 - Relação entre tensão de aderência/deslizamento proposto pelo CEB/FIP [FIB (2003)] 
A Tabela 2.4 apresenta os valores dos parâmetros da curva da Figura 2.11 para a situação de concreto confinado e não confinado.

Tabela 2.4 - Parâmetros para avaliação da tensão de aderência [FIB (2003)]

\begin{tabular}{|c|c|c|}
\hline \multicolumn{3}{|c|}{ Concreto confinado } \\
\hline $\begin{array}{c}\text { Condição } \\
\text { de } \\
\text { aderência }\end{array}$ & Boa & Outras \\
\hline $\mathrm{s}_{1}$ & \multicolumn{2}{|c|}{$1 \mathrm{~mm}$} \\
\hline $\mathrm{s}_{2}$ & \multicolumn{3}{|c|}{$3 \mathrm{~mm}$} \\
\hline $\mathrm{s}_{3}$ & \multicolumn{2}{|c|}{--------} \\
\hline$\alpha$ & 0,4 \\
\hline$\tau_{\mathrm{max}}$ & $2,5\left(\mathrm{f}_{\mathrm{ck}}\right)^{1 / 2}$ & $1,25\left(\mathrm{f}_{\mathrm{ck}}\right)^{1 / 2}$ \\
\hline$\tau_{\mathrm{f}}$ & \multicolumn{2}{|c|}{$0,4 \tau_{\max }$} \\
\hline
\end{tabular}

\begin{tabular}{|c|c|c|}
\hline \multicolumn{3}{|c|}{ Concreto não confinado } \\
\hline $\begin{array}{c}\text { Condição } \\
\text { de } \\
\text { aderência }\end{array}$ & Boa & Outras \\
\hline $\mathrm{S}_{1}$ & \multicolumn{2}{|c|}{$0,6 \mathrm{~mm}$} \\
\hline $\mathrm{S}_{2}$ & \multicolumn{2}{|c|}{$0,6 \mathrm{~mm}$} \\
\hline \multirow[t]{2}{*}{$\mathrm{S}_{3}$} & $1 \mathrm{~mm}$ & $2,5 \mathrm{~mm}$ \\
\hline & \multicolumn{2}{|c|}{0,4} \\
\hline$\tau_{\max }$ & $2,0\left(f_{\mathrm{ck}}\right)^{1 / 2}$ & $1,0\left(\mathrm{f}_{\mathrm{ck}}\right)^{1 / 2}$ \\
\hline$\tau_{\mathrm{f}}$ & \multicolumn{2}{|c|}{$0,15 \tau_{\max }$} \\
\hline
\end{tabular}

São consideradas boas condições de aderência: barras com inclinação de 45 à $90^{\circ}$ com a horizontal ou barras com inclinação inferior a $45^{\circ}$ com a horizontal e distanciadas a menos de $250 \mathrm{~mm}$ do fundo da peça ou $300 \mathrm{~mm}$ do seu topo.

Observou-se que o modelo da Figura 2.11 não informa como considerar o efeito de escoamento da armadura, sendo, portanto válido apenas para o regime elástico. Quando a barra começa a escoar em um ponto, um ramo descendente deve ser usado para esta seção onde a deformação no aço supera a de escoamento.

Engstrom (1992) apud FIB (2003) para levar em conta o efeito do escoamento da barra propôs o gráfico apresentado na Figura 2.12. 


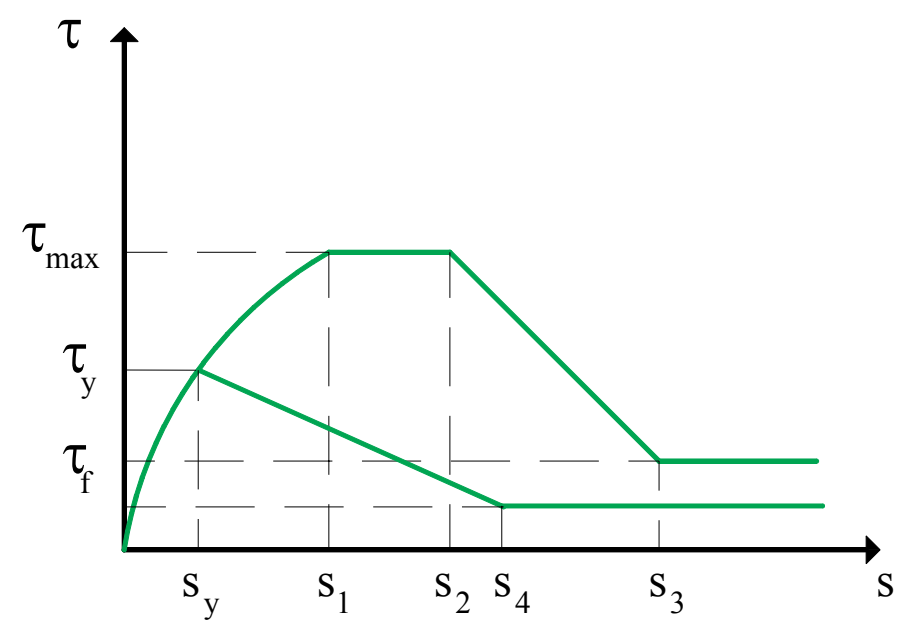

Figura 2.12 - Relação entre a tensão de aderência/deslizamento [FIB (2003)]

No caso de concreto confinado os novos parâmetros $\mathrm{S}_{4}$ e $\tau_{\mathrm{f}, \mathrm{pl}}$ tem valores de 0,5 $\mathrm{s}_{3}$ e $0,5 \tau_{\mathrm{f}}$ respectivamente.

No caso de ligações com barras tracionadas contínuas com presença de juntas a serem preenchidas, como mostra a Figura 2.13, ao ser submetida a tensões apresentaram, provavelmente, a primeira fissura em uma das interfaces junta/elemento. Ao se aumentar o carregamento a capacidade de rearranjo dos esforços é, normalmente, insuficiente para formar o aparecimento de outras fissuras, concentrando as deformações na primeira fissura até um valor máximo de abertura $\mathrm{W}_{\mathrm{u}}$.

Vale salientar que diversos estudos comprovaram que caso apareçam fissuras em ambas as interfaces, e não em apenas uma, devido a pouca aderência, por exemplo, a máxima abertura de fissura em cada interface $\left(\mathrm{W}_{\mathrm{ui}}\right)$ será igual ou menor que a abertura máxima de uma única interface $\mathrm{w}_{\mathrm{u}}$.

$$
w_{u i} \leq w_{u}
$$



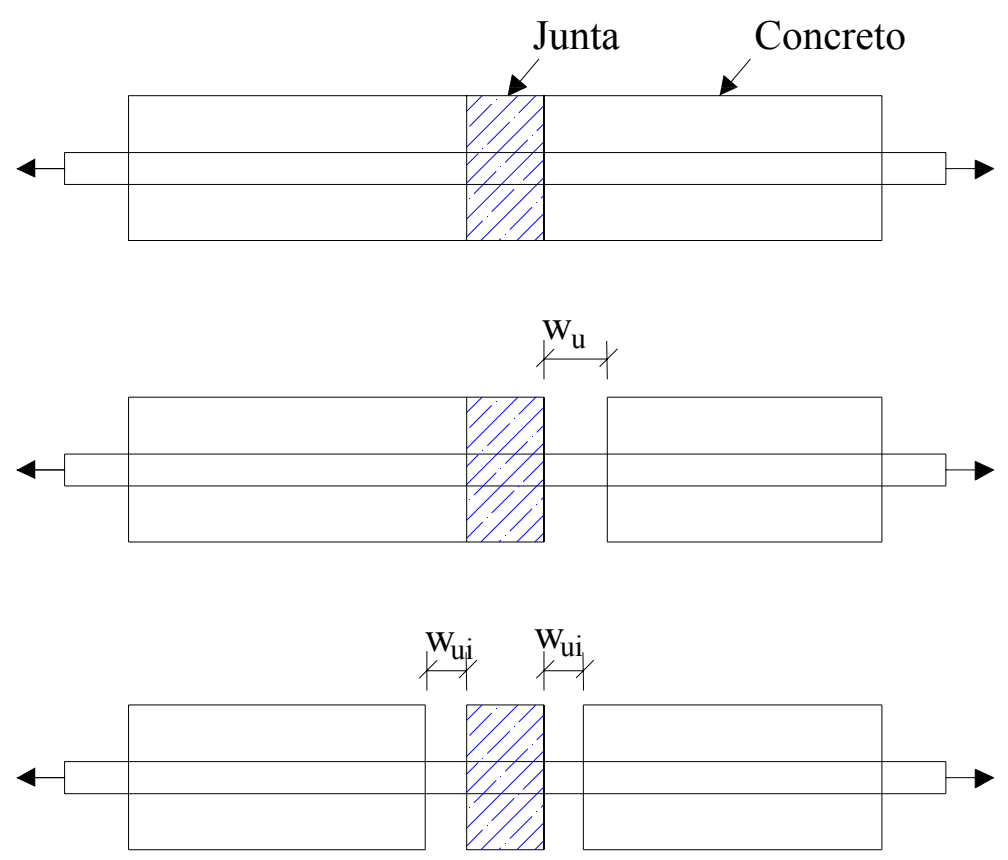

Figura 2.13 - Configuração da abertura de fissura [FIB (2003)]

Para se estimar os valores de abertura de fissura das ligações de barras tracionadas envoltas em concreto a FIB (2003) propõe um diagrama simplificado força $\mathrm{x}$ abertura de fissura dado na Figura 2.14.

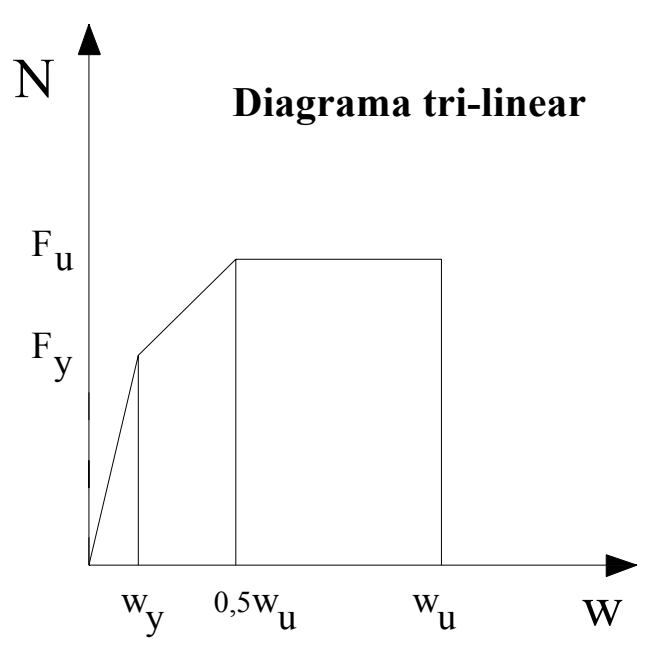

Figura 2.14 - Diagrama simplificado força x abertura de fissura [FIB (2003)] 
$\mathrm{O}$ valor de $\mathrm{w}_{\mathrm{y}}$ e dado por:

$w_{y}=0,576 \cdot\left(\frac{\phi_{d} \cdot f_{y}^{2}}{\tau_{\max } \cdot E_{s}}\right)^{0,714}+\frac{f_{y} \cdot 4 \cdot \phi_{d}}{E_{s}}$

Onde:

$w_{y} \quad=$ Abertura de fissura na armadura tracionadas

$\phi_{d} \quad=$ Diâmetro da armadura

$f_{y} \quad=$ Tensão de escoamento do aço

$\tau_{\max }=$ Máxima tensão de aderência

$E_{s} \quad=$ Módulo de elasticidade do aço

\subsubsection{Transferência de forças de cisalhamento}

Uma das formas de se transmitir esforços de cisalhamento entre elementos é através de barras transversais (chumbadores) inseridas em concreto submetidas a esforços horizontais. Essa transferência de forças provoca o surgimento de um estado de tensões não uniformes no concreto como mostra a Figura 2.15 e que submetem o chumbador à flexão com um momento fletor máximo próximo a interface.
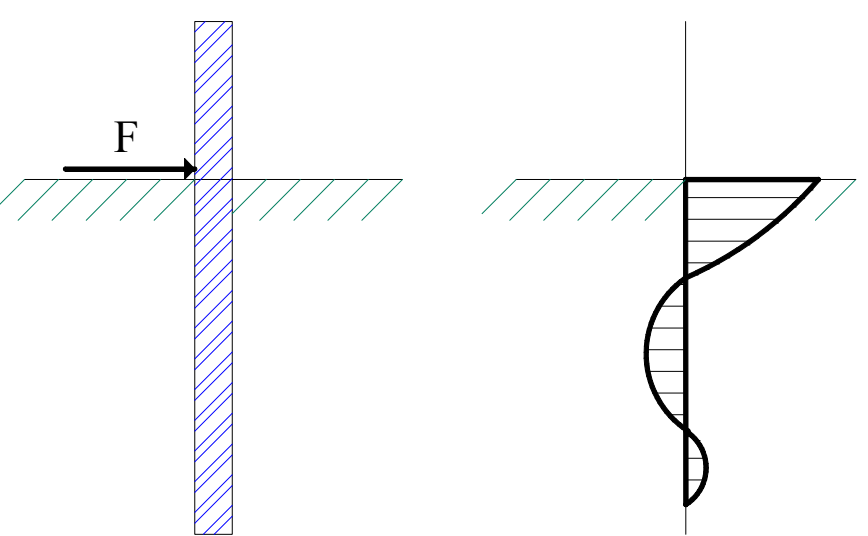

Figura 2.15 - Tensões no concreto devido ao efeito de pino para análise linear 
Dependendo das dimensões, posição e resistência do chumbador além da resistência do concreto que o envolve diversos tipos de rupturas podem ser previstos.

Quando o chumbador não tem resistência muito menor que a do concreto que o circunda o modo de ruptura previsto em cálculo é através da formação de rótulas plásticas na seção de máximo momento fletor.

Quando se tem chumbadores inseridos em dois elementos haverá formação de rótulas plásticas em cada um destes elementos e a carga última é dada pela formação da segunda rótula plástica.

Estas rótulas podem formar-se simultaneamente quando as resistências dos elementos que envolvem o chumbador forem às mesmas ou formar-se em períodos diferentes para resistências distintas. Neste caso a primeira rotula plástica se forma no elemento de menor resistência enquanto que o elemento de maior resistência ainda está no regime elástico. Posteriormente forma-se a segunda rotula plástica no elemento mais resistente.

Percebe-se, entretanto, que ao se formar a primeira rotula a rigidez da ligação é reduzida.

A Figura 2.16 mostra a configuração do chumbador após a formação das rotulas plásticas para o caso de haver ou não uma altura livre entre os elementos.

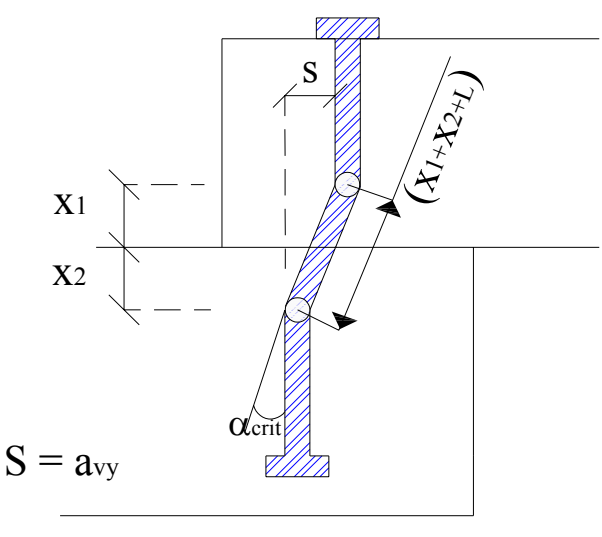

(a) Sem altura livre entre os elementos

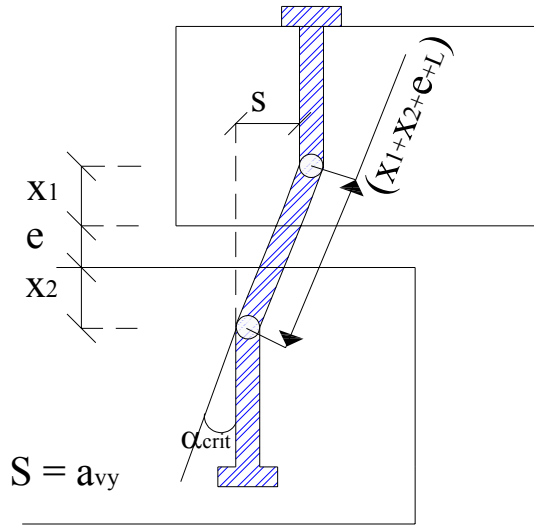

(b) Com altura livre entre os elementos

Figura 2.16 - Formação de rótulas plásticas em chumbadores inseridos em dois elementos [FIB (2003)] 
Hojlund-Rasmussen (1963) apud FIB (2003) adotando a teoria de plasticidade, sugere para representar a força máxima que provoca o surgimento da rótula plástica e a distância desta força a interface do elemento respectivamente as eq. (2.9) e (2.11).

$$
\begin{aligned}
& F_{p}=c_{1} \cdot \phi_{c h}^{2} \cdot \sqrt{f_{y} \cdot f_{c c, \text { max }}} \\
& q_{c}=3 \cdot c_{1}^{2} \cdot f_{c c, \text { max }} \cdot \phi_{c h} \\
& x=\frac{F_{p}}{q_{c}}=\frac{\sqrt{\frac{f_{y}}{f_{c c, \max }}}}{3 \cdot c_{1}} \cdot \phi_{c h}
\end{aligned}
$$

Sendo:

$F_{p} \quad=$ Força responsável pela formação da segunda rótula plástica no chumbador

$c_{1}=$ Coeficiente para consideração do efeito de compressão tri-axial

$\phi_{c h} \quad=$ Diâmetro do chumbador

$f_{y} \quad=$ Tensão de escoamento do aço

$f_{c c, \max }=$ maior valor de resistência à compressão dentre os elementos que envolvem o chumbador

No caso de haver um carregamento excêntrico ou restrições de deslocamento o coeficiente $c_{1}$ da eq. (2.12) deve ser modificado para levar em conta estes efeitos. Engstrom (1992) sugere $c_{r}=\sqrt{2}$ para o caso de restrição total e $c_{r}=\frac{\sqrt{2}+1}{2}$ no caso de restrição parcial. Para carregamento assimétrico o coeficiente $c_{\mathrm{e}}$ é dado por eq.(2.14)

$$
\begin{aligned}
& c_{1}=c_{r} \cdot c_{e} \\
& c_{r}=\sqrt{1+\frac{M_{y, r e d}}{M_{y}}} \\
& c_{e}=\sqrt{1+\left(\varepsilon \cdot c_{1}\right)^{2}}-\varepsilon \cdot c_{1} \\
& \varepsilon=\frac{3 \cdot e}{\phi_{c h}} \cdot \sqrt{\frac{f_{c c, \text { max }}}{f_{y}}}
\end{aligned}
$$


Onde:

$c_{r} \quad=$ Coeficiente para consideração de restrição ao deslocamento

$c_{e} \quad=$ Coeficiente para consideração da excentricidade da carga aplicada no chumbador

$M_{y, r e d}=$ Momento de plastificação do chumbador no ponto de fixação

$M_{y} \quad=$ Momento de plastificação do chumbador

$e \quad=$ Excentricidade da carga aplicada no chumbador

Engstrom (1990) apud FIB (2003) complementando os estudos de transferência de forças de cisalhamento em chumbadores inserido em concreto propõe que as rotulas plásticas se formam quando a inclinação total do chumbador atinge o valor crítico dado pela eq. (2.16). Esta inclinação crítica é proporcional à curvatura da seção crítica do chumbador quando seu escoamento é atingido.

$\alpha_{c r i t}=k \cdot \frac{f_{y}}{E_{s} \cdot \phi_{c h}}$

$\alpha_{c r i t}=\frac{a_{v y}}{x} \quad$ (chumbador inserido em um único elemento de concreto)

$\alpha_{c r i t}=\frac{a_{v y}}{l_{p p}}$ (chumbador inserido em dois elementos de concreto)

$l_{p p}=x_{1}+x_{2}+h_{a}$

Sendo:

$k \quad=1,75 \mathrm{~m}$ [Engstrom 1992]

$E_{s} \quad=$ Módulo de elasticidade do aço

$a_{v y} \quad=$ Deformação angular crítica

$h_{a} \quad=$ Altura livre entre os elementos de concreto que envolve o chumbador

Além do efeito de pino ao qual o chumbado está submetido, pode-se contabilizar o efeito do atrito entre as interfaces do concreto. Estudos realizados com ligações vigapilar utilizando chumbadores ancorados em duas extremidades considerando o efeito do 
atrito têm mostrado um acréscimo da capacidade resistiva cisalhante da ligação dada por:

$$
\begin{aligned}
& F_{p}=c_{1} \cdot \phi_{c h}^{2} \cdot \sqrt{f_{y, \text { red }} \cdot f_{c c, \text { max }}}+\mu_{s} \cdot \sigma_{n} \cdot A_{s} \\
& f_{y, \text { red }}=f_{y}-\sigma_{n}
\end{aligned}
$$

Onde:

$\mu_{s} \quad=$ Coeficiente de atrito na interface

$\sigma_{n} \quad=$ Tensão atuante no chumbador quando o mecanismo é formado

$A_{s} \quad=$ Área da seção transversal do chumbador

Dulácska (1972) apud FIB (2003) estudou o comportamento de chumbadores inseridos em elementos de concreto inclinados de um ângulo $\theta$ com a superfície plana. Verificou-se que a capacidade resistente da ligação a cisalhamento não mais era dada pela eq.(2.9), mas sim por:

$$
\begin{aligned}
& F_{p}=\gamma \cdot k \cdot \operatorname{sen}(\theta) \cdot f_{y} \cdot \phi_{c h}^{2} \cdot\left[\sqrt{1+\frac{f_{c c}}{3 \cdot \gamma^{2} \cdot k \cdot \operatorname{sen}(\theta)^{2} \cdot f_{y}}}-1\right] \\
& k=3 \cdot c^{2}
\end{aligned}
$$

Com:

$\theta \quad=$ Ângulo de inclinação do chumbador com a superfície plana

\subsubsection{Transferência de forças de compressão}

Em elementos de concreto pré-moldados os esforços de compressão, na sua maioria, são transmitidos através de juntas horizontais. Bjluger (1988) defende que a deformabilidade das juntas de argamassas varia com a resistência a compressão destas e sua geometria. Para o cálculo da deformabilidade de uma ligação com n juntas Bjluger (1988) propõe:

$$
\lambda_{c}=n \cdot D_{j}+\frac{h}{\sum_{i} \frac{a}{n_{i} \cdot D_{i}}}
$$


Onde:

$D_{j} \quad=$ Deformabilidade da junta

$h \quad=$ Espessura da junta

$a \quad=$ Largura da junta

$i \quad=$ Número de juntas

A Tabela 2.5 apresenta a deformabilidade de juntas entre painéis e pilares com material de preenchimento de concreto e argamassa.

Tabela 2.5 - Deformabilidade das juntas de argamassa e concreto [BJLUGER (1998)]

\begin{tabular}{|l|c|c|c|c|}
\hline \multirow{2}{*}{ Tipo de junta } & \multirow{2}{*}{$\begin{array}{c}\text { Material de } \\
\text { preenchimento }\end{array}$} & \multicolumn{3}{|c|}{$\begin{array}{r}\text { Resistência à compressão do concreto ou argamassa } \\
\text { em contato com os elementos pré-moldados } \\
(\mathrm{m} / \mathrm{MPa})\end{array}$} \\
\cline { 3 - 6 } & & Até $1 \mathrm{MPa}$ & $5 \mathrm{MPa}$ & $>10 \mathrm{MPa}$ \\
\hline \multirow{2}{*}{ Entre painéis } & Argamassa & $10^{-4}$ & $0,610^{-4}$ & $0,410^{-4}$ \\
\cline { 2 - 5 } & Concreto & ------- & ------- & $0,210^{-4}$ \\
\hline \multirow{2}{*}{ Entre pilares } & Argamassa & ------- & ------- & $0,510^{-4}$ \\
\cline { 2 - 6 } & Concreto & ------ & ------ & $0,210^{-4}$ \\
\hline
\end{tabular}

\subsection{PRINCIPAIS ESTUDOS REALIZADOS}

Como visto no capítulo de introdução deste trabalho, diversos estudos foram desenvolvidos para análise do comportamento das ligações em elementos pré-moldados.

Em seu trabalho Dolan, Stanton e Anderson (1987) apresentam resumidamente os resultados do programa PCI 1/4 desenvolvido nos Estados Unidos para análise do comportamento da ligação de elementos pré-moldados mais usuais.

Foram realizados testes individuais em oito tipos de ligação, mostradas na Figura 2.17, submetidas a carregamentos gravitacionais, forças laterais ou carregamentos cíclicos equivalentes. 


\section{$\mathrm{BC} 15$}

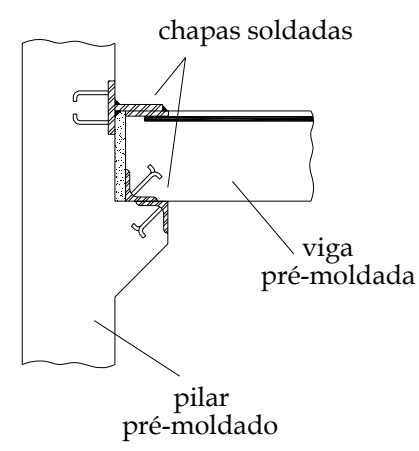

$\mathrm{BC} 26$

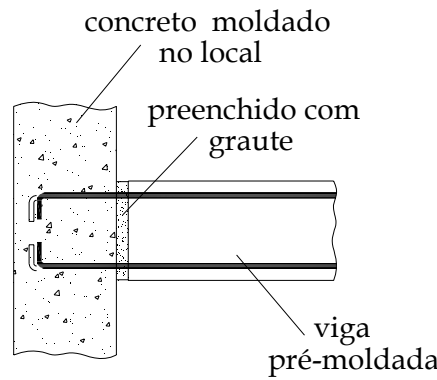

$\mathrm{BC} 27$

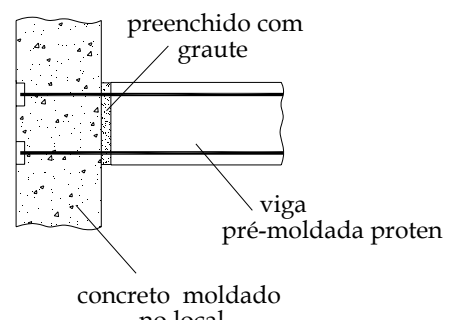

BC16A

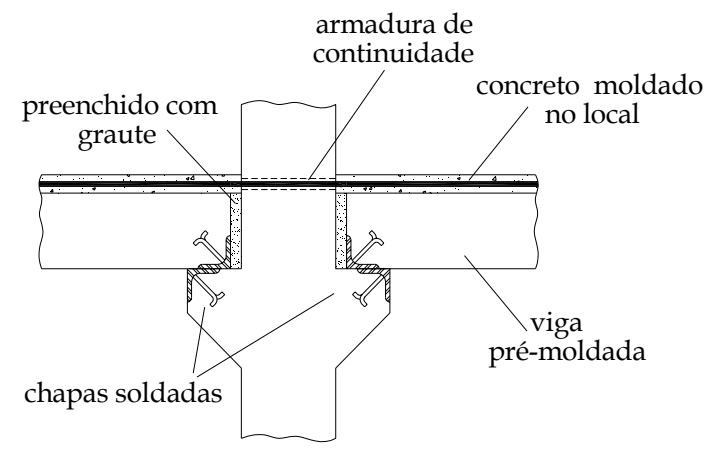

$\mathrm{CC} 1$ e $\mathrm{BC} 25$

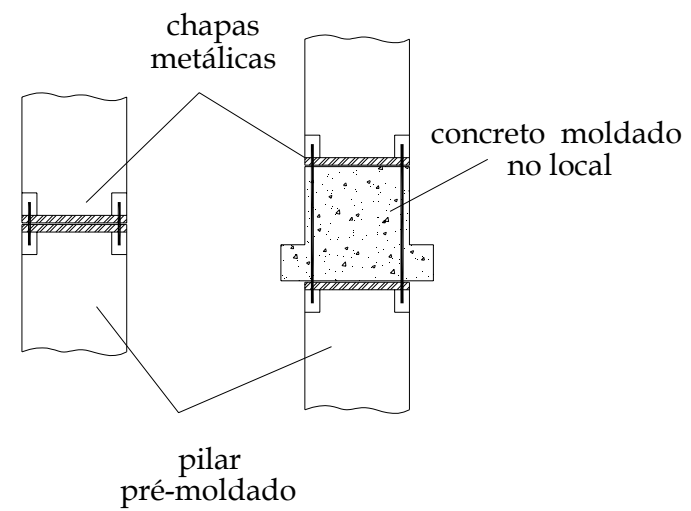

BC28 E BC29

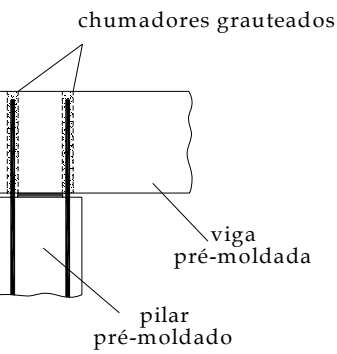

Figura 2.17 - Ligações BC15, BC16A, BC 26, CC1 e BC 25, BC 27, BC 28 e BC 29 [DOLAN, Stanton e Anderson (1987)]

Os resultados mostram que:

As ligações BC15, BC16A, BC25, BC26, BC28 e BC 29 tiveram sua resistência última no mínimo igual à prevista para momento fletor negativo. 
$\checkmark$ A ligação BC16A possui uma capacidade resistente a momento fletor positivo da ordem de $30 \%$ da capacidade a momento fletor negativo.

$\checkmark$ A ligação BC15 apresenta uma capacidade resistente a momento fletor positivo da ordem de $65 \%$ da capacidade a momento fletor negativo.

$\checkmark$ As ligações BC25 e CC1 apresentaram capacidade resistente a momento fletor negativo próximas a capacidade resistente a momento fletor positivo.

$\checkmark$ As ligações BC28 e BC29 suportaram pequenos momentos e sofreram grandes deformações.

$\checkmark$ A presença de fios pós-tracionados na ligação BC27 promoveu boa rigidez inicial, equivalendo-se a um concreto de $\mathrm{E}_{\mathrm{c}}=51000 \mathrm{MPa}$.

$\mathrm{Na}$ Tabela 2.6 se encontra o resumo dos momentos previstos e suportados no experimento.

Tabela 2.6 - Resumo dos momentos previstos e suportados [DOLAN, STANTON e ANDERSON (1987)]

\begin{tabular}{|c|c|c|c|c|c|c|}
\hline \multirow{2}{*}{$\begin{array}{l}\text { Tipo de } \\
\text { ligação }\end{array}$} & \multicolumn{3}{|c|}{ Momento negativo } & \multirow{2}{*}{\begin{tabular}{|c}
$\begin{array}{c}\text { Momento } \\
\text { positivo }\end{array}$ \\
Capacidade \\
medida \\
$(\mathrm{kN} . \mathrm{m})$
\end{tabular}} & \multicolumn{2}{|c|}{ Máxima rotação } \\
\hline & $\begin{array}{c}\text { Momento } \\
\text { de projeto } \\
\text { (kN.m) }\end{array}$ & $\begin{array}{c}\text { Capacidade } \\
\text { prevista } \\
(\mathrm{kN} . \mathrm{m})\end{array}$ & $\begin{array}{c}\text { Capacidade } \\
\text { medida } \\
(\mathrm{kN} . \mathrm{m})\end{array}$ & & $\begin{array}{c}\text { Negativo } \\
(\%)\end{array}$ & $\begin{array}{c}\text { Positivo } \\
(\%)\end{array}$ \\
\hline $\mathrm{BC} 15$ & 161,34 & 215,12 & 246,87 & 163,82 & 3,7 & 1,20 \\
\hline $\mathrm{BC} 16 \mathrm{~A}$ & 161,34 & 215,12 & 395,44 & 137,61 & 10,0 & 4,00 \\
\hline $\mathrm{BC} 25$ & 179,30 & 281,10 & 512,38 & 477,69 & 4,0 & 4,00 \\
\hline $\mathrm{CC} 1$ & 115,24 & 184,39 & 172,07 & 177,95 & 4,0 & 3,65 \\
\hline $\mathrm{BC} 26$ & 161,34 & 215,12 & 350,25 & $\begin{array}{l}----- \\
\end{array}$ & 12,5 & ------ \\
\hline $\mathrm{BC} 27$ & 235,68 & 290,93 & 269,80 & ------ & 8,3 & ------ \\
\hline $\mathrm{BC} 28$ & 32,87 & 45,08 & 65,07 & ------ & 4,1 & ------ \\
\hline $\mathrm{BC} 29$ & 32,87 & 45,08 & 61,01 & 35,92 & 3,9 & 3,75 \\
\hline
\end{tabular}

Em Elliott, Davies e Gorgun (1994) apresenta-se, a partir de dados isolados de testes de compressão e flexão, uma forma simples de se reproduzir o comportamento da ligação da Figura 2.18 através do método dos componentes. 


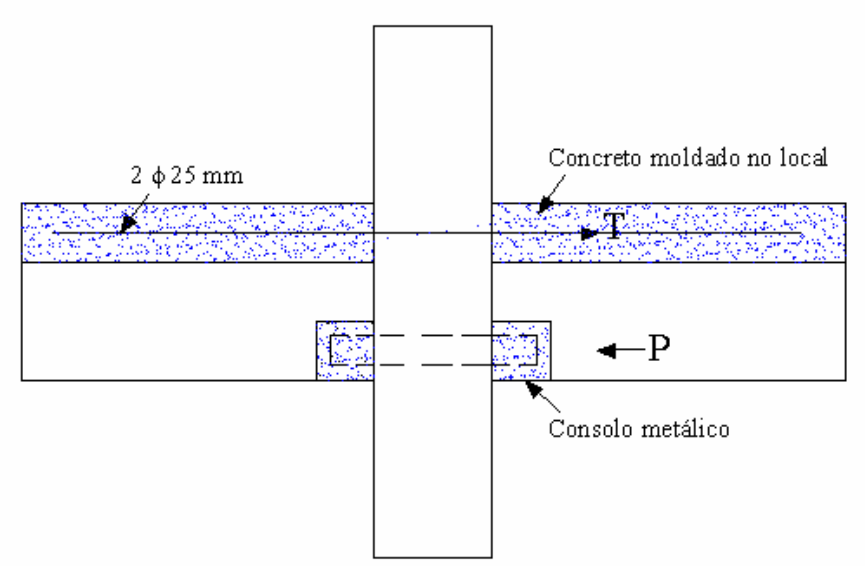

Figura 2.18 - Ligação estudada [ELLIOTT, DAVIES e GORGUN (1994)]

Ao se submeter à estrutura a momentos negativos aparece uma zona de compressão próxima ao consolo e uma zona de tração próxima à capa.

Para determinar a deformação $\delta_{\mathrm{B}}$ da zona de compressão foram confeccionados 8 prismas de concreto pré-moldado com variação da espessura da junta de concreto moldado no local de $\mathrm{t}=0 \mathrm{at}=100 \mathrm{~mm}$.

Foram criadas 2 séries de ensaios, série A (com ensaio de 5 modelos) para análise das juntas submetidas apenas à compressão e as séries $\mathrm{B}$ (com ensaio de 3 modelos) para juntas submetidas à flexão pura através do ensaio de 4 pontos. Para este ultimo ensaio os prismas continham 2 barras de $\phi 10 \mathrm{~mm}$.

A Tabela 2.7 demonstra os resultados experimentais verificados para as séries A.

Tabela 2.7- Resultados do ensaio a compressão do prisma [ELLIOTT,DAVIES e GORGUN (1994)]

\begin{tabular}{|c|c|c|c|c|c|}
\hline $\begin{array}{c}\text { Tipo de } \\
\text { ligação }\end{array}$ & $\begin{array}{c}\text { Espessura } \\
\mathrm{t}(\mathrm{mm})\end{array}$ & $\begin{array}{c}\text { Resistência } \\
\mathrm{CPM} \\
\left(\mathrm{N} / \mathrm{mm}^{2}\right)\end{array}$ & $\begin{array}{c}\text { Resistência } \\
\mathrm{CML} \\
\left(\mathrm{N} / \mathrm{mm}^{2}\right)\end{array}$ & $\begin{array}{c}\text { E efetivo } \\
\left(\mathrm{kN} / \mathrm{mm}^{2}\right)\end{array}$ & $\begin{array}{c}\text { Resistência } \\
\text { última } \\
\left(\mathrm{N} / \mathrm{mm}^{2}\right)\end{array}$ \\
\hline $\mathrm{A} 1$ & ----- & 40,85 & 21,20 & 26,30 & 31,8 \\
\hline A2 & 0 & 40,85 & 21,20 & 20,00 & 30,0 \\
\hline A3 & 25 & 40,85 & 21,20 & 18,70 & 28,0 \\
\hline A4 & 50 & 40,85 & 21,20 & 13,86 & 24,0 \\
\hline A5 & 100 & 40,85 & 21,20 & 13,30 & 20,0 \\
\hline
\end{tabular}

Na Figura 2.19 encontra se a curva força deformação para os ensaios de compressão e flexão dos prismas respectivamente. 


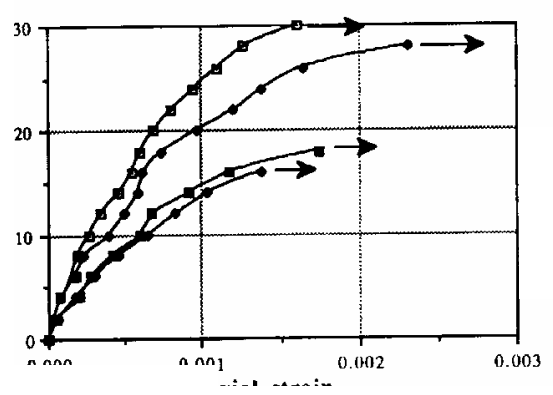

$$
\begin{aligned}
& \square \mathrm{t}=0 \\
& \mathrm{t}=25 \\
& \mathrm{t}=50 \\
& \mathrm{t}=100
\end{aligned}
$$

Série A

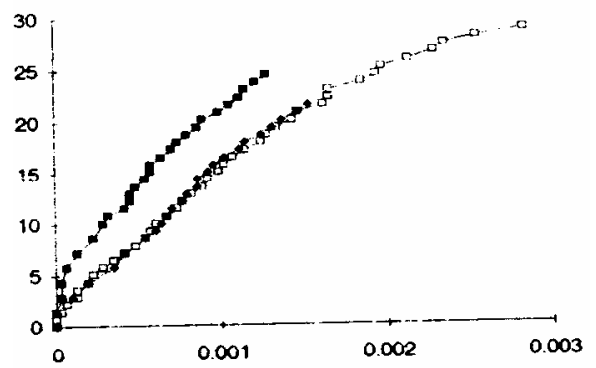

$\mathrm{C} 40 / \mathrm{t}=0$

$\square \mathrm{C} 40 / \mathrm{t}=25$

$\mathrm{C} 40 / \mathrm{t}=50$

Série B

Figura 2.19 - Diagrama tensão x deformação [ELLIOTT,DAVIES e GORGUN (1994)]

Para análise a deformação $\delta_{\mathrm{T}}$ da zona de tração foram criados prismas como o da

Figura 2.20. As resistências dos concretos permaneceram as mesmas que para o ensaio a compressão e flexão na zona de compressão.

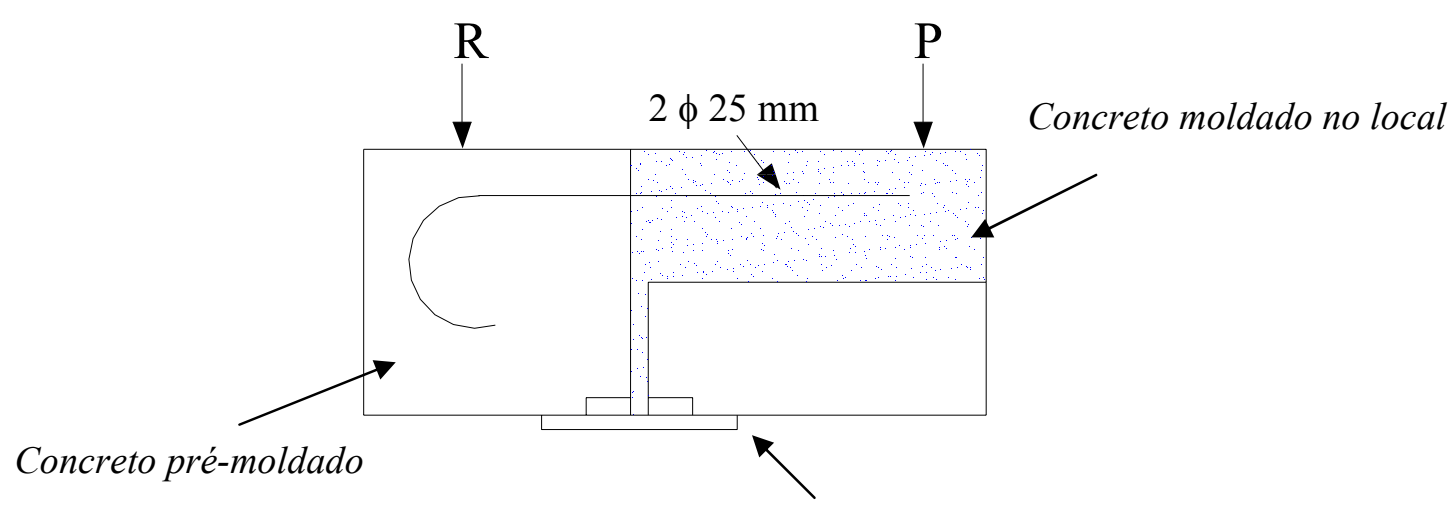

Suporte metálico

Figura 2.20 - Ensaio a tração do prisma [ELLIOTT,DAVIES e GORGUN (1994)] 
Através das deformações das zonas de compressão e tração foi determinada a rotação através da relação $\phi=\frac{\left(\delta_{T}-\delta_{B}\right)}{D}$, sendo $\mathrm{D}$ a altura útil da ligação, calculado o momento através de $M=F \cdot l$, com 1 o comprimento da força aplicada ao pilar e obtida a curva momento-rotação da ligação.

Comparando à curva momento-rotação obtida dos ensaios experimentais realizados com a estrutura com um todo com a curva feita através do uso do método dos componentes observou-se um comportamento bastante próximo. Entretanto as resistências últimas e as rotações últimas previstas através do método analítico foram ligeiramente inferiores às obtidas através do ensaio experimental. Isso se deve capacidade de redistribuição de momentos da estrutura.

Koronen (1996) apresenta os resultados de ensaios de oito tipos de ligações viga-pilar semi-rígida diferentes de uma estrutura aporticada visando analisar o comportamento destas ligações quanto ao deslocamento e momento fletor na base do pilar.

As variáveis estudadas foram à presença de elastômero ou chapas metálicas, comprimento do elastômero, número e posição de roletes metálicos e presença de chumbadores com e sem protensão.

A Figura 2.21 apresenta as ligações estudadas por Koronen (1996).

Com base nos resultados observou-se que quando comparado com as ligações articuladas (protótipo C3 e C6) as ligações C4 e C5 tiveram uma redução nos deslocamentos e momentos na base do pilar de 90 e $70 \%$ respectivamente.

A ligação $\mathrm{C} 1$ apresentou, quando comparada a articulações, uma redução de $60 \%$ nos deslocamentos e $40 \%$ nos momentos na base do pilar. Já a ligação C2 as reduções foram de 30 e $20 \%$ respectivamente. Constata-se que para obterem-se menores deslocamentos e momentos na base dos pilares o aparelho de apoio deve ter o maior comprimento possível.

Segundo Koronen (1996) a presença de placas metálicas, roletes metálicos ou chumbadores protendidos garantiram a ligação maior rigidez, porém é mais econômico otimizar o tamanho da ligação metálica. 

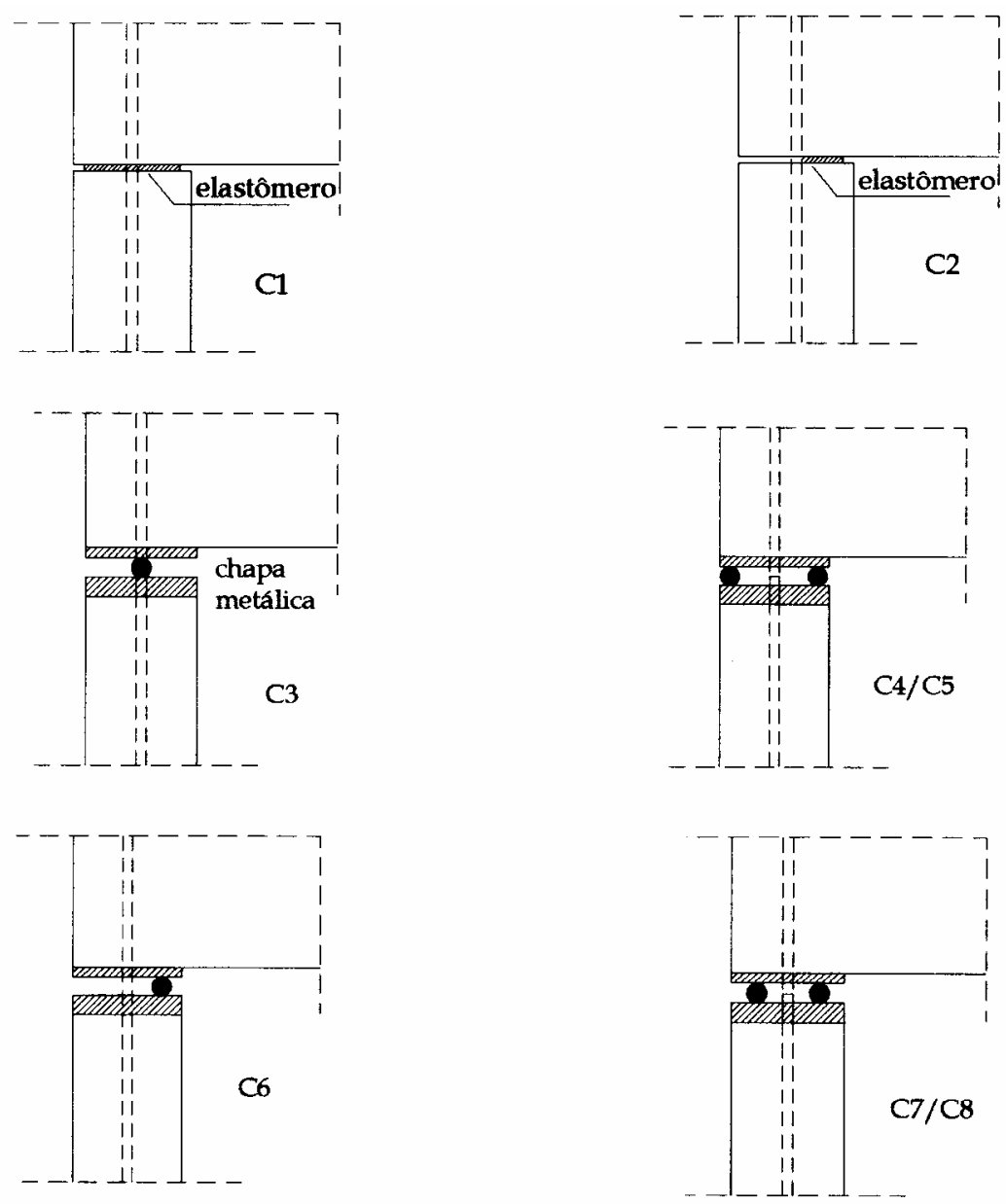

Figura 2.21 - Ligações viga-pilar estudadas [KORONEN (1996)]

Inserido no projeto promovido pelo CERIB "Study and Research Center of the French Precast Concrete Industry”, Chefdebien (1998) apresenta em seu trabalho os resultados de dois modelos de ligações viga-pilar usualmente utilizados na França com o propósito de estudar o comportamento semi-rígido destas ligações que em projetos são consideradas rotuladas.

As ligações estudadas são mostradas na Figura 2.22 e consistiam de almofada de apoio, chumbadores e capa de concreto moldado no local com resistência de $25 \mathrm{MPa}$. A resistência dos elementos pré-moldados (pilar e viga) foi de $60 \mathrm{MPa}$. 


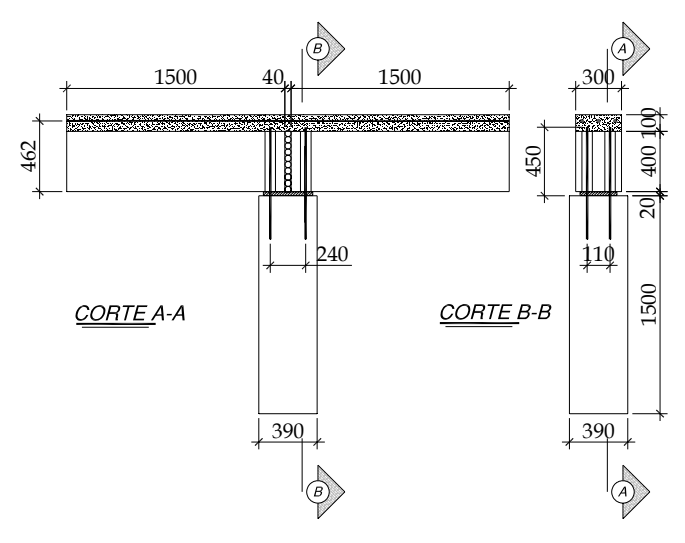

(a)

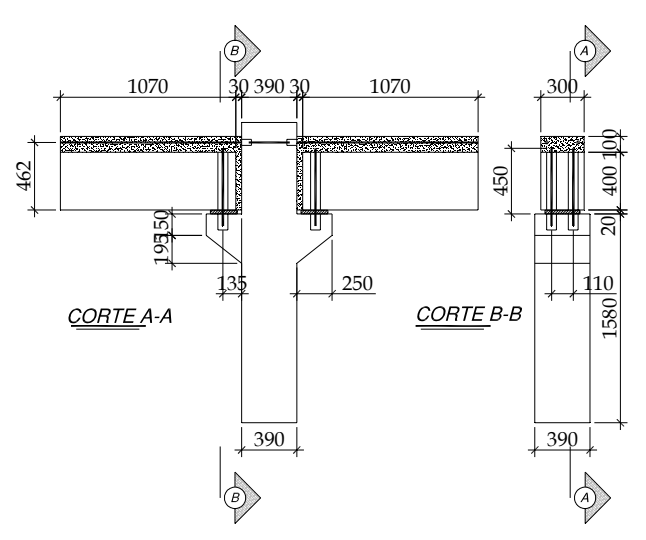

(b)

Figura 2.22 - Ligações viga-pilar estudada por Chefdebien [CHEFDEBIEN (1998)]

Para entender melhor a influência de cada componente da ligação variou-se o material da almofada de apoio, preenchimento vertical e quantidade de armadura da capa de concreto para cada um dos seis modelos como mostra a Tabela 2.8.

Tabela 2.8 - Características dos modelos ensaiados por Chefdebien [CHEFDEBIEN (1998)]

\begin{tabular}{|c|c|c|c|}
\hline Modelo & Almofada de apoio & $\begin{array}{c}\text { Preenchimento } \\
\text { vertical (chumbador) }\end{array}$ & $\begin{array}{c}\text { Armadura de } \\
\text { continuidade }\end{array}$ \\
\hline BC1 & Argamassa & Concreto & $3 \phi 12$ \\
\hline BC2 \& BC5 & Argamassa & Concreto & $3 \phi 16$ \\
\hline BC3 & Neoprene & Poliestireno & $3 \phi 16$ \\
\hline BC4 & Argamassa & Poliestireno & $3 \phi 16$ \\
\hline BC6 & Argamassa & Concreto & $2 \phi 16$ \\
\hline
\end{tabular}

Os modelos foram carregados simetricamente através de 2 atuadores hidráulicos com controle de força como mostra a Figura 2.23. Foi aplicado um carregamento vertical de $200 \mathrm{kN}$ sobre o topo da ligação nos modelos BC1, BC2, BC3 e BC5 com o objetivo de simular o carregamento de andares superiores da estrutura. As rotações foram mensuradas através de transdutores posicionados próximos a face do pilar e sob os pontos de carregamento. Para o modelo BC6 transdutores adicionais foram locados no pilar para medição da rotação da viga. 


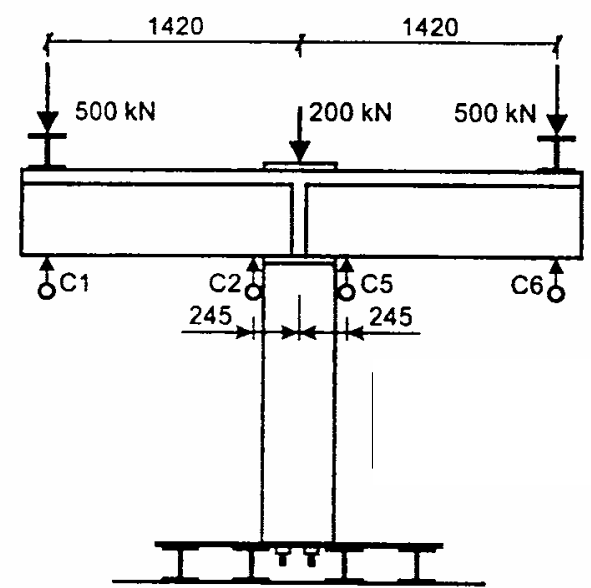

Ligação dos modelos BC 1 a BC 5

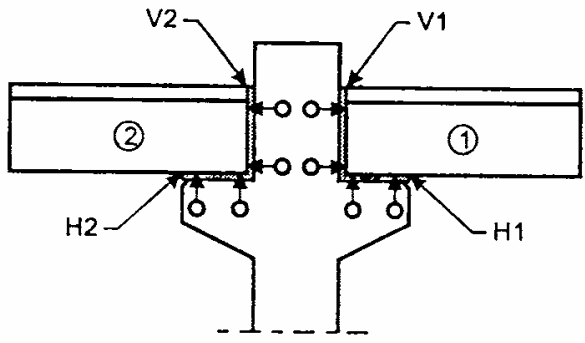

Ligação do modelo BC 6

Figura 2.23 - Instrumentação dos modelos ensaiados [CHEFDEBIEN (1998)]

Para todos os ensaios observaram-se fissuras verticais na interface da viga com o pilar. A ruptura iniciou-se com o escoamento da armadura presente na capa de concreto.

O resultado do experimento é mostrado na Tabela 2.9.

Tabela 2.9 - Resultados característicos das ligações [CHEFDEBIEN (1998)]

\begin{tabular}{|c|c|c|c|c|}
\hline Modelo & $\mathrm{M}_{\mathrm{y}}(\mathrm{kN} . \mathrm{m})$ & $\mathrm{K}_{\mathrm{sy}}(\mathrm{kN} . \mathrm{m} / \mathrm{rad})$ & $\mathrm{M}_{\mathrm{r}}(\mathrm{kN} . \mathrm{m})$ & $\theta_{\mathrm{r}}(\mathrm{rad})$ \\
\hline BC1 & 104 & 91600 & 137 & \\
\hline BC2 & 163 & 108000 & 210 & \\
\hline BC3 & 72 & 11300 & 189 & 0.064 \\
\hline BC4 & 124 & 30000 & 195 & \\
\hline BC5 & 159 & 11970 & 233 & 0.084 \\
\hline BC6 & 104 & 41300 & 153 & 0.038 \\
\hline
\end{tabular}

$\mathrm{M}_{\mathrm{y}}=$ Momento de escoamento; $\mathrm{K}_{\mathrm{sy}}=$ Rigidez secante correspondente ao $\mathrm{M}_{\mathrm{y}}$ $\mathrm{M}_{\mathrm{r}}=$ Momento resistente $; \theta_{\mathrm{r}}=$ Rotação para o $\mathrm{M}_{\mathrm{r}}$.

Através da curva momento fletor-rotação mostrada na Figura 2.24 percebem-se dois comportamentos distintos. Para os modelos que possuíam almofadas de apoio e preenchimento vertical rígido as curvas foram quase bi-linear enquanto que os modelos que possuíam materiais flexíveis apresentaram comportamentos não lineares. 


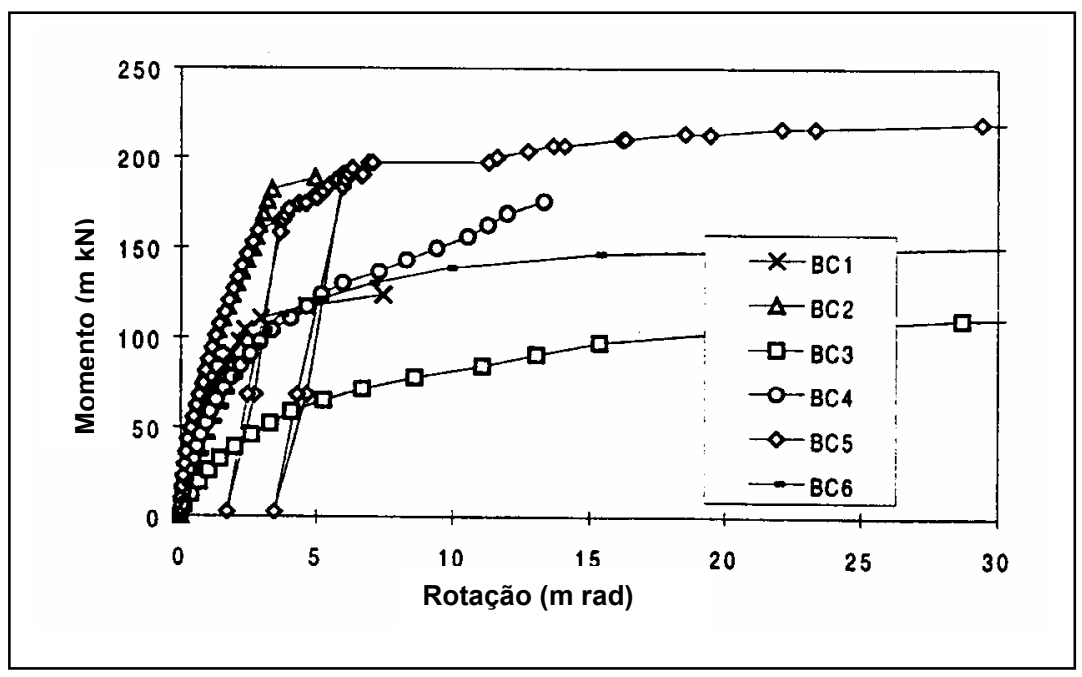

Figura 2.24 - Curva momento fletor-rotação dos modelos [CHEFDEBIEN (1998)]

Elliott et al (1998) e Elliott et al (2003) em trabalhos conjunto entre a universidade de Nottingham e City University apresentam os ensaios experimentais de ligações vigapilar semi-rígidas de concreto pré-moldado com o objetivo de determinar comportamento estrutural destas, verificando a relação entre a resistência e rigidez das ligações à flexão com ao tipo de conector, geometria da subestrutura e forma de carregamento. Trabalhos de Virdi et al (1998) complementam estes estudos determinando o carregamento último para estruturas indeslocáveis com ligações rígidas, articuladas e semi-rígidas e validando os resultados de análise computacional em 3D.

Para este trabalho foram estudados 3 tipos de ligação mais usuais na Inglaterra e criados 28 modelos para ensaio. Estas ligações são mostradas na Figura 2.25.

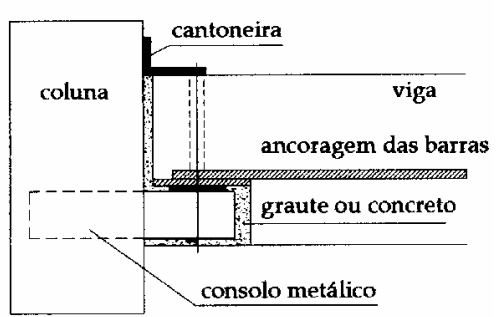

(a)

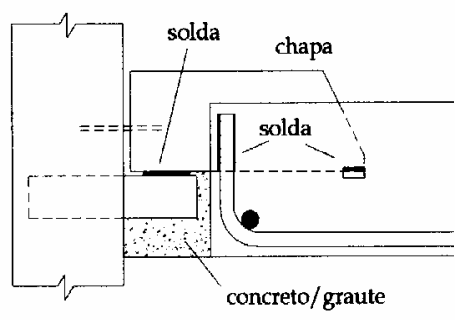

(b)

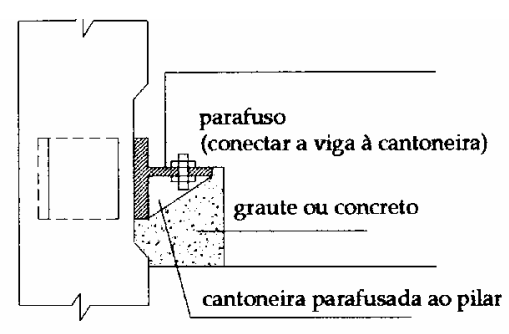

(c)

Figura 2.25 - Três tipos de ligações viga-pilar estudadas [ELLIOTT et al (1998)] 
Para o ensaio experimental as dimensões do pilar se mantiveram constantes $(300 \mathrm{~mm} \times 300 \mathrm{~mm})$, porém as dimensões das vigas variaram de acordo com o tipo de conector utilizado (de $300 \mathrm{~mm}$ x $300 \mathrm{~mm}$ a $600 \mathrm{~m}$ x 300mm). Em alguns modelos foram colocadas lajes alveolares de $200 \mathrm{~mm}$ x $1200 \mathrm{~mm}$ protentidas e armaduras longitudinais de $25 \mathrm{~mm}$.

A Figura 2.26 apresenta o esquema dos modelos ensaiados.

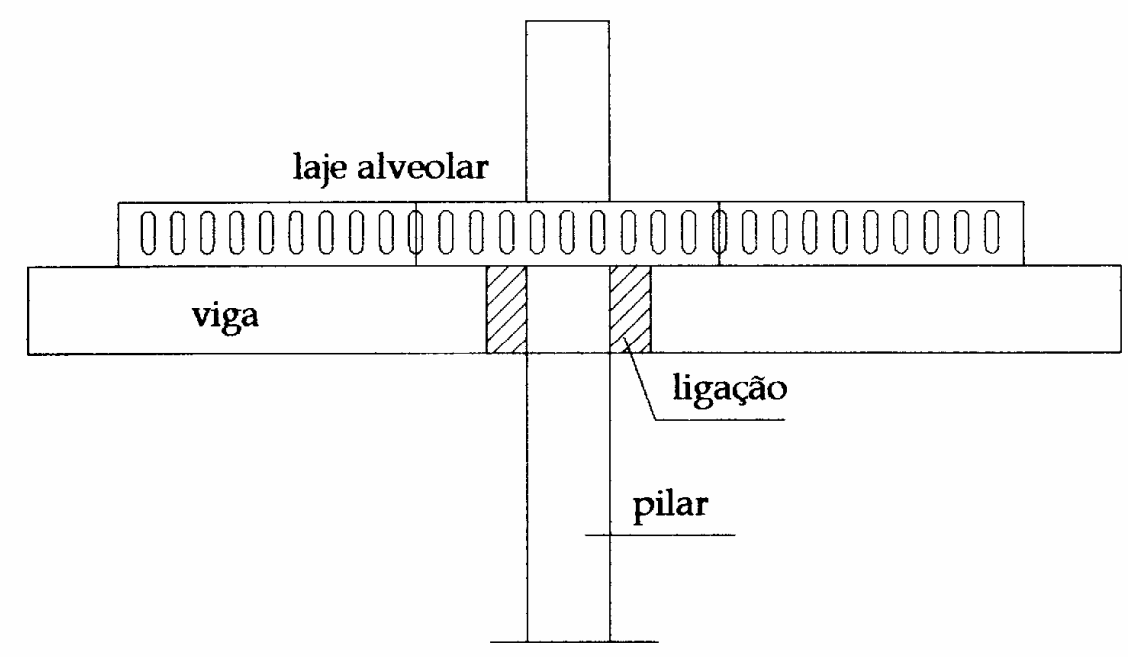

Figura 2.26 - Ligação viga-pilar estudada [ELLIOTT et al (1998)]

O ensaio experimental consistiu em aplicar um carregamento sobre a estrutura de forma a esta estar submetida a momentos fletores. Foram ensaiadas ligações assimétricas (pilares de extremidade) e ligações simétricas (pilares intermediários).

A Figura 2.27 apresenta o sistema estrutural estudado.

Para o ensaio de ligações assimétricas aplicou-se carregamento horizontal submetendo a ligação a momentos positivos e negativos separadamente. Já para ligações simétricas primeiro se aplicou carregamento horizontal sobre o pilar gerando momentos positivos e negativos e posteriormente apenas carregamento gravitacional gerando momento negativo na ligação. 


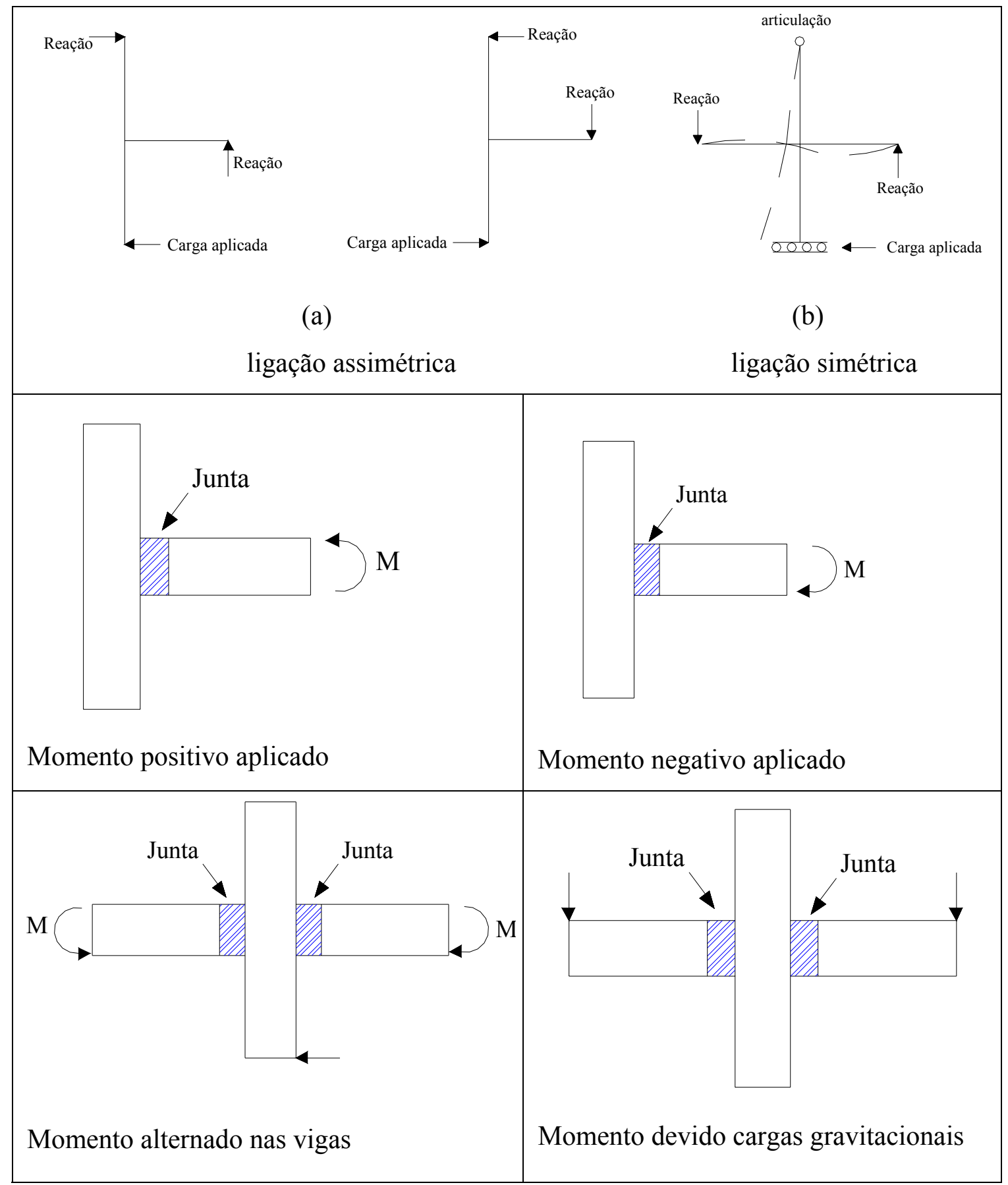

Figura 2.27 - Carregamento da estrutura [ELLIOTT et al (2003)]

Para medir a rotação relativa ente a viga e o pilar foram utilizados ora inclinômetros ora transdutores.

Através de gráficos momento-fletor-rotação verificou-se que estruturas assimétricas com carga horizontal apresentavam rigidez inicial elevada seguido de rápido comportamento dúctil. Já as estruturas simétricas sob mesmo carregamento apresentaram rigidez inicial pouco menor que as assimétricas, porém possuíam momentos de plastificação maiores. 
Quando comparado os carregamentos horizontais sobre a ligação simétricas com carregamentos apenas gravitacionais, observou-se uma diminuição da resistência e rigidez da ligação. Isso se deve a presença dos momentos fletores alternados nas vigas que criaram grandes momentos no pilar.

Em resumo, a rigidez e resistência das ligações de concreto pré-moldado dependem, em ordem de importância:

Tipo do conector - Chapas soldadas mostraram se mais eficientes

$\checkmark$ Geometria da subestrutura - Ligações simétricas geram comportamentos melhores que estruturas assimétricas

$\checkmark$ Forma de carregamento - Carregamentos gravitacionais permitem a estrutura suportar maiores momentos que sob carregamentos horizontais.

Devido a este trabalho ser continuidade de Miotto (2002) decidiu-se por apresentá-lo por último.

Miotto (2002) relata os resultados experimentais de dois modelos de uma ligação viga-pilar apresentada na Figura 2.28 e propõe um modelo analítico para representar os momentos de plastificação e rigidezes da ligação.

A ligação estudada é composta por um chumbador retilíneo, almofada de apoio à base de argamassa e uma capa de concreto com armadura longitudinal dentro do pilar.

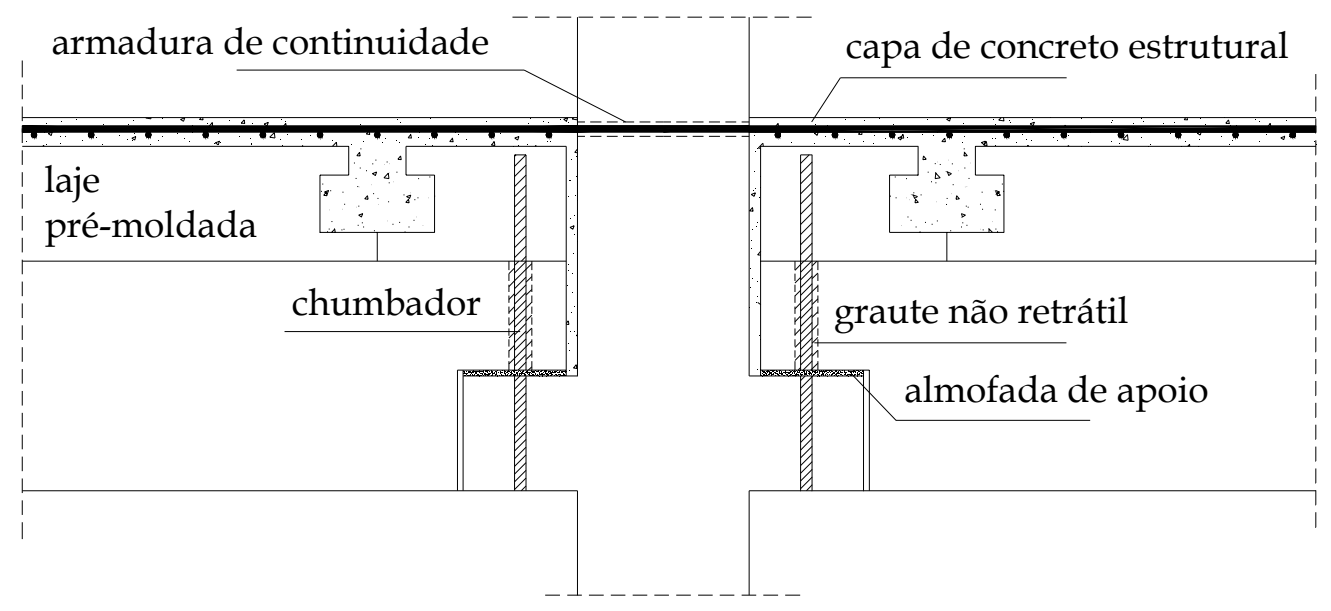

Figura 2.28 - Ligação estudada por Miotto [MIOTTO (2002)] 
Sobre o pilar foram aplicados carregamentos alternados que através do pórtico de reação geravam sobre a estrutura momentos fletores positivos e negativos. Estes carregamentos alternados foram aplicados em ciclos de aproximadamente 20, 40 e $60 \%$ da carga última prevista e depois levado o modelo à ruptura a momento fletor negativo no modelo 1 e a momento fletor positivo no modelo 2 .

A forma de carregamento é apresentada na Figura 2.29.

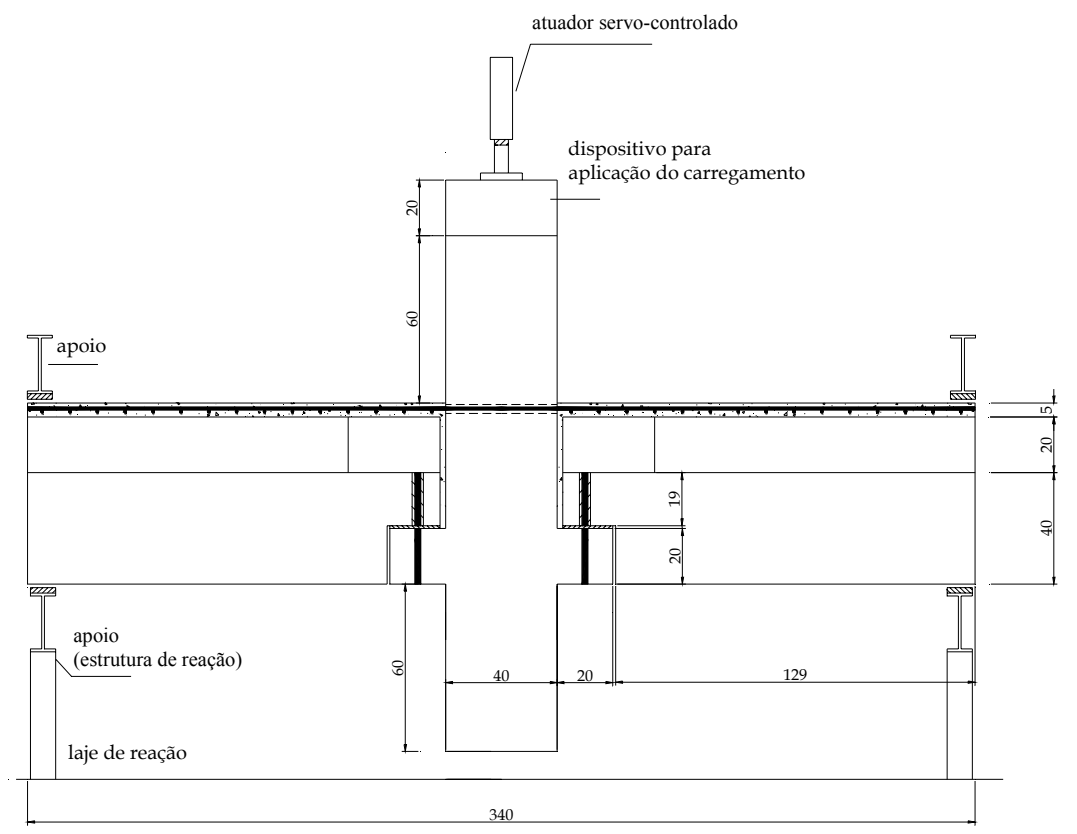

Figura 2.29 - Esquema de ensaio [MIOTTO (2002)]

Observou-se que para o modelo 1 a ruptura se deu devido ao escoamento da armadura de continuidade enquanto para o modelo 2 interrompeu-se o carregamento a um momento fletor positivo de $42 \mathrm{kN}$.m devido a grande deformação do modelo.

Na Tabela 2.10 encontra o resumo dos resultados obtidos.

Tabela 2.10 - Resumo dos resultados experimentais [MIOTTO (2002)]

\begin{tabular}{|l|c|c|c|c|}
\cline { 2 - 5 } \multicolumn{1}{c|}{} & \multicolumn{2}{c|}{ Momento Negativo } & \multicolumn{2}{c|}{ Momento positivo } \\
\cline { 2 - 5 } \multicolumn{1}{c|}{} & Modelo 1 & Modelo 2 & Modelo 1 & Modelo 2 \\
\hline $\mathrm{M}_{\text {fissuração }}(\mathrm{kN} . \mathrm{m})$ & 42 & 26 & 8,5 & 17 \\
\hline $\mathrm{M}_{\text {plastificação }}(\mathrm{kN} . \mathrm{m})$ & 215 & - & - & 25 \\
\hline $\mathrm{K}_{\text {fissuração }}(\mathrm{kN} . \mathrm{m} / \mathrm{rad})$ & 303380 & 266827 & 168921 & 89210 \\
\hline $\mathrm{K}_{\text {plastificação }}(\mathrm{kN} . \mathrm{m} / \mathrm{rad})$ & 75114 & 66064 & 10990 & 7370 \\
\hline
\end{tabular}


Para o modelo analítico foi utilizado o método dos componentes. Tanto para determinação dos momentos positivos como negativos foi proposto um diagrama trilinear da curva momento-rotação definido pelos pontos A e B representando o momento de fissuração e de plastificação respectivamente.

As Figuras 2.30 e 2.31 apresentam as curvas momento-rotação usadas e a configuração em equilíbrio das forças para momentos negativos e positivos respectivamente.
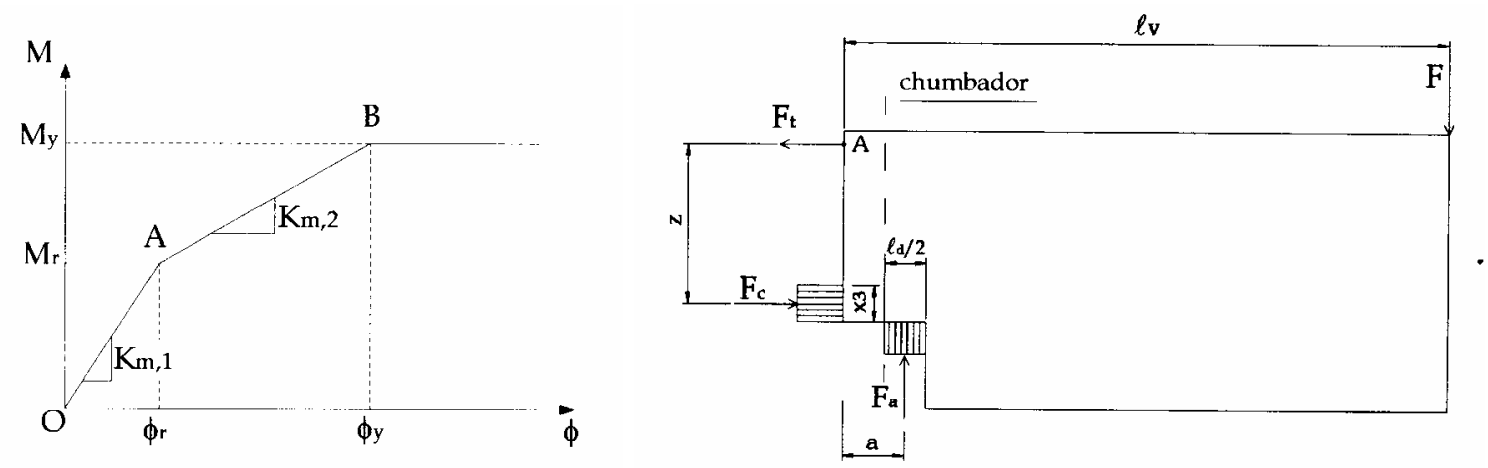

Figura 2.30 - Curva momento fletor- rotação e configuração das forças em equilíbrio para o momento negativo [MIOTTO (2002)]
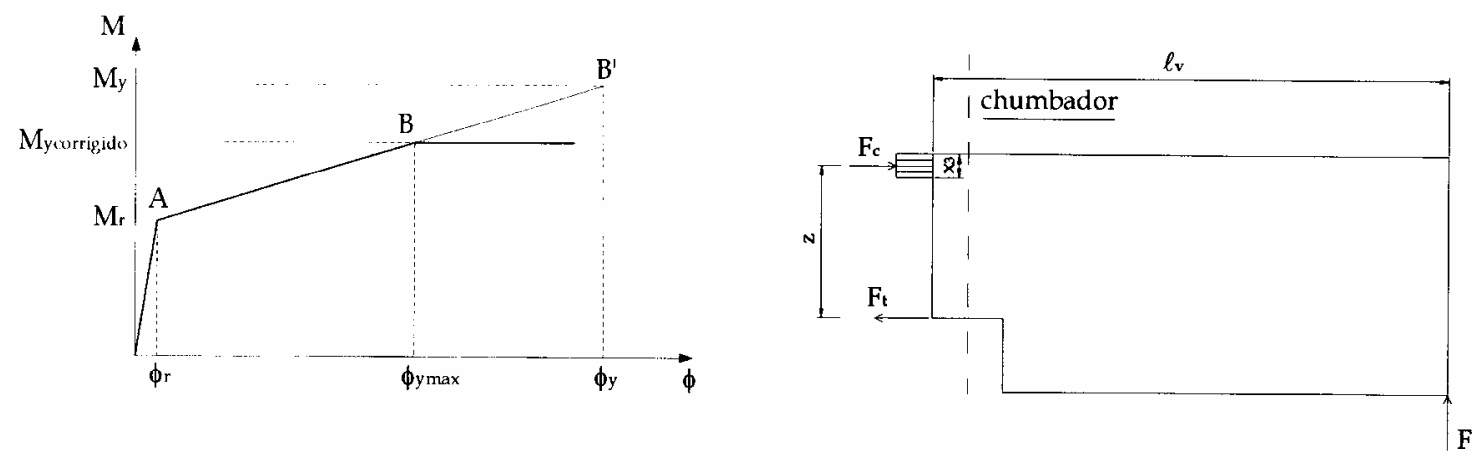

Figura 2.31 - Curva momento fletor-rotação e configuração das forças em equilíbrio para o momento positivo [MIOTTO (2002)]

Os valores de momento e rigidez da ligação estão definidos na Tabela 2.11. Na Figura 2.32 encontra-se gráfico momento-rotação comparando as curvas experimentais e analíticas. 
Onde:

$\mathrm{f}_{\text {ccapa }}=$ Resistência à tração indireta do concreto da capa

$\mathrm{I}_{1} \quad=$ Momento de inércia

$\mathrm{x}_{1}=$ Posição da linha neutra no estádio I

$\mathrm{h}=$ Altura da seção

$\alpha_{\text {eg }}=$ Relação entre o módulo de elasticidade do graute e da capa de concreto

$\mathrm{f}_{\mathrm{y}} \quad=$ Resistência de escoamento da armadura de continuidade

$\mathrm{A}_{\mathrm{S}} \quad=$ Área da armadura de continuidade

$\mathrm{Z} \quad=$ Braço de alavanca

$1_{\mathrm{V}} \quad=$ Comprimento da viga

$1_{\mathrm{d}} \quad=$ Comprimento do dente gerber

e $\quad=$ Espaçamento entre a viga e o consolo

$\mathrm{D}_{\text {njg }}=$ Deformabilidade da junta

d = Altura útil da seção

$\mathrm{x}_{3}=$ Posição da linha neutra no estádio III

$\alpha_{\mathrm{w}} \quad=0,4$

$\mathrm{s}_{1} \quad=1$

$\phi \quad=$ Diâmetro médio das barras da armadura de continuidade

$\alpha_{\mathrm{e}} \quad=$ Relação entre o módulo de elasticidade do aço e da capa de concreto

$\tau_{\max }=$ Tensão de aderência máxima

$\mathrm{E}_{\mathrm{S}} \quad=$ Módulo de elasticidade do aço

$\mathrm{f}_{\text {cgt }}=$ Resistência à tração indireta do graute

c $\quad=$ Parâmetro para restrição ao giro e existência de atrito

$\phi_{\mathrm{b}} \quad=$ Diâmetro do chumbador

$\mathrm{f}_{\mathrm{yb}}=$ Resistência de escoamento da armadura de continuidade

$\mathrm{f}_{\mathrm{ccmax}}=$ Maior valor do concreto/graute entre os elementos inseridos no chumbador

$\mathrm{h}=$ Altura da seção

$\mathrm{h}_{\mathrm{a}} \quad=$ Espessura da almofada de apoio

$\mathrm{k} \quad=1,75 \mathrm{~m}$

$\alpha \quad=1,5$ 

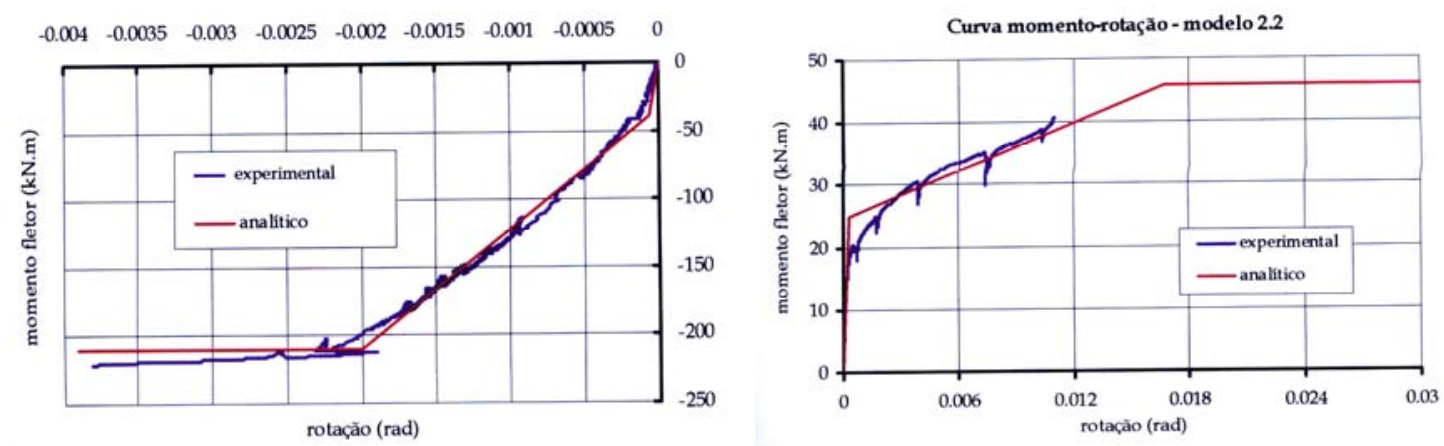

Figura 2.32 - Comparação do modelo analítico e experimental [MIOTTO (2002)]

Ao final conclui-se que:

$\checkmark$ Para o mesmo sentido de momento, as curvas momento-rotação dos modelos de pilar interno e externo têm formatos semelhantes. Porém percebeu-se a diferença de resistência para os diferentes sentidos de momento aplicados

$\checkmark$ O momento fletor resistente positivo é da ordem de $20 \%$ do momento fletor resistente negativo

$\checkmark$ Para a situação de momentos positivos os valores de rigidez inicial são bons, porém sofrem acentuada redução depois de fissurada.

$\checkmark$ Pode se afirmar que o modelo analítico proposto baseado no método dos componentes representa adequadamente o comportamento da ligação estudada.

Com a finalidade de melhorar o comportamento da ligação a momento fletor positivo de Miotto (2002) a ligação estudada neste trabalho é detalhada no capítulo a seguir. 


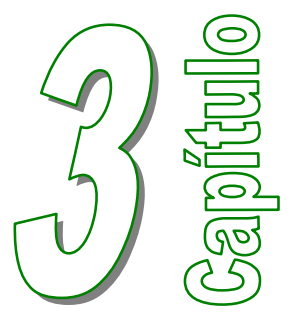

\subsection{CONSIDERAÇÕES INICIAIS}

O programa experimental descrito nesta seção consiste no estudo de dois modelos de uma ligação viga-pilar. O modelo I representa o pilar intermediário enquanto que o modelo E representa o pilar de extremidade. A diferença entre eles é a presença da armadura de continuidade transpassando o pilar para o modelo I.

Sobre os modelos foram aplicados carregamentos alternados, em ciclos, de curta duração de forma que na ligação atue momentos fletores positivos e negativos.

Os tópicos a seguir estão divididos em projeto da ligação, confecção, montagem, caracterização dos materiais, instrumentação e procedimentos de ensaio.

A Tabela 3.1 mostra a representação e os momentos atuantes em cada modelo.

Tabela 3.1 - Resumo do programa experimental

\begin{tabular}{|c|c|c|}
\hline Modelo & Representação & Momento atuante \\
\hline I & Pilar intermediário & Positivo/Negativo \\
\hline E & Pilar de extremidade & Positivo/Negativo \\
\hline
\end{tabular}

\subsection{PROJETO DA LIGAÇÃO}

As características geométricas da ligação viga-pilar estudada para os dois modelos são ilustradas nas Figuras 3.1 e 3.2. 
CORTE A-A
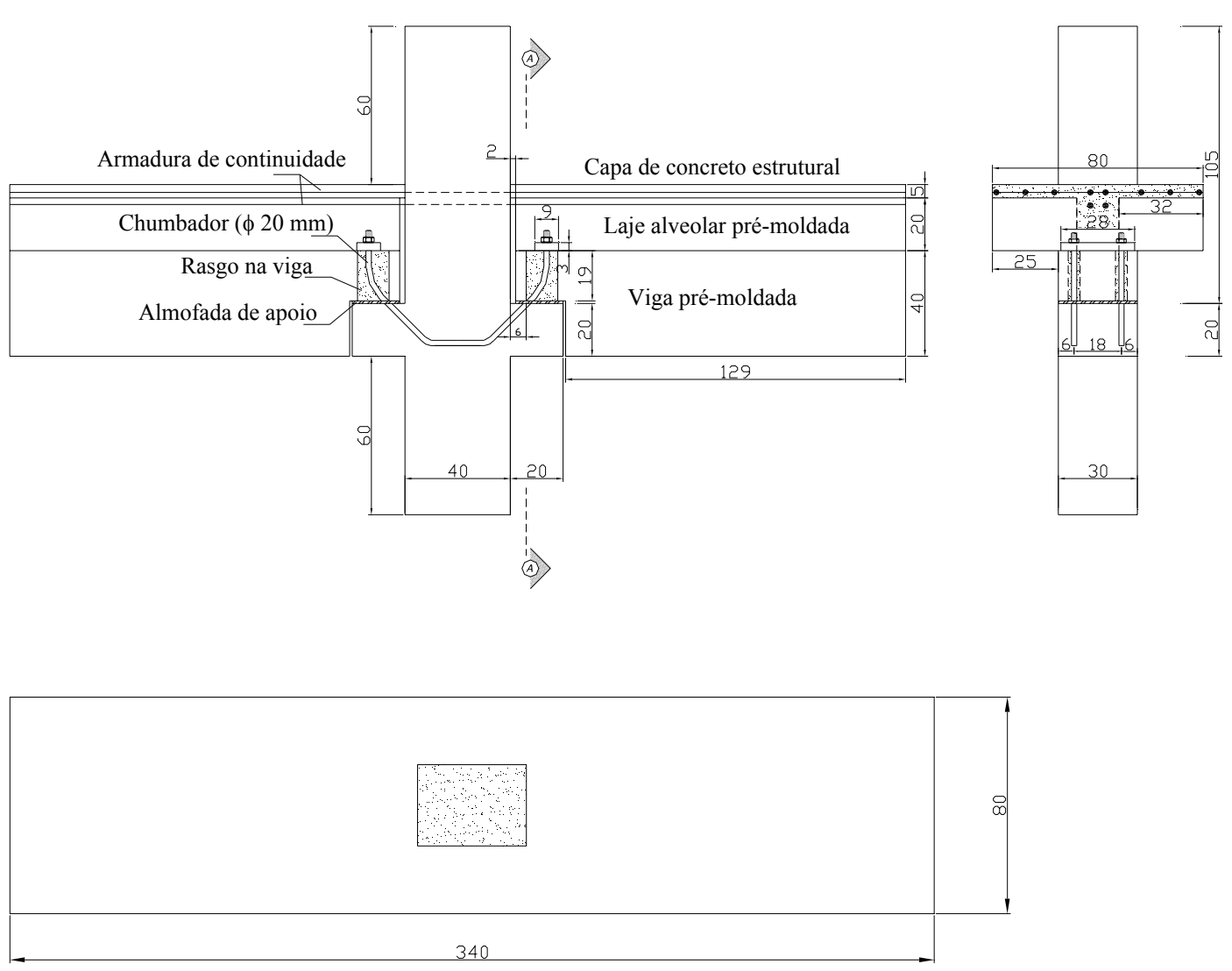

Figura 3.1 - Características geométricas do modelo I

CORTE A-A
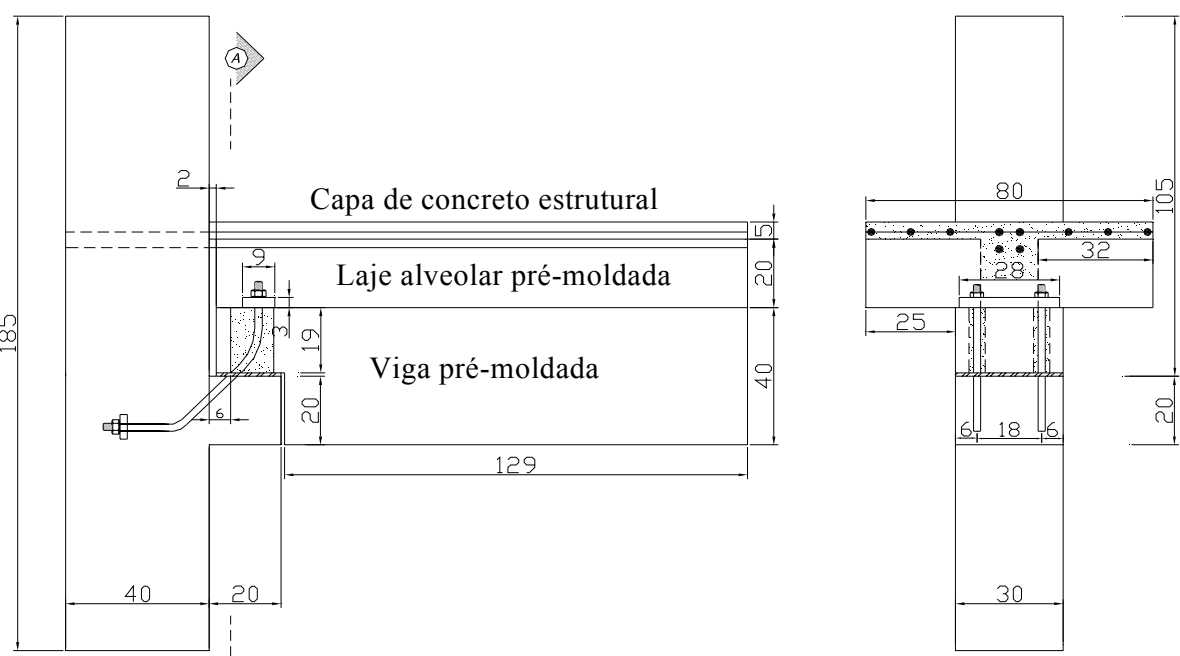

Figura 3.2 - Características geométricas do modelo E 


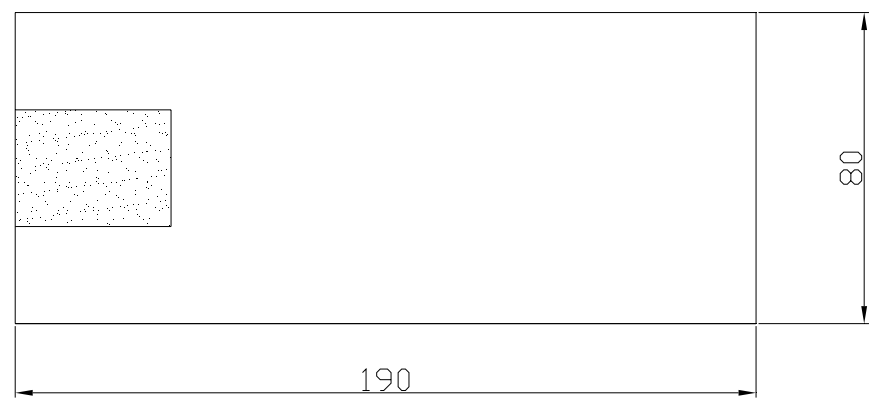

Figura 3.2 - Características geométricas do modelo E (continuação)

As dimensões adotadas seguiram as realizadas em Miotto (2002) e correspondem a uma estrutura com lajes de vão de $6 \mathrm{~m}$ x $6 \mathrm{~m}$ solicitadas por um carregamento último de $10 \mathrm{kN} / \mathrm{m}^{2}$.

Visando garantir uma resistência a momento fletor negativo quando da atuação do peso próprio e sobrecarga da capa, as armaduras que transpassam o pilar foram colocadas em dois níveis e realizadas duas etapas de concretagem. A primeira concretagem foi feita até a altura da laje pré-moldada (encobrindo o $1^{\mathrm{o}}$ nível das armaduras de transpasse do pilar), em seguida a capa foi armada e feita à segunda concretagem.

\subsubsection{Especificação do concreto}

Para a confecção das vigas e pilar pré-moldados a resistência especificada foi de $35 \mathrm{MPa}$ e para o concreto moldado em loco entre as lajes pré-moldadas e a capa foi especificado uma resistência de $25 \mathrm{MPa}$.

\subsubsection{Armadura de projeto}

O cálculo do dimensionamento das vigas, pilares e capa foi baseado em Miotto (2002) com adaptações. O aço utilizado foi CA -50 de diâmetros variando de 6.3 a 20 $\mathrm{mm}$.

No cálculo da armadura resistente a momento fletor negativo dos modelos I e E optou-se por passar $50 \%$ da armadura calculada por dentro do pilar, sendo os $50 \%$ restantes distribuídos ao longo da capa. 
Os chumbadores, também feitos de CA-50, foram dimensionados respeitando os limites de raio para curvatura e comprimento de ancoragem, baseado na norma NBR 6118:2003 e no manual CPCA Concrete Design Handbook da Association Canadienne du Ciment Portland. A ancoragem do chumbador foi garantida pelo comprimento embutido dentro do concreto do pilar e através de uma chapa metálica de $28 \mathrm{~mm}$ x 9 mm e espessura de $31 \mathrm{~mm}$ presa aos chumbadores por porcas e arruelas na parte superior da viga.

As Figuras 3.3 e 3.4 mostram a perspectiva e detalhamento da chapa metálica.

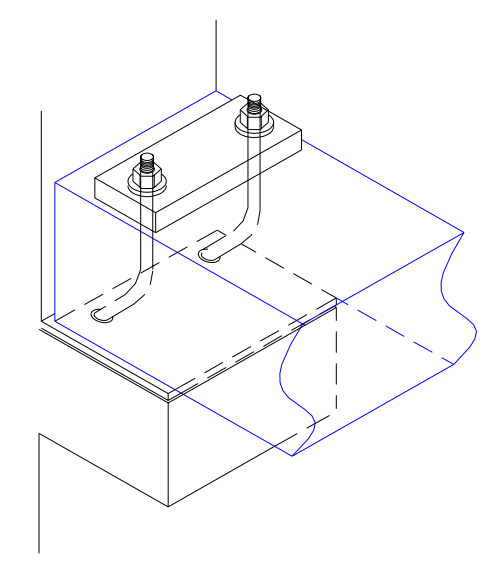

Figura 3.3 - Perspectiva da ligação no consolo do pilar

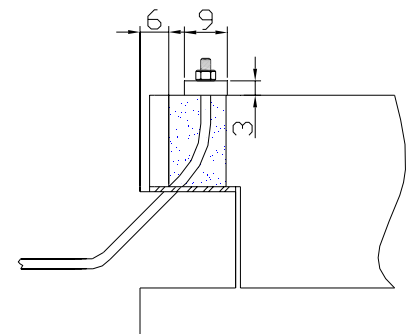

(A)

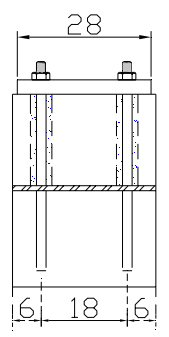

(B)

Corte lateral Vista superior

Figura 3.4 - Detalhamento da ancoragem do chumbador

Os detalhamentos das armaduras são mostrados nas Figuras 3.5 a 3.9. 


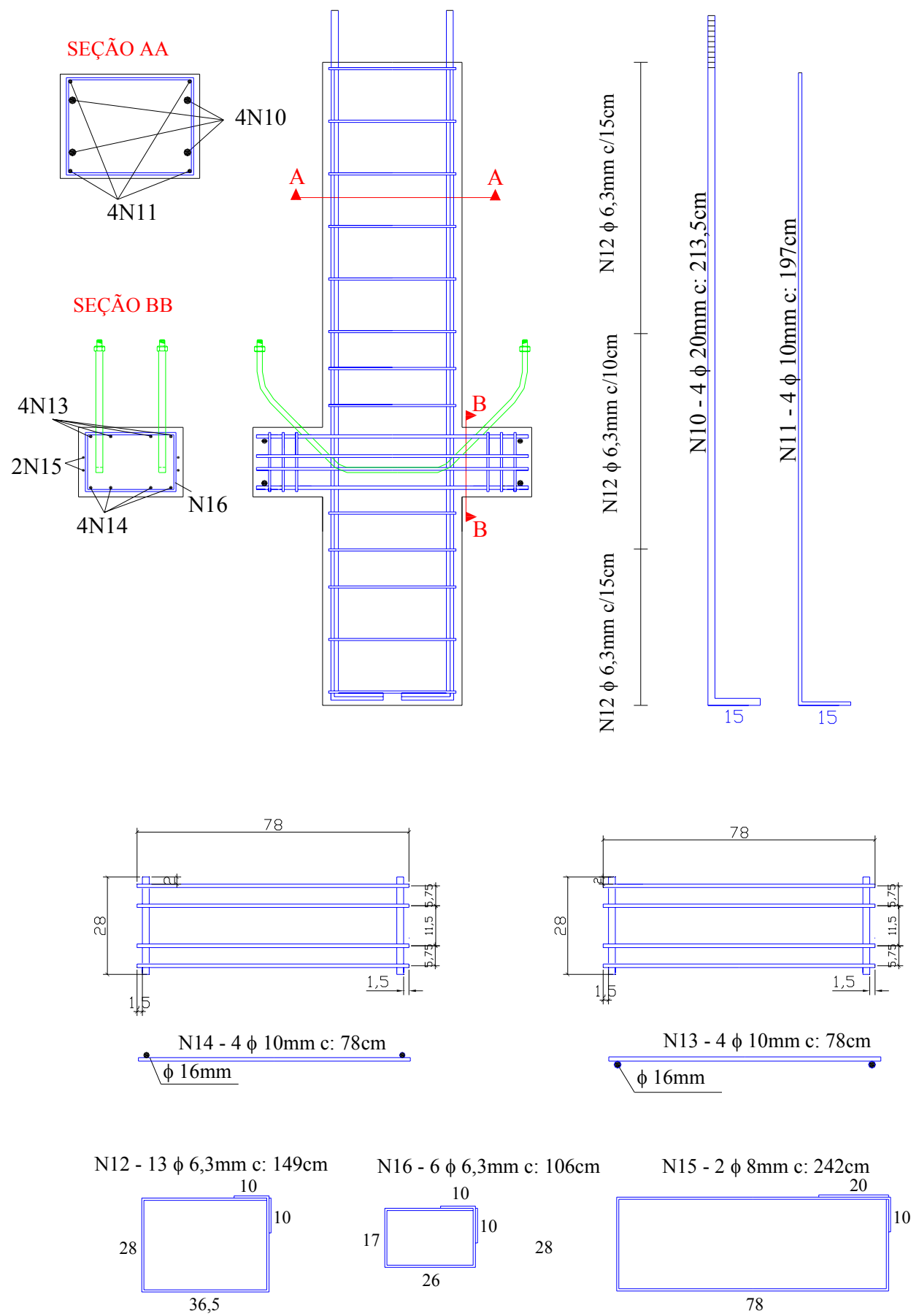

Figura 3.5 - Detalhamento da armação do pilar do modelo I 


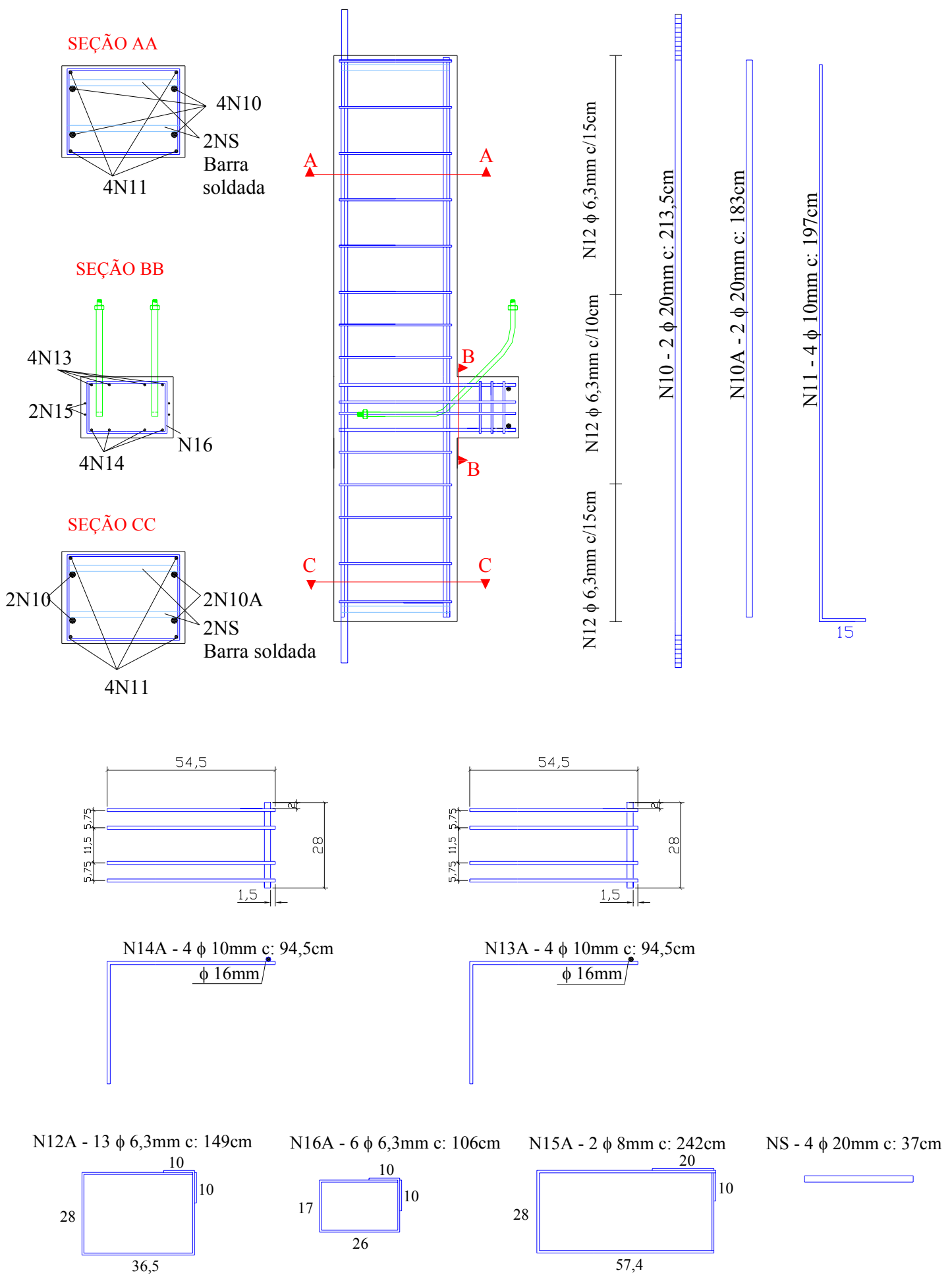

Figura 3.6 - Detalhamento da armação do pilar do modelo E 

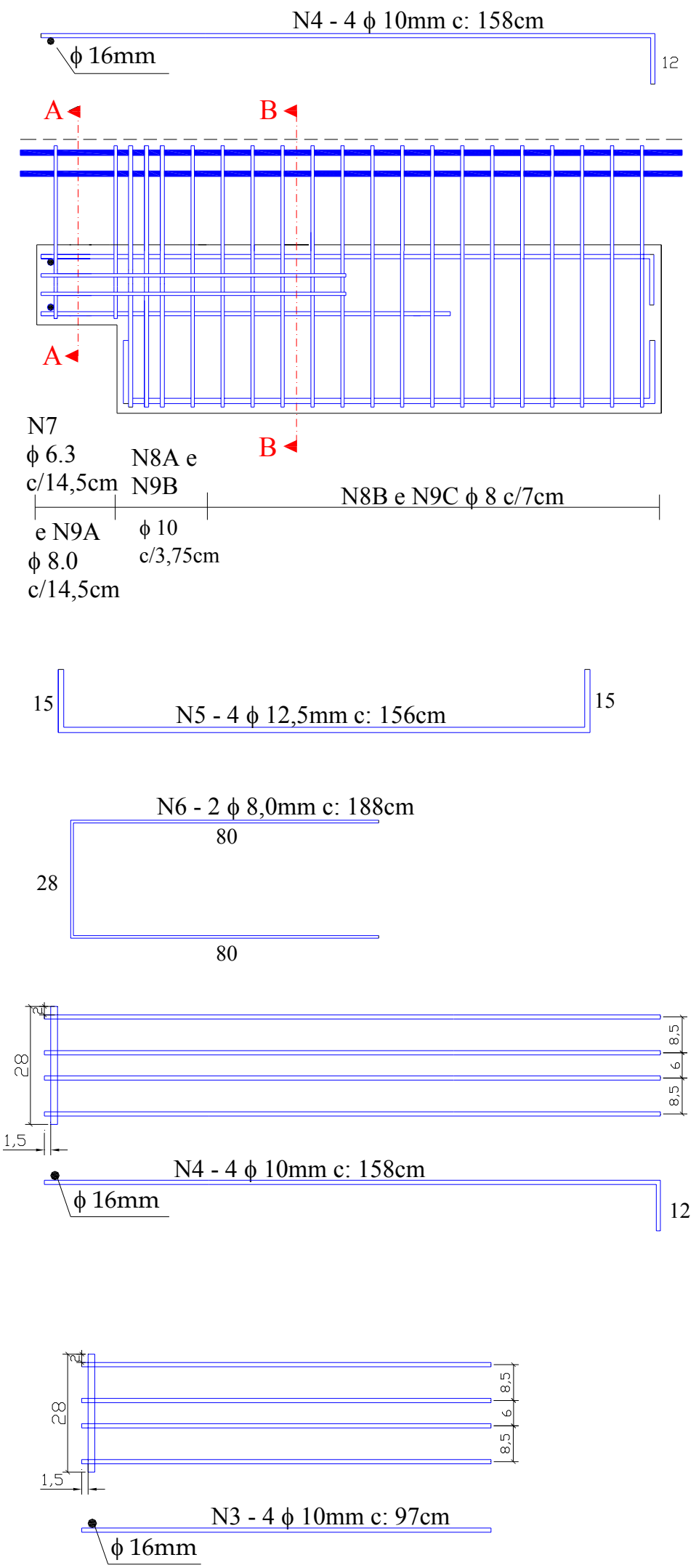

Figura 3.7 - Detalhamento da armação da viga 
SEÇÃO AA

N1 - armadura de continuidade (dentro do pilar)

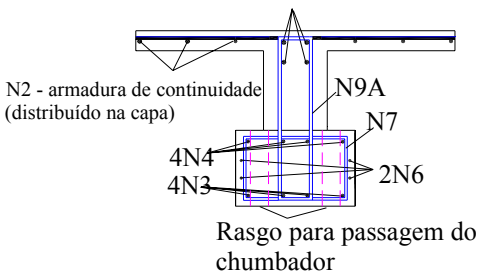

SEÇÃO BB

N1 - armadura de continuidade (dentro do pilar)

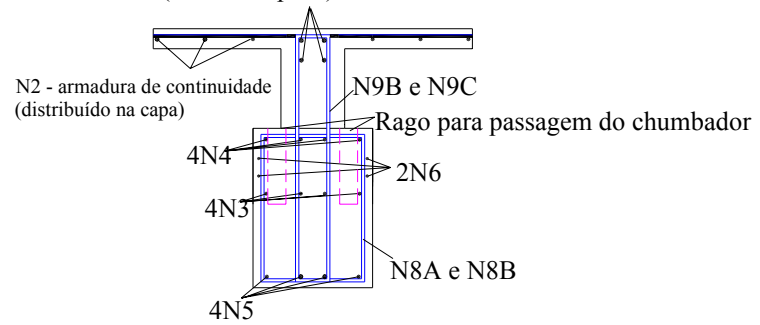

$4 \mathrm{~N} 5$
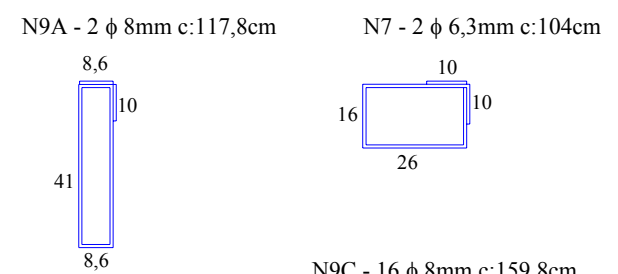

N9C - $16 \phi 8 \mathrm{~mm}$ c: $159,8 \mathrm{~cm}$
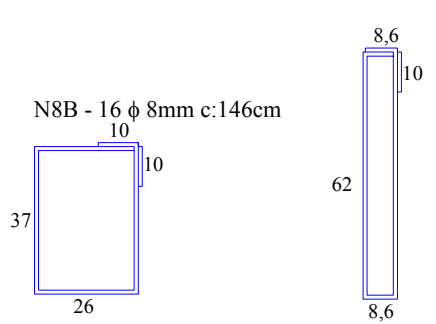

N8A - $3 \phi 10 \mathrm{~mm}$ c: $146 \mathrm{~cm}$

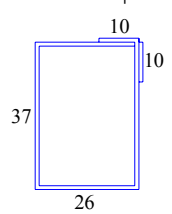

N9B - $3 \phi 10 \mathrm{~mm}$ c: $159,8 \mathrm{~cm}$

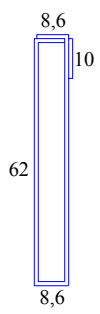

Figura 3.7 - Detalhamento da armação da viga (continuação)

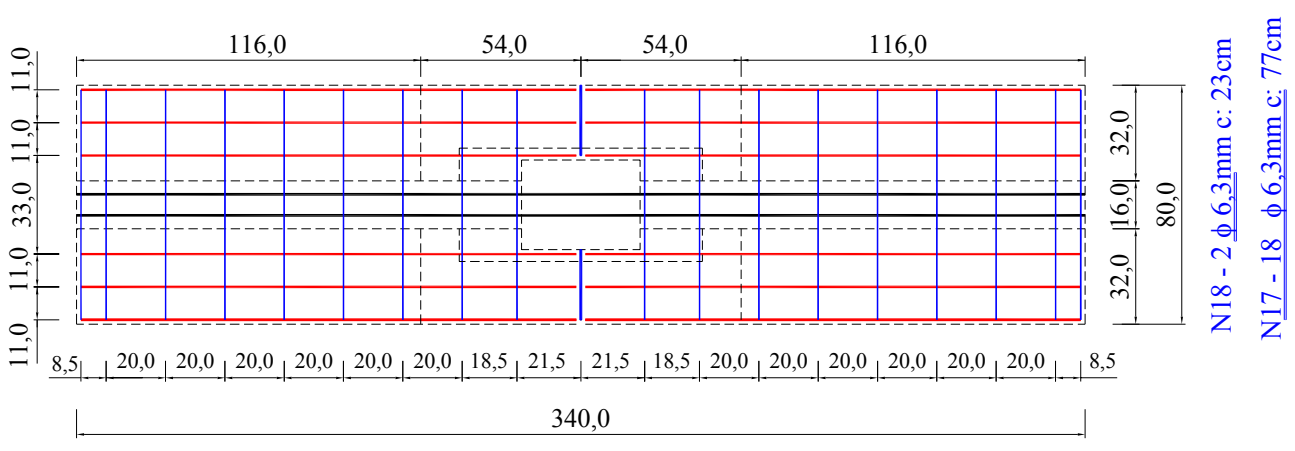

$\mathrm{N} 1-4 \phi 12,5 \mathrm{~mm}$ c: $337 \mathrm{~cm}$

$\mathrm{N} 2-6 \phi 10 \mathrm{~mm}$ c: $337 \mathrm{~cm}$

Figura 3.8 - Detalhamento da armação da capa do modelo I 

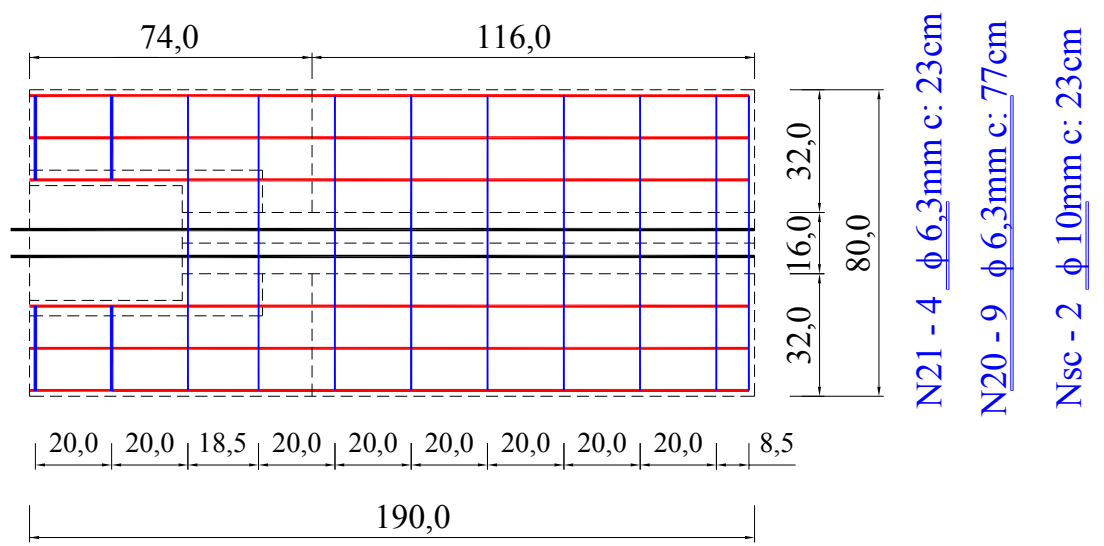

$\mathrm{N} 1-4 \phi 12,5 \mathrm{~mm}$ c: $193,5 \mathrm{~cm}$

N19- 6 ф 10mm c: $187 \mathrm{~cm}$

Figura 3.9 - Detalhamento da armação da capa do modelo E

Para evitar a possibilidade de ruptura do concreto na extremidade tanto do consolo do pilar como da viga, as armaduras dos tirantes foram ancoradas soldando uma barra transversal de diâmetro $16 \mathrm{~mm}$, superior portanto ao diâmetro do tirante $(\phi 10 \mathrm{~mm})$.

Para o modelo E foi necessário soldar barras de $\phi 20 \mathrm{~mm}\left(\mathrm{~N}_{\mathrm{s}}\right)$ e $\phi 10 \mathrm{~mm}\left(\mathrm{~N}_{\mathrm{sc}}\right)$ no pilar e capa respectivamente para garantir ancoragem e suportarem esforços horizontais presentes durante o ensaio.

A Figura 3.10 ilustra a soldagem das armaduras do tirante
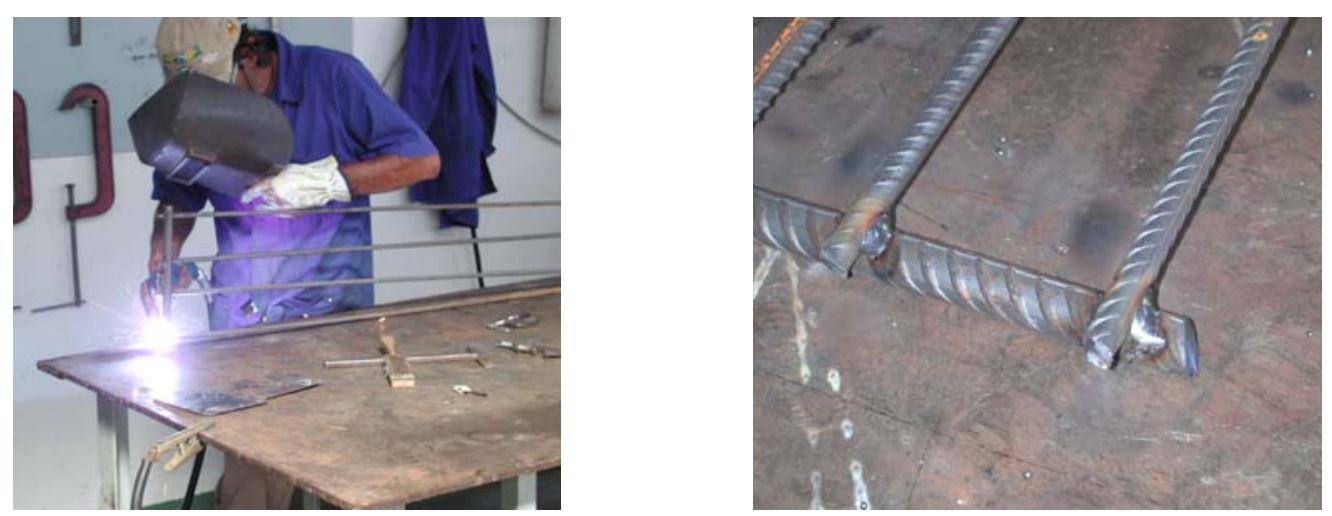

Figura 3.10 - Soldagem dos tirantes das vigas e dos pilares 


\subsubsection{Graute}

Para o preenchimento dos furos nas vigas e pilares foi utilizado o graute auto adensável com retração compensada. A resistência especificada foi similar a do concreto pré-moldado, ou seja, de $35 \mathrm{MPa}$.

A Tabela 3.2 define os locais de utilização e nomenclatura dos grautes.

Tabela 3.2 - Tipo e local de utilização dos grautes

\begin{tabular}{|c|l|}
\hline Graute & \multicolumn{1}{|c|}{ Local de utilização } \\
\hline Graute 1 & Preenchimento dos furos das vigas e dos espaços entre as vigas e o pilar \\
\hline Graute 2 & Preenchimento dos furos dos pilares \\
\hline
\end{tabular}

\subsubsection{Almofada de apoio}

Para os ensaios dos modelos I e E foi colocada entre o consolo do pilar e a viga uma almofada de apoio à base de argamassa de cimento e areia com a função de promover uma distribuição mais uniforme das tensões de contato entre os elementos e também permitir os movimentos de rotação. O traço da almofada de apoio escolhido foi baseado em estudos realizados na EESC-USP, em especial Montedor (2004), e buscou agregar características de baixo módulo de elasticidade e resistência similar a de projeto do concreto das vigas e pilares.

\subsection{CONFECÇÃO DOS ELEMENTOS}

\subsubsection{Fôrma}

As fôrmas das vigas e pilares foram confeccionadas com madeira compensada plastificada de $15 \mathrm{~mm}$ de espessura.

Para a passagem da armadura de continuidade dentro do pilar foram utilizados canos de PVC que posteriormente foram preenchidos com graute (graute 2). Para a passagem do chumbador na viga concretada elaborou-se um anteparo de madeira preso na parte inferior da fôrma da viga para posterior retirada.

A Figura 3.11 mostra as fôrmas dos pilares e vigas. 

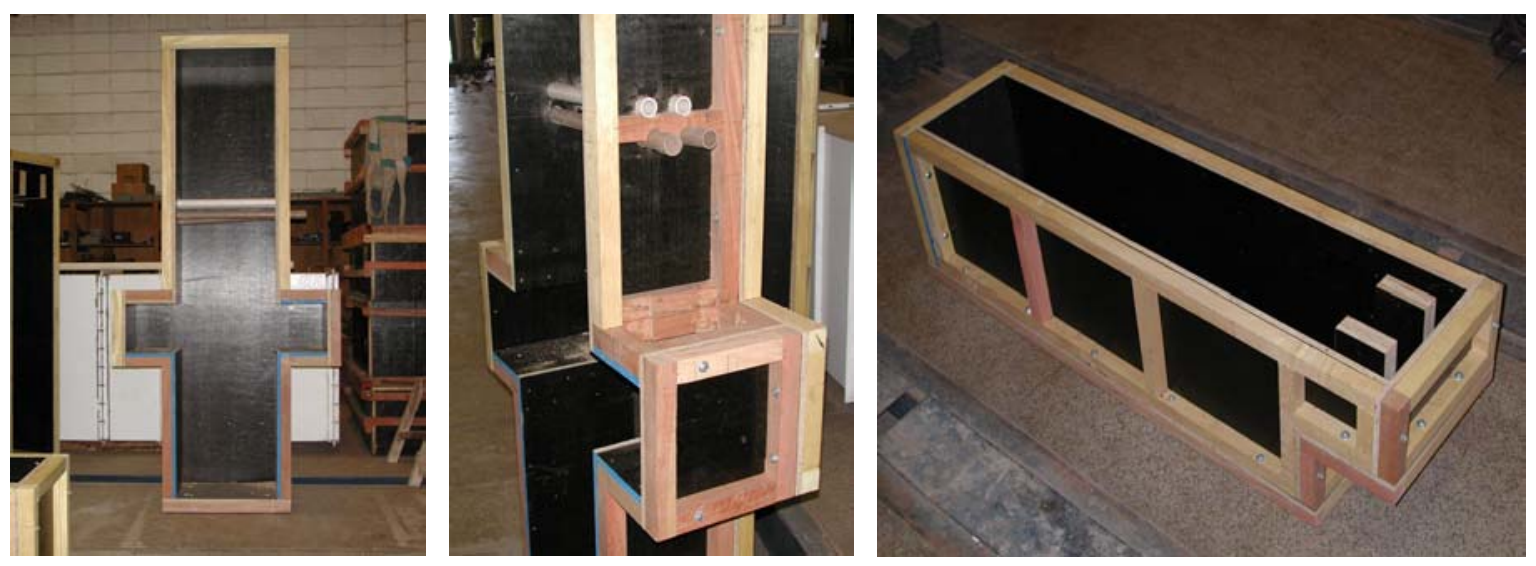

Figura 3.11 - Fôrmas das vigas e do pilar

\subsubsection{Armação dos elementos pré-moldados}

A armação das peças é mostrada nas Figuras 3.12 e 3.13.
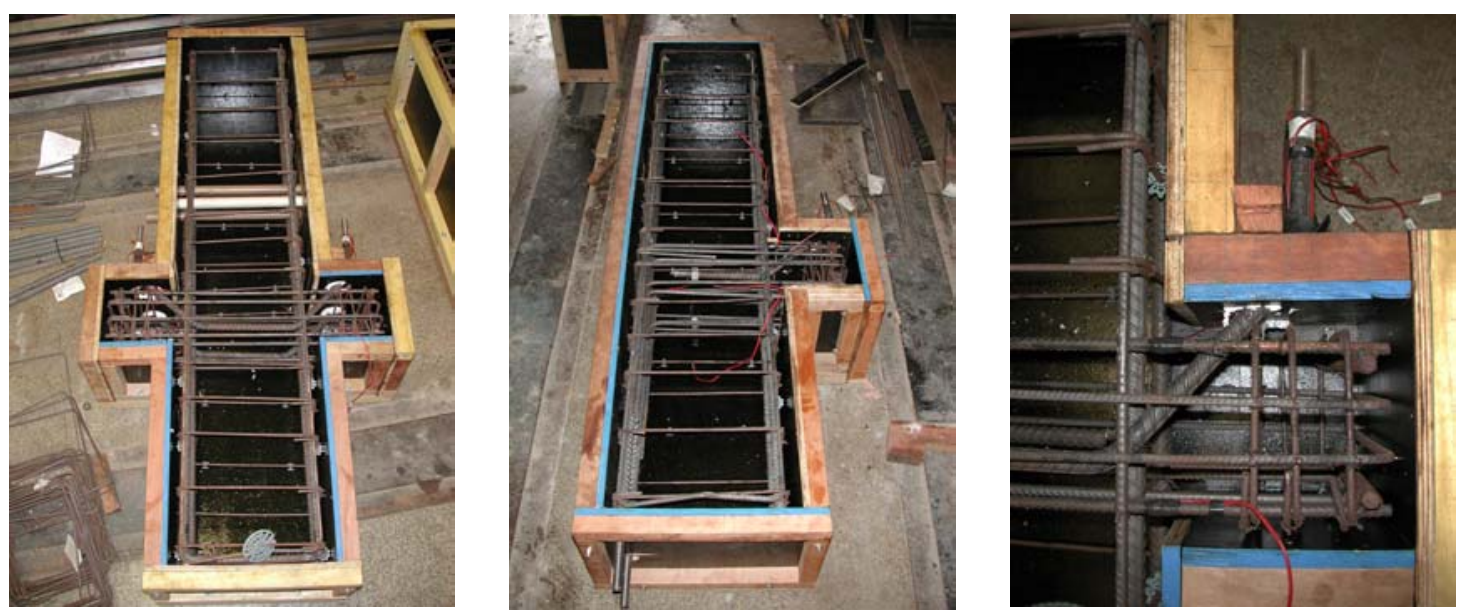

Figura 3.12 - Armação dos pilares dos modelos I e E
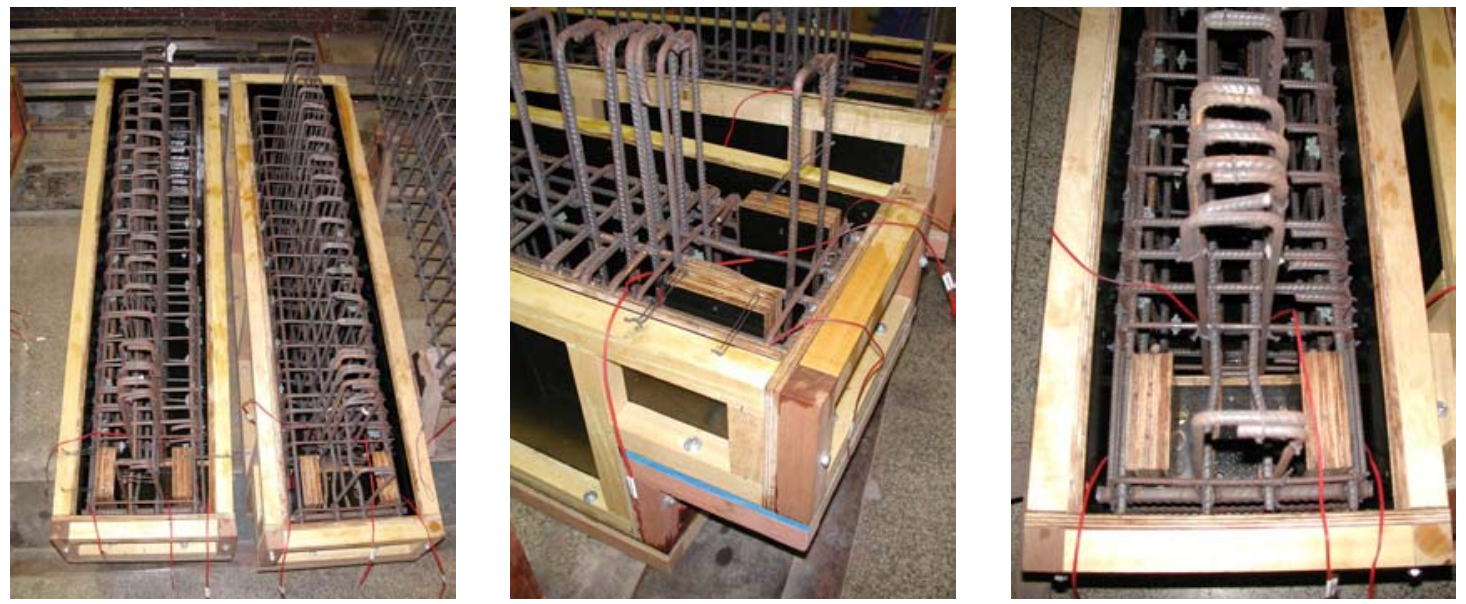

Figura 3.13 - Armação das vigas 


\subsubsection{Concretagem dos elementos pré-moldados}

Para o modelo I a confecção dos elementos pré-moldados foi utilizado concreto convencional usinado fornecido pela Constroeste de São Carlos com resistência especificada de $35 \mathrm{MPa}$ e slump $8 \pm 1$. Para o modelo $\mathrm{E}$ as vigas e pilares foram confeccionados com concreto misturado no laboratório de Estruturas EESC - USP com o traço descrito na Tabela 3.3. Devido à pequena capacidade da betoneira os pilares foram confeccionados em um dia e as vigas no dia seguinte. Os slumps verificados para os pilares e vigas do modelo $\mathrm{E}$ foram de 10,35 e $16,5 \mathrm{~cm}$ respectivamente.

Tabela 3.3 - Traço de concreto utilizado na confecção da viga e pilar do modelo E

\begin{tabular}{|c|c|}
\hline Material & Consumo $\left(\mathrm{kg} / \mathrm{m}^{3}\right)$ \\
\hline Cimento CP II E 32 - ITAU & 445,5 \\
\hline Areia seca & 561,33 \\
\hline Brita 1 & 1011,28 \\
\hline Água & 198,25 \\
\hline Relação a/c & 0,445 \\
\hline Traço em massa & $1: 1,26: 2,27$ \\
\hline
\end{tabular}

Para a confecção da capa e o espaço entre as lajes, optou-se por um concreto elaborado no laboratório de Estruturas EESC -USP devido ao pequeno volume necessário. A descrição do traço é apresentada na Tabela 3.4. Os slumps obtidos encontram-se na Tabela 3.5.

Tabela 3.4 - Traço do concreto utilizado na confecção da capa e entre lajes - Laboratório EESC USP

\begin{tabular}{|c|c|}
\hline Material & Consumo $\left(\mathrm{kg} / \mathrm{m}^{3}\right)$ \\
\hline Cimento ARI - PLUS CIMINAS & 302 \\
\hline Areia seca & 739,9 \\
\hline Brita 1 & 1223,1 \\
\hline água & 196,3 \\
\hline Relação a/c & 0,65 \\
\hline Traço em massa & $1: 2,45: 4,05$ \\
\hline
\end{tabular}


Tabela 3.5 - Slump obtido entre as lajes e capa nos modelos I e E

\begin{tabular}{|c|c|c|}
\hline Slump & Modelo I & Modelo E \\
\hline Entre lajes & $10,1 \mathrm{~cm}$ & $5,5 \mathrm{~cm}$ \\
\hline Capa & $8,8 \mathrm{~cm}$ & $6,8 \mathrm{~cm}$ \\
\hline
\end{tabular}

Após a chegada do caminhão betoneira (para o modelo I) e mistura do concreto na betoneira (modelo E) foi realizado o ensaio de abatimento do troco cone e iniciada a concretagem com auxílio de carriolas. O adensamento do concreto foi feito com vibrador de imersão de $25 \mathrm{~mm}$.

Após ter sido dado o acabamento da viga, foi utilizada uma escova de aço para aumentar a rugosidade na zona entre os estribos, permitindo assim melhor aderência entre o concreto da viga e o concreto entre lajes e da capa.

A Figura 3.14 apresenta as etapas de concretagem do modelo I

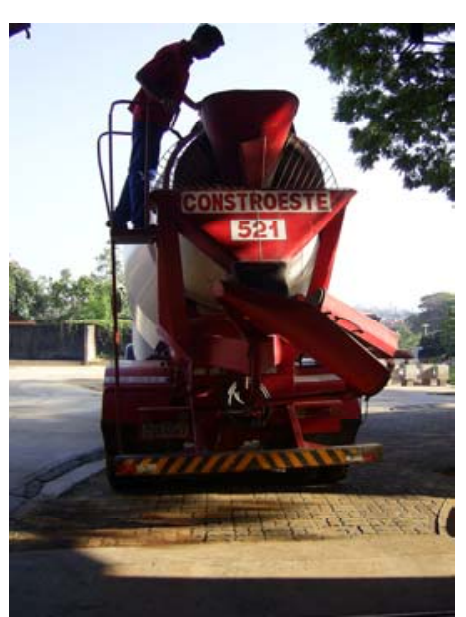

Concreto usinado

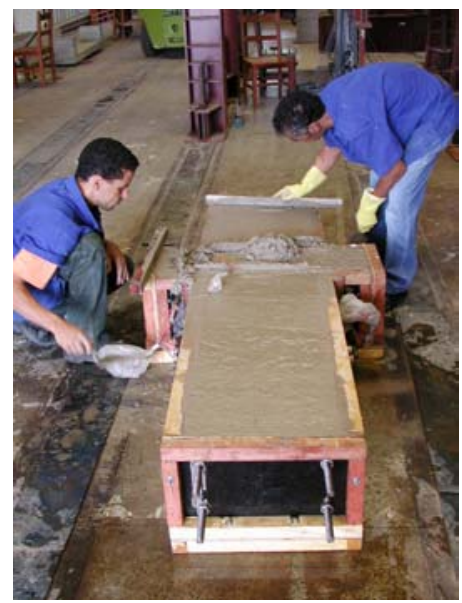

Acabamento do pilar

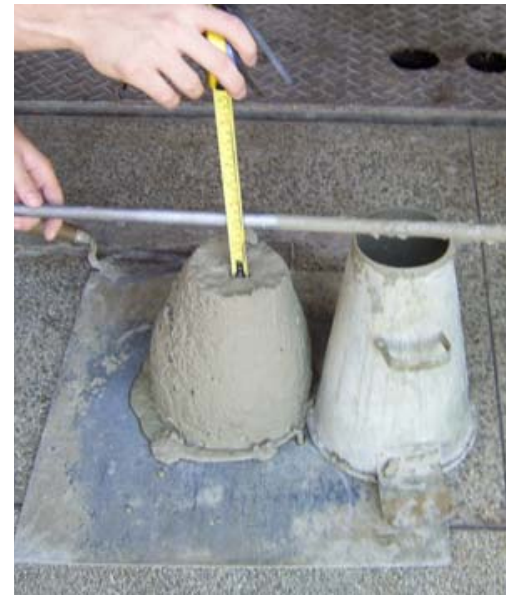

Medida do slump

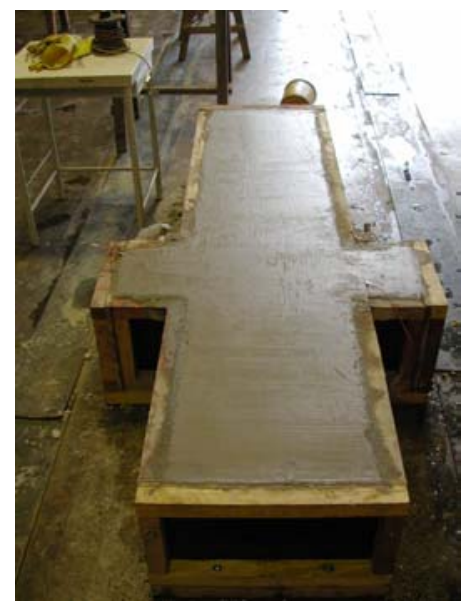

Pilar acabado

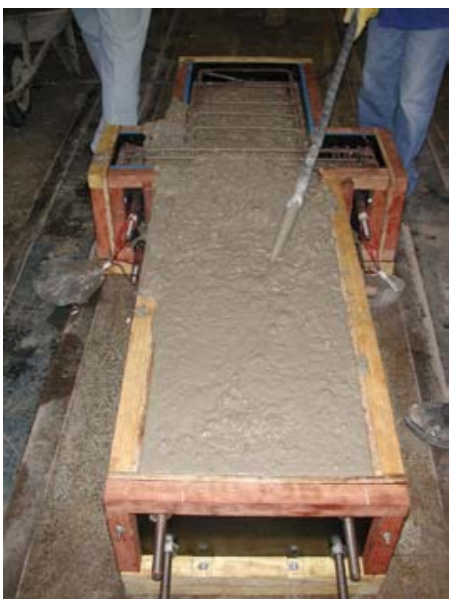

Concretagem do pilar

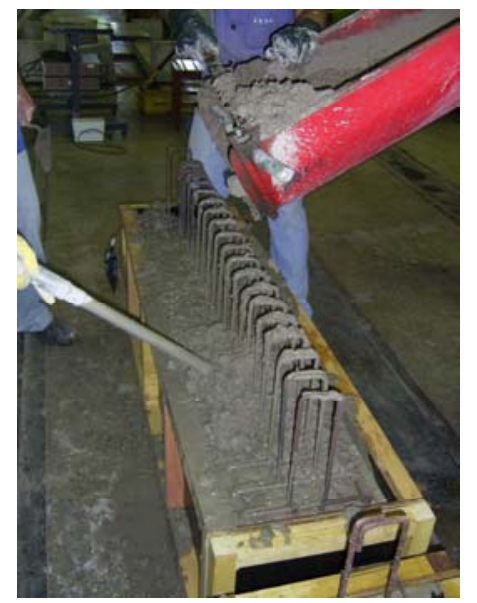

Concretagem da viga

Figura 3.14 - Concretagem do modelo I 


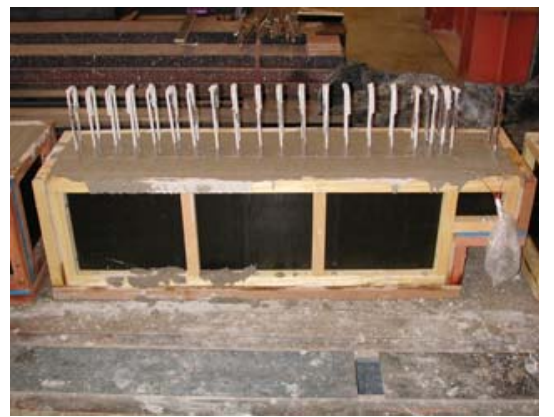

Viga acabada

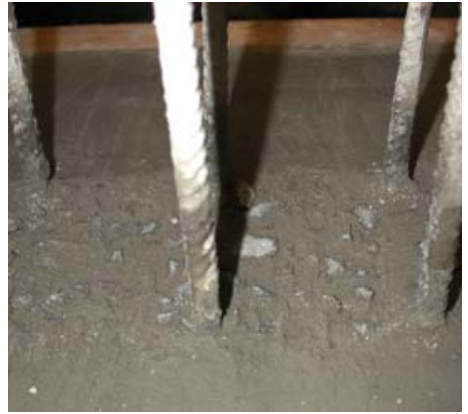

Rugosidade da viga

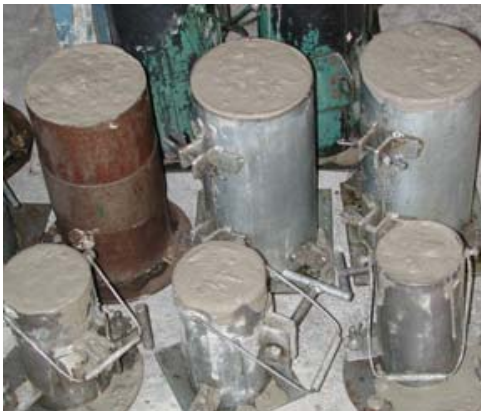

Corpos-de-prova

Figura 3.14 - Concretagem do modelo I (continuação)

A Figura 3.15 mostra as diferenças na concretagem do modelo E, ou seja, o uso de betoneira do laboratório e moldagem do pilar de canto.

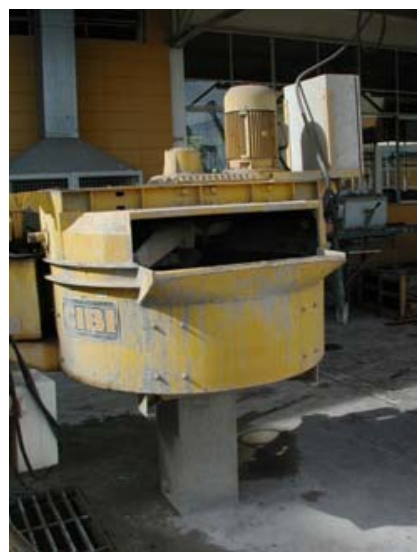

Betoneira do laboratório EESC

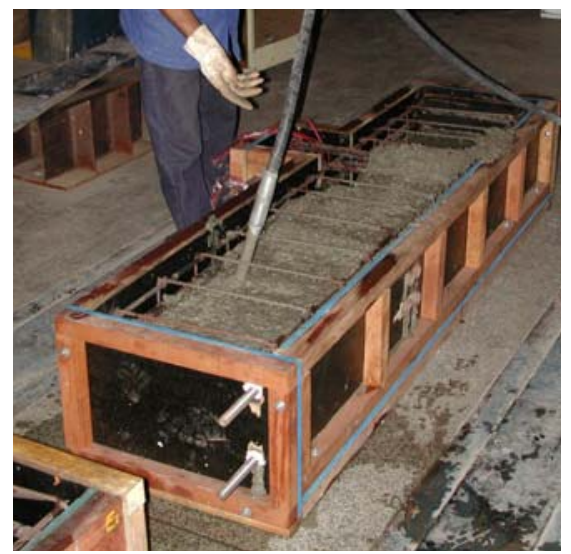

Concretagem do pilar

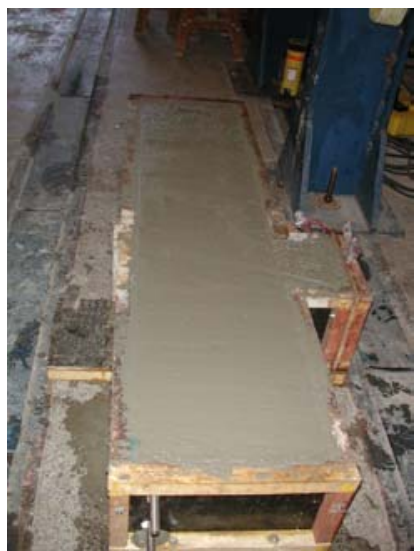

Pilar acabado

Figura 3.15 - Concretagem do modelo E

Os elementos foram curados por 3 dias e cobertos com lona plástica, a fim de minimizar a retração. A desforma se deu depois de 28 dias para o modelo I e 7 dias para o modelo E.

\subsubsection{Graute}

Para o preenchimento dos furos das vigas e dos pilares foi usado o graute FOSGROUT - PLUS da FOSROC. A elaboração do traço do graute foi feita de acordo com a recomendação do fabricante cujo fator água/graute era de 0,126. Para o 
preenchimento dos furos dos pilares, devido os furos do pilar estarem na horizontal, decidiu-se usar um fator água/graute de 0,2 tornando-o mais fluido e facilitando assim seu preenchimento e evitando nichos.

A Tabela 3.6 apresenta as características dos grautes utilizados.

Tabela 3.6 - Características do graute

\begin{tabular}{|c|c|c|c|}
\hline Graute & Local de utilização & Consumo $\left(\mathrm{kg} / \mathrm{m}^{3}\right)$ & $\begin{array}{c}\text { Fator } \\
\text { água/graute }\end{array}$ \\
\hline Graute 1 & $\begin{array}{c}\text { Preenchimento dos furos das vigas e dos } \\
\text { espaços entre as vigas e o pilar }\end{array}$ & 2251 & 0,126 \\
\hline Graute 2 & Preenchimento dos furos dos pilares & 2251 & 0,200 \\
\hline
\end{tabular}

\subsubsection{Almofada de apoio}

O traço escolhido para a composição da almofada de apoio consiste em cimento, areia, vermiculita, látex estireno-butadieno, fibras polipropileno, aditivo e água como mostrado na Tabela 3.7 .

Tabela 3.7 - Traço da almofada de apoio

\begin{tabular}{|c|c|c|c|c|c|c|}
\hline Cimento & Areia & Vermiculita & Látex & Fibras & Água & Aditivo \\
\hline 1 & 0,27 & 0,03 & 0,3 & $4 \%$ & 0,1 & 0,01 \\
\hline
\end{tabular}

As almofadas de apoio foram confeccionadas com as dimensões do consolo, ou seja, $30 \mathrm{~cm}$ x $20 \mathrm{~cm}$ e moldadas em mesa vibratória como ilustra a Figura 3.16.

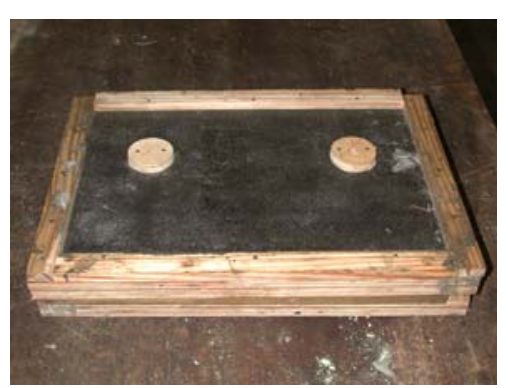

Fôrma da almofada de apoio

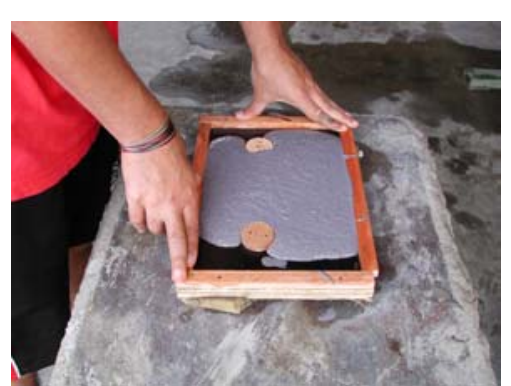

Moldagem em mesa vibratória

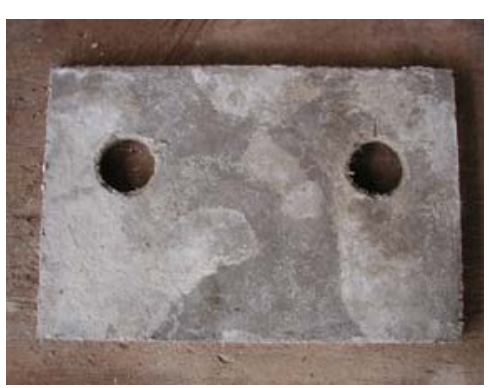

Aspecto final

Figura 3.16 - Moldagem da almofada de apoio 


\subsection{MONTAGEM DOS MODELOS}

A montagem de ambos os modelos seguiu as seguintes etapas:
a. Posicionamento do pilar e colocação da almofada de apoio
b. Posicionamento das vigas sobre o consolo e fixação das chapas metálicas
c. Grauteamento do espaço entre o pilar e a viga e o rasgo da viga
d. Colocação da armação de continuidade e grauteamento
e. Posicionamento das lajes alveolares pré-moldadas
f. Concretagem do espaço entre as lajes pré-moldadas
g. Armação da capa
h. Concretagem da capa

A concretagem primeiramente do espaço entre as lajes pré-moldadas até a altura da laje com duas barras de $12,5 \mathrm{~mm}$ passando por dentro do pilar permitirá que a ligação já se comporte como ligação semi-rígida quando a capa for concretada.

A Figura 3.17 mostra as etapas de montagem do modelo I.

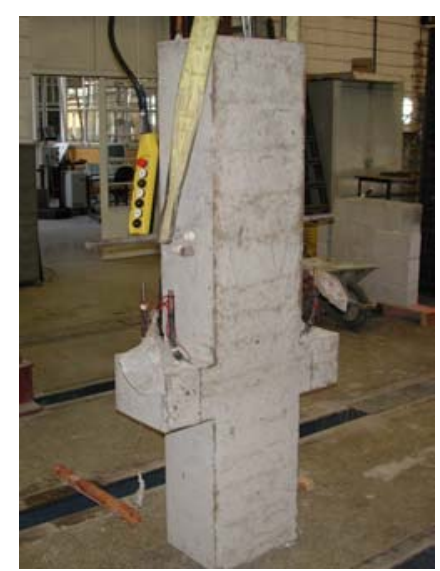

Içamento do pilar

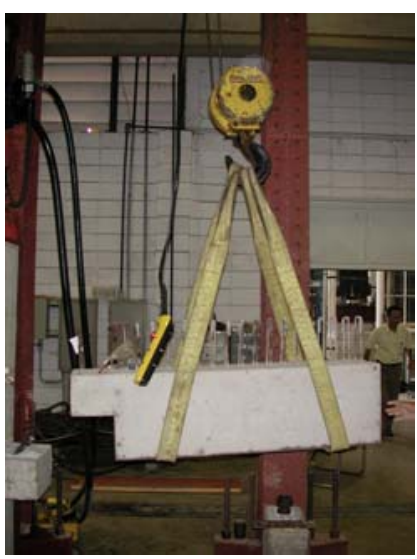

Içamento da viga

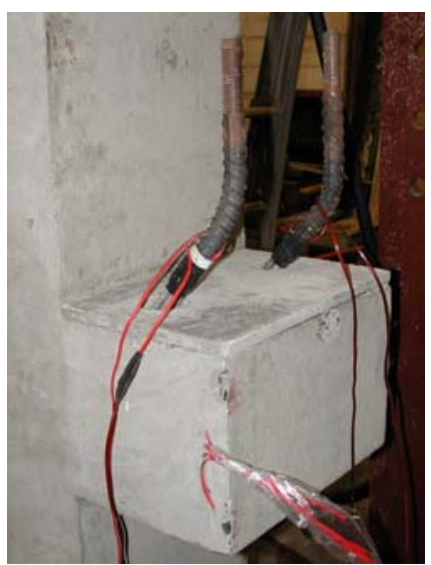

Almofada de apoio

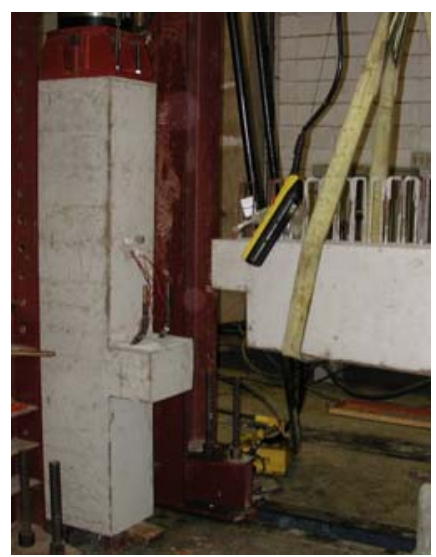

Posicionamento da viga

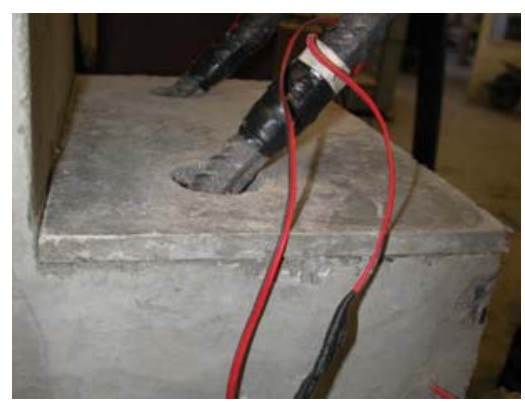

Detalhe da almofada de apoio sobre o consolo

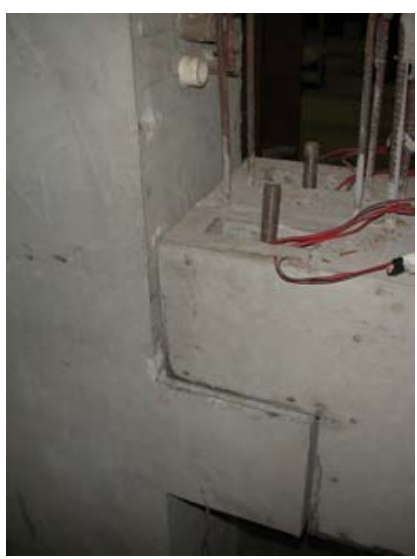

Viga apoiada no consolo

Figura 3.17 - Etapas da montagem do modelo I 


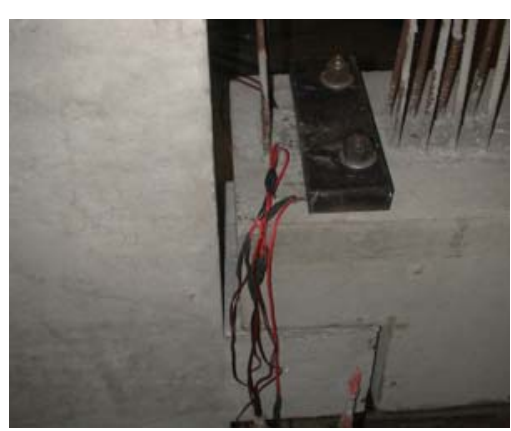

Fixação da chapa metálica

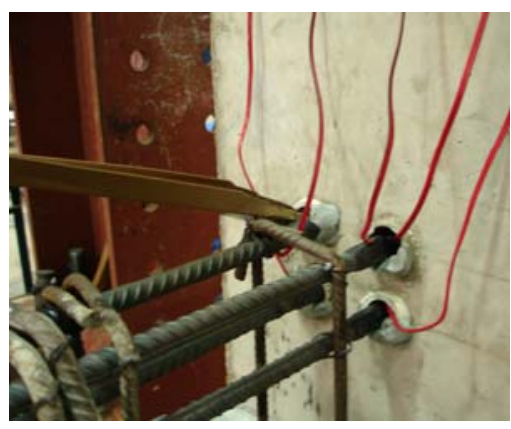

Grauteamento das barras

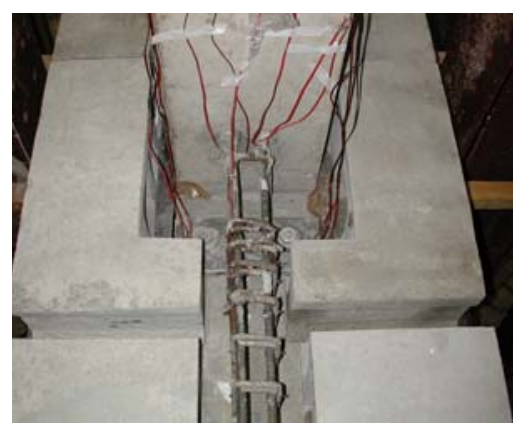

Detalhe do corte das lajes

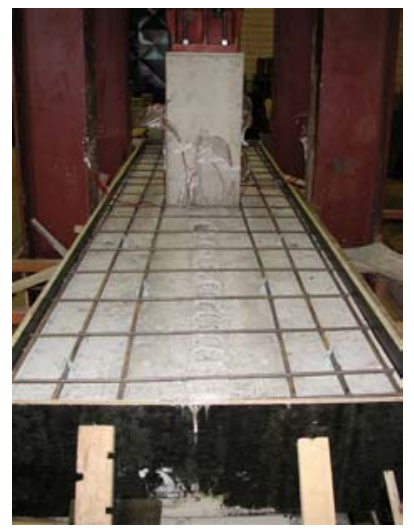

Armação da capa

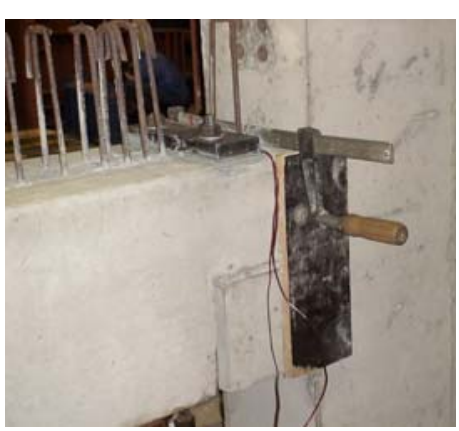

Fôrma para grauteamento

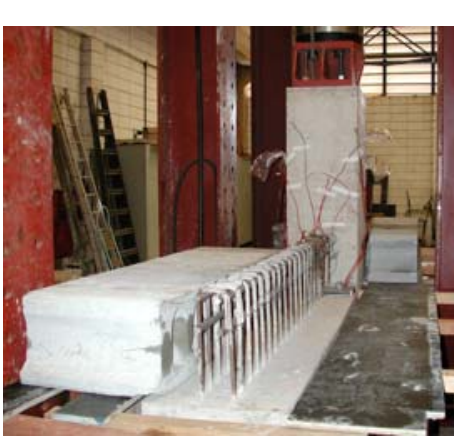

Posicionamento das lajes

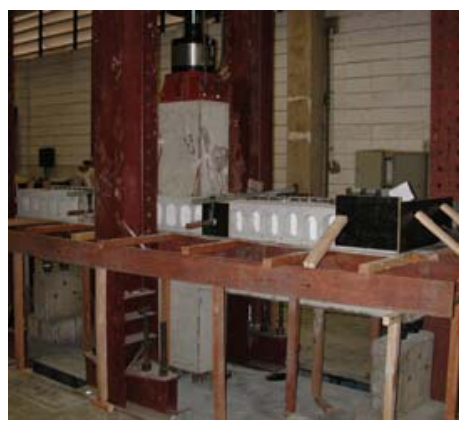

Fôrma para concretagem

entre as lajes

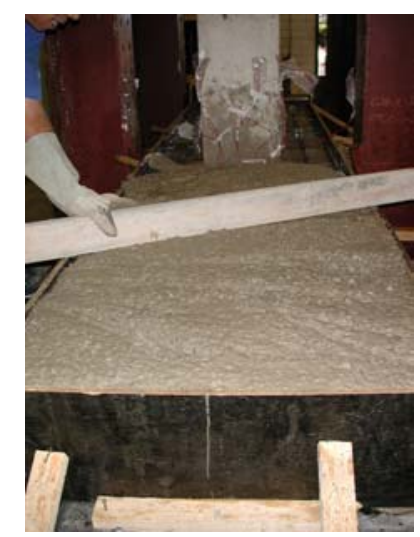

Concretagem da capa

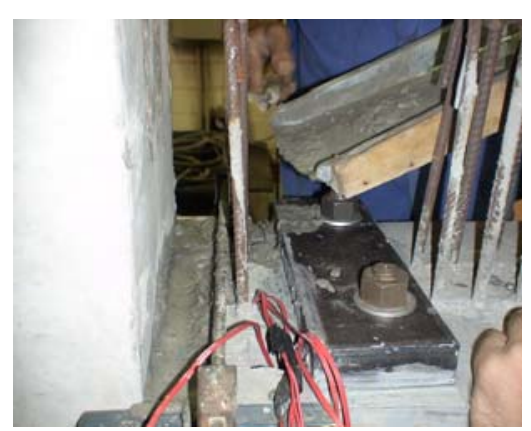

Grauteamento entre viga/pilar e rasgo da viga

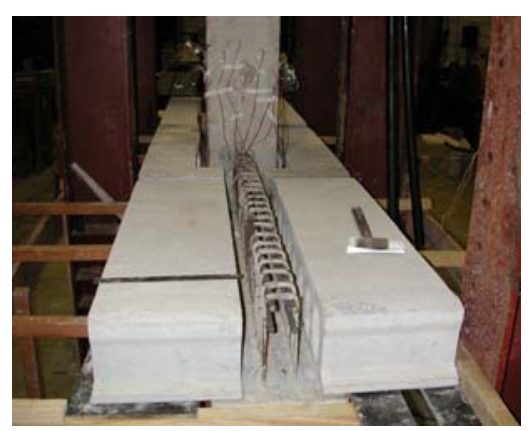

Lajes pré-moldadas

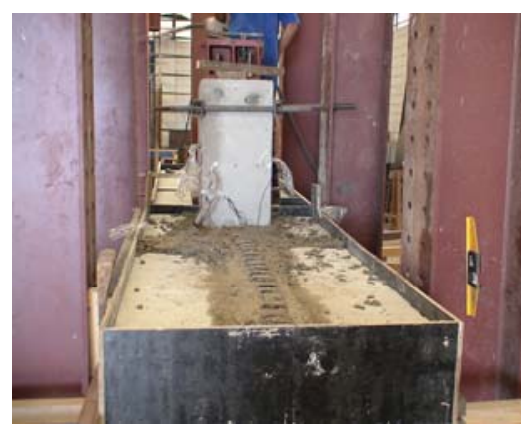

Concretagem entre as lajes

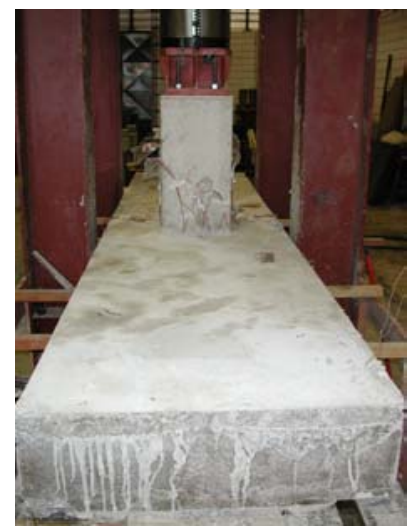

Capa acabada

Figura 3.17 - Etapas da montagem do modelo I (continuação) 
Para a montagem do modelo E foi necessário acrescentar algumas etapas mostradas na Figura 3.18. Logo após o içamento dos pilares foi colocada uma chapa metálica de dimensões $360 \mathrm{~mm}$ x $200 \mathrm{~mm}$ x 22,2 $\mathrm{mm}$ na parte inferior dos pilares visando restringir os movimentos horizontais e cantoneiras de perfil L de $100 \mathrm{~mm} x$ $6,35 \mathrm{~mm}$.

Após o grauteamento das barras que transpassam o pilar foram colocadas chapas metálicas de $170 \mathrm{~mm}$ x $140 \mathrm{~mm}$ x 25,4 mm para garantir ancoragem destas. Por fim antes da concretagem da capa, foram soldadas barras de diâmetro $10 \mathrm{~mm}$ as barras longitudinais da capa também visando garantir a ancoragem.

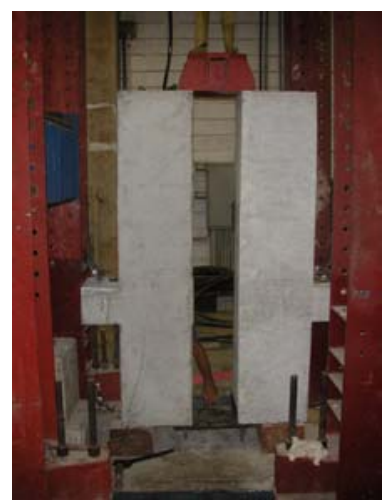

Pilar com chapa e cantoneiras

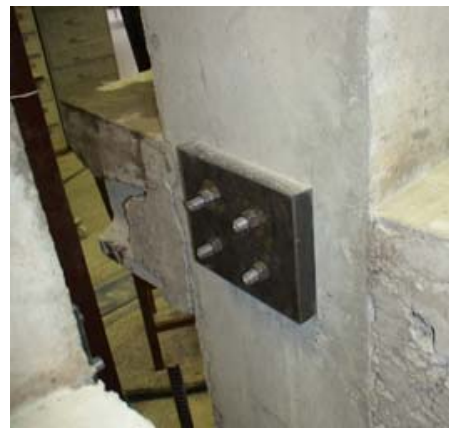

Chapa de ancoragem da Soldagem da armadura da armadura transpasse do capa pilar
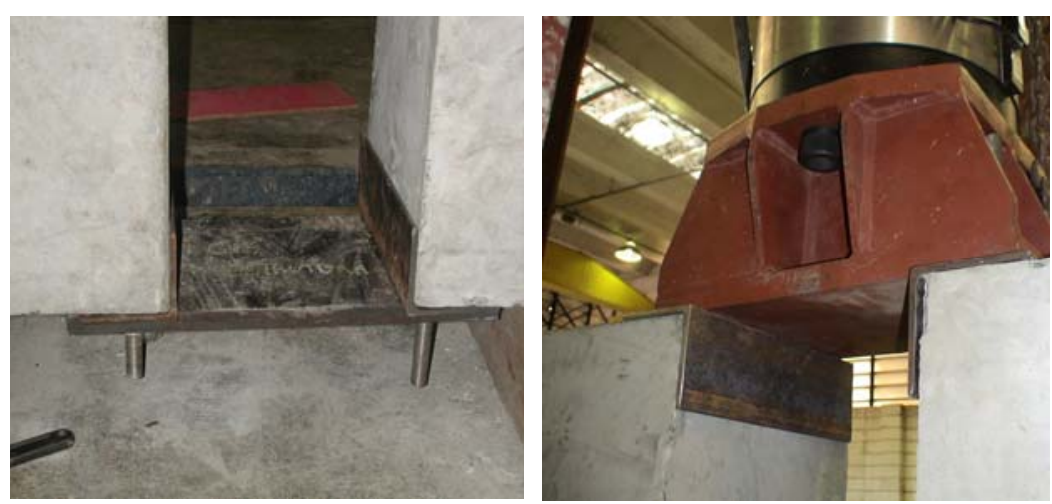

Detalhe da chapa e Detalhe da cantoneira cantoneira inferior superior

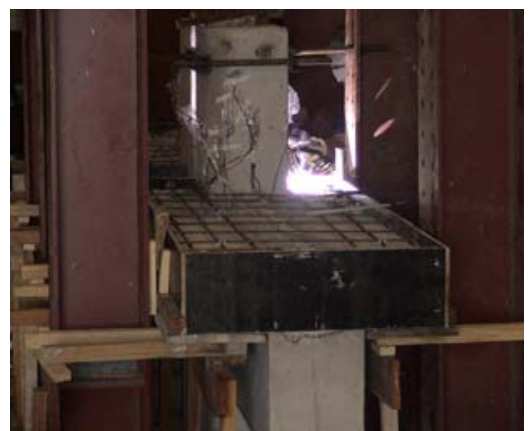




\subsection{PROPRIEDADES MECÂNICAS DOS MATERIAIS}

\subsubsection{Concreto}

As propriedades mecânicas do concreto foram obtidas através de corpos-deprova cilíndricos de $150 \mathrm{~mm}$ x $300 \mathrm{~mm}$ que foram desformados 1 dia após a concretagem e mantidos na câmera úmida até a data do ensaio, o que equivale a 52 dias para o modelo I e 64 dias para o modelo E.

Para a determinação da resistência à compressão, resistência à tração através de compressão diametral e módulo de elasticidade foram empregado 3, 3 e 4 corpos-deprova respectivamente para cada modelo que foram rompidos na máquina servo controlada INSTRON 8506.

Os valores das resistências à compressão e tração por compressão diametral dos corpos-de-prova foram calculados de acordo a eq. (3.1) e eq. (3.2) respectivamente. $\mathrm{O}$ módulo de elasticidade tangente foi obtido baseado na norma NBR 8522:1984.

$f_{c j}=\frac{N}{A}$

Onde:

$f_{c j} \quad=$ Resistência à compressão dos corpos de prova na data $\mathrm{j}$

$N \quad=$ Carga de ruptura

$A \quad=$ Área da seção do corpo de prova

$f_{c t, s p}=\frac{2 F}{\pi \cdot d \cdot h} \cdot 0,85$

Onde:

$f_{c t, s p}=$ Resistência à tração por compressão diametral

$F \quad=$ Força máxima aplicada

$d \quad=$ Diâmetro do corpo de prova

$h \quad=$ Comprimento do corpo de prova 
As Tabelas 3.8 a 3.16 apresentam os resultados das resistências à compressão, tração por compressão diametral e módulo de elasticidade obtidos para cada um dos modelos. As Figuras 3.19 a 3.21 ilustram a forma dos ensaios descritos nas tabelas correspondentes.

Tabela 3.8 - Resistência à compressão das vigas e dos pilares

\begin{tabular}{|c|c|c|c|}
\hline \multirow{2}{*}{$\begin{array}{c}\text { Corpo-de- } \\
\text { prova }\end{array}$} & \multicolumn{2}{|c|}{ Resistência à compressão (MPa) } \\
\cline { 2 - 4 } & Modelo I & \multicolumn{2}{|c|}{ Modelo E } \\
\cline { 2 - 4 } & Pilar & Viga \\
\hline CP 1 & 51,2 & 52,6 & 47,3 \\
\hline CP 2 & 51,9 & 52,8 & 45,2 \\
\hline CP 3 & 49,6 & 54,1 & 46,5 \\
\hline Média & $\mathbf{5 0 , 9}$ & $\mathbf{5 3 , 2}$ & $\mathbf{4 6 , 3}$ \\
\hline
\end{tabular}

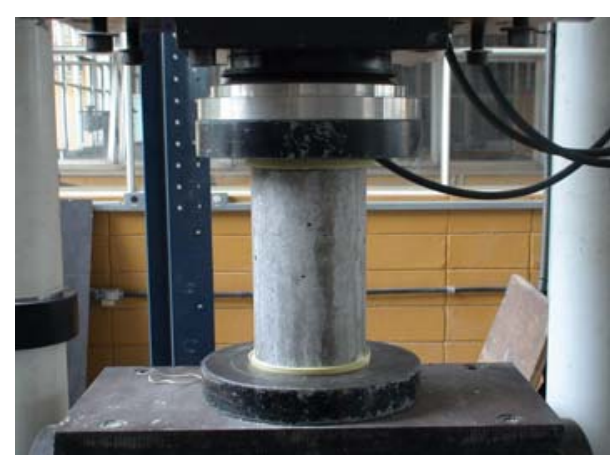

Figura 3.19 - Ensaio à compressão dos corpos-de-prova

Tabela 3.9 - Resistência à compressão do concreto entre as lajes

\begin{tabular}{|c|c|c|}
\hline \multirow{2}{*}{$\begin{array}{c}\text { Corpo-de- } \\
\text { prova }\end{array}$} & Rodelo I & Modelo E \\
\cline { 2 - 3 } & 32,4 & 40,8 \\
\hline CP 1 & 33,4 & 40,8 \\
\hline CP 2 & 34,4 & 40,6 \\
\hline CP 3 & $\mathbf{3 3 , 4}$ & $\mathbf{4 0 , 7}$ \\
\hline Média & & \\
\hline
\end{tabular}

Tabela 3.10 - Resistência à compressão da capa de concreto

\begin{tabular}{|c|c|c|}
\hline \multirow{2}{*}{$\begin{array}{c}\text { Corpo-de- } \\
\text { prova }\end{array}$} & Modelo I & Modelo E \\
\cline { 2 - 3 } & 37,2 & 45,0 \\
\hline CP 1 & 33,9 & 42,8 \\
\hline CP 2 & 34,9 & 40,8 \\
\hline CP 3 & $\mathbf{3 5 , 3}$ & $\mathbf{4 2 , 9}$ \\
\hline Média & & \\
\hline
\end{tabular}


Tabela 3.11 - Resistência à tração por compressão diametral do concreto das vigas e dos pilares

\begin{tabular}{|c|c|c|c|}
\hline \multirow{2}{*}{$\begin{array}{c}\text { Corpo- } \\
\text { de-prova }\end{array}$} & \multicolumn{2}{|c|}{$\begin{array}{c}\text { Resistência à tração por } \\
\text { compressão diametral (MPa) }\end{array}$} \\
\cline { 2 - 4 } & Modelo I & \multicolumn{2}{|c|}{ Modelo E } \\
\cline { 3 - 4 } & 2,74 & 2,41 & 3,02 \\
\hline CP 1 & 2,95 & 2,89 & 3,12 \\
\hline CP 2 & 2,20 & 3,28 & 2,91 \\
\hline CP 3 & $\mathbf{2 , 6 3}$ & $\mathbf{2 , 8 6}$ & $\mathbf{3 , 0 1}$ \\
\hline Média &
\end{tabular}

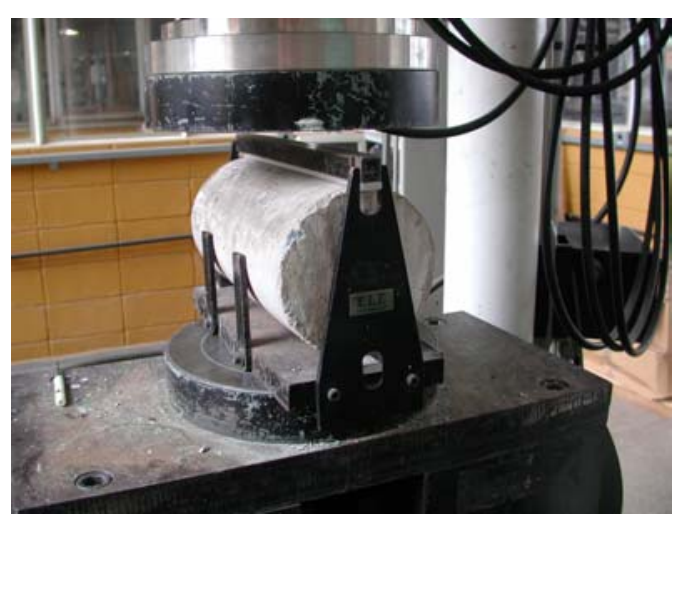

Figura 3.20 - Ensaio de tração por compressão diametral dos corpos-de-prova

Tabela 3.12 - Resistência à tração por compressão diametral do concreto entre as lajes

\begin{tabular}{|c|c|c|}
\hline \multirow{2}{*}{$\begin{array}{c}\text { Corpo-de- } \\
\text { prova }\end{array}$} & \multicolumn{2}{|c|}{ Resistência à tração por compressão diametral (MPa) } \\
\cline { 2 - 3 } & Modelo I & Modelo E \\
\hline CP 1 & 2,31 & 2,14 \\
\hline CP 2 & 2,00 & 2,63 \\
\hline CP 3 & --- & 2,40 \\
\hline Média & $\mathbf{2 , 1 5}$ & $\mathbf{2 , 3 9}$ \\
\hline
\end{tabular}

Tabela 3.13 - Resistência à tração por compressão diametral da capa de concreto

\begin{tabular}{|c|c|c|}
\hline \multirow{2}{*}{$\begin{array}{c}\text { Corpo-de- } \\
\text { prova }\end{array}$} & Modelo I & Modelo E \\
\cline { 2 - 3 } & 2,07 & 2,73 \\
\hline CP 1 & 2,48 & 2,20 \\
\hline CP 2 & 2,34 & 2,15 \\
\hline CP 3 & $\mathbf{2 , 3 0}$ & $\mathbf{2 , 3 6}$ \\
\hline Média & & \\
\hline
\end{tabular}


Tabela 3.14 - Módulo de elasticidade tangente das vigas e dos pilares

\begin{tabular}{|c|c|c|c|}
\hline \multirow{2}{*}{$\begin{array}{c}\text { Corpo-de- } \\
\text { prova }\end{array}$} & \multicolumn{3}{|c|}{ Módulo de elasticidade (GPa) } \\
\cline { 2 - 4 } & \multirow{2}{*}{ Modelo I } & \multicolumn{2}{|c|}{ Modelo E } \\
\cline { 3 - 4 } & Pilar & Viga \\
\hline CP 1 & 38,6 & 40,7 & 36,9 \\
\hline CP 2 & 39,0 & 38,4 & 37,1 \\
\hline CP 3 & 39,7 & 41,3 & 37,9 \\
\hline CP 4 & 38,4 & 40,7 & 38,5 \\
\hline Média & $\mathbf{3 8 , 9}$ & $\mathbf{4 0 , 3}$ & $\mathbf{3 7 , 6}$ \\
\hline
\end{tabular}

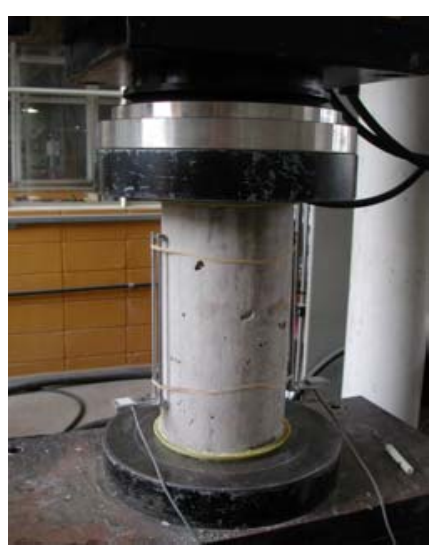

Figura 3.21 - Ensaio de módulo de elasticidade dos corpos-de-prova

Tabela 3.15 - Módulo de elasticidade tangente do concreto entre as lajes

\begin{tabular}{|c|c|c|}
\hline \multirow{2}{*}{$\begin{array}{c}\text { Corpo-de- } \\
\text { prova }\end{array}$} & Modelo I & Módulo de elasticidade $(\mathrm{GPa})$ \\
\cline { 2 - 3 } & 31,8 & 36,3 \\
\hline CP 1 & 34,4 & 35,3 \\
\hline CP 2 & 33,1 & 35,3 \\
\hline CP 3 & $\mathbf{3 3 , 1}$ & $\mathbf{3 5 , 6}$ \\
\hline Média & & Modelo E \\
\hline
\end{tabular}

Tabela 3.16 - Módulo de elasticidade tangente da capa de concreto

\begin{tabular}{|c|c|c|}
\hline \multirow{2}{*}{$\begin{array}{c}\text { Corpo-de- } \\
\text { prova }\end{array}$} & \multicolumn{2}{|c|}{ Módulo de elasticidade (GPa) } \\
\cline { 2 - 3 } & Modelo I & Modelo E \\
\hline CP 1 & 31,6 & 37,2 \\
\hline CP 2 & 33,1 & 36,0 \\
\hline CP 3 & 32,0 & 39,7 \\
\hline Média & $\mathbf{3 2 , 2}$ & $\mathbf{3 7 , 6}$ \\
\hline
\end{tabular}




\subsubsection{Armadura}

As propriedades mecânicas do aço foram obtidas na máquina servo controlada INSTRON 8506 para todos os diâmetros utilizados. Na tabela 3.17 estão indicados os valores da tensão de escoamento $\left(\mathrm{f}_{\mathrm{y}}\right)$ e ruína $\left(\mathrm{f}_{\mathrm{u}}\right)$ para cada diâmetro e são válidos para os dois modelos. O módulo de elasticidade foi adotado igual a $210 \mathrm{GPa}$.

Tabela 3.17 - Propriedades mecânicas do aço

\begin{tabular}{|c|c|c|c|}
\hline Diâmetro & Corpo-de-prova & $\mathrm{f}_{\mathrm{y}}(\mathrm{MPa})$ & $\mathrm{f}_{\mathrm{u}}(\mathrm{MPa})$ \\
\hline \multirow{4}{*}{$6,3 \mathrm{~mm}$} & $\mathrm{CP} 1$ & 770 & 870 \\
\hline & $\mathrm{CP} 2$ & 720 & 890 \\
\hline & $\mathrm{CP} 3$ & 690 & 883 \\
\hline & Média & 727 & 881 \\
\hline \multirow{4}{*}{$8,0 \mathrm{~mm}$} & $\mathrm{CP} 1$ & 639 & 733 \\
\hline & $\mathrm{CP} 2$ & 641 & 730 \\
\hline & $\mathrm{CP} 3$ & 648 & 737 \\
\hline & Média & 643 & 734 \\
\hline \multirow{4}{*}{$10,0 \mathrm{~mm}$} & $\mathrm{CP} 1$ & 636 & 735 \\
\hline & $\mathrm{CP} 2$ & 613 & 721 \\
\hline & $\mathrm{CP} 3$ & 646 & 745 \\
\hline & Média & 632 & 734 \\
\hline \multirow{4}{*}{$12,5 \mathrm{~mm}$} & CP 1 & 612 & 725 \\
\hline & $\mathrm{CP} 2$ & 603 & 709 \\
\hline & $\mathrm{CP} 3$ & 612 & 727 \\
\hline & Média & 609 & 721 \\
\hline \multirow{4}{*}{$16,0 \mathrm{~mm}$} & CP 1 & 586 & 719 \\
\hline & $\mathrm{CP} 2$ & 586 & 719 \\
\hline & $\mathrm{CP} 3$ & 607 & 718 \\
\hline & Média & 593 & 718 \\
\hline \multirow{4}{*}{$20,0 \mathrm{~mm}$} & $\mathrm{CP} 1$ & 601 & 734 \\
\hline & $\mathrm{CP} 2$ & 618 & 746 \\
\hline & CP 3 & 620 & 749 \\
\hline & Média & 613 & 743 \\
\hline
\end{tabular}


As Figuras 3.22 e 3.23 apresentam os equipamentos e o ensaio para a determinação das propriedades mecânicas de aço.

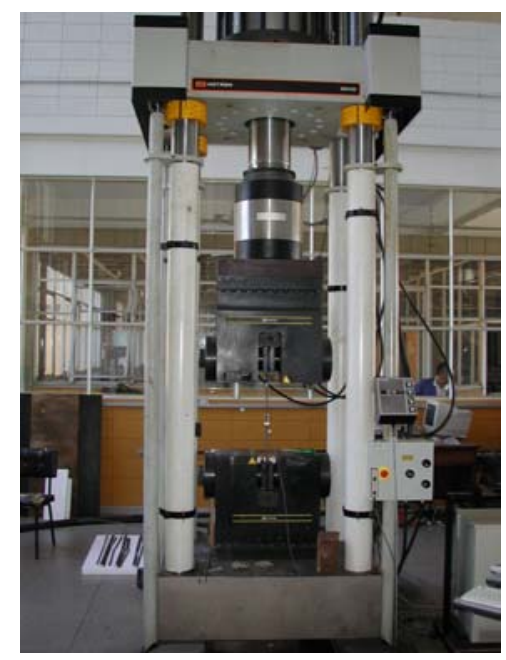

Equipamento usado para ensaio

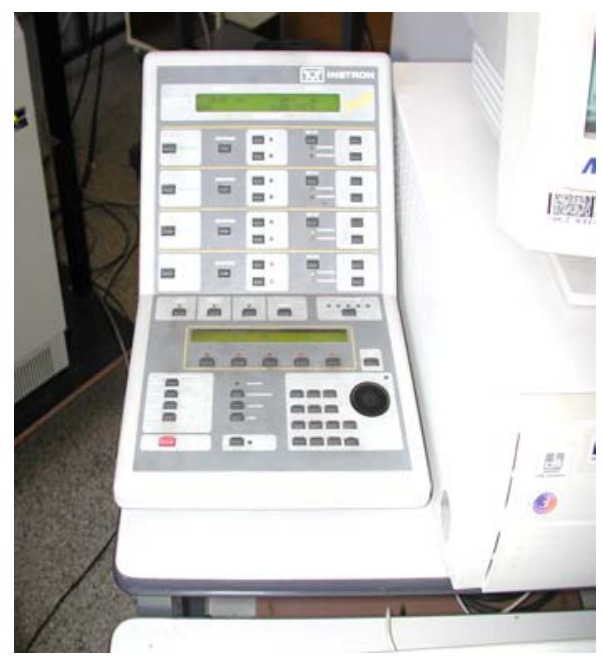

Sistema de aquisição de dados

Figura 3.22- Equipamento utilizado para o ensaio das propriedades mecânicas do aço
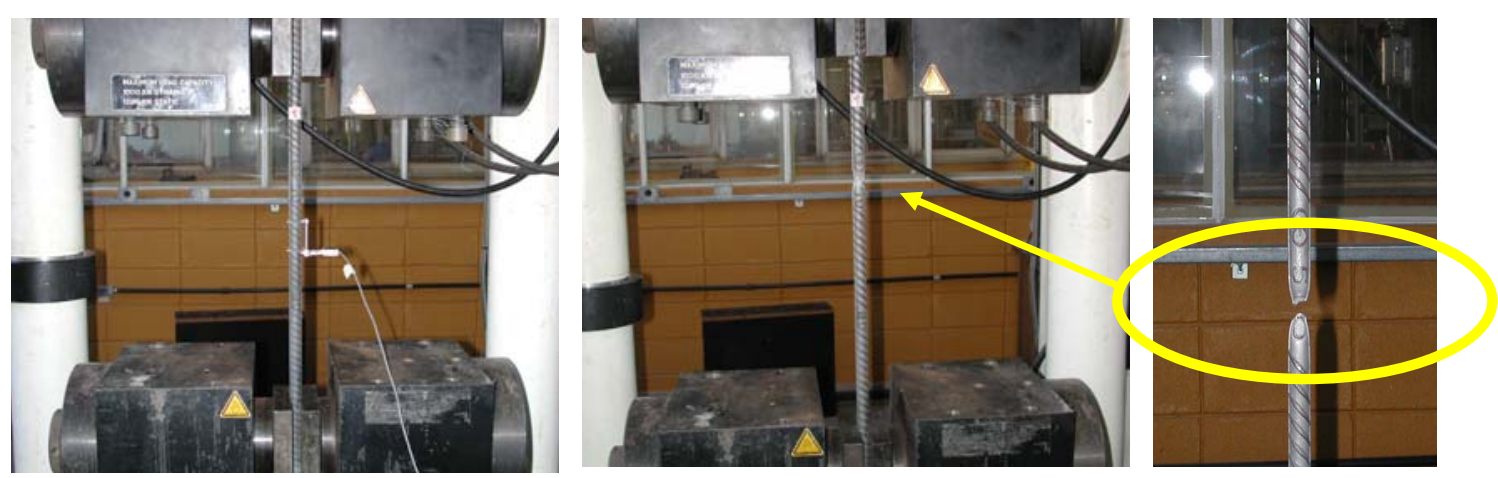

Figura 3.23 - Ensaio para determinação das propriedades mecânicas do aço

\subsubsection{Graute}

As características mecânicas dos grautes foram obtidas através de corpos-deprova cilíndricos de $50 \mathrm{~mm}$ x $100 \mathrm{~mm}$. As condições de cura e data de ruptura foram similares à realizada no concreto, ou seja, foram desformados após 1 dia de moldados e mantidos na câmara úmida até a data do ensaio quando foram rompidos. Para o modelo I os grautes 1 e 2 foram rompidos a 21 e 14 dias respectivamente. Para o modelo E estes valores são de 48 e 45 dias respectivamente. 
As Tabelas 3.18, 3.19 e 3.20 apresentam os resultados da resistência à compressão, resistência à tração por compressão diametral e módulo de elasticidade de ambos os grautes confeccionados.

Tabela 3.18 - Resistência à compressão dos grautes

\begin{tabular}{|c|c|c|c|}
\hline \multirow{2}{*}{ Graute } & \multirow{2}{*}{ Corpo-de-prova } & \multicolumn{2}{|c|}{ Resistência à compressão (MPa) } \\
\cline { 2 - 4 } & CP 1 & Modelo I & Modelo E \\
\hline \multirow{3}{*}{ Graute 1 } & CP 2 & 33,1 & 42,9 \\
\cline { 2 - 4 } & CP 3 & 44,0 & 48,4 \\
\cline { 2 - 4 } & Média & $\mathbf{3 7 , 2}$ & 45,2 \\
\cline { 2 - 4 } & CP 1 & 29,2 & $\mathbf{4 5 , 5}$ \\
\hline \multirow{3}{*}{ Graute 2 } & CP 2 & 27,3 & 37,6 \\
\cline { 2 - 4 } & CP 3 & 26,0 & 25,3 \\
\cline { 2 - 4 } & Média & $\mathbf{2 7 , 5}$ & $\mathbf{2 9 , 1}$ \\
\cline { 2 - 4 } & & & 24,4 \\
\hline
\end{tabular}

Tabela 3.19 - Resistência à tração por compressão diametral dos grautes

\begin{tabular}{|l|c|c|c|}
\hline \multirow{2}{*}{ Graute } & \multirow{2}{*}{ Corpo-de-prova } & \multicolumn{2}{|c|}{$\begin{array}{r}\text { Resistência à tração por compressão } \\
\text { diametral (MPa) }\end{array}$} \\
\cline { 3 - 4 } & & Modelo I & Modelo E \\
\cline { 2 - 4 } & CP 1 & 2,36 & 2,51 \\
\cline { 2 - 4 } & CP 2 & 2,82 & 2,93 \\
\cline { 2 - 4 } & CP 3 & 2,30 & $1,46^{*}$ \\
\cline { 2 - 4 } & Média & $\mathbf{2 , 4 9}$ & 2,72 \\
\hline \multirow{3}{*}{ Graute 2 } & CP 1 & 2,44 & 1,78 \\
\cline { 2 - 4 } & CP 2 & 1,91 & 1,88 \\
\cline { 2 - 4 } & CP 3 & 2,22 & $\mathbf{1 , 9 3}$ \\
\cline { 2 - 4 } & Média & $\mathbf{2 , 1 9}$ & 2,13 \\
\hline
\end{tabular}

* Valor descartado 
Tabela 3.20 - Módulo de elasticidade tangente dos grautes

\begin{tabular}{|c|c|c|c|}
\hline \multirow{2}{*}{ Graute } & \multirow{2}{*}{ Corpo-de-prova } & \multicolumn{2}{|c|}{ Módulo de elasticidade (GPa) } \\
\cline { 2 - 4 } & & Modelo I & Modelo E \\
\hline \multirow{3}{*}{ Graute 1 } & CP 1 & 30,0 & 33,7 \\
\cline { 2 - 4 } & CP 2 & 32,8 & 32,4 \\
\cline { 2 - 4 } & CP 3 & 29,6 & 31,4 \\
\cline { 2 - 4 } & Média & $\mathbf{3 0 , 8}$ & $\mathbf{3 2 , 5}$ \\
\hline \multirow{3}{*}{ Graute 2 } & CP 1 & 28,1 & 19,0 \\
\cline { 2 - 4 } & CP 2 & 28,3 & 13,3 \\
\cline { 2 - 4 } & CP 3 & 29,0 & 17,1 \\
\cline { 2 - 4 } & Média & $\mathbf{2 8 , 5}$ & $\mathbf{1 6 , 5}$ \\
\hline
\end{tabular}

\subsubsection{Almofada de apoio}

Para determinação das características mecânicas das almofadas de apoio foram moldados 10 corpos-de-prova cilíndricos de $50 \mathrm{~mm}$ x $100 \mathrm{~mm}$ e 2 placas de $150 \mathrm{~mm}$ x $150 \mathrm{~mm} \times 10 \mathrm{~mm}$. O tempo de desforma foi de 1 dia e a cura feita através da câmera úmida por 6 dias para o modelo I e 4 dias para o modelo E. A ruptura dos elementos deu se aos 14 dias de moldagem.

As Tabelas 3.21 a 3.24 apresentam os resultados das resistências à compressão, tração por compressão diametral e módulo de elasticidade para os corpos-de-prova. As Figuras 3.24 a 3.27 ilustram os corpos-de-prova sendo ensaiados.

Tabela 3.21- Resistência à compressão da almofada de apoio

\begin{tabular}{|c|c|c|}
\hline \multirow{2}{*}{$\begin{array}{c}\text { Corpo-de- } \\
\text { prova }\end{array}$} & \multicolumn{2}{|c|}{ Resistência à compressão (MPa) } \\
\cline { 2 - 3 } & Modelo I & Modelo E \\
\hline CP 1 & 28,3 & 28,4 \\
\hline CP 2 & 27,2 & 32,0 \\
\hline CP 3 & 28,4 & 31,3 \\
\hline Média & $\mathbf{2 8}$ & $\mathbf{3 0 , 5}$ \\
\hline
\end{tabular}

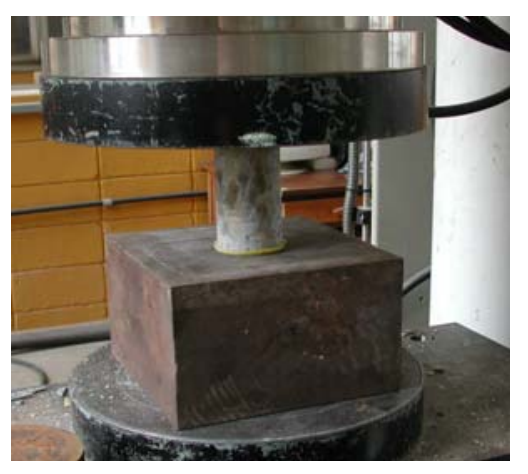

Figura 3.24 - Ensaio à compressão dos corpos-de-prova 
Tabela 3.22 - Resistência à tração por compressão diametral da almofada de apoio

\begin{tabular}{|c|c|c|}
\hline \multirow{2}{*}{$\begin{array}{c}\text { Corpo-de- } \\
\text { prova }\end{array}$} & \multicolumn{2}{|c|}{$\begin{array}{r}\text { Resistência à tração por compressão } \\
\text { diametral }(\mathrm{MPa})\end{array}$} \\
\cline { 2 - 3 } & Modelo I & Modelo E \\
\hline CP 1 & 1,79 & 2,34 \\
\hline CP 2 & 2,88 & 2,94 \\
\hline CP 3 & 2,89 & 2,10 \\
\hline Média & $\mathbf{2 , 5 2}$ & $\mathbf{2 , 4 6}$ \\
\hline
\end{tabular}

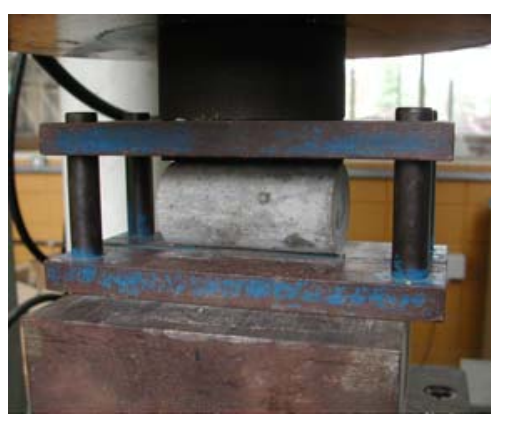

Figura 3.25 - Ensaio à tração por compressão diametral dos corpos-de-prova

Tabela 3.23 - Módulo de elasticidade tangente dos corpos-de-prova

\begin{tabular}{|c|c|c|}
\hline \multirow{2}{*}{$\begin{array}{c}\text { Corpo-de- } \\
\text { prova }\end{array}$} & \multicolumn{2}{|c|}{ Módulo de elasticidade (GPa) } \\
\cline { 2 - 3 } & Modelo I & Modelo E \\
\hline CP 1 & 12,1 & 9,3 \\
\hline CP 2 & 10,9 & 12,5 \\
\hline CP 3 & 12,0 & ------- \\
\hline Média & $\mathbf{1 1 , 7}$ & $\mathbf{1 0 , 9}$ \\
\hline
\end{tabular}

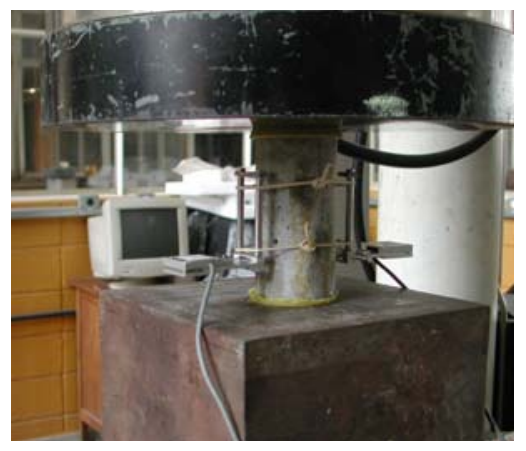

Figura 3.26 - Ensaio do módulo de elasticidade dos corpos-de-prova

Tabela 3.24 - Rigidez das placas

\begin{tabular}{|c|c|c|}
\hline \multirow{2}{*}{ Placa } & \multicolumn{2}{|c|}{ Rigidez da almofada (MPa) } \\
\cline { 2 - 3 } & Modelo I & Modelo E \\
\hline Placa 1 & 337 & 380 \\
\hline Placa 2 & 364 & 352 \\
\hline Média & $\mathbf{3 5 0}$ & $\mathbf{3 6 6}$ \\
\hline
\end{tabular}

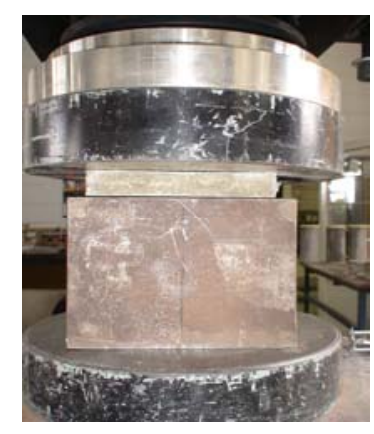

Figura 3.27 - Ensaio da rigidez da placa 


\subsection{EQUIPAMENTOS E INSTRUMENTAÇÃO}

Os equipamentos e instrumentos de medição utilizados para realização dos ensaios estão descritos na Tabela 3.25. São discriminadas a marca, modelo, características e finalidade de cada equipamento.

Tabela 3.25 - Equipamentos e instrumentos de medição usados no ensaio

\begin{tabular}{|c|c|c|c|c|c|}
\hline $\begin{array}{l}\text { Equipamento/ } \\
\text { Instrumento }\end{array}$ & Marca & Modelo & \multicolumn{2}{|c|}{ Características } & Finalidade \\
\hline $\begin{array}{l}\text { Sistema de aquisição de } \\
\text { dados de extensômetria }\end{array}$ & $\begin{array}{c}\text { Vishay } \\
\text { Measurement } \\
\text { s Group, Inc. }\end{array}$ & $\begin{array}{l}\text { SYSTEM } \\
5000\end{array}$ & \multicolumn{2}{|c|}{$\begin{array}{c}\text { Sistema de } \\
\text { aquisição de dados }\end{array}$} & $\begin{array}{c}\text { Aquisição } \\
\text { automática } \\
\text { de dados }\end{array}$ \\
\hline $\begin{array}{l}\text { Atuador servo- } \\
\text { controlado }\end{array}$ & INSTRON & A1891Y & \multicolumn{2}{|c|}{$\begin{array}{c}\text { Capacidade } \\
\text { nominal de } 500 \mathrm{kN}\end{array}$} & $\begin{array}{l}\text { Aplicação de } \\
\text { força com } \\
\text { controle de } \\
\text { deslocamento }\end{array}$ \\
\hline $\begin{array}{c}\text { Extensômetro elétrico } \\
\text { de resistência }\end{array}$ & KYOWA & $\begin{array}{c}\text { KFG }-5- \\
120-C 1-11\end{array}$ & \multicolumn{2}{|c|}{$\begin{array}{c}\mathrm{GF}=2.12 \\
\text { Base } 5 \mathbf{~ m m}\end{array}$} & $\begin{array}{l}\text { Medição das } \\
\text { deformações }\end{array}$ \\
\hline \multirow{5}{*}{$\begin{array}{l}\text { Transdutor de } \\
\text { deslocamento }\end{array}$} & \multirow{5}{*}{ KYOWA } & Tipo & $\begin{array}{l}\text { Curso } \\
\text { (mm) }\end{array}$ & $\begin{array}{l}\text { Resolução } \\
\text { (mm) }\end{array}$ & \multirow{5}{*}{$\begin{array}{l}\text { Medição dos } \\
\text { deslocamento } \\
\text { s }\end{array}$} \\
\hline & & DT-100A & 100 & 0,04 & \\
\hline & & DT-10D & 10 & 0,003 & \\
\hline & & DTH-A-10 & 10 & $\mathbf{0 , 0 0 1}$ & \\
\hline & & DTH-A-20 & 20 & $\mathbf{0 , 0 0 2}$ & \\
\hline \multirow{2}{*}{ Inclinômetros } & KYOWA & BKK-A-5MI & \multicolumn{2}{|c|}{$\begin{array}{c}\text { Curso máximo } 10 \\
\text { graus }\end{array}$} & \multirow{2}{*}{$\begin{array}{l}\text { Mediçãa } \\
\text { rotações }\end{array}$} \\
\hline & MSI & ----- & \multicolumn{2}{|c|}{$\begin{array}{c}\text { Curso máximo } 3 \\
\text { graus }\end{array}$} & \\
\hline $\begin{array}{l}\text { Máquina de ensaio } \\
\text { servo - controlada }\end{array}$ & INSTRON & 8506 & \multicolumn{2}{|c|}{$\begin{array}{c}\text { Capacidade de } 2500 \\
\text { kN }\end{array}$} & $\begin{array}{l}\text { Caracteriza } \\
\text { ção dos } \\
\text { materiais }\end{array}$ \\
\hline
\end{tabular}

\subsubsection{Instrumentação interna}

A instrumentação interna corresponde aos extensômetros fixados nas armaduras. As Figuras 3.28 a 3.33 mostram a instrumentação nos chumbadores, vigas, pilares e capa respectivamente. Cabe mencionar que a denominação EX 9/11, por exemplo, da Figura 2.29, significa que para a viga da esquerda o extensometro é o EX 9 e para a viga da direita é o EX 11. 
CORTE B-B

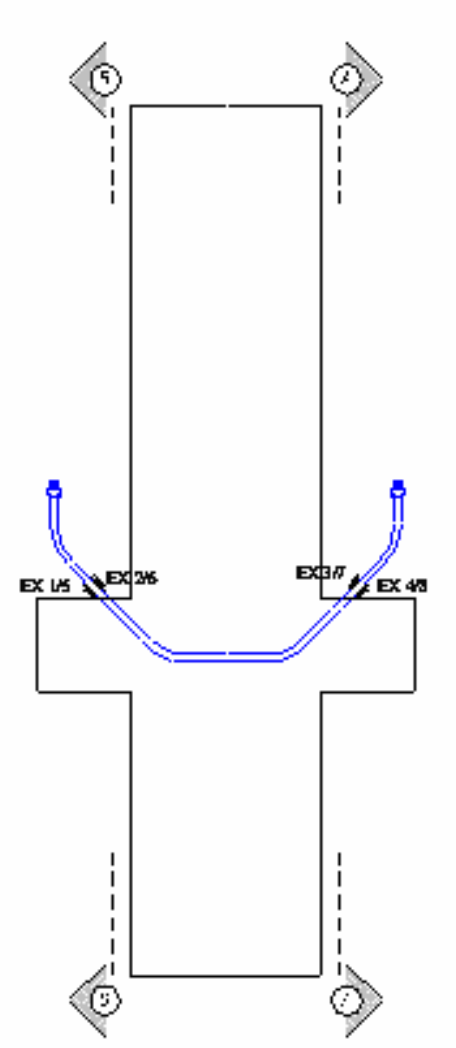

CORTE $A-A$
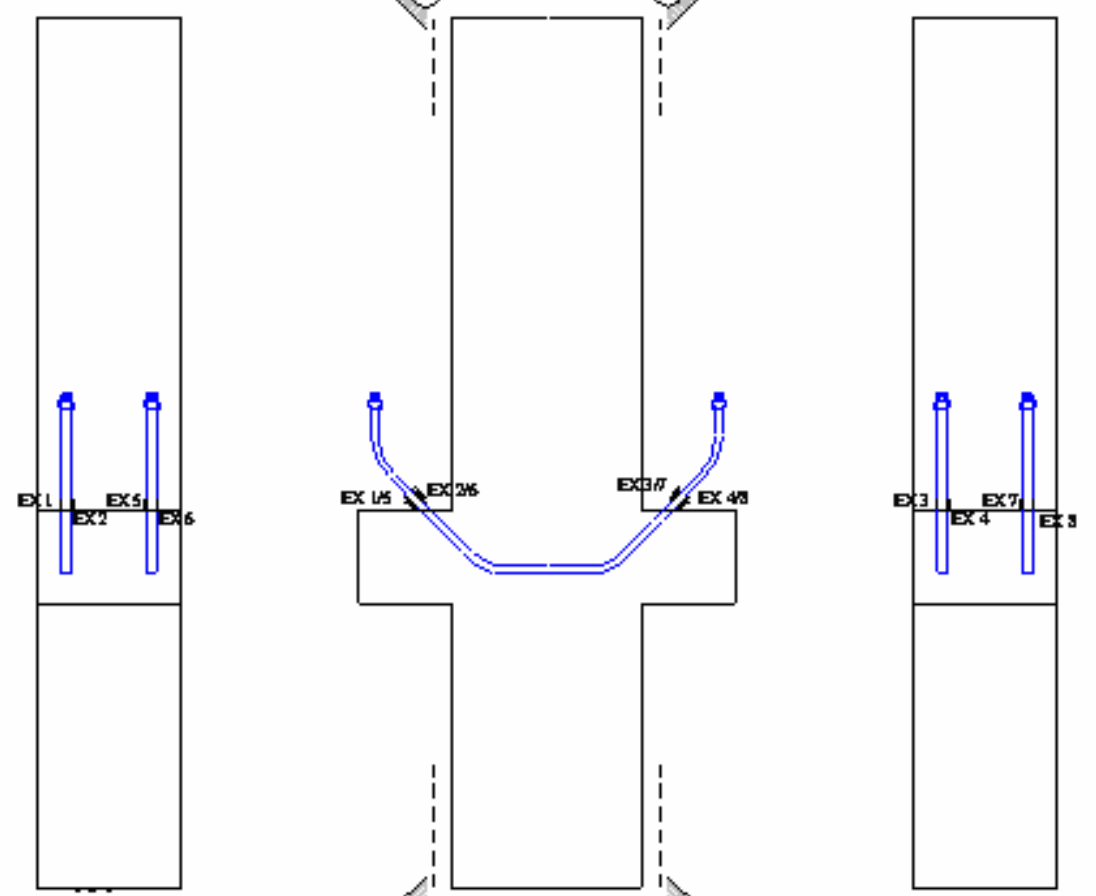

Figura 3.28 - Extensômetros dos chumbadores

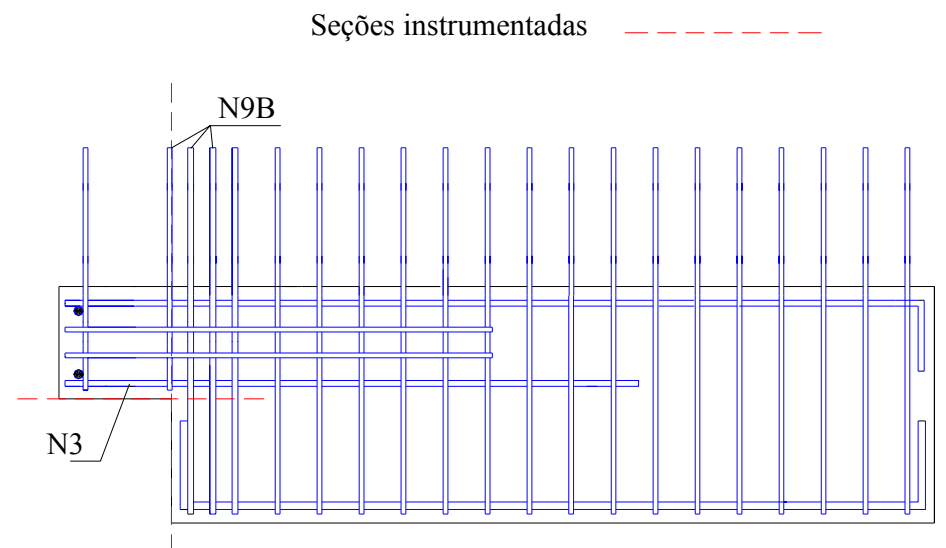

N9B - $3 \phi 10 \mathrm{~mm}$
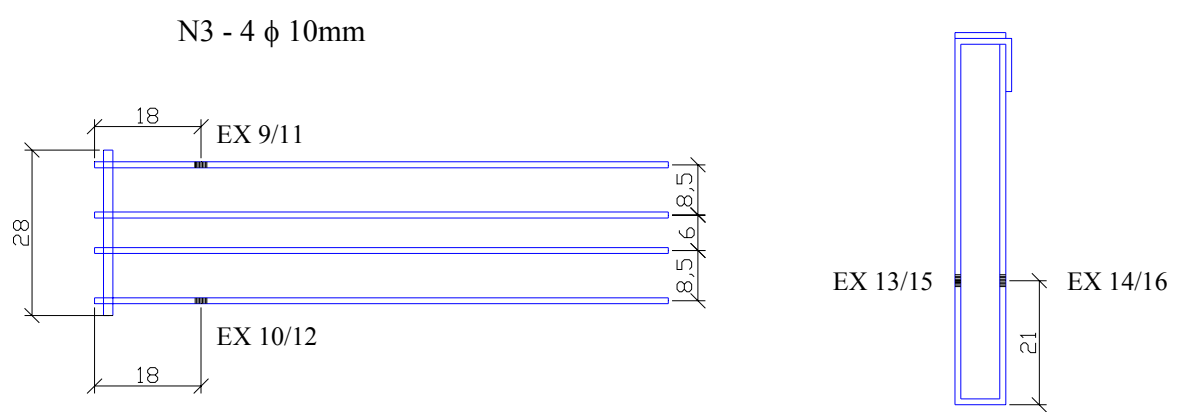

Figura 3.29 - Extensômetros das vigas 
Seções instrumentadas

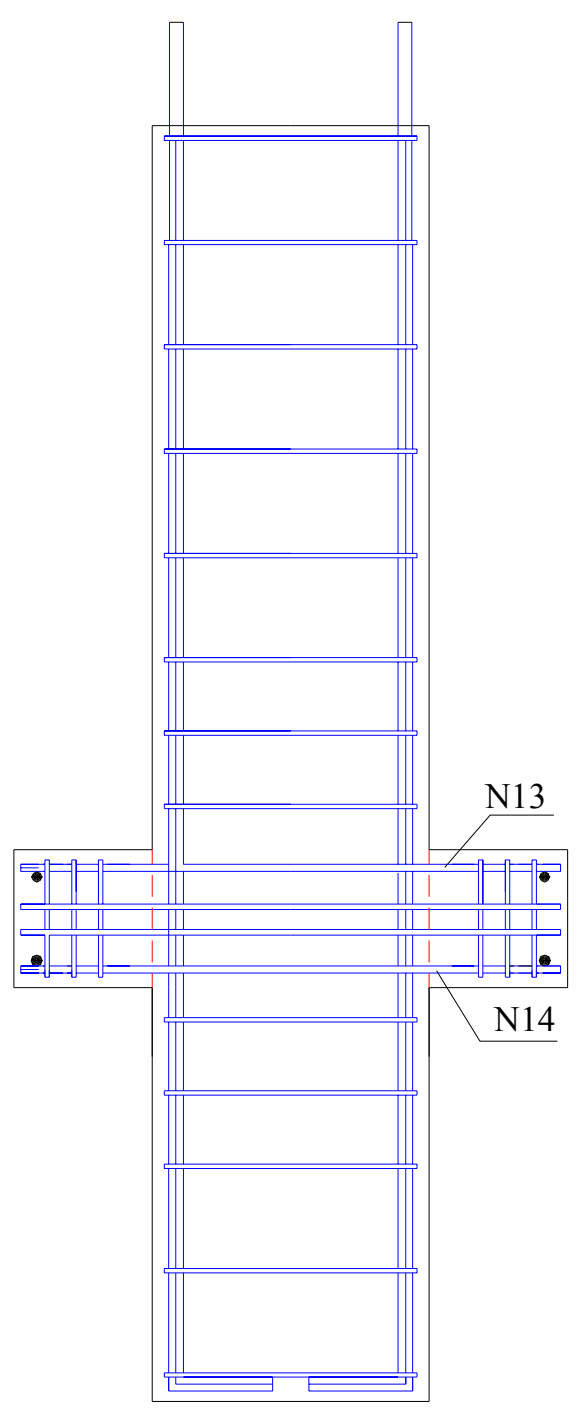

N13 - 4 ф 10mm

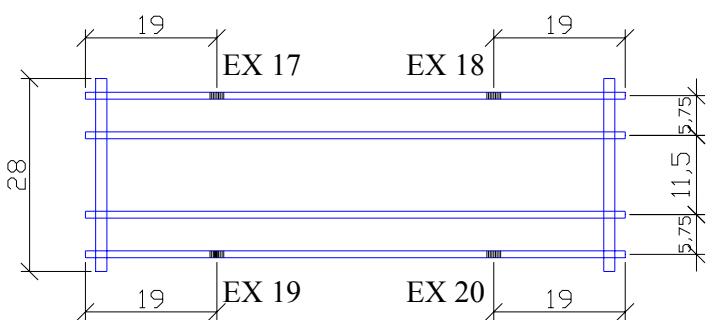

N13

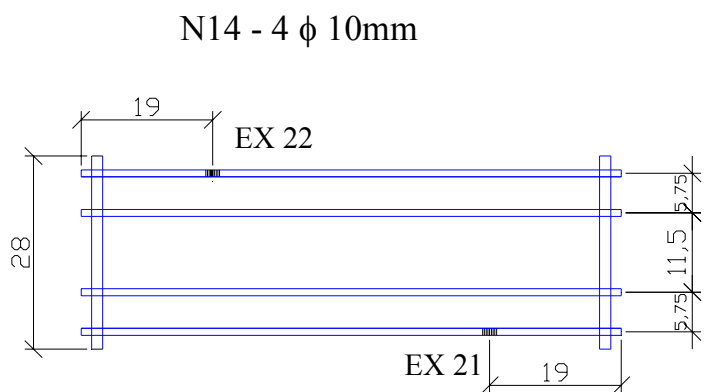

Figura 3.30- Extensômetros do pilar do modelo I 
Seções instrumentadas

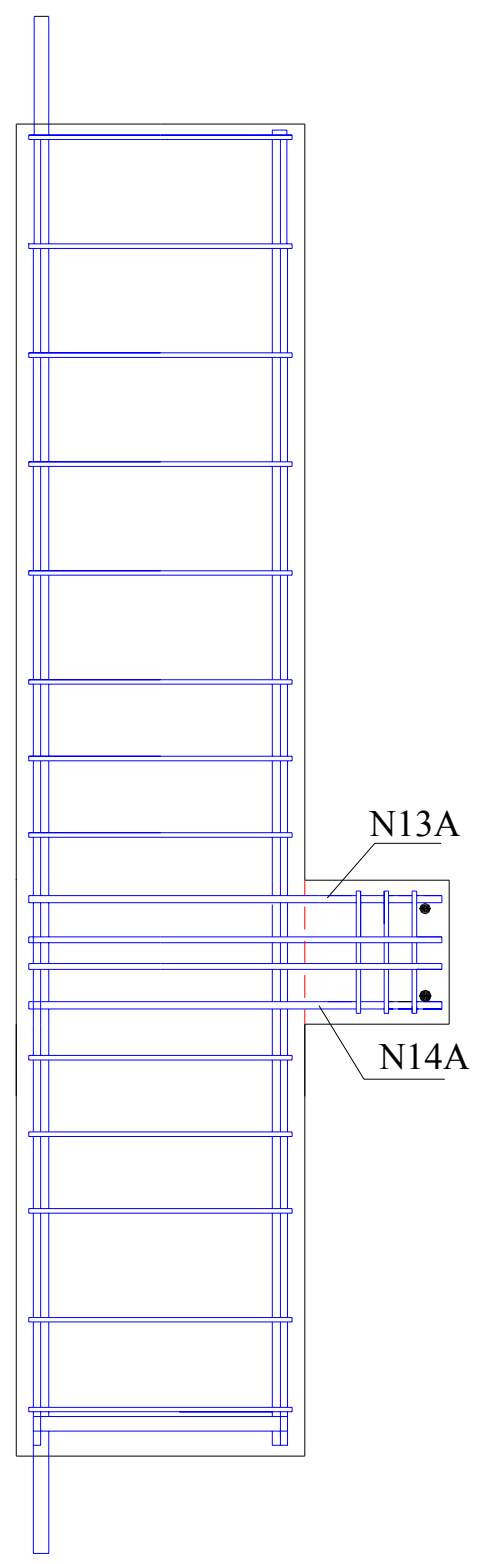

$\mathrm{N} 13 \mathrm{~A}-4 \phi 10 \mathrm{~mm}$

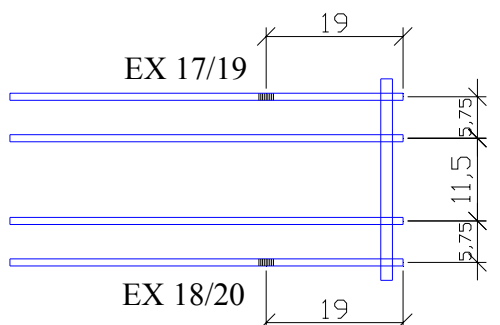

$\mathrm{N} 14 \mathrm{~A}-4 \phi 10 \mathrm{~mm}$

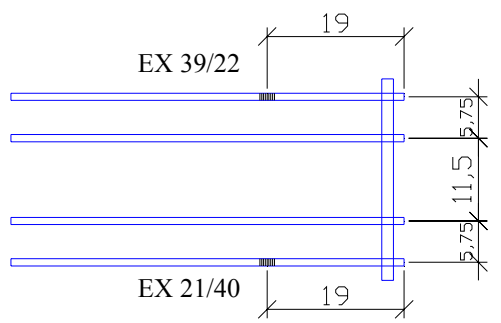

Figura 3.31 - Extensômetros do pilar do modelo E 


\section{Seções instrumentadas}

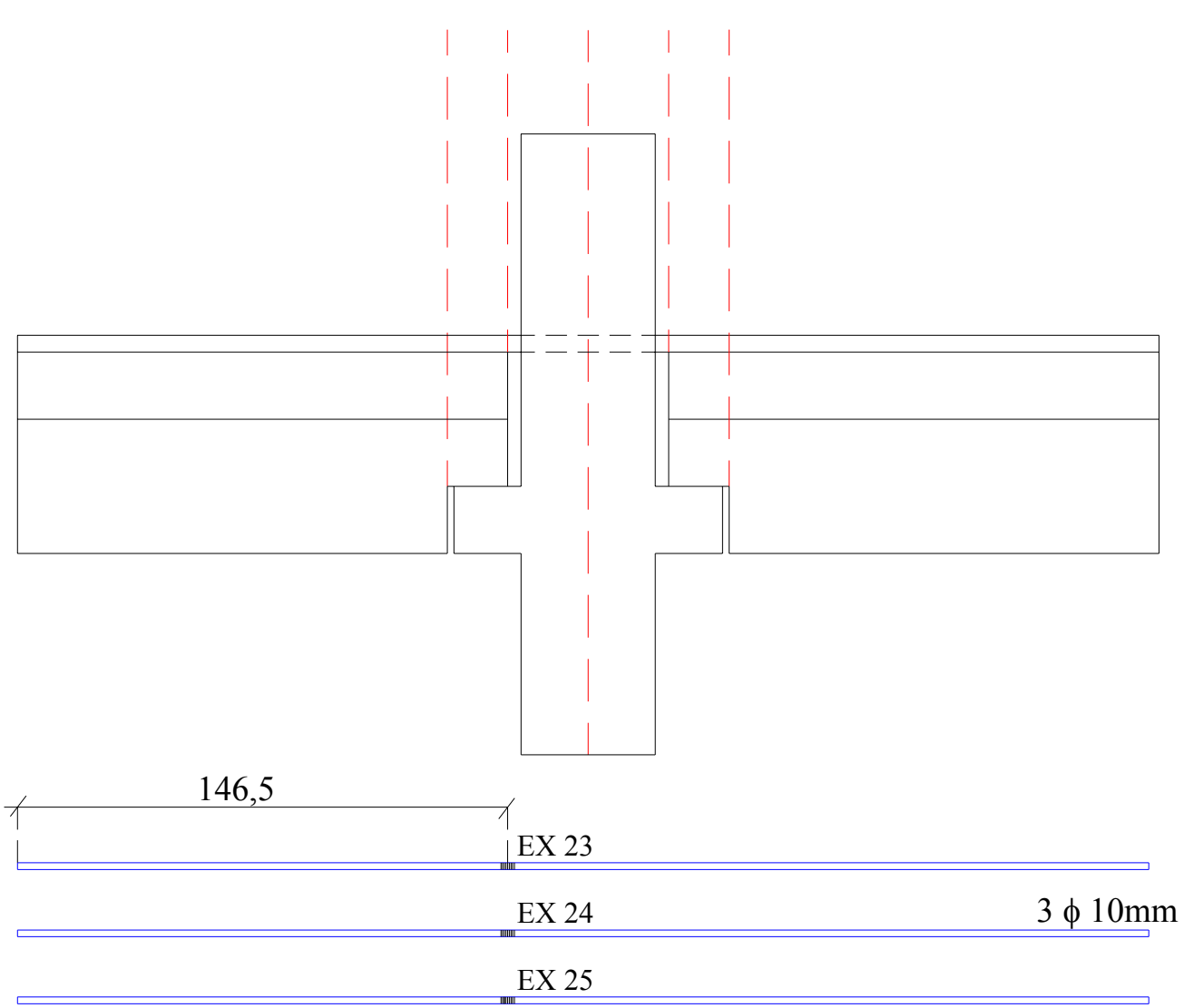

EX 26 EX 27 EX 28 EX 29

\begin{tabular}{c} 
EX 26 EX 27 EX 28 EX 29 \\
\hline $20 x^{2} x^{22} x^{20}$
\end{tabular}

EX 32 EX 33 EX 34 EX 35

EX $30 \quad$ EX 31

$4 \phi 12,5 \mathrm{~mm}$

\begin{tabular}{|ccc}
\hline \hline EX 36 & EX 37 \\
& EX 38 & \\
\hline $\operatorname{EX~39}$ & $3 \phi 10 \mathrm{~mm}$ \\
\hline $\operatorname{EX~} 40$ & \\
\hline
\end{tabular}

camada inferior

camada superior

Figura 3.32 - Extensômetros da armadura da capa de concreto do modelo I 
Seções instrumentadas
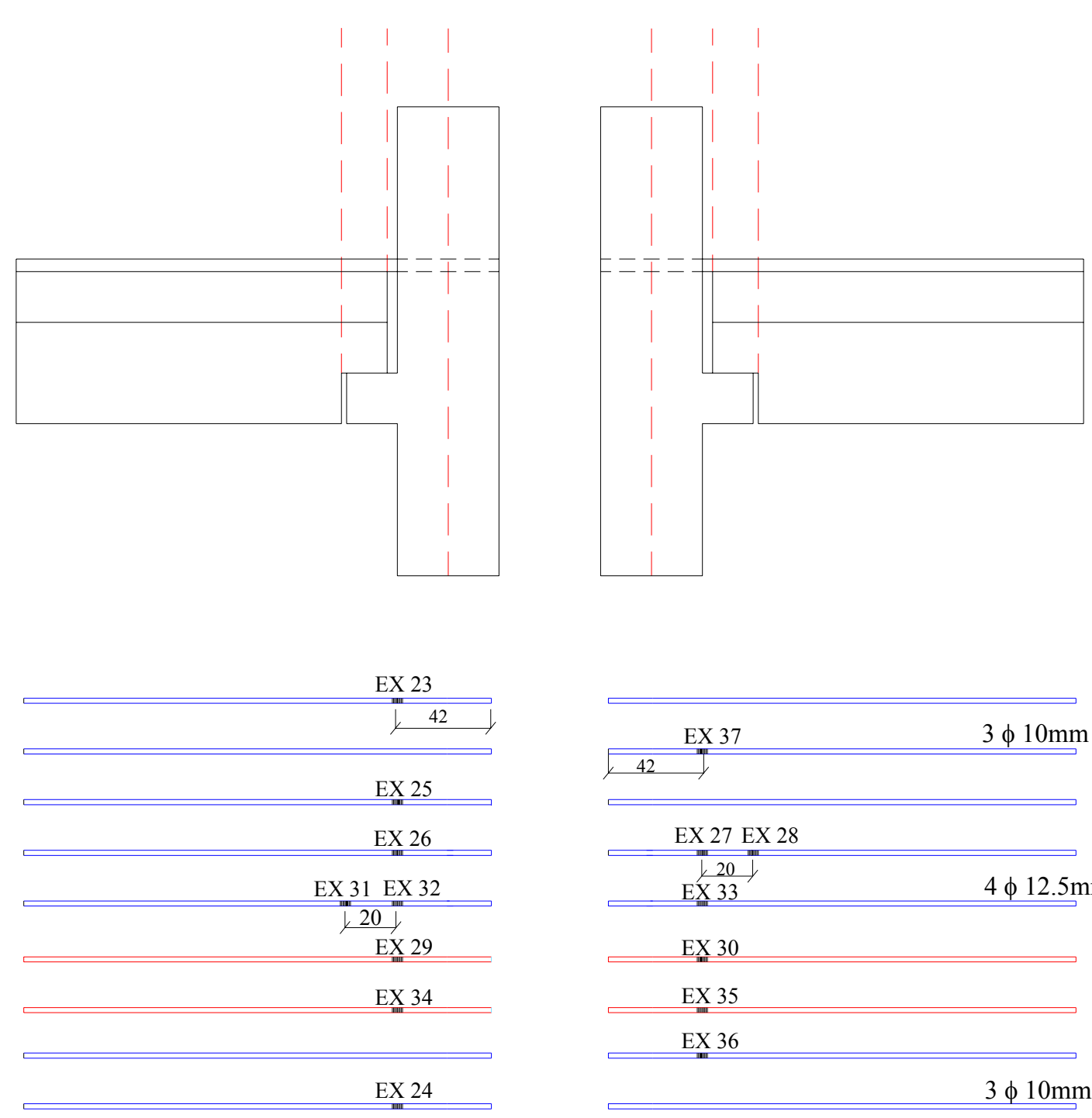

\begin{tabular}{|c|c|}
\hline \multicolumn{2}{|c|}{ EX 27 EX 28} \\
\hline $\begin{array}{r}20 \\
\text { EX } 33\end{array}$ & $4 \phi 12.5 \mathrm{mr}$ \\
\hline EX 30 & \\
\hline \multicolumn{2}{|l|}{ EX 35} \\
\hline \multicolumn{2}{|l|}{ EX 36} \\
\hline & $3 \phi 10 \mathrm{~mm}$ \\
\hline EX 38 & \\
\hline
\end{tabular}

camada inferior

camada superior

Figura 3.33 - Extensômetros da armadura da capa de concreto do modelo E 


\subsubsection{Instrumentação externa}

Para possibilitar a avaliação dos deslocamentos dos modelos foram colocados transdutores e relógios comparadores. Para a medição da rotação na seção entre o pilar e a viga foram colocados inclinômetros na capa de concreto e na região do consolo. $\mathrm{O}$ modelo esquemático de toda a instrumentação externa é mostrado na Figura 3.34 e é valido tanto para o modelo I como E.

Na Figura 3.35 são mostradas as vistas gerais da instrumentação dos modelos, assim como as ampliações dos relógios comparadores e inclinômetros na região do consolo do pilar, da capa de concreto e os transdutores presentes na viga e consolo.

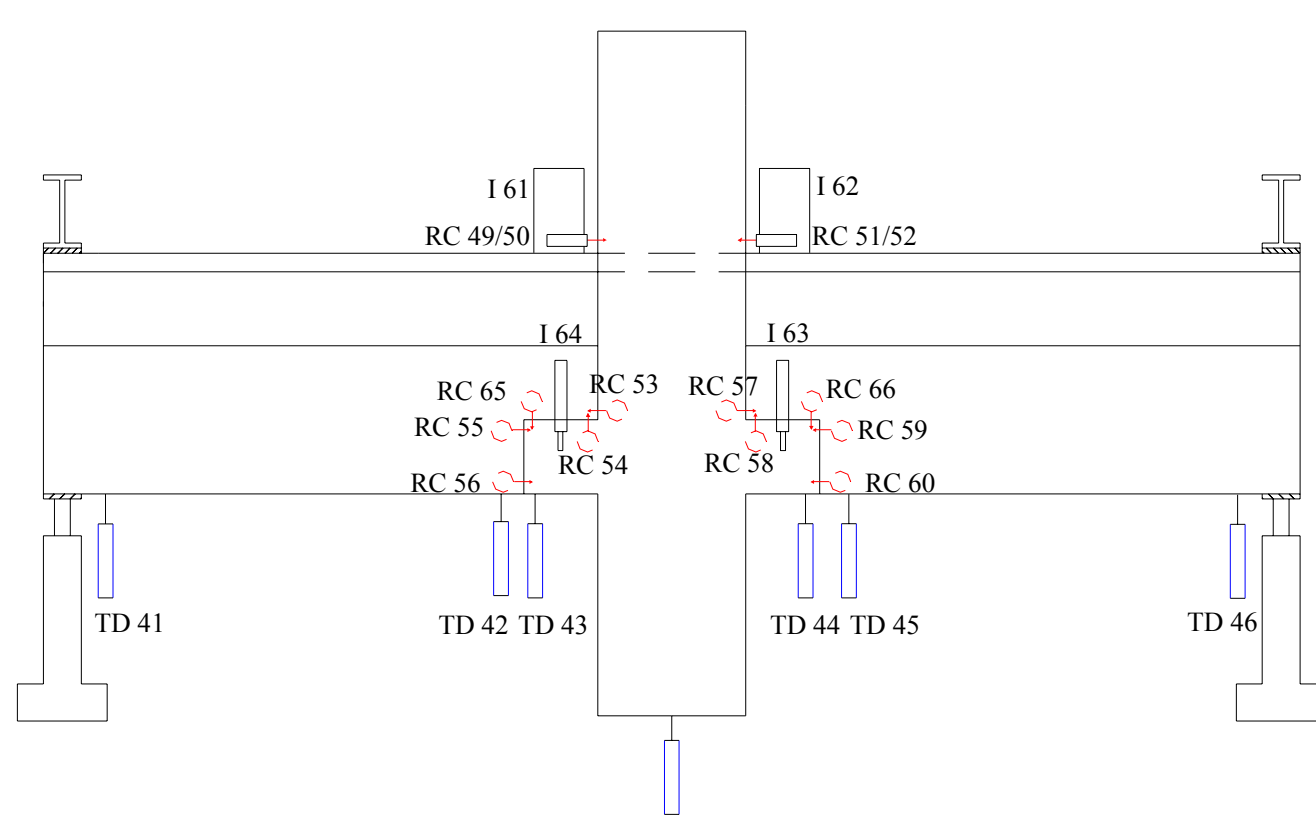

TD $47 / 48$

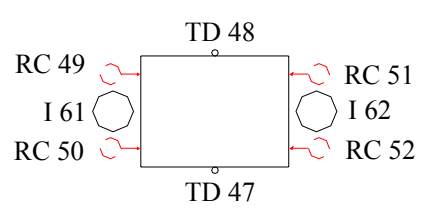

$\mathrm{TD}=$ Transdutor

$\mathrm{RC}=$ Relógio comparador

$\mathrm{I}=$ Inclinômetro

Figura 3.34 - Instrumentação externa de ambos os modelos 


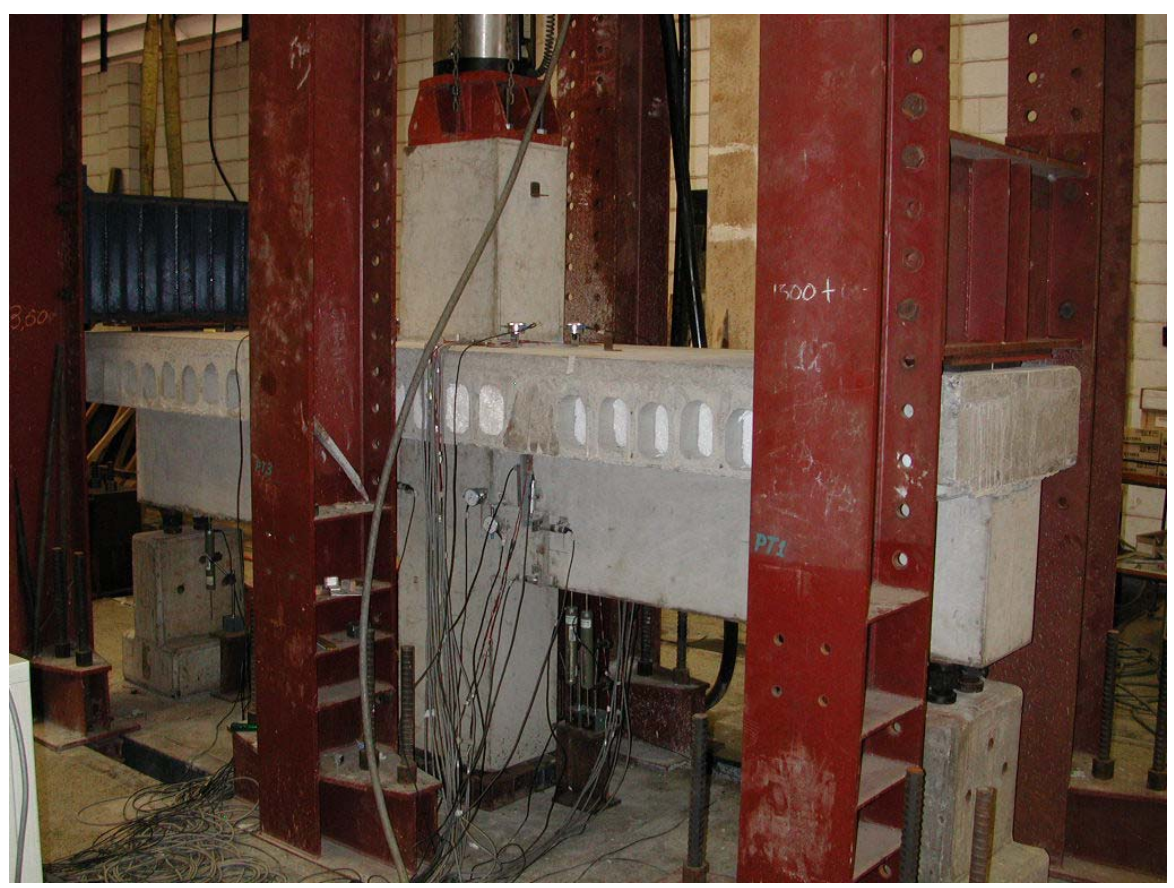

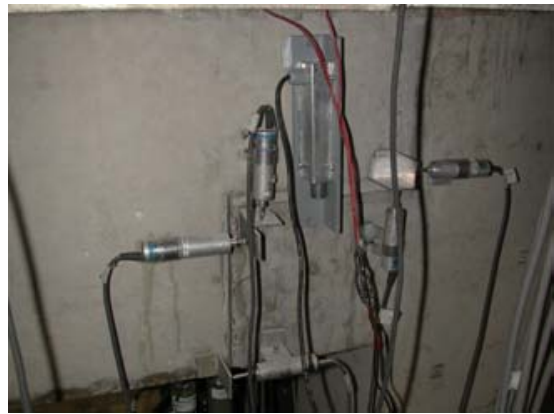

Relógios comparadores e inclinômetros no consolo

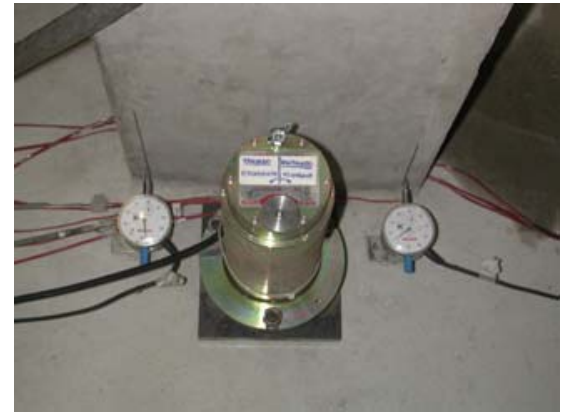

Relógios comparadores e inclinômetros na capa

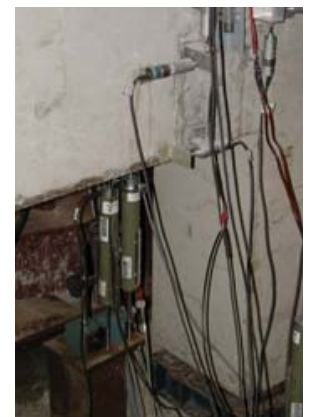

Transdutores sobre a viga e consolo

Figura 3.35 - Vista geral e detalhamento da instrumentação externa

\subsection{PROCEDIMENTO DE ENSAIO}

Para a realização do ensaio utilizou-se um atuador servo controlado com capacidade de $500 \mathrm{kN}$ para aplicar carregamentos alternados, de curta duração e com controle de deslocamentos sobre o pilar que através do pórtico de reação geravam carregamentos de F/2 no canto de cada viga. Para apoiar as vigas no pórtico de reação usaram-se chapas metálicas e de elastômero.

A Figura 3.36 ilustra o esquema de ensaio válido para os dois modelos. As Figuras 3.37 e 3.38 ilustram a vista e o detalhamento dos modelos para o ensaio respectivamente. 


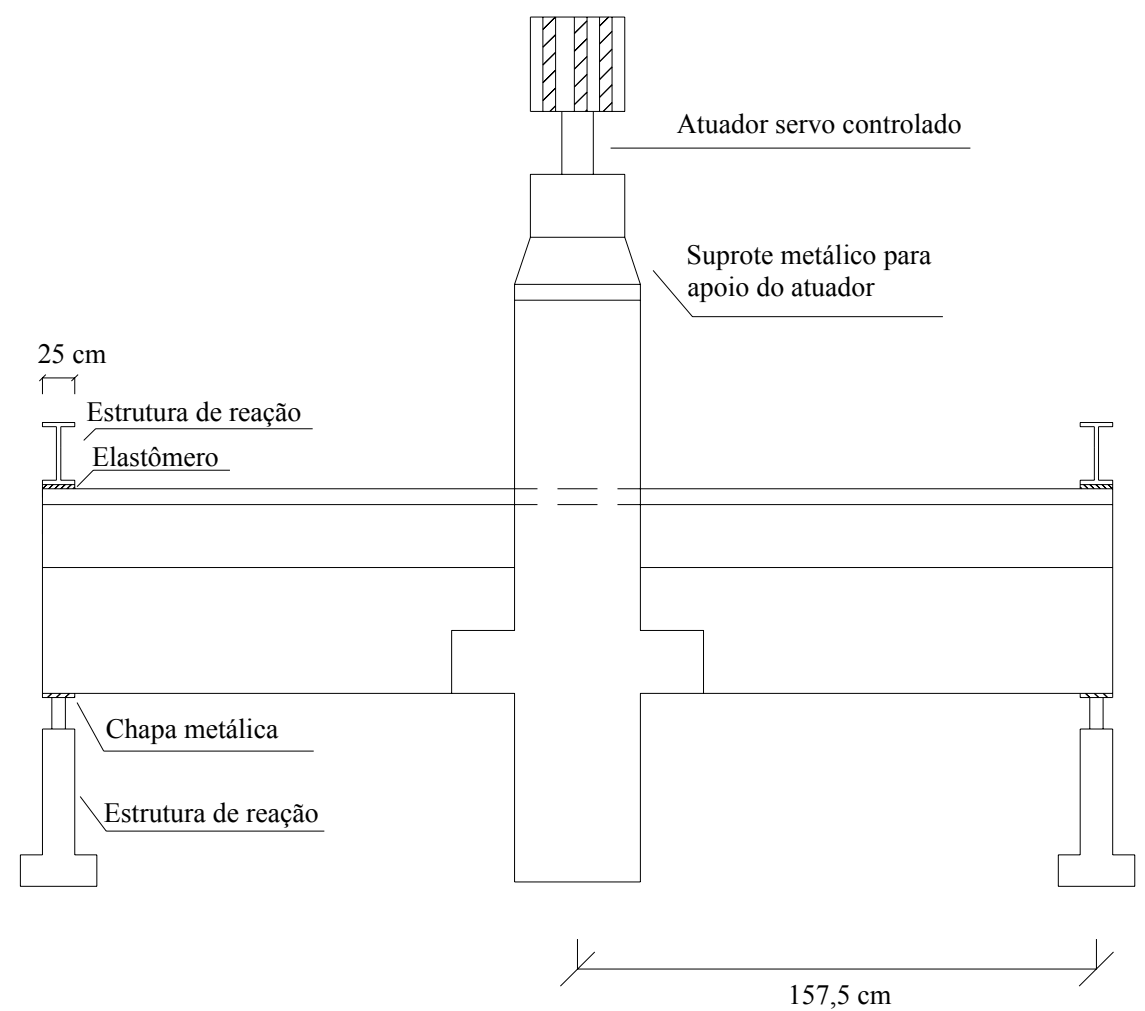

Figura 3.36 - Esquema de ensaio dos modelos

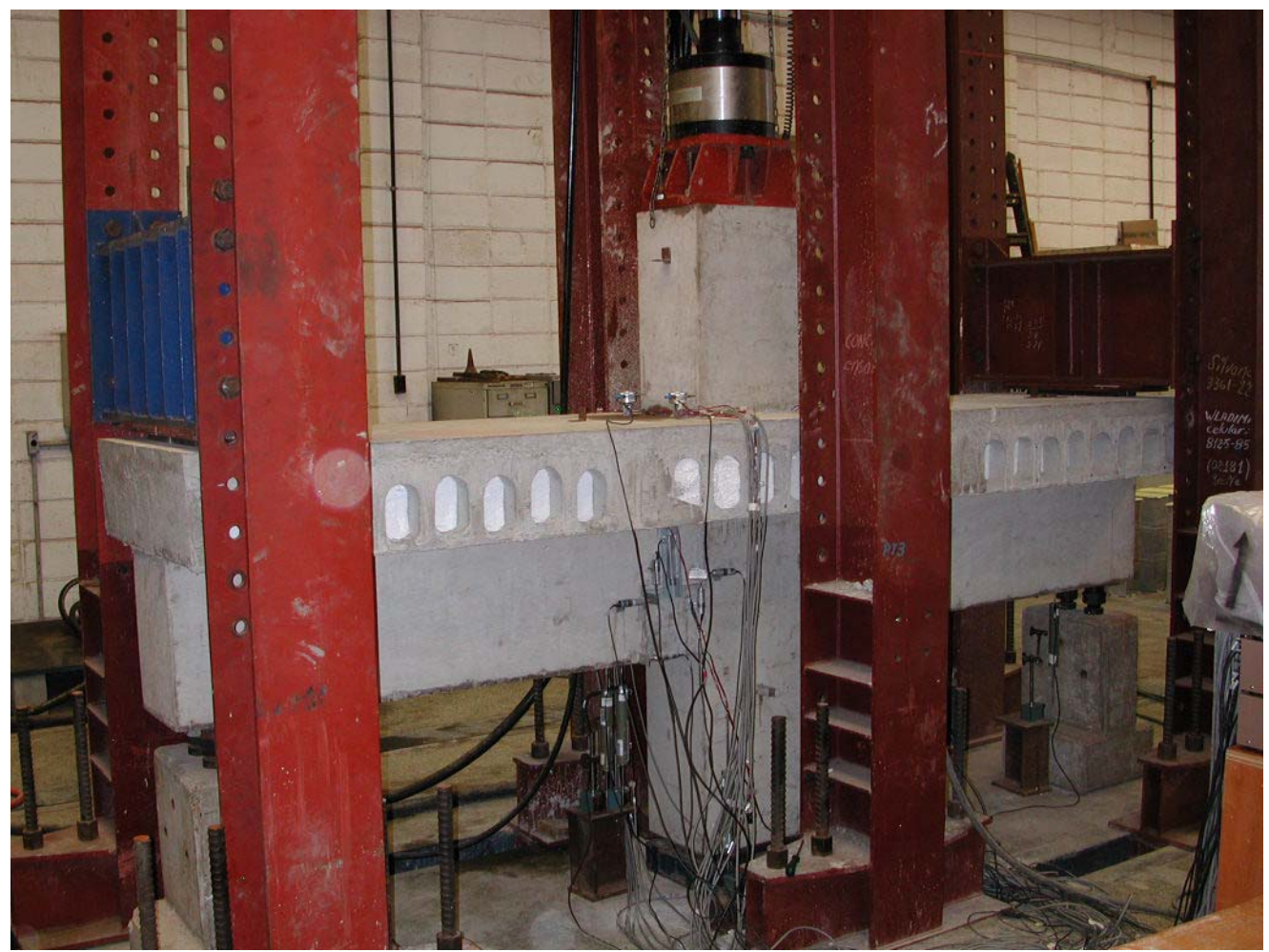

Figura 3.37 - Vista do modelo para o ensaio 


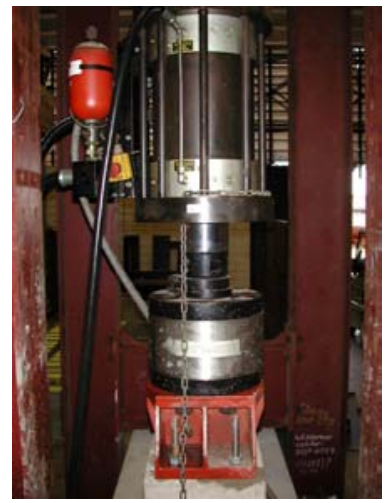

Atuador servo controlado

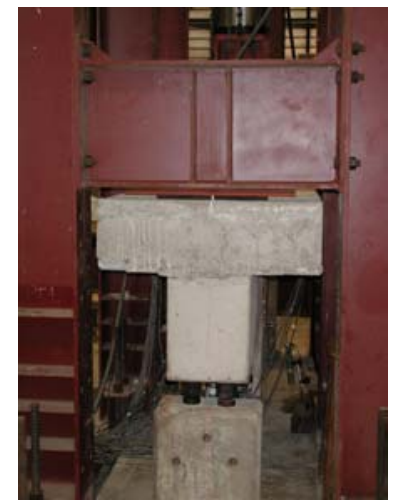

Detalhe da estrutura de apoio superior

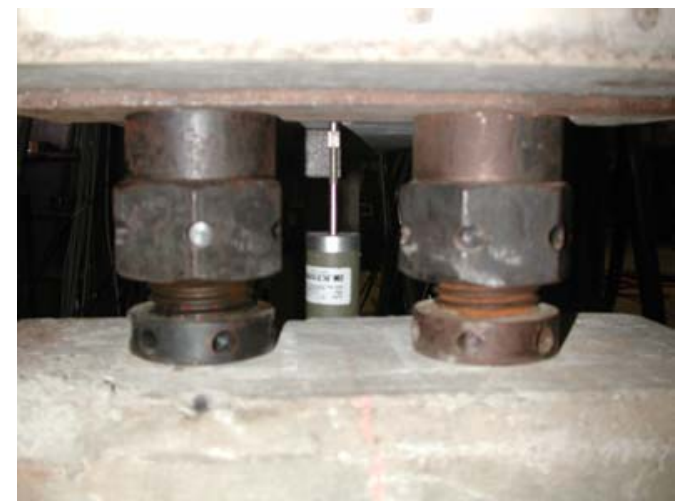

Detalhe da estrutura de apoio inferior

Figura 3.38 - Detalhe da estrutura de ensaio

Antes de iniciar o procedimento de carregamento propriamente dito foi aplicada uma carga de $5 \%$ do valor de ruptura esperado (etapa de escorvamento) para verificação do funcionamento dos equipamentos e para eliminar acomodações dos modelos.

Para o modelo I o carregamento alternado foi realizado através de 21 ciclos, onde os 20 primeiros visavam representar o estado de utilização correspondendo à aplicação de uma carga de $60 \%$ da prevista para ruptura tanto positiva quanto negativa. No $21^{0}$ ciclo levou-se a peça até o escoamento da armadura a momento fletor negativo e em seguida inverteu-se o carregamento até atingir a ruptura no momento fletor positivo. As marcações das fissuras foram feitas no primeiro e último ciclo.

Para o modelo E a forma de carregamento foi similar, porém devido à aparição de fissuras na região de aplicação da carga no pilar reduziu-se o número de ciclos para 16. No último ciclo onde o modelo foi levado à ruptura foram colocados perfis metálicos e calços para maior confinamento da região fissurada do modelo.

As Figuras 3.39 e 3.40 mostram uma vista geral e um detalhamento dos perfis metálicos e calços empregados no momento de ruptura a momento fletor negativo. Quando se rompeu o modelo a momento fletor positivo os perfis metálicos foram posicionados na parte inferior do pilar e o calço na parte superior do pilar. 


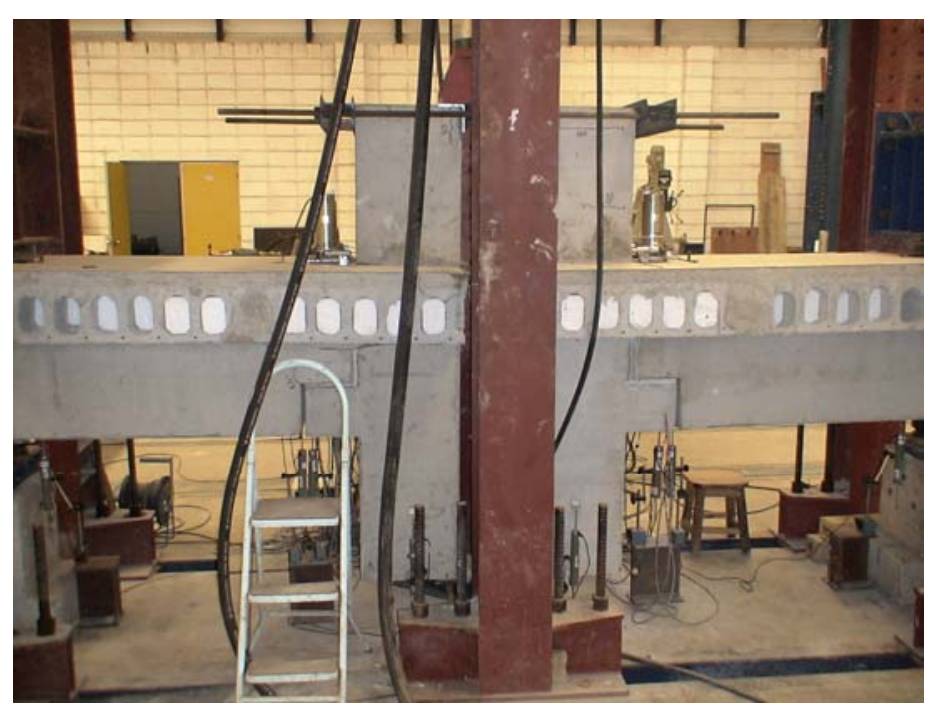

Figura 3.39 - Reforço com perfis metálicos e calço para modelo E

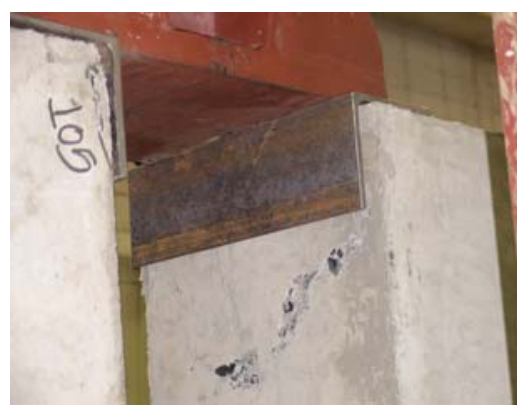

Fissuração do pilar

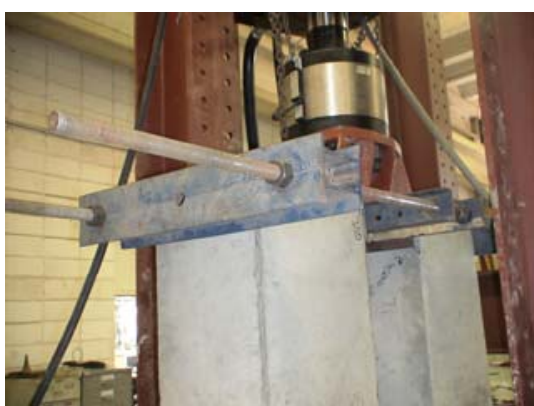

Reforço com perfis metálicos

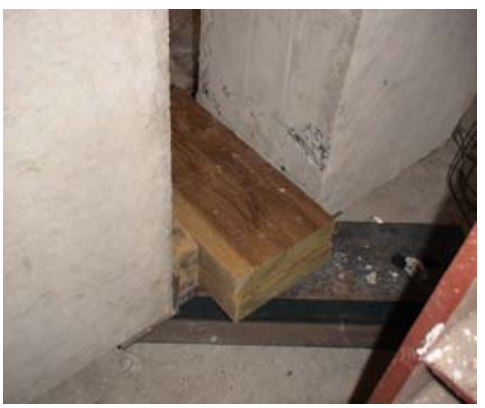

calço

Figura 3.40 - Detalhe do carregamento modelo E

A Tabela 3.26 define os valores de cargas e respectivos momentos gerados na ligação para cada ciclo do modelo I. Similar, a Tabela 3.27 apresenta os ciclos do modelo E. Para o cálculo da força prevista de ruptura a momento fletor negativo no modelo I utilizou-se à área total da armadura da capa enquanto que para o modelo E por não haver mais a continuidade da armadura da capa, utilizou-se apenas as armaduras que transpassam o pilar acrescidas de $33 \%$ da área de aço presente na capa.

Vale salientar que os valores positivos das forças (pistão movendo-se para cima) geram momentos fletores negativos na ligação enquanto valores de forças negativas (pistão movendo-se para baixo) geram momentos fletores positivos como mostra a Figura 3.41. 


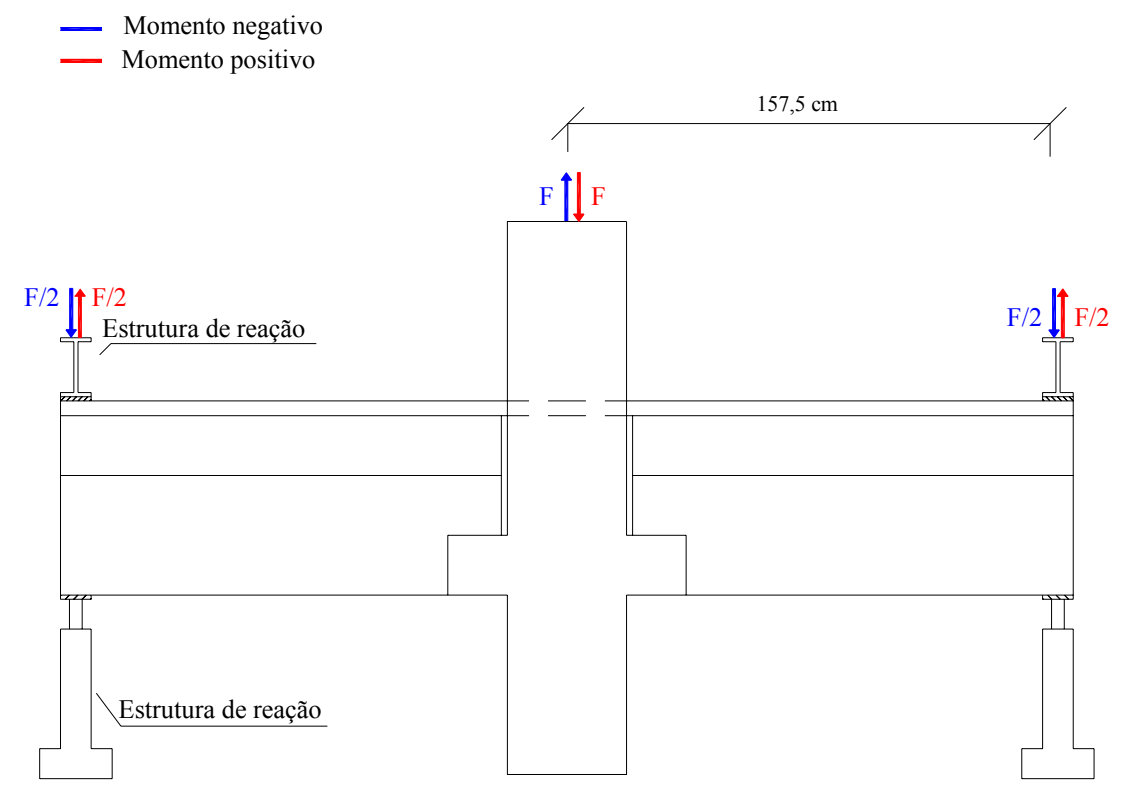

Figura 3.41 - Sentido das forças aplicadas

Tabela 3.26 - Procedimento de carregamento do modelo I

\begin{tabular}{|c|c|c|}
\hline \multicolumn{2}{|c|}{ Procedimento da aplicação de carga do modelo I } \\
\hline Etapa & Força $(\mathrm{kN})$ & Momento $(\mathrm{kNm})$ \\
\hline $\begin{array}{c}\text { Escorvamento } \\
\text { (v: 0,005 mm/s) }\end{array}$ & +12 & $-9,45$ \\
\hline $\begin{array}{c}\text { Ciclo 1 } \\
\text { (v: 0,01 mm/s) }\end{array}$ & -6 & $+4,73$ \\
\hline Ciclo 2 a 20 \\
$($ v: 0,08 mm/s) & -72 & $-118,13$ \\
\hline Ciclo 21 & +150 & $+56,70$ \\
\hline (v: 0,01 mm/s) & -72 & $-118,13$ \\
\hline & +289 & $+56,70$ \\
\hline
\end{tabular}

Obs: Forças de ruptura previstas $+247,-120 \mathrm{kN}$ 
Tabela 3.27 - Procedimento de carregamento do modelo E

\begin{tabular}{|c|c|c|}
\hline \multicolumn{3}{|c|}{ Procedimento da aplicação de carga do modelo E } \\
\hline Etapa & Força $(\mathrm{kN})$ & Momento $(\mathrm{kNm})$ \\
\hline \multirow{2}{*}{$\begin{array}{l}\text { Escorvamento } \\
(\mathrm{v}: 0,005 \mathrm{~mm} / \mathrm{s})\end{array}$} & $+8,4$ & $-6,62$ \\
\hline & -6 & $+4,73$ \\
\hline \multirow{2}{*}{$\begin{array}{c}\text { Ciclo } 1 \\
(\mathrm{vc}: 0,01 \mathrm{~mm} / \mathrm{s})(\mathrm{vd}: 0,03 \mathrm{~mm} / \mathrm{s})\end{array}$} & +110 & $-86,63$ \\
\hline & -72 & $+56,70$ \\
\hline \multirow{2}{*}{$\begin{array}{l}\text { Ciclo } 2 \text { a } 15 \\
(\mathrm{v}: 0,08 \mathrm{~mm} / \mathrm{s})\end{array}$} & +100 & $-78,75$ \\
\hline & -72 & $+56,70$ \\
\hline \multirow{2}{*}{$\begin{array}{c}\text { Ciclo } 16 \\
(\mathrm{vc}: 0,01 \mathrm{~mm} / \mathrm{s})(\mathrm{vd}: 0,03 \mathrm{~mm} / \mathrm{s})\end{array}$} & +206 & $-162,23$ \\
\hline & -177 & $+139,39$ \\
\hline
\end{tabular}

Obs: Forças de rupturas previstas $+168,-120 \mathrm{kN}$

vc: velocidade de carregamento, vd: velocidade de descarregamento. 


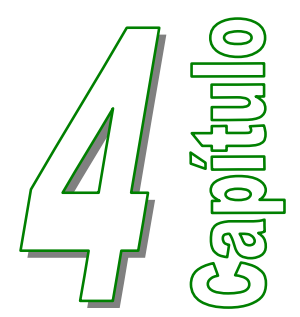

\subsection{CONSIDERAÇÕES INICIAIS}

Este capítulo apresenta os resultados dos ensaios experimentais, determinando a curva momento fletor-rotação da ligação, propõe um modelo analítico para o cálculo dos momentos resistentes, comparando-os com os resultados experimentais, e avalia a influência das rigidezes da ligação estudada através de simulações em estrutura típica de concreto pré-moldado.

Apesar dos resultados experimentais mostrarem uma curva momento-rotação não linear, para o cálculo da rigidez e formulação do modelo analítico foi utilizada uma curva bi-linear caracterizada pelo momento de plastificação $\left(\mathrm{M}_{\mathrm{y}}\right)$ e rotação correspondente $\left(\phi_{\mathrm{y}}\right)$ para cada sentido do momento solicitante como mostra a Figura 4.1.

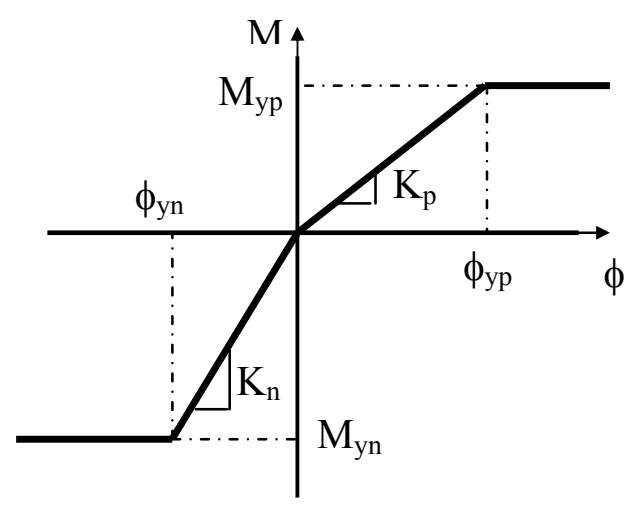

Figura 4.1 - Curva bi-linear utilizada para representar o comportamento da ligação 


\subsection{RESULTADOS EXPERIMENTAIS}

Através dos ensaios dos modelos I e E verificou-se que ruptura da ligação ocorreu por escoamento da armadura da capa quando atuante um momento fletor negativo de -227 (modelo I) e $-162,2 \mathrm{kNm}$ (modelo E) e escoamento do chumbador quando atuante um momento fletor positivo de 144,1 (modelo I) e 139,3 kNm (modelo E). Os máximos momentos suportados para cada modelo são resumidos na Tabela 4.1.

Tabela 4.1 - Momentos máximos atuantes em cada modelo

\begin{tabular}{|c|c|c|}
\cline { 2 - 3 } \multicolumn{1}{c|}{} & Momento negativo $(\mathrm{kNm})$ & Momento positivo $(\mathrm{kNm})$ \\
\hline Modelo I & -227 & 144,1 \\
\hline Modelo E & $-162,2$ & 139,3 \\
\hline
\end{tabular}

Analisando a fissuração dos modelos, para o momento negativo, devido à concentração de tensões de tração na capa, esta apresentou grande grau de fissuração com distribuição simétrica e paralela a face do pilar como mostram as Figuras 4.2 e 4.3.

Para o modelo I as fissuras iniciaram se a uma força de $96 \mathrm{kN}$ saindo das quinas dos pilares e se estendendo ao longo da capa em ambos os lados até aproximadamente $90 \mathrm{~cm}$. Para o modelo E as fissuras tiveram início a uma força de $76 \mathrm{kN}$ e devido a um desprendimento entre a capa e o pilar o grau de fissuração foi bem menor, atingindo uma extensão de aproximadamente $50 \mathrm{~cm}$.
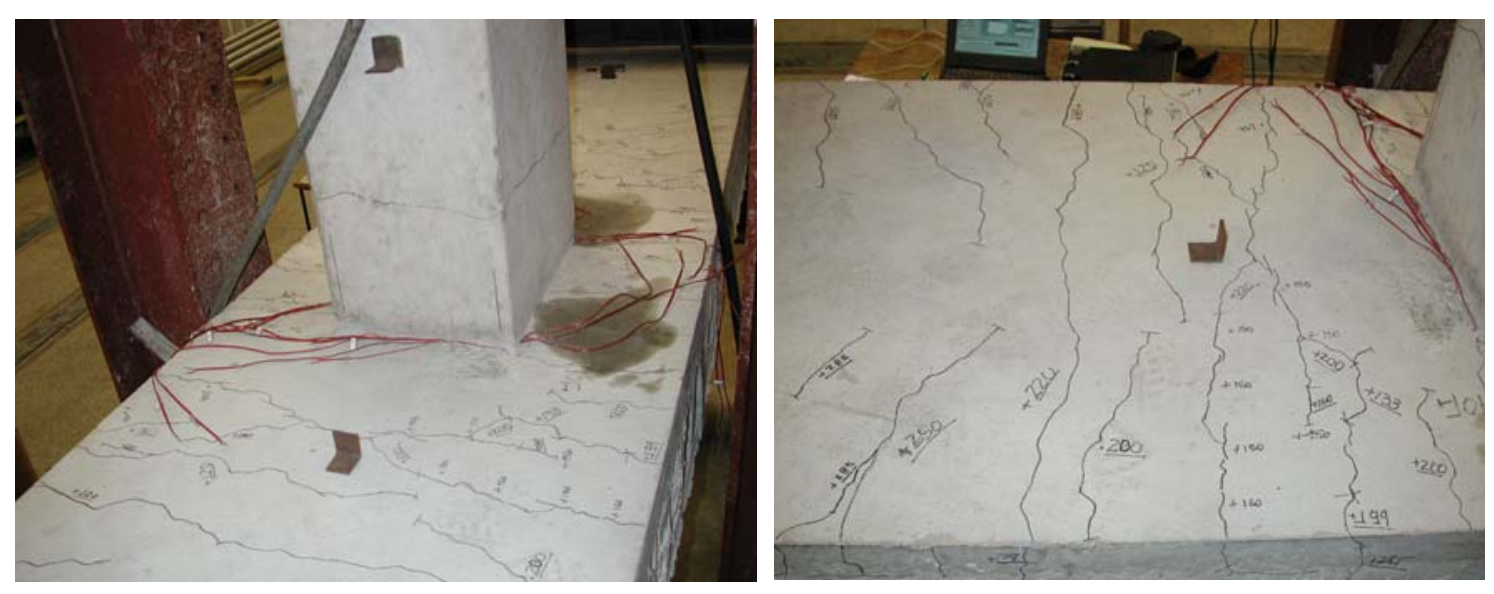

Figura 4.2 - Fissuração da capa de concreto do modelo I 


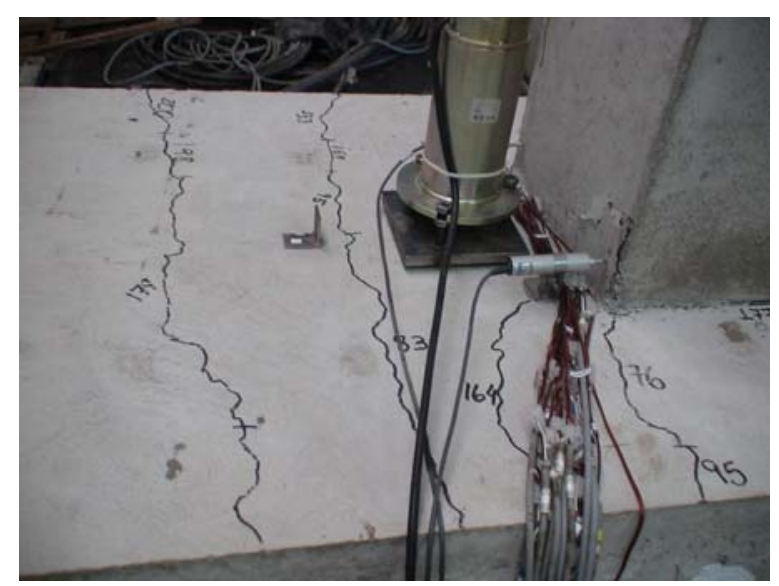

Figura 4.3 - Fissuração da capa de concreto do modelo E

Para o momento positivo a fissuração concentrou-se no graute de preenchimento entre o pilar e a viga e na região do dente gerber. Tanto para o modelo I como para o modelo E a primeira fissura surgiu no graute de preenchimento, a uma força de $-60 \mathrm{kN}$ e $-72 \mathrm{kN}$ respectivamente. À medida que a força era aplicada começaram a surgir fissuras verticais no dente gerber.

A almofada de apoio apresentou fissuração vertical na sua parte central a uma força de $-72 \mathrm{kN}$ para o modelo I e $-64 \mathrm{kN}$ para o modelo $\mathrm{E}$.

As Figuras 4.4 e 4.5 mostram a fissuração provocada pela ação dos momentos fletores positivos nos modelos I e E respectivamente.
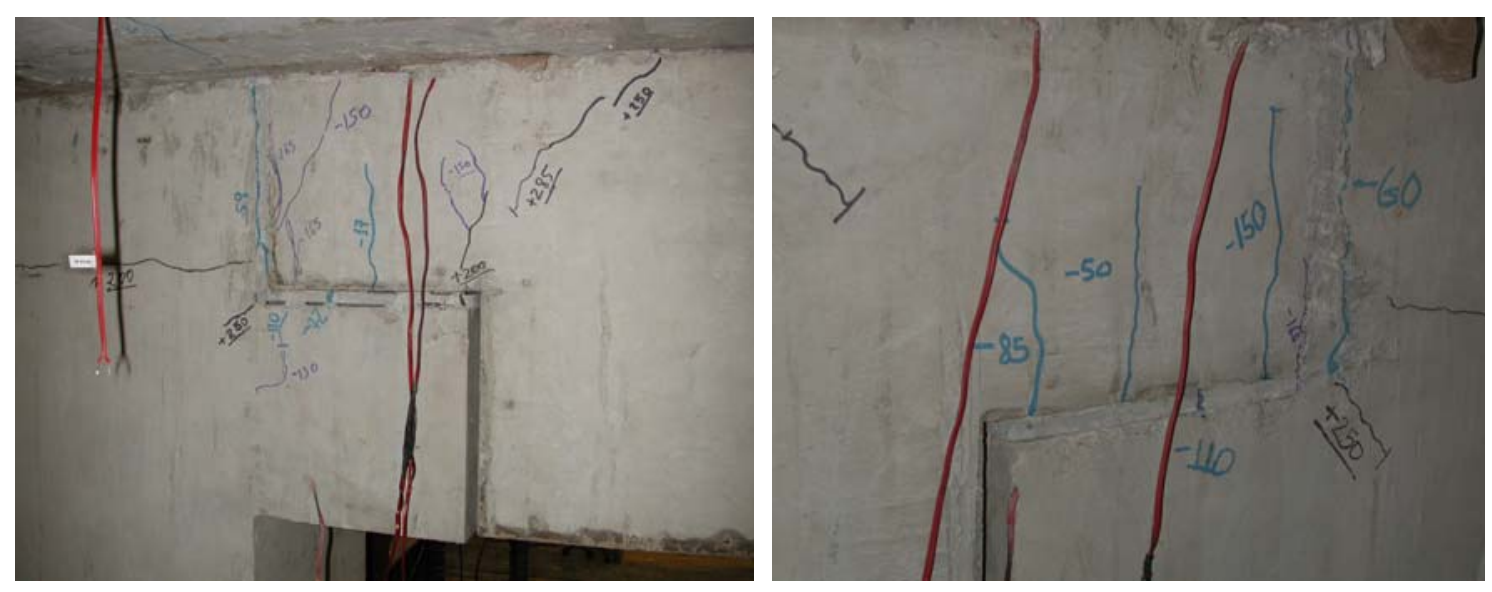

Figura 4.4 - Fissuração do graute e dente gerber do modelo I 

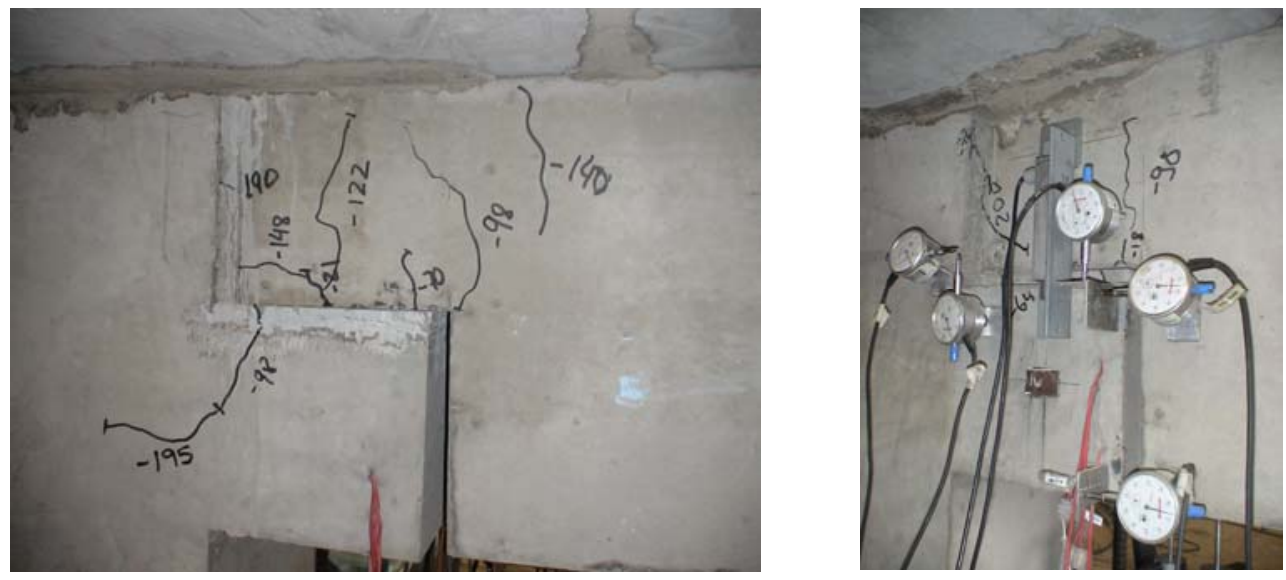

Figura 4.5 - Fissuração do graute e dente gerber do modelo E

\subsubsection{Determinação da curva momento fletor-rotação}

A curva momento fletor-rotação foi obtida através do cálculo dos momentos atuantes e das leituras dos relógios comparadores presentes na capa de concreto e na região do dente gerber da viga como mostra a Figura 4.6.

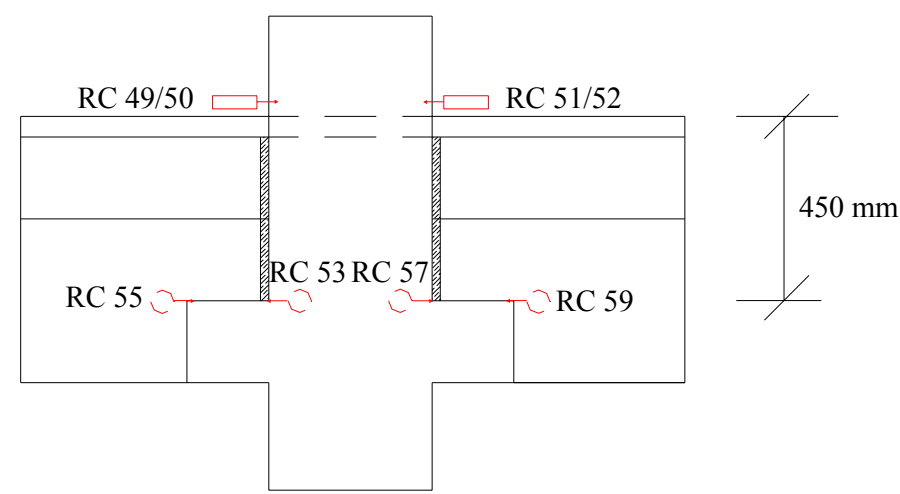

Figura 4.6 - Detalhamento dos relógios comparadores utilizados no cálculo da curva momentorotação

Os valores dos momentos atuantes na ligação foram determinados através da eq. (4.1) e as rotações através da eq. (4.2)

$$
M=\frac{-F}{2} \cdot l
$$




$$
\phi=\frac{\text { média }(R C 49 / 50 / 51 / 52)+\text { média }(R C 53 / 55 / 57 / 59)}{450}
$$

Onde:

$$
\begin{aligned}
F & =\text { Força aplicada pelo atuador em } \mathrm{kN} \\
l & =\text { Distância entre o ponto de aplicação da carga e o eixo do pilar equivalente a } \\
& 1,575 \mathrm{~m} \\
\mathrm{RC} & =\text { Leitura dos relógios comparadores em valor absoluto dado em milímetros } \\
M & =\text { Momento atuante em } \mathrm{kNm} \\
\phi & =\text { Rotação em radianos }
\end{aligned}
$$

Para análise do modelo E foi calculada a rigidez para os dois pilares e, portanto a rotação apresentada pela eq. (4.2) passa a ser dada por:

Pilar situado à esquerda

$$
\phi=\frac{\text { média }(R C 49 / 50)+\text { média }(R C 53 / 55)}{450}
$$

Pilar situado à direita

$$
\phi=\frac{\text { média }(R C 51 / 52)+\text { média }(R C 57 / 59)}{450}
$$

Sobre as leituras dos relógios comparadores foram descontadas as parcelas de deformação que ocorreriam mesmo se a ligação fosse monolítica, uma vez que esta servirá de referência e será considerada perfeitamente rígida e, portanto de deformabilidade nula.

Estas parcelas de deformação descontadas para análise da rotação do modelo são descritas abaixo e separadas para o caso de ação de momentos fletores negativos e positivos.

\section{Momento fletor negativo}

Para o momento fletor negativo foram descontadas as parcelas referentes à: 
$\checkmark$ Deformação por compressão do concreto pré-moldado da viga

$\checkmark$ Deformação devido à fissuração assistemática na região de tração da ligação.

A Fissura assistemática corresponde a uma abertura única no elemento. Supõe-se que formada a primeira fissura, à medida que se aumenta o carregamento não há o aparecimento de novas fissuras, mas sim uma concentração de deformações na primeira fissura até um valor máximo $\mathrm{w}_{\mathrm{u}}$.

A parcela da deformação por compressão $\left(\delta_{c}\right)$ foi determinada através da eq.

$$
\begin{gathered}
\delta_{c}=\varepsilon_{\text {concreto }} \cdot L_{1} \\
\varepsilon_{\text {concreto }}=\frac{\sigma_{\text {concreto }}}{E_{\text {concreto }}} \\
\sigma_{\text {concreto }}=\frac{M \cdot x}{I}
\end{gathered}
$$

Onde:

$$
\begin{array}{ll}
\varepsilon_{\text {concreto }} & =\text { Deformação por compressão do concreto pré-moldado } \\
L_{1} & =\text { Comprimento do relógio comparador de aproximadamente } 100 \mathrm{~mm} \\
\sigma_{\text {concreto }} & =\text { Tensão de compressão no concreto pré-moldado } \\
E_{\text {concreto }} & =\text { Módulo de elasticidade do concreto pré-moldado } \\
M & =\text { Momento atuante } \\
x & =\text { Linha neutra } \\
I & =\text { Momento de inércia }
\end{array}
$$

A fissuração assistemática é dada $w_{\text {ass }}=\Delta l_{\text {rel }}-\Delta l_{\text {concreto }}$. A parcela a ser descontada $\Delta l_{\text {concreto }}$ é determinada através da eq. (4.8)

$$
\begin{aligned}
& \Delta l_{\text {concreto }}=\varepsilon_{\text {capa }} \cdot L_{1} \\
& \varepsilon_{\text {capa }}=\frac{\sigma_{\text {capa }}}{E_{\text {capa }}}
\end{aligned}
$$




$$
\sigma_{\text {capa }}=\frac{M \cdot\left(h_{c}-x_{1}\right)}{I_{1}}
$$

Onde:

$\Delta l_{\text {rel }} \quad=$ Leitura do relógio comparador

$\varepsilon_{\text {capa }}=$ Deformação por tração do concreto da capa

$\sigma_{\text {capa }}=$ Tensão de tração no concreto da capa

$E_{\text {capa }}=$ Módulo de elasticidade do concreto da capa

$h_{c} \quad=$ Altura da seção igual a $450 \mathrm{~mm}$

$x_{1}=$ Linha neutra no estádio I

$I_{1} \quad=$ Momento de inércia no estádio I

\section{Momento fletor positivo}

Para o momento fletor positivo foi descontada a parcela referente à:

$\checkmark$ Deformação devido à fissuração assistemática na região de tração da ligação.

A parcela de deformação por compressão do concreto foi desprezada para momento positivo, pois a região da capa apresenta baixas tensões de compressão.

A formulação da parcela devido à fissuração assistemática é dada pela eq. (4.8), porém com as deformações, tensões e módulo de elasticidades do elemento prémoldado (região tracionada).

Cabe mencionar que apesar de haver inclinômetros na capa de concreto e na região do consolo para medição direta das rotações verificou-se que as suas leituras apresentavam uma discrepância bastante grande quando comparada aos relógios. Acredita-se que isto se deva ao fato do tempo de carregamento ser superior ao tempo necessário para estabilização da leitura de rotação.

\subsubsection{Curva momento-rotação do modelo I}

Para a obtenção da curva momento-rotação do modelo I foi feito um estudo das rigidezes do lado esquerdo e o lado direito do modelo, baseado nas médias das leituras 
dos relógios comparadores de cada lado, e comparada com a rigidez obtida pela média das leituras dos relógios comparadores de ambos os lados.

Verificou-se que a variação dos valores de rigidez de cada lado não foram superiores a $15 \%$ da rigidez calculada para a média de todos os relógios, comprovando que ambos os lados tiveram um comportamento semelhante e que a escolha da média dos relógios é representativa do comportamento do modelo.

Cabe mencionar que devido a erros de leitura os relógios RC 53 e 57 foram descartados.

\section{Momento fletor negativo}

A Figura 4.7 mostra a curva momento-rotação do modelo I sob ação de momentos fletores negativos nos 21 ciclos ao qual o modelo foi submetido. No primeiro ciclo nota-se um trecho inicial com rigidez elevada seguido de um trecho menos rígido. A partir do segundo ciclo a rigidez se mantém constante, porém menor que a do primeiro ciclo. Para um momento de - $227 \mathrm{kNm}$ a ligação não mais suporta carga.

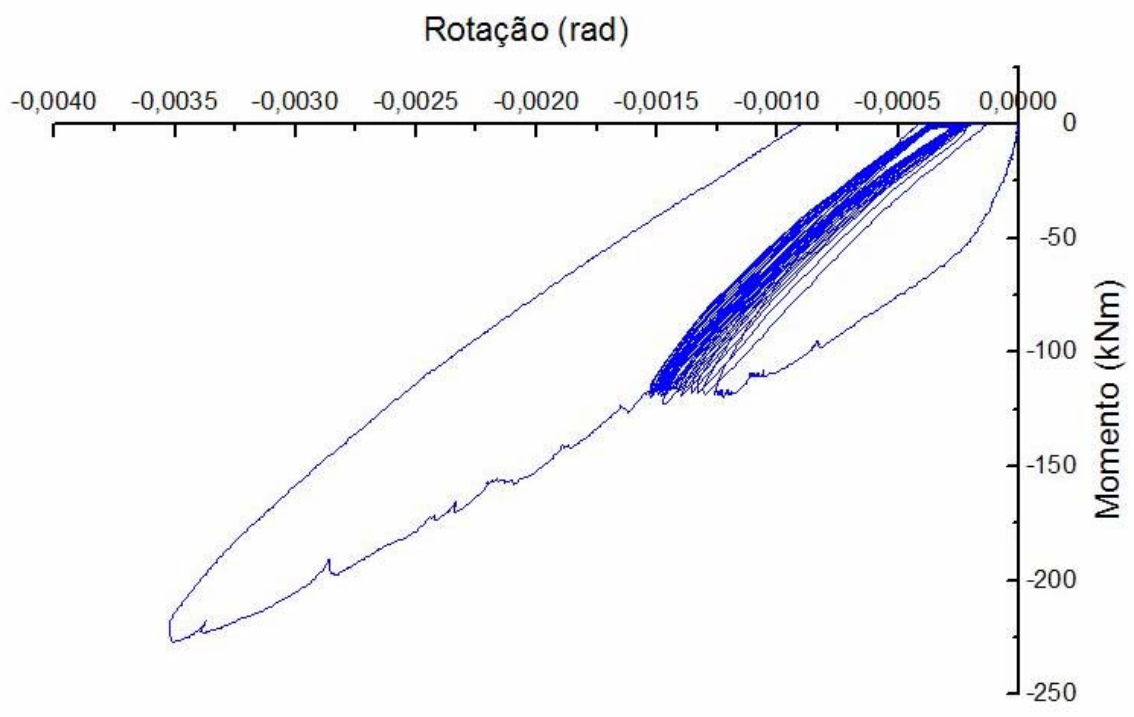

Figura 4.7 - Curva momento-rotação dos ciclos 1-20 do modelo I - momento negativo

Com base na Figura 4.7 criou-se a envoltória dos ciclos de forma a representar o comportamento da ligação quando descontadas as rotações residuais ocorridas durante o ciclo 2 ao 20 . 
A Figura 4.8 mostra esta envoltória.

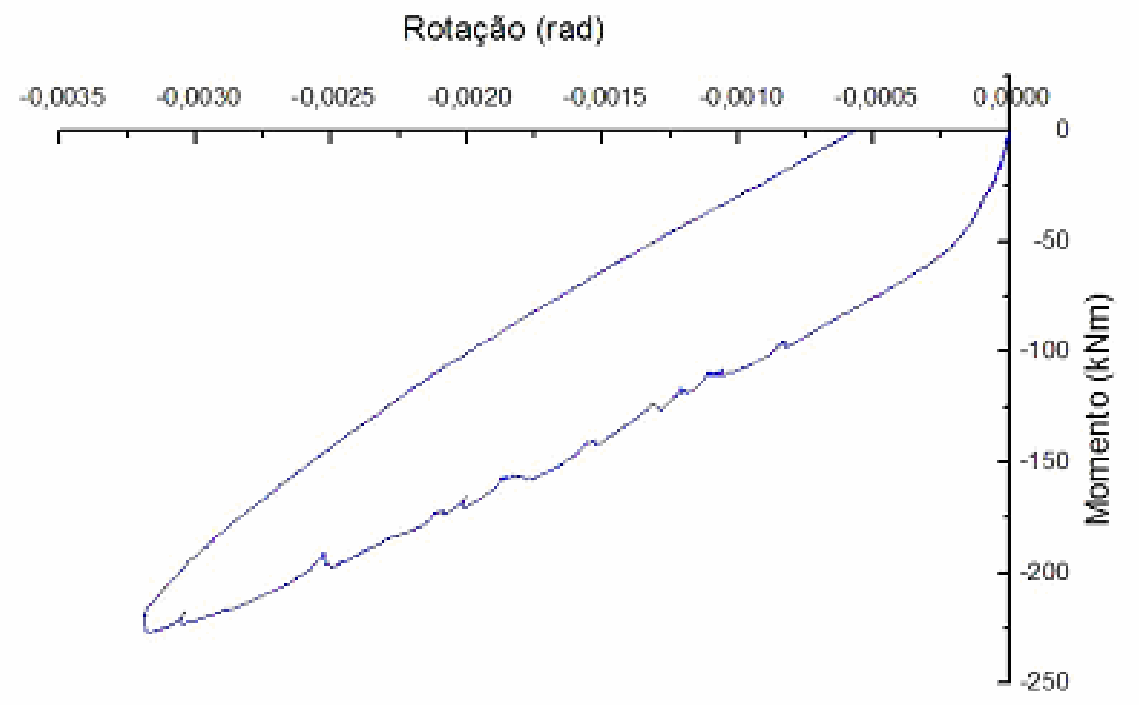

Figura 4.8 - Envoltória da curva momento-rotação do modelo I - momento negativo

A rigidez da ligação foi definida através da inclinação da curva bi-linear descrita na seção 4.1 deste capítulo. Decidiu-se por determinar a rigidez da ligação em duas situações. A primeira para o caso (aproximado) da estrutura ser carregada até ocorrer à ruptura, rigidez dada pela envoltória, e a segunda, quando a estrutura já sofreu sucessivos carregamentos e descarregamentos, dada pelo último ciclo.

A Figura 4.9 apresenta a curva bi-linear obtida pela envoltória.

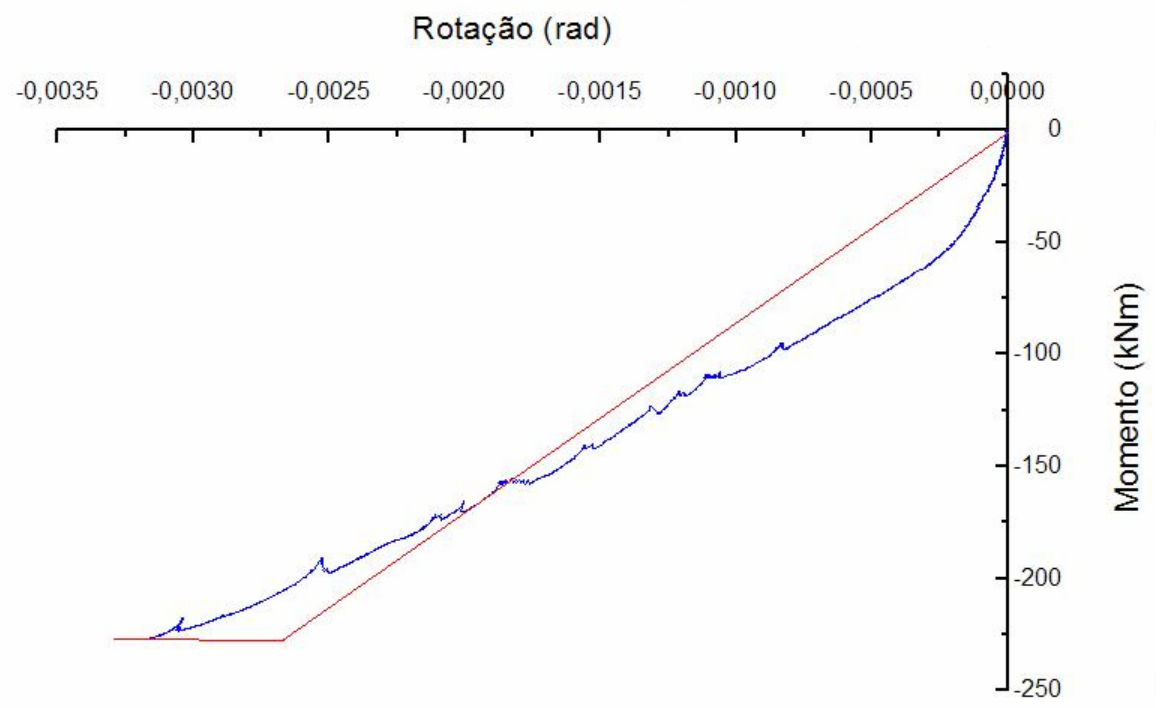

Figura 4.9 - Curva bi-linear do modelo I a momento negativo obtido pela envoltória 
As Figuras 4.10 e 4.11 apresentam a curva momento-rotação do último ciclo e a sua curva bi-linear respectivamente.

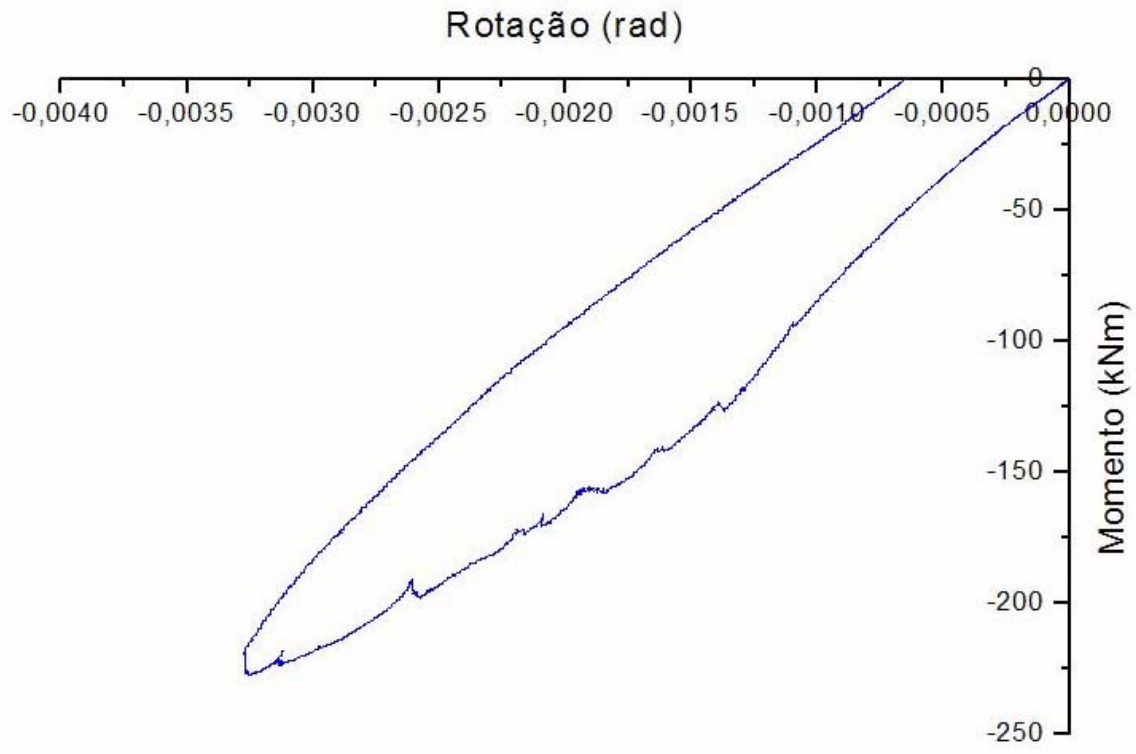

Figura 4.10 - Curva momento negativo-rotação do último ciclo do modelo I

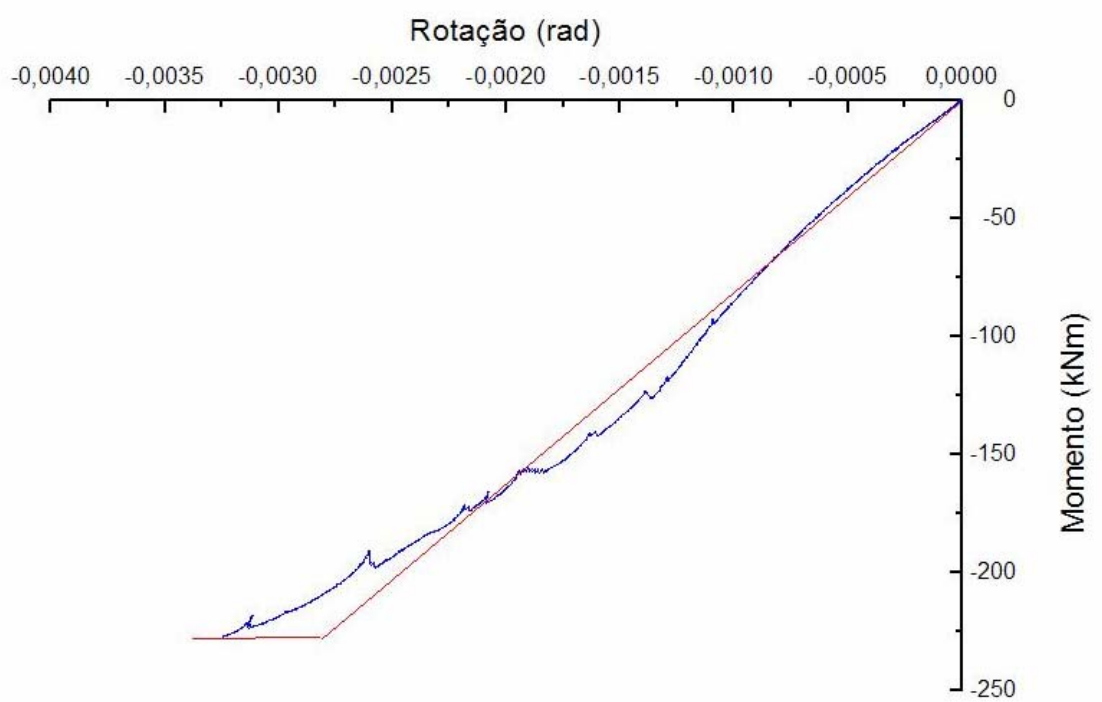

Figura 4.11 - Curva bi-linear do modelo I a momento negativo obtido pelo último ciclo 
A Tabela 4.2 apresenta as rigidezes a momento fletor negativo da ligação do modelo I.

Tabela 4.2 - Valores das rigidezes para momento fletor negativo do modelo I

\begin{tabular}{|l|c|c|}
\cline { 3 - 3 } \multicolumn{2}{|c|}{} & Rigidez $(\mathrm{MNm} / \mathrm{rad})$ \\
\hline \multirow{2}{*}{ Momento fletor negativo } & Envoltória & 84,0 \\
\cline { 2 - 3 } & Ultimo ciclo & 79,6 \\
\hline
\end{tabular}

\section{Momento fletor positivo}

A Figura 4.12 mostra a curva momento-rotação do modelo I sob ação de momentos fletores positivos nos 21 ciclos ao qual o modelo foi submetido. Nota-se que o comportamento da ligação é similar ao momento negativo, ou seja, no primeiro ciclo há um trecho inicial de grande rigidez seguido de uma redução. A partir do $2^{\circ}$ ciclo a rigidez permanece constante e inferior a verificada para o primeiro ciclo. Para um momento de 144,1 kNm a ligação não mais suporta carga.

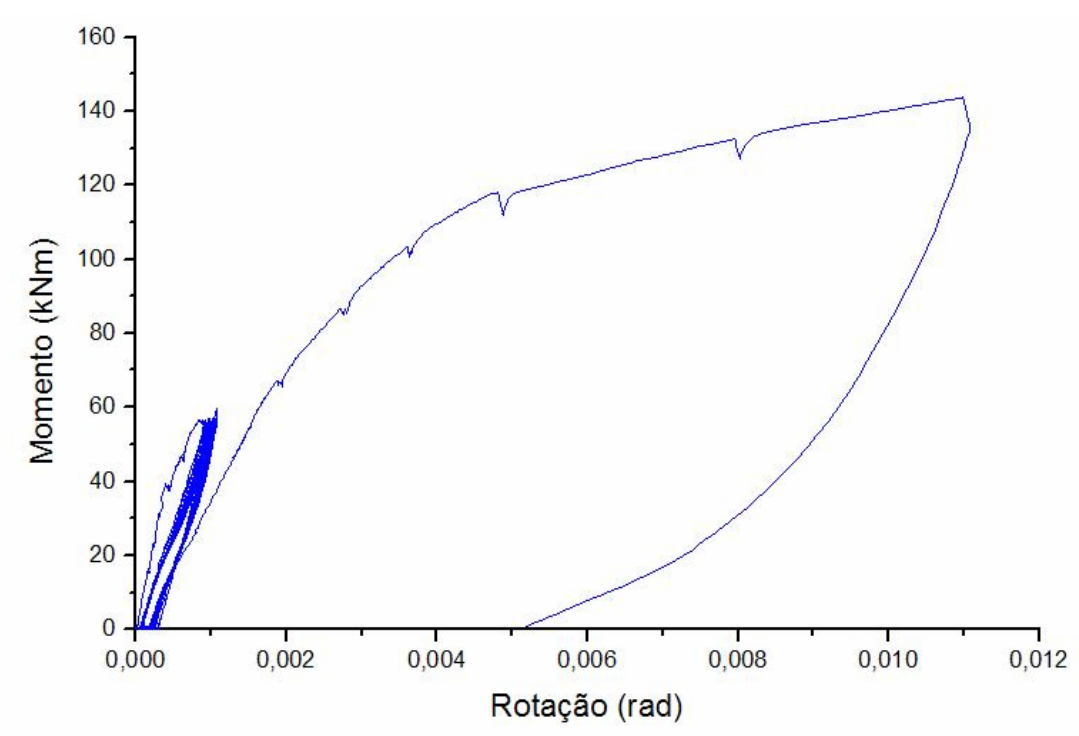

Figura 4.12 - Curva momento-rotação dos ciclos 1-20 do modelo I - momento positivo

Nota-se que no ultimo ciclo (ciclo 21) até o momento de $56,7 \mathrm{kNm}$ a inclinação da curva e, portanto a rigidez da ligação, não acompanha a do ciclo 20 como esperado. Esta diferença nas rotações deve-se a acomodações do modelo. 
A envoltória foi determinada também como no momento negativo, ou seja, descontadas as rotações residuais devido aos ciclos 2-20 e é apresentada na Figura 4.13.

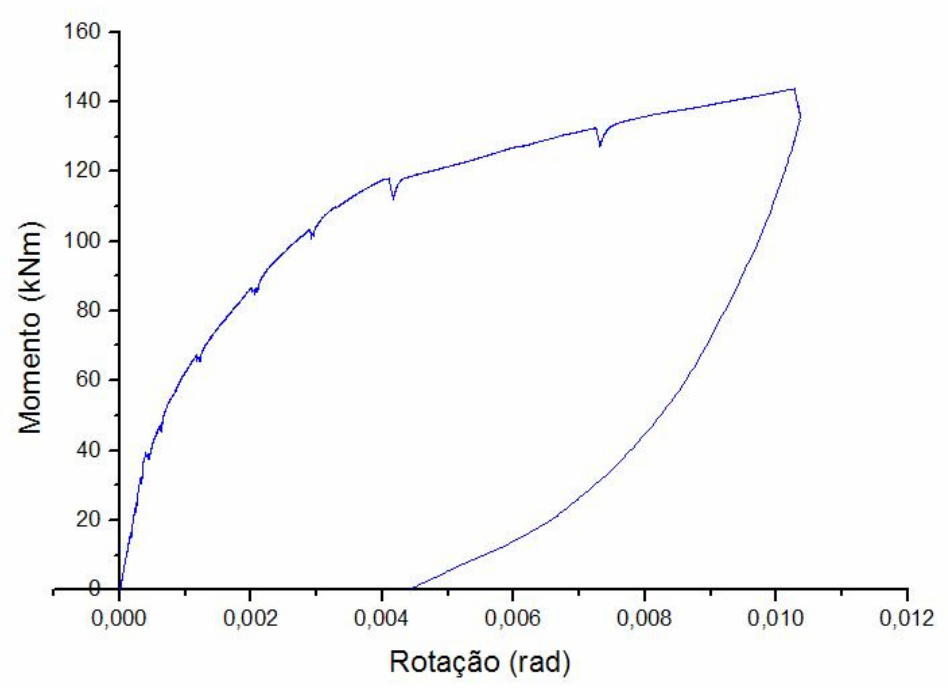

Figura 4.13- Envoltória da curva momento-rotação do modelo I - momento positivo

É possível perceber que a ligação possui grande capacidade de rotação antes de atingir sua tensão de ruptura. Isto é comprovado quando comparada à rotação entre o início do carregamento até o momento de $120 \mathrm{kNm}$ e entre o momento de $120 \mathrm{kNm}$ e $144 \mathrm{kNm}$. No primeiro trecho há uma rotação de 0,0051 rad enquanto o segundo de $0,0059 \mathrm{rad}$.

As Figuras 4.14, 4.15 e 4.16 definem a rigidez da envoltória, a curva momentorotação do último ciclo de carregamento e sua rigidez para o momento fletor positivo.

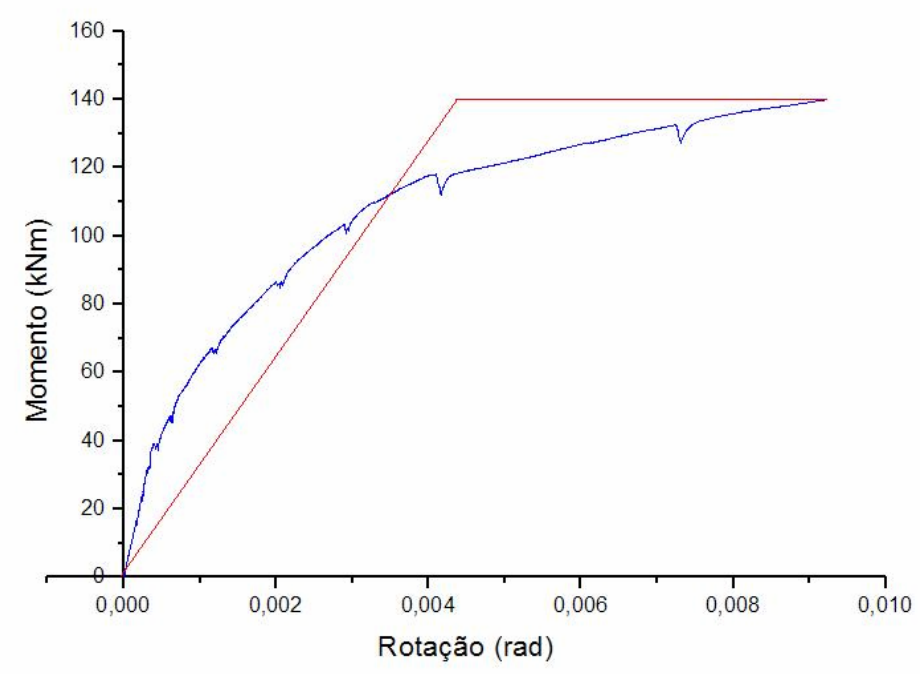

Figura 4.14 - Curva bi-linear do modelo I a momento positivo obtido pela envoltória 


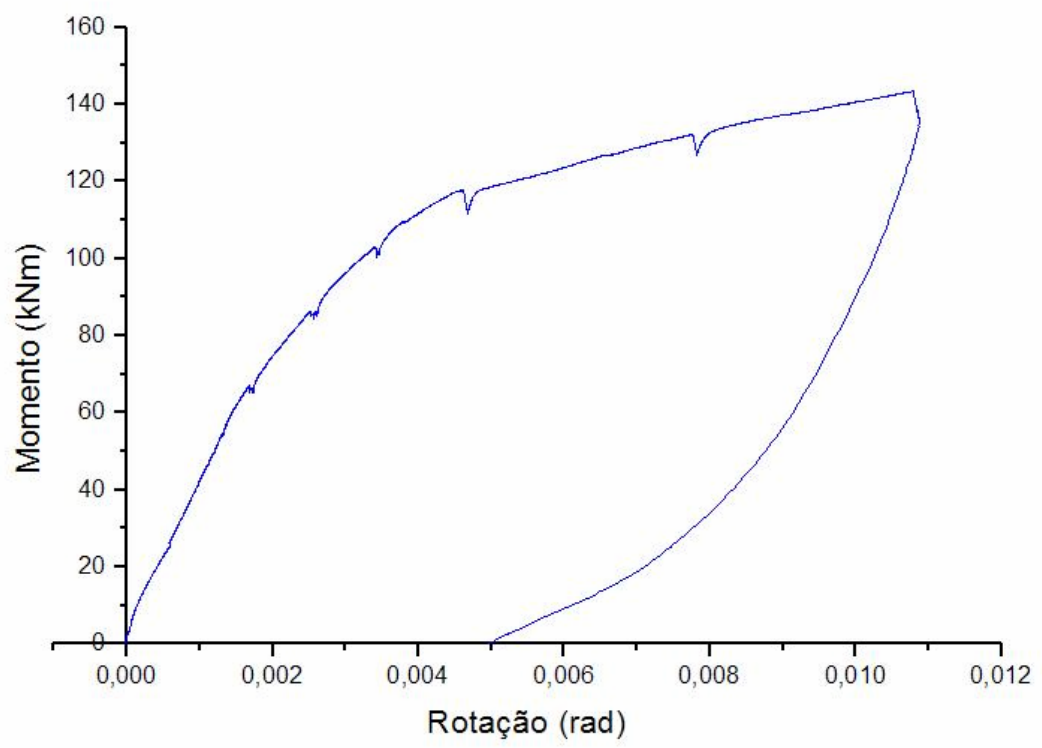

Figura 4.15- Curva momento positivo-rotação do último ciclo do modelo I

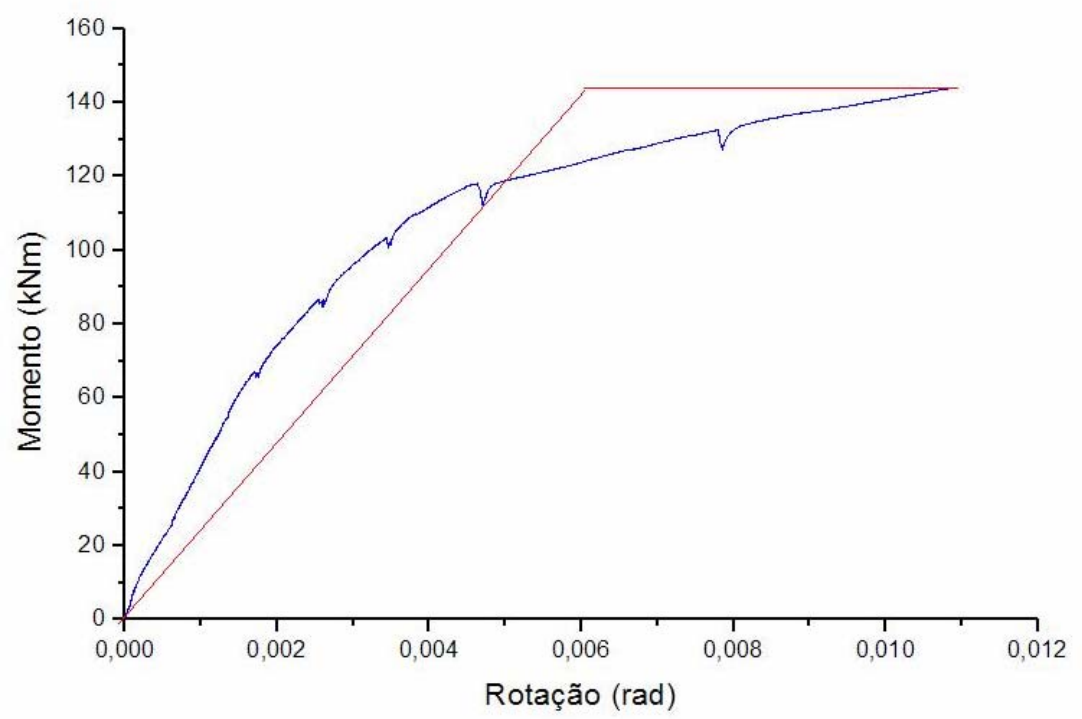

Figura 4.16 - Curva bi-linear do modelo I a momento positivo obtida pelo último ciclo

A Tabela 4.3 apresenta as rigidezes a momento fletor positivo da ligação do modelo I.

Tabela 4.3 - Valores das rigidezes para momento fletor positivo do modelo I

\begin{tabular}{|l|c|c|}
\cline { 3 - 3 } \multicolumn{2}{c|}{} & Rigidez $(\mathrm{MNm} / \mathrm{rad})$ \\
\hline \multirow{2}{*}{ Momento fletor positivo } & Envoltória & 33,3 \\
\cline { 2 - 3 } & Ultimo ciclo & 28,8 \\
\hline
\end{tabular}




\subsubsection{Curva momento rotação do modelo $\mathrm{E}$}

Para o modelo E foram analisadas as rigidezes do pilar situado à esquerda e denominado $\mathrm{E}_{\mathrm{e}}$ e o pilar situado à direita e denominado $\mathrm{E}_{\mathrm{d}}$ como mostra a Figura 4.17.

Assim como para modelo I, no modelo E foi feito um estudo das rigidezes para as diversas combinações de relógios comparadores garantindo que ao se utilizar às médias dos relógios comparadores para o pilar $E_{\mathrm{e}}$ e para o pilar $\mathrm{E}_{\mathrm{d}}$ os resultados obtidos representam o comportamento da ligação.

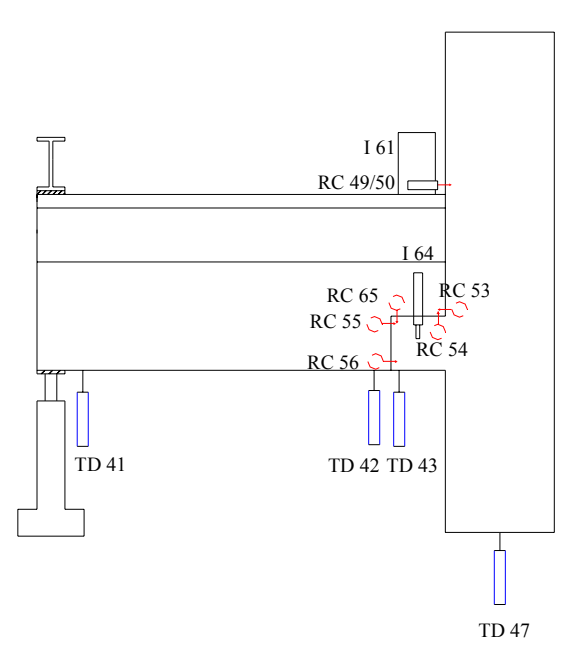

Pilar $\mathrm{E}_{\mathrm{e}}$

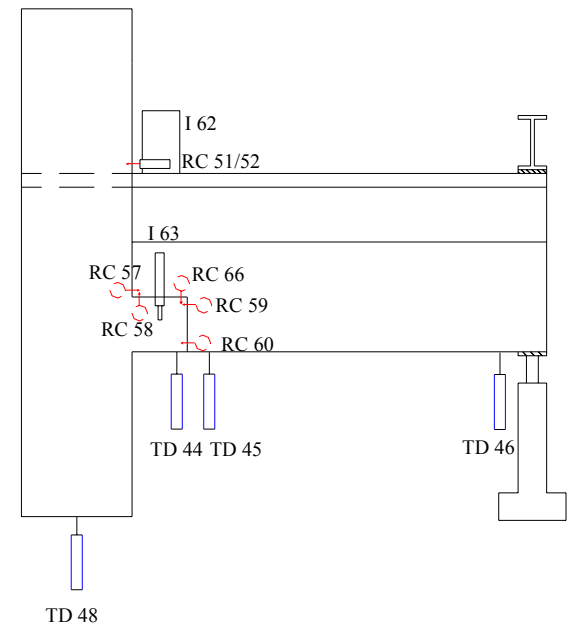

Pilar $\mathrm{E}_{\mathrm{d}}$

Figura 4.17 - Identificação do $E_{e}$ e $E_{d}$ para o modelo E

$\underline{\text { Momento fletor negativo }}$

\section{$\underline{\text { Pilar } \underline{E}_{\underline{e}}}$}

A Figura 4.18 mostra a curva momento-rotação do pilar $\mathrm{E}_{\mathrm{e}}$ do modelo $\mathrm{E}$ sob ação de momentos fletores negativos nos 16 ciclos ao qual o modelo foi submetido. No primeiro ciclo nota-se um trecho inicial com rigidez elevada até o momento de -58 $\mathrm{kNm}$, quando surgem as primeiras fissuras, seguido de uma perda na rigidez que é mantida praticamente constante até o ciclo 5. No ciclo 6 há novamente uma perda de rigidez e que se mantém constante até o último ciclo. Para o momento fletor de $-162,2$ kNm a ligação não mais suporta carga. 


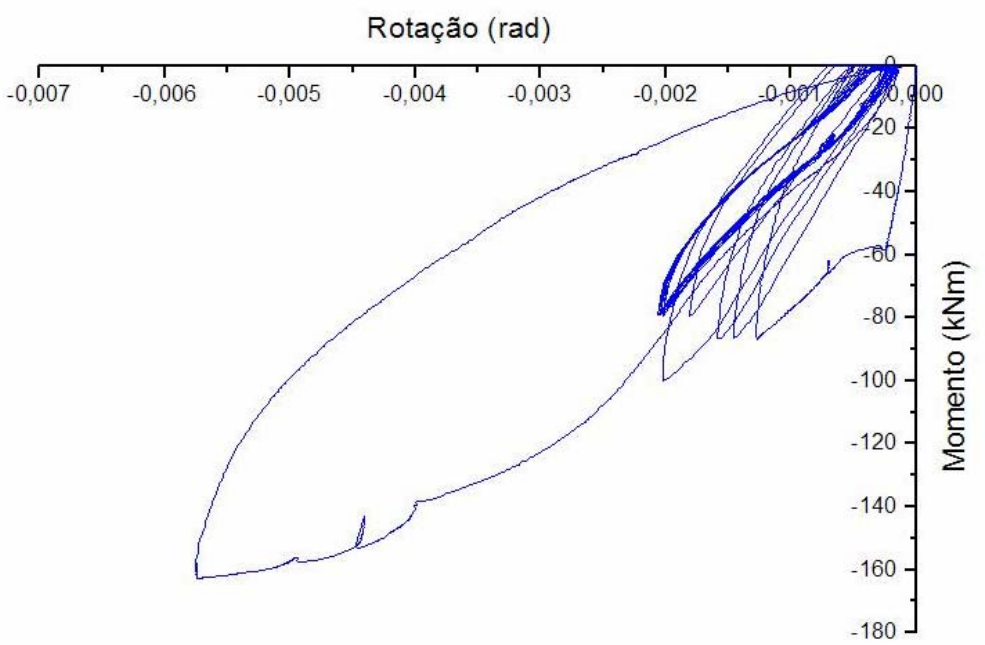

Figura 4.18 - Curva momento-rotação dos ciclos 1-16 do modelo E/ pilar $\mathrm{E}_{\mathbf{e}}-$ momento negativo

A determinação da envoltória foi obtida descontando as rotações residuais verificadas nos ciclos e é mostrada na Figura 4.19.

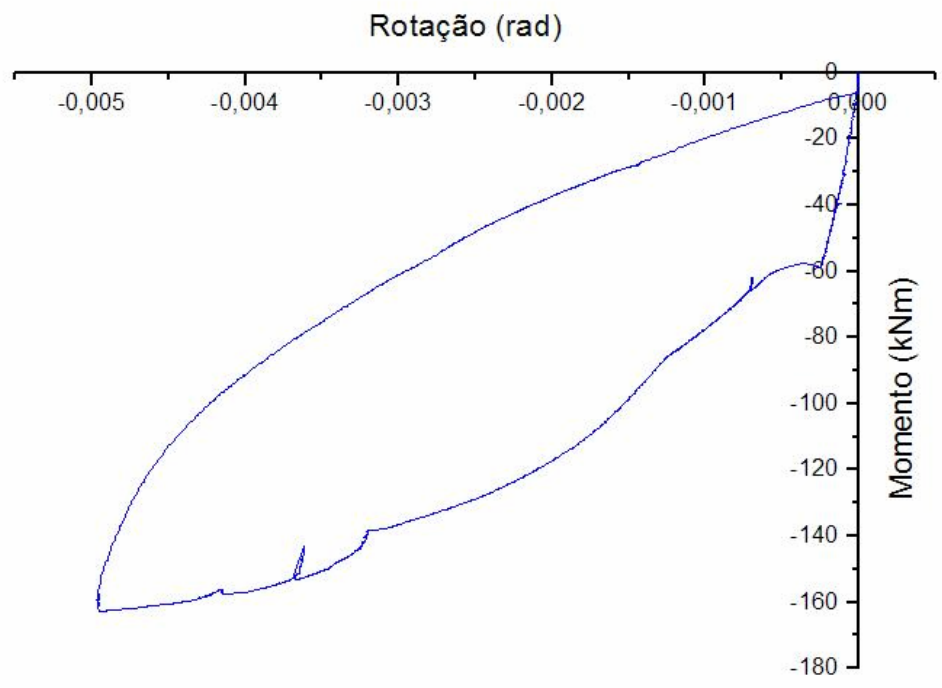

Figura 4.19 - Envoltória da curva momento rotação do modelo E/ pilar $\mathbf{E}_{\mathbf{e}}$ - momento negativo

Percebe-se que o comportamento da ligação a momento negativo é similar a do modelo I até o momento de $-58 \mathrm{kNm}$. Para este nível de carregamento houve perda de aderência em algumas barras de $\phi 10 \mathrm{~mm}$ presentes na capa de concreto que por falta de ancoragem permitiu um deslocamento da capa em relação ao pilar causando uma 
abertura de fissura em torno de $5 \mathrm{~mm}$ nesta região. A presença desta abertura permitiu ao modelo ter uma maior rotação que antes da fissuração.

A Figura 4.20 mostra a abertura de fissura devido ao deslocamento da capa.
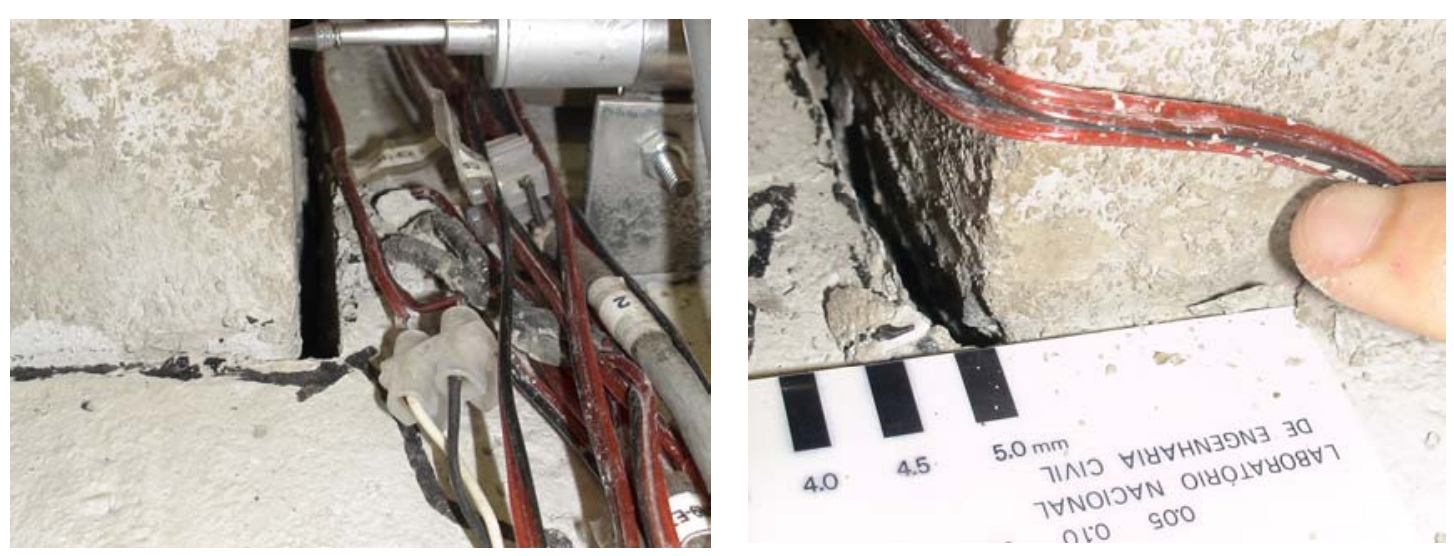

Figura 4.20 - Desprendimento entre a capa de concreto e o pilar

A rigidez a momento fletor negativo do modelo E foi feita da mesma maneira que do modelo I, ou seja, através da curva bi-linear e para duas situações; da envoltória e do último ciclo. As Figuras 4.21, 4.22 e 4.23 mostram respectivamente a curva para obtenção da rigidez através da envoltória, curva momento-rotação do último ciclo e rigidez do último ciclo.

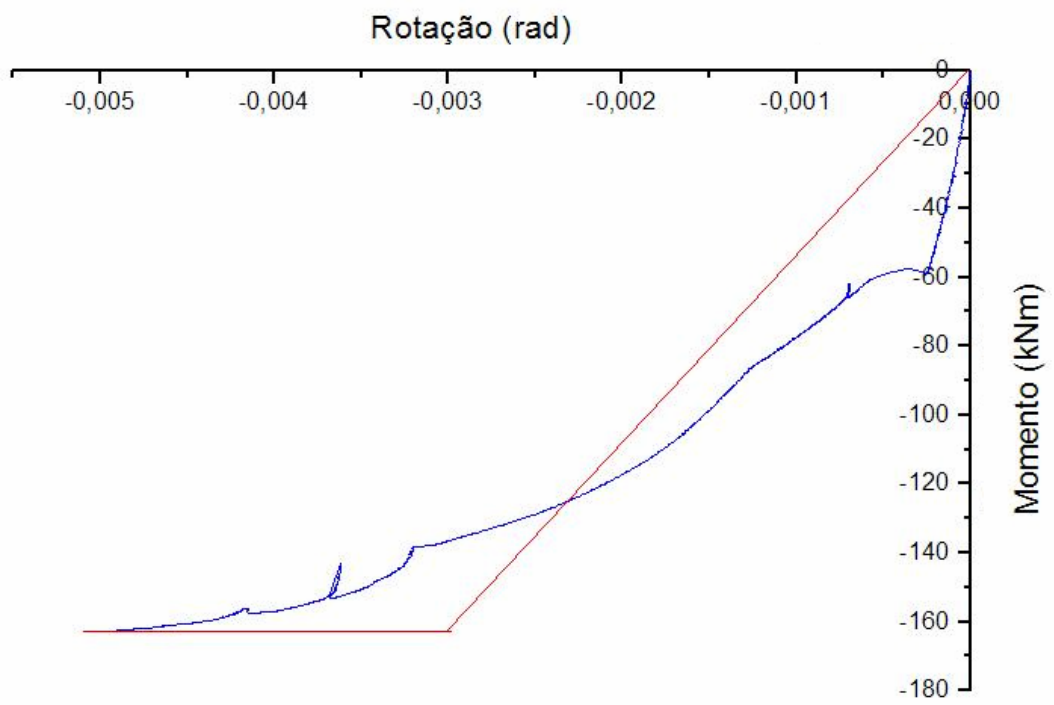

Figura 4.21 - Curva bi-linear do modelo E/ pilar $\mathbf{E}_{\mathrm{e}}$ a momento negativo obtido pela envoltória 


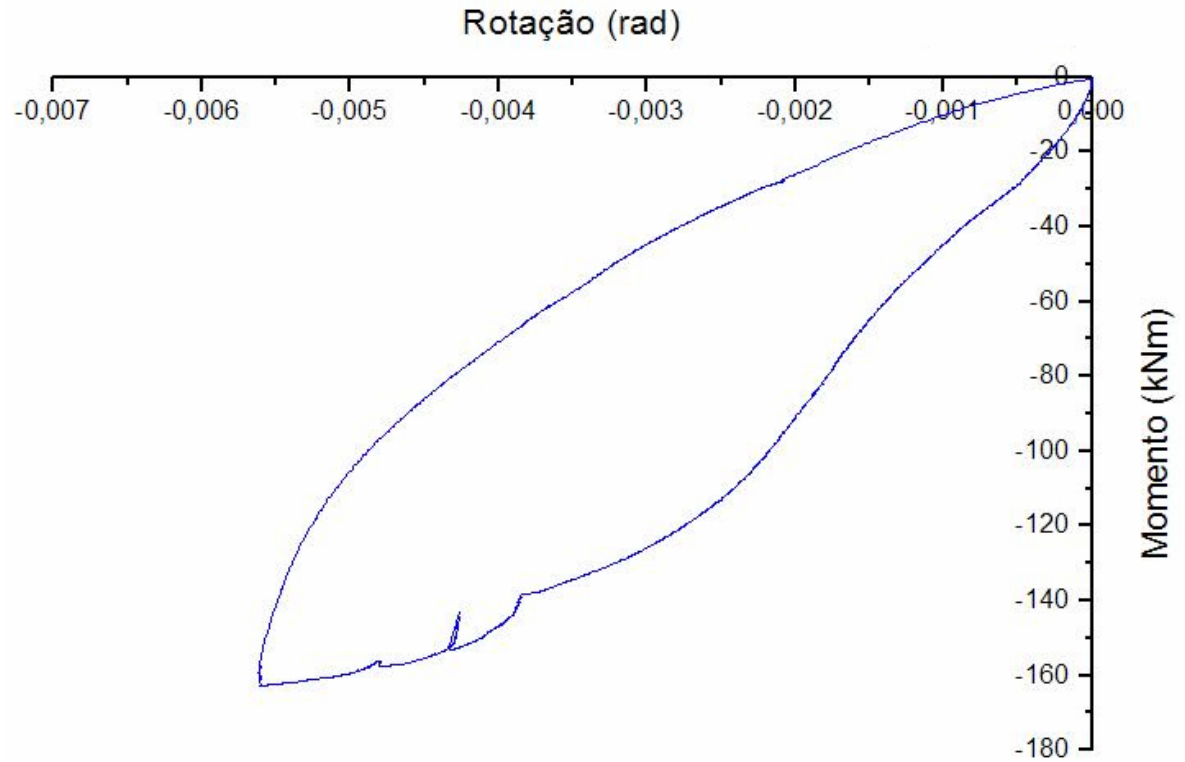

Figura 4.22 - Curva momento negativo-rotação do último ciclo do modelo E/ pilar $E_{e}$

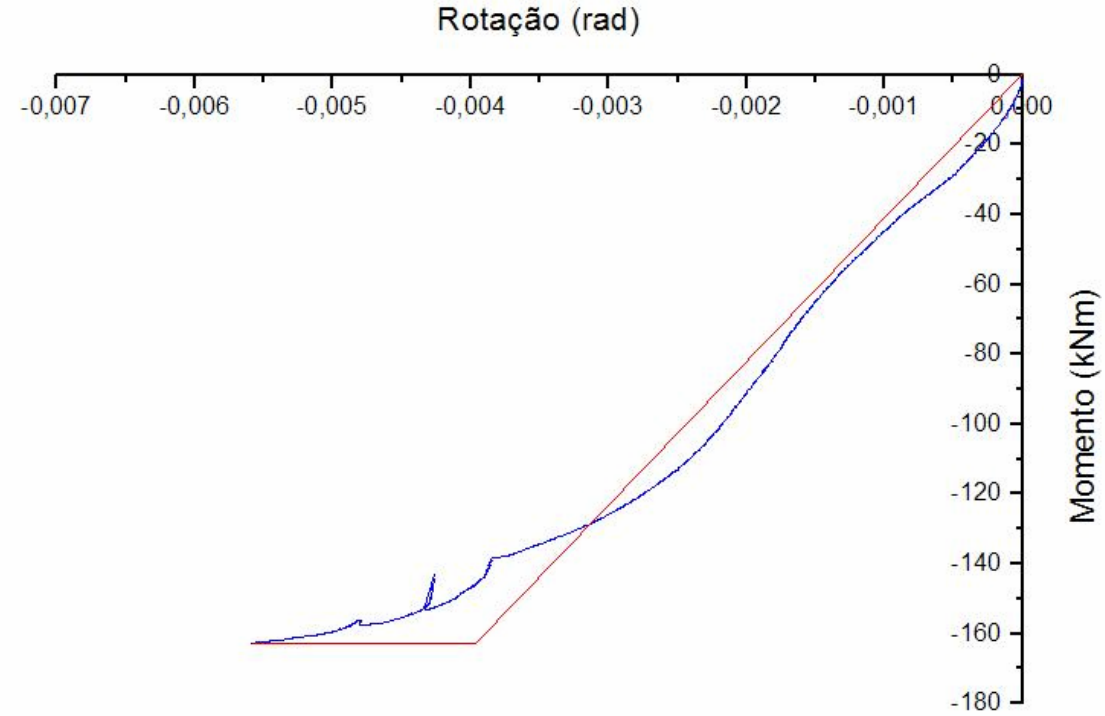

Figura 4.23 - Curva bi-linear do modelo E/ pilar $\mathbf{E}_{\mathrm{e}}$ a momento negativo obtido pelo último ciclo

A Tabela 4.4 apresenta os valores das rigidezes obtidas

Tabela 4.4 - Valores das rigidezes para o momento fletor negativo do modelo E/ pilar $\mathbf{E}_{\mathbf{e}}$

\begin{tabular}{|l|c|c|}
\cline { 3 - 3 } & & Rigidez $(\mathrm{MNm})$ - Pilar $\mathrm{E}_{\mathrm{e}}$ \\
\hline \multirow{2}{*}{ Momento negativo } & Envoltória & 54,3 \\
\cline { 2 - 3 } & Último ciclo & 40.7 \\
\hline
\end{tabular}


$\underline{\text { Pilar } \underline{E}_{\mathrm{d}}}$

A Figura 4.24 mostra a curva momento-rotação do pilar $\mathrm{E}_{\mathrm{d}}$ do modelo $\mathrm{E}$ sob ação de momentos fletores negativos nos 16 ciclos ao qual o modelo foi submetido.

$\mathrm{O}$ comportamento dos ciclos do pilar $\mathrm{E}_{\mathrm{d}}$ é similar ao do pilar $\mathrm{E}_{\mathrm{e}}$, porém este apresenta rotações maiores desde o início do carregamento.

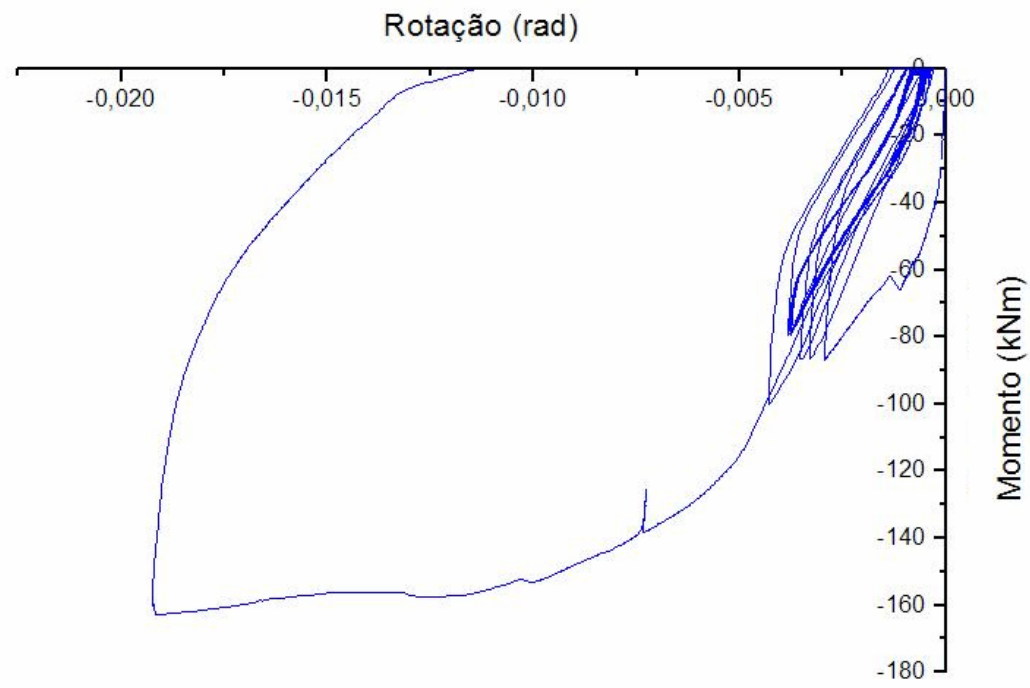

Figura 4.24- Curva momento-rotação dos ciclos 1-16 do modelo $E$ / pilar $\mathbf{E}_{\mathbf{d}}$ - momento negativo

A envoltória dos ciclos, o último ciclo e as curvas bi-lineares para cálculo das rigidezes são apresentados nas Figuras 4.25, 4.26, 4.27 e 4.28 respectivamente.

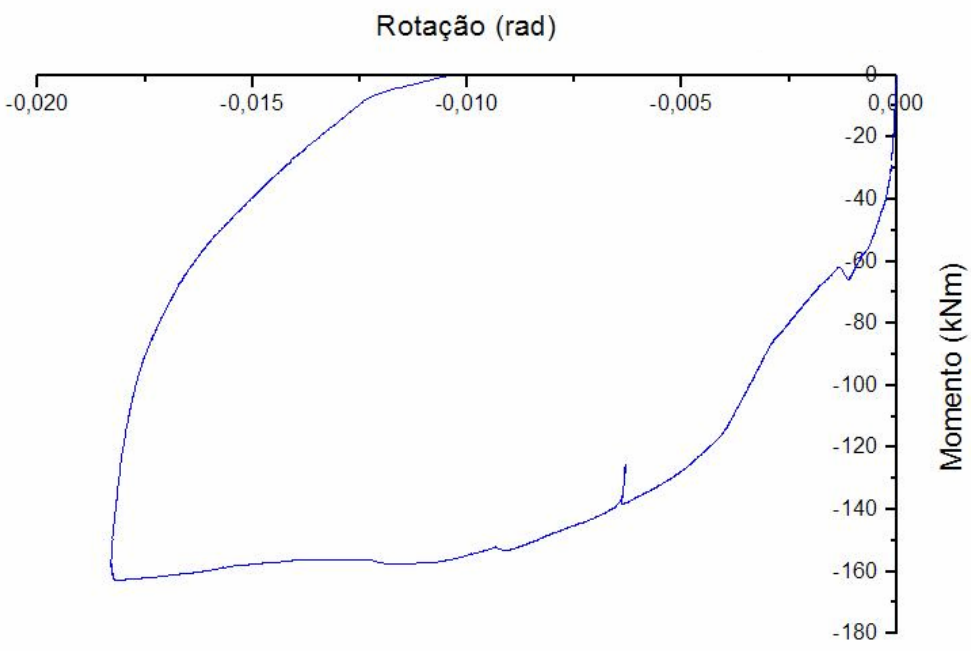

Figura 4.25- Envoltória da curva momento rotação do modelo E/ pilar $\mathbf{E}_{\mathbf{d}}$ - momento negativo 


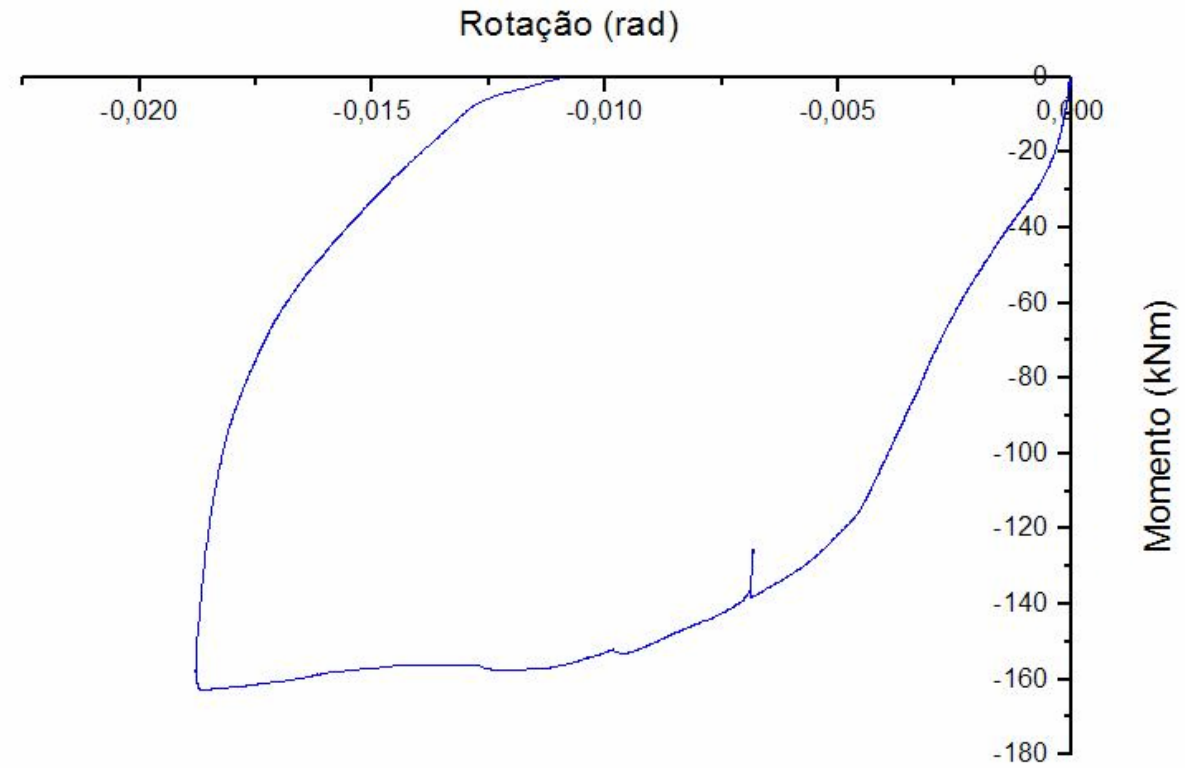

Figura 4.26- Curva momento negativo-rotação do último ciclo do modelo $E$ /pilar $E_{d}$

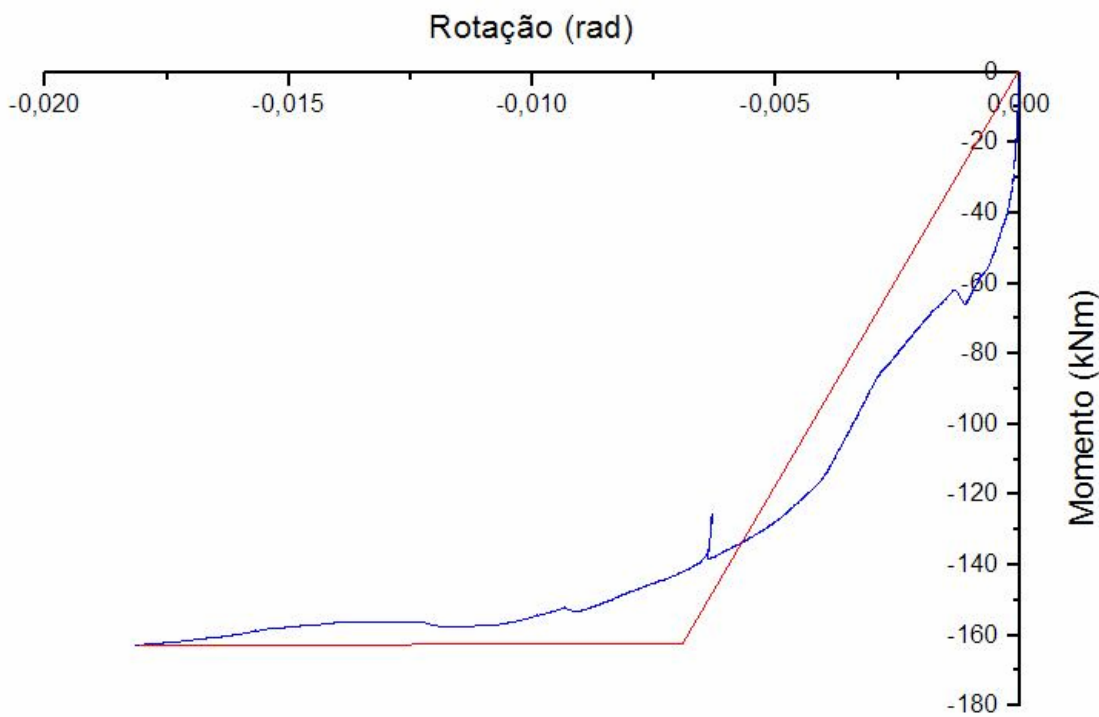

Figura 4.27- Curva bi-linear do modelo $E$ / pilar $E_{d}$ a momento negativo obtido pela envoltória 


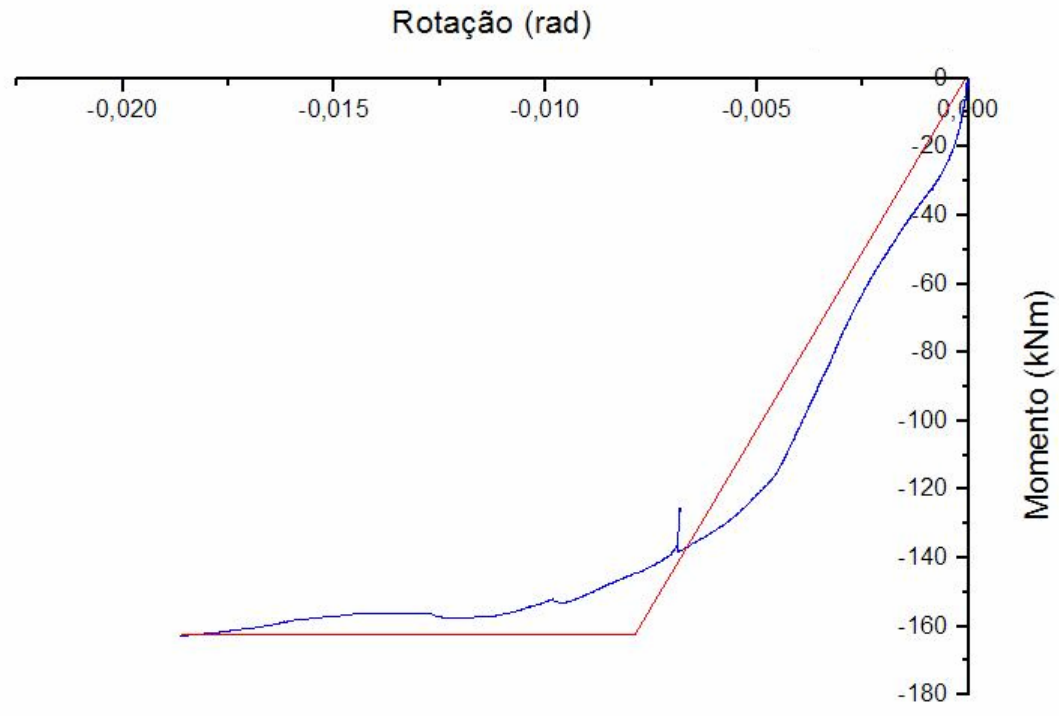

Figura 4.28- Curva bi-linear do modelo $E$ / pilar $\mathbf{E}_{\mathbf{d}}$ a momento negativo obtido pelo último ciclo

A Tabela 4.5 apresenta os valores de rigidezes obtidos a momento fletor negativo tanto para o pilar $\mathrm{E}_{\mathrm{e}}$ como para o pilar $\mathrm{E}_{\mathrm{d}}$.

Tabela 4.5 - Rigidezes a momento fletor negativo do modelo $\mathrm{E}$

\begin{tabular}{|l|c|c|c|}
\cline { 3 - 4 } \multicolumn{2}{c|}{} & ${\text { Pilar } \mathrm{E}_{\mathrm{e}}(\mathrm{MNm} / \mathrm{rad})}_{\text {Pilar }_{\mathrm{d}}(\mathrm{MNm} / \mathrm{rad})}$ \\
\hline \multirow{2}{*}{ Momento negativo } & Envoltória & 54,3 & 25,1 \\
\cline { 2 - 4 } & Último ciclo & 40,7 & 20,4 \\
\hline
\end{tabular}

$\underline{\text { Momento fletor positivo }}$

$\underline{\text { Pilar } \underline{E}_{\mathrm{e}}}$

A Figura 4.29 mostra a curva momento-rotação do pilar $\mathrm{E}_{\mathrm{e}}$ do modelo $\mathrm{E}$ sob ação de momentos fletores positivos nos 16 ciclos ao qual o modelo foi submetido. Verifica-se que apesar dos modelos I e E suportarem um momento próximo (140kNm), o pilar $\mathrm{E}_{\mathrm{e}}$ do modelo $\mathrm{E}$ sofreu menores rotações, principalmente após o momento 120 $\mathrm{kNm}$ onde a variação da rotação foi de 0,0026 rad para contra 0,0059 do modelo I. 
Outra observação a ser feita é que assim como no modelo I, a inclinação da curva do último ciclo não acompanha a curva anterior apresentando inclusive um maior grau de afastamento. Acredita-se que o aumento nas acomodações foi devido à abertura de fissura entre a capa e o pilar quando atuava o momento fletor negativo.

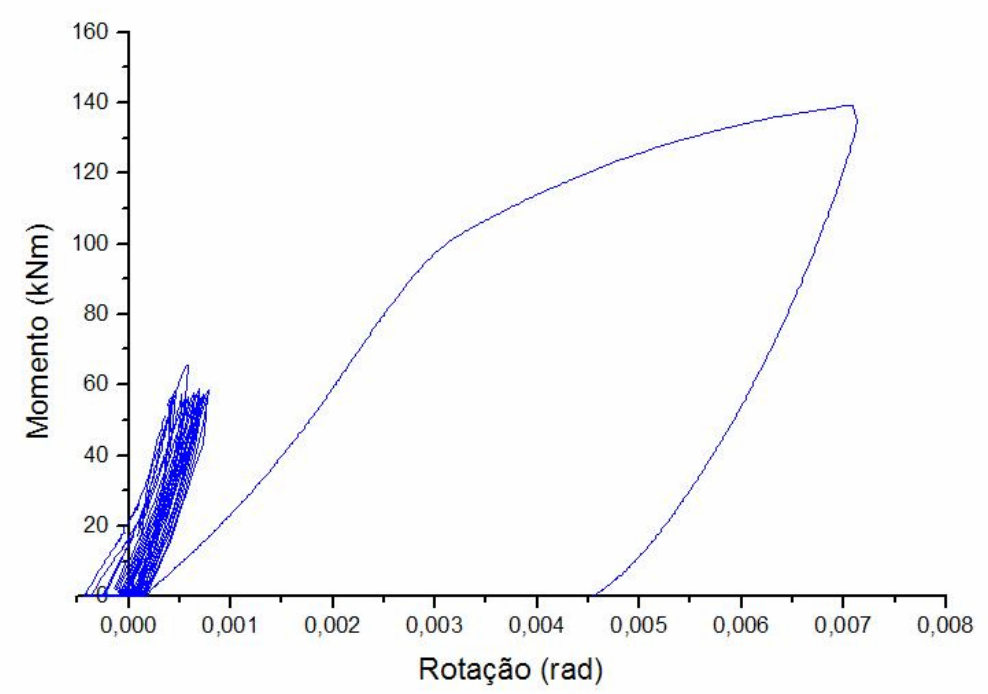

Figura 4.29- Curva momento-rotação dos ciclos 1-16 do modelo E/ pilar $\mathbf{E}_{\mathbf{e}}-$ momento positivo

A envoltória dos ciclos para o momento positivo do modelo E foi feita de forma similar a do modelo I, ou seja, retirando as rotações residuais ocorridas dentre o ciclo 2 e 15. A Figura 4.30 apresenta a envoltória.

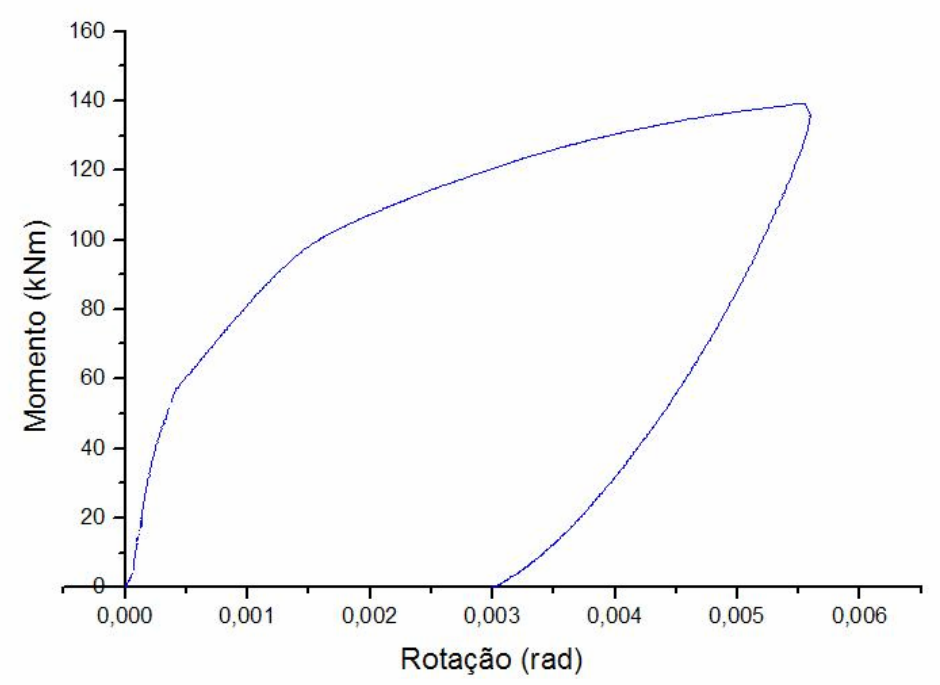

Figura 4.30- Envoltória da curva momento-rotação do modelo E/ pilar $\mathbf{E}_{\mathbf{e}}$ - momento positivo

A Figura 4.31 apresenta a curva momento-rotação do último ciclo a momento fletor positivo. 


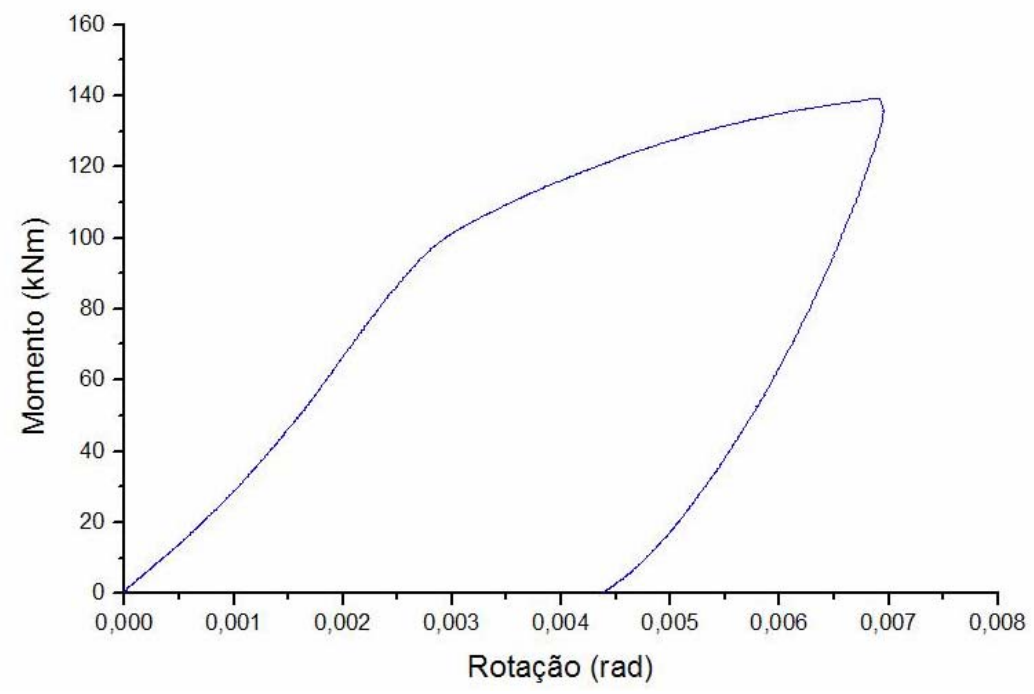

Figura 4.31- Curva momento positivo-rotação do último ciclo do modelo E/ pilar $\mathbf{E}_{\mathbf{e}}$

As Figuras 4.32 e 4.33 mostram as rigidezes obtidas através da envoltória e através do último carregamento respectivamente.

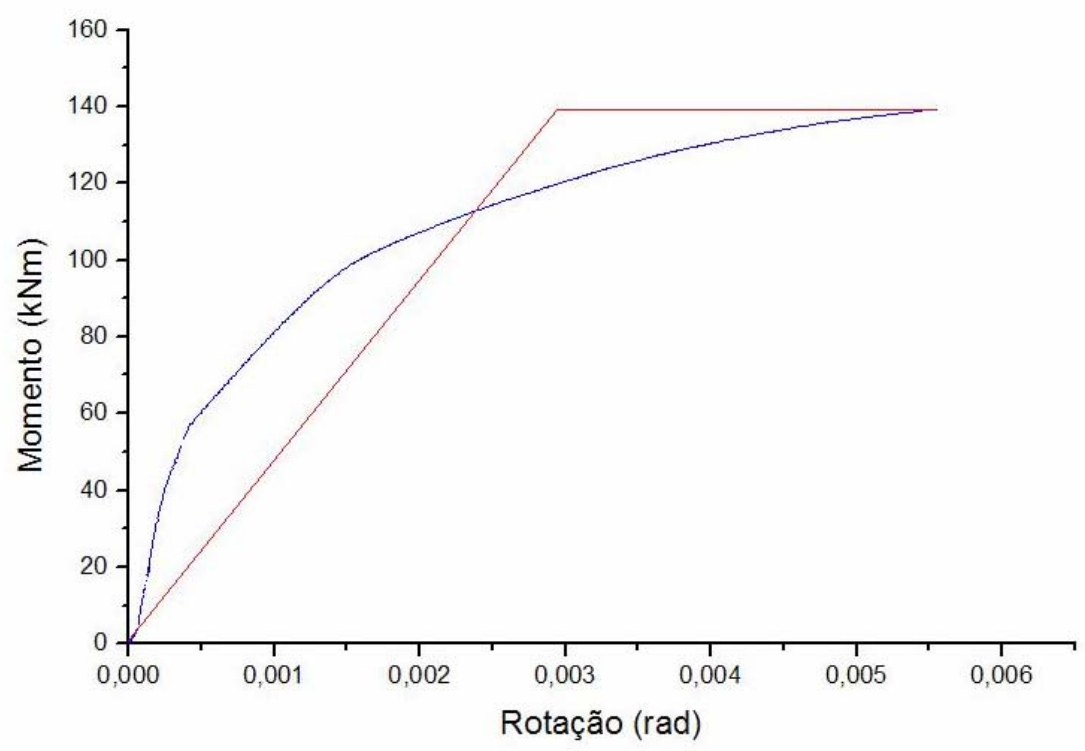

Figura 4.32- Curva bi-linear do modelo $\mathrm{E} /$ pilar $\mathrm{E}_{\mathrm{e}}$ a momento positivo obtido pela envoltória 


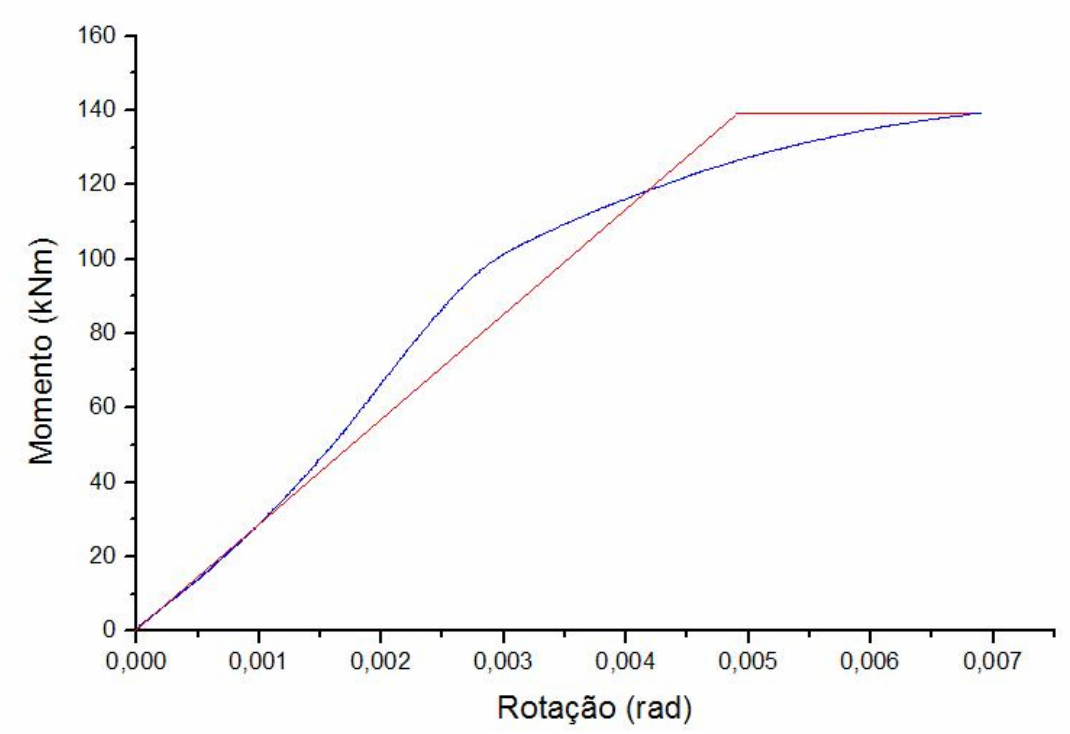

Figura 4.33- Curva bi-linear do modelo $\mathrm{E} /$ pilar $\mathrm{E}_{\mathbf{e}}$ a momento positivo obtida pelo último ciclo

A Tabela 4.6 apresenta os resultados das rigidezes do pilar $\mathrm{E}_{\mathrm{e}}$ a momento fletor positivo

Tabela 4.6 - Valores das rigidezes para momento fletor positivo do modelo E/ pilar $\mathbf{E}_{\mathbf{e}}$

\begin{tabular}{|l|c|c|}
\cline { 3 - 3 } \multicolumn{2}{c|}{} & \multicolumn{1}{|c|}{$\operatorname{Rigidez}(\mathrm{MNm} / \mathrm{rad})-$ Pilar $\mathrm{E}_{\mathrm{e}}$} \\
\hline \multirow{2}{*}{ Momento positivo } & Envoltória & 47,4 \\
\cline { 2 - 3 } & Último ciclo & 28,0 \\
\hline
\end{tabular}

\section{$\underline{\text { Pilar } \underline{E}_{\underline{d}}}$}

A Figura 4.34 mostra a curva momento-rotação do pilar $\mathrm{E}_{\mathrm{d}}$ do modelo E sob ação de momentos fletores positivos nos 16 ciclos ao qual o modelo foi submetido. Percebe-se que o comportamento dos ciclos do pilar $\mathrm{E}_{\mathrm{d}}$ é similar ao do pilar $\mathrm{E}_{\mathrm{e}}$, apresentando, porém, rotações um pouco maiores e um afastamento superior entre a curva do último ciclo e a do ciclo anterior. 


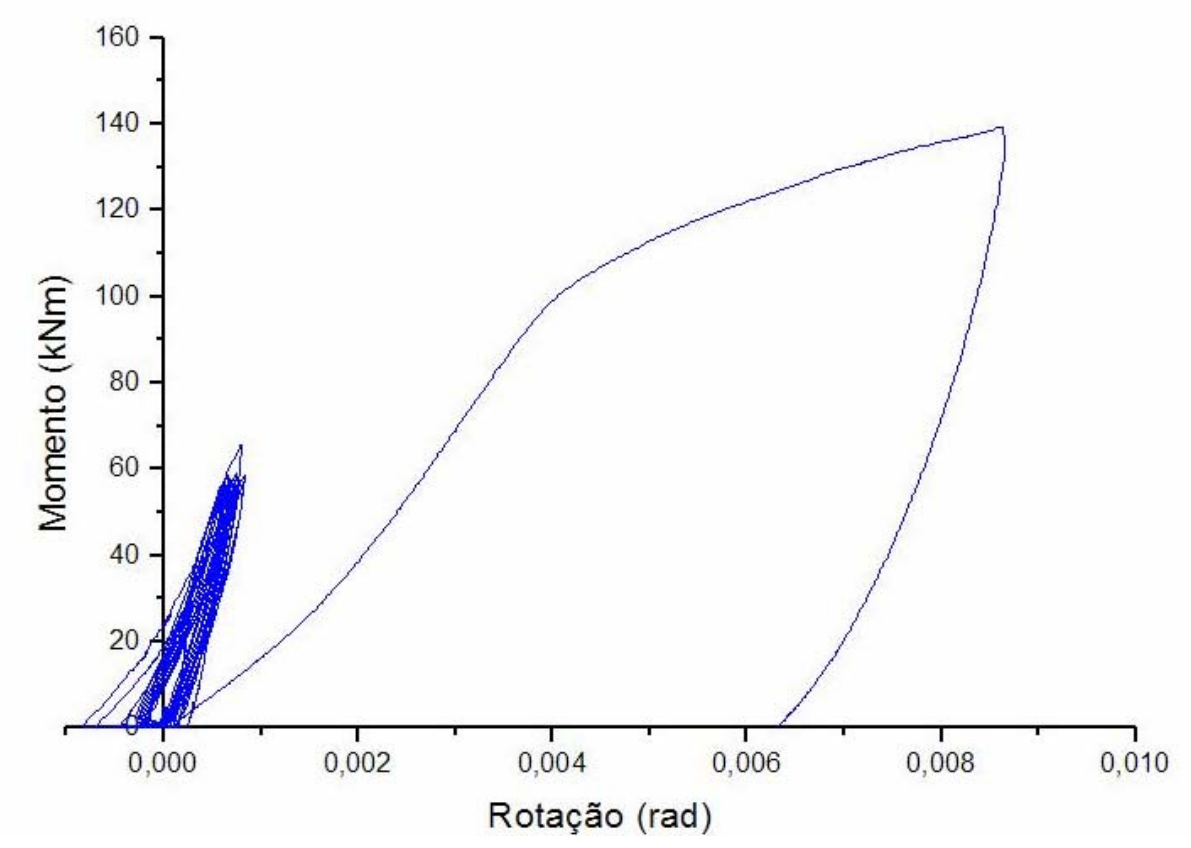

Figura 4.34- Curva momento-rotação dos ciclos 1-16 do modelo E/ pilar $\mathbf{E}_{\mathbf{d}}$ - momento positivo

A Figura 4.35 apresenta a envoltória do pilar $E_{d}$ enquanto que a Figura 4.36 apresenta a curva momento-rotação do último ciclo.

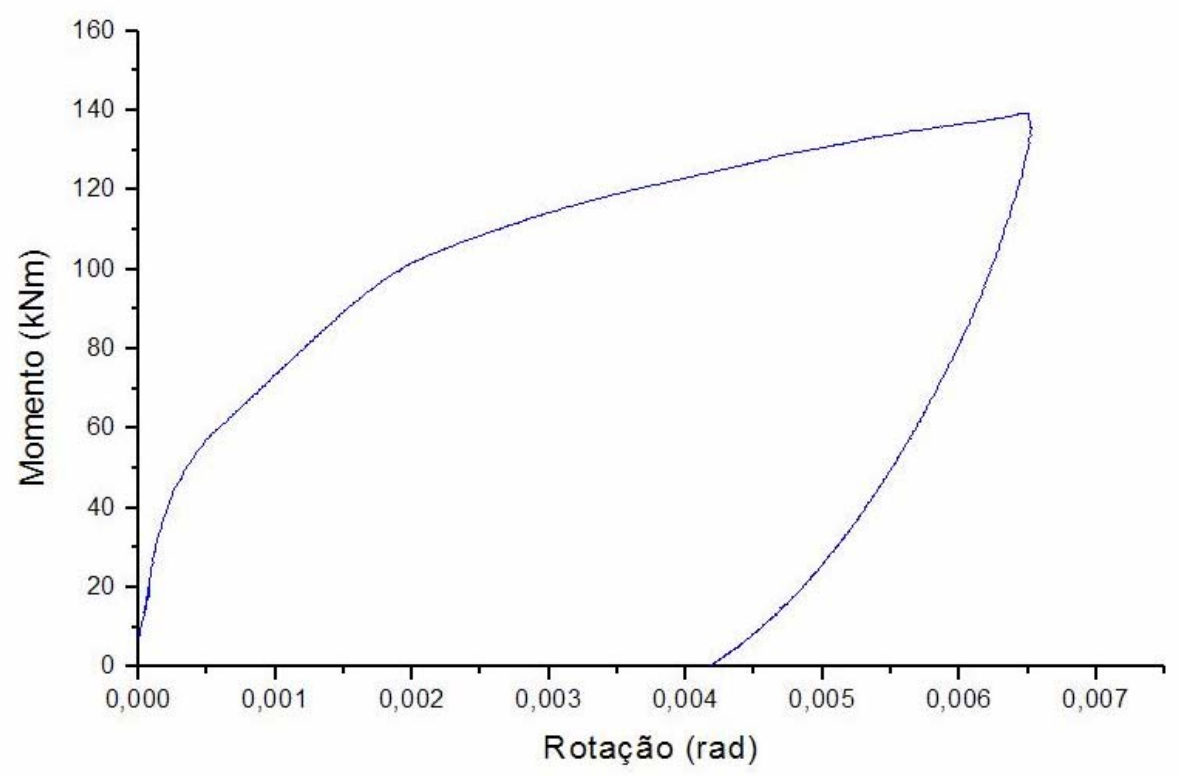

Figura 4.35- Envoltória da curva momento-rotação do modelo E/ pilar $\mathbf{E}_{\mathbf{d}}-$ momento positivo 


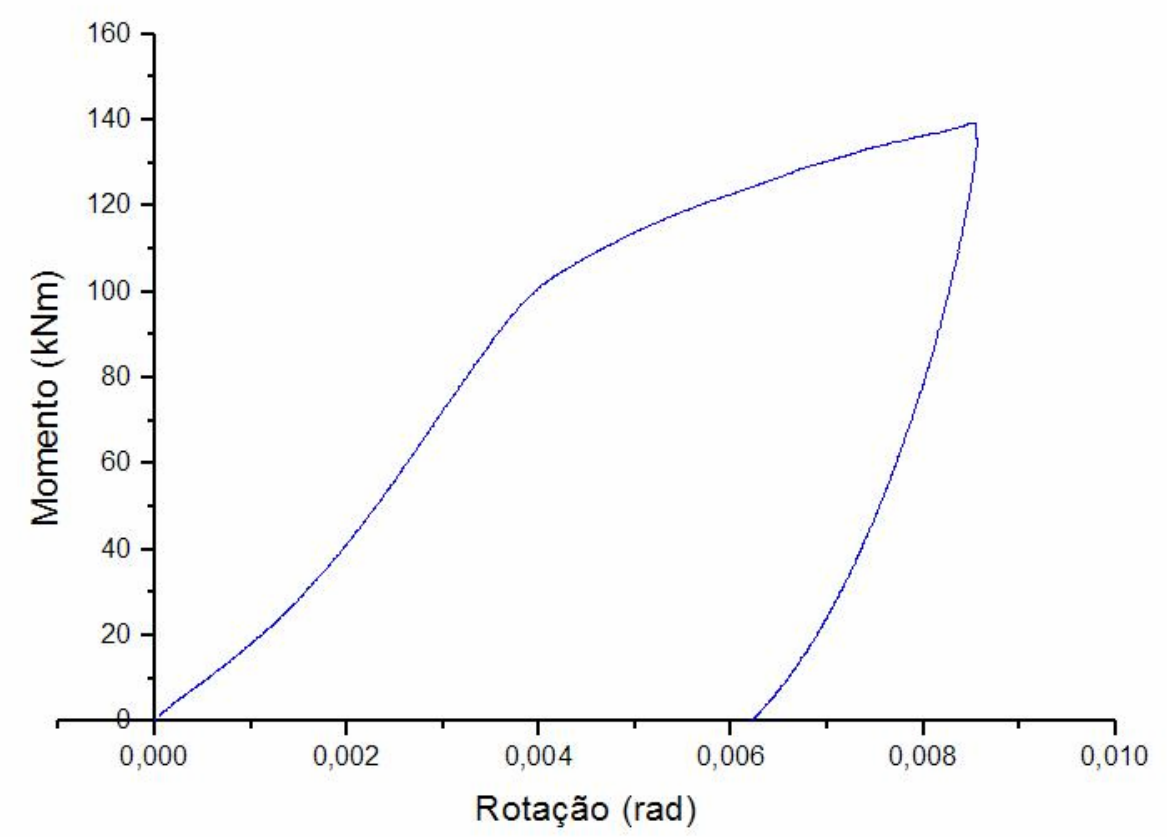

Figura 4.36- Curva momento positivo-rotação do último ciclo do modelo E/ pilar $\mathbf{E}_{\mathbf{d}}$

As Figuras 4.37 e 4.38 apresentam respectivamente as curvas bi-lineares obtidas através da envoltória e através do último ciclo.

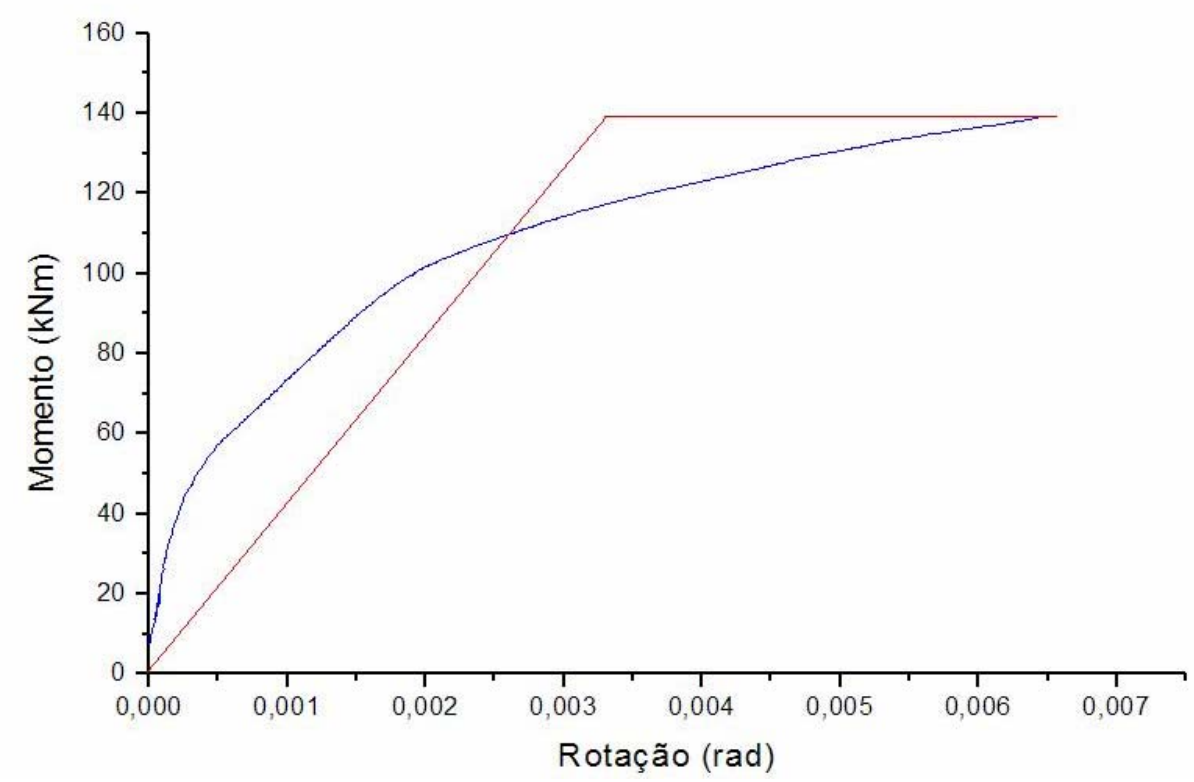

Figura 4.37- Curva bi-linear do modelo E/ pilar $\mathbf{E}_{\mathbf{d}}$ a momento positivo obtido pela envoltória 


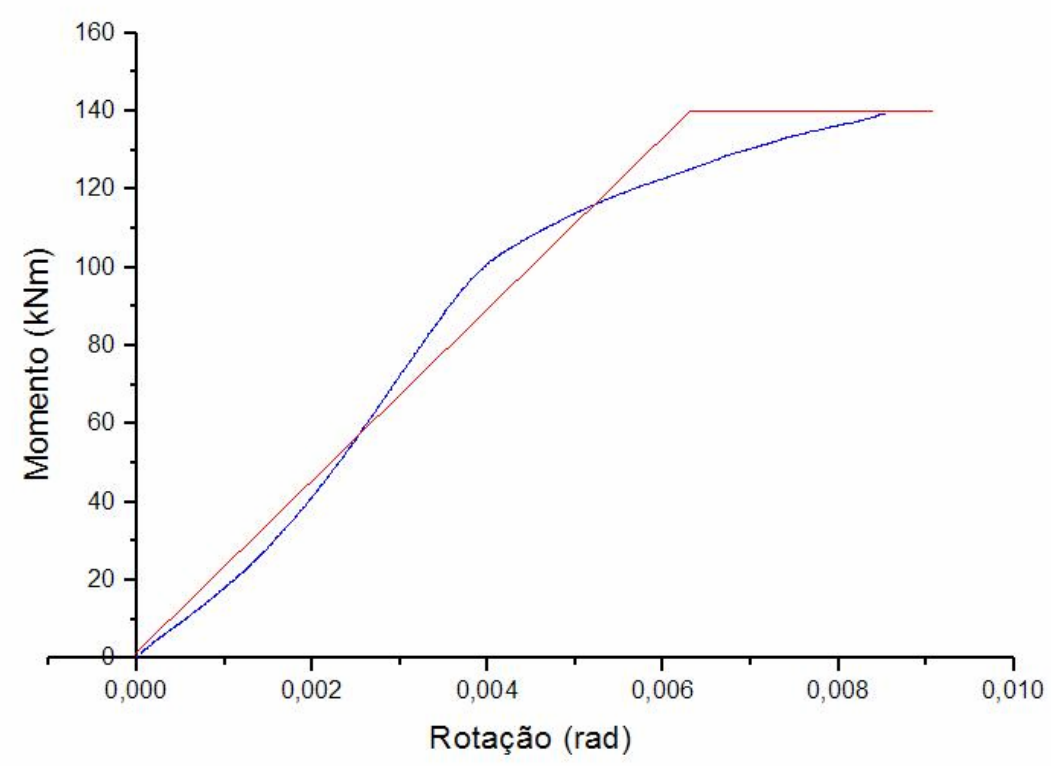

Figura 4.38- Curva bi-linear do modelo $\mathbf{E} /$ pilar $\mathbf{E}_{\mathbf{d}}$ a momento positivo obtida pelo último ciclo

A Tabela 4.7 apresenta os valores de rigidezes obtidos a momento fletor positivos tanto para o pilar $\mathrm{E}_{\mathrm{e}}$ como para o pilar $\mathrm{E}_{\mathrm{d}}$.

Tabela 4.7 - Rigidezes a momento fletor positivo do modelo E

\begin{tabular}{|c|c|c|c|}
\hline & & Pilar $\mathrm{E}_{\mathrm{e}}(\mathrm{MNm} / \mathrm{rad})$ & Pilar $E_{d}(\mathrm{MNm} / \mathrm{rad})$ \\
\hline \multirow{2}{*}{ Momento negativo } & Envoltória & 47,4 & 42,1 \\
\hline & Último ciclo & 28,0 & 22,8 \\
\hline
\end{tabular}

Com o objetivo de resumir todos os dados experimentais descritos acima as Figuras 4.39 e 4.40 apresentam as curvas momento-rotação do modelo I, pilar $\mathrm{E}_{\mathrm{e}}$ do modelo $\mathrm{E}$ e pilar $\mathrm{E}_{\mathrm{d}}$ do modelo $\mathrm{E}$ obtidos através das envoltórias e últimos ciclos respectivamente. 


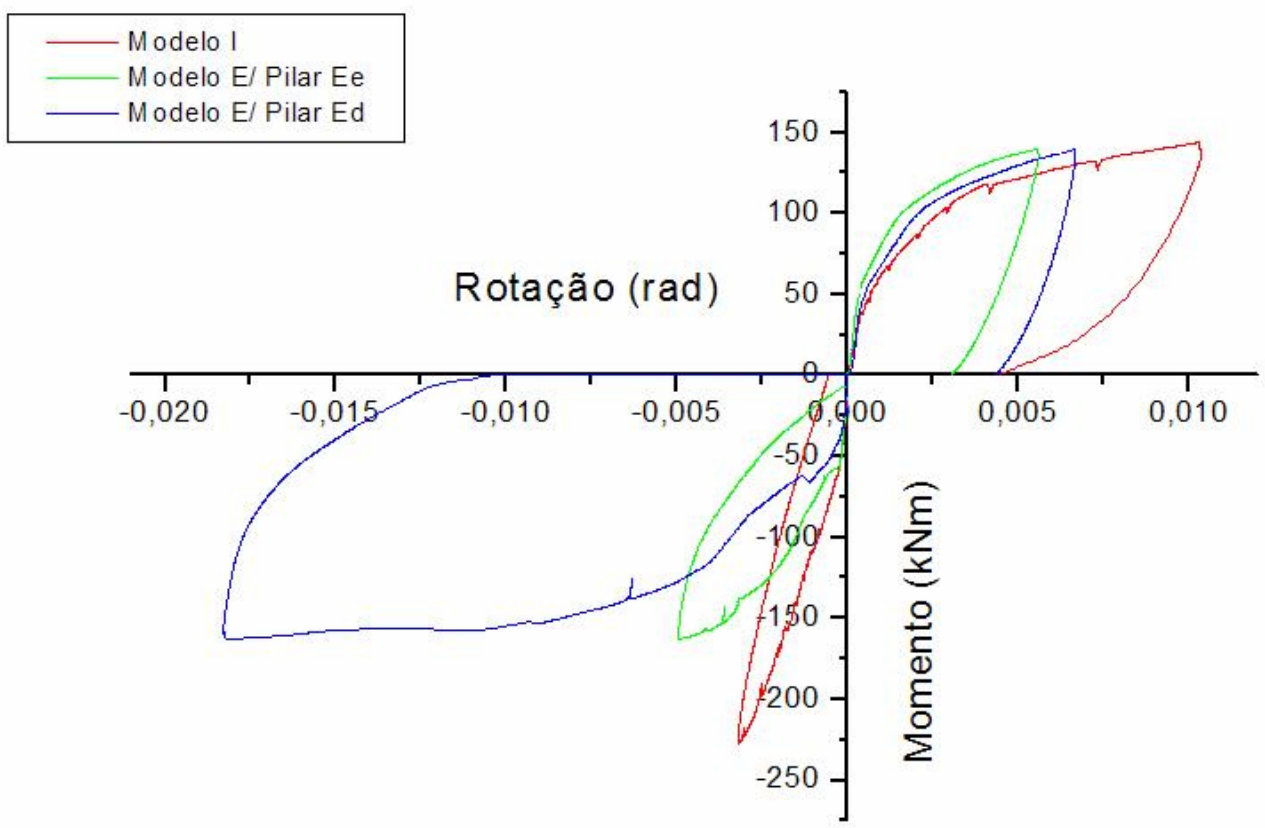

Figura 4.39 - Curva momento-rotação das envoltórias dos modelos I e E

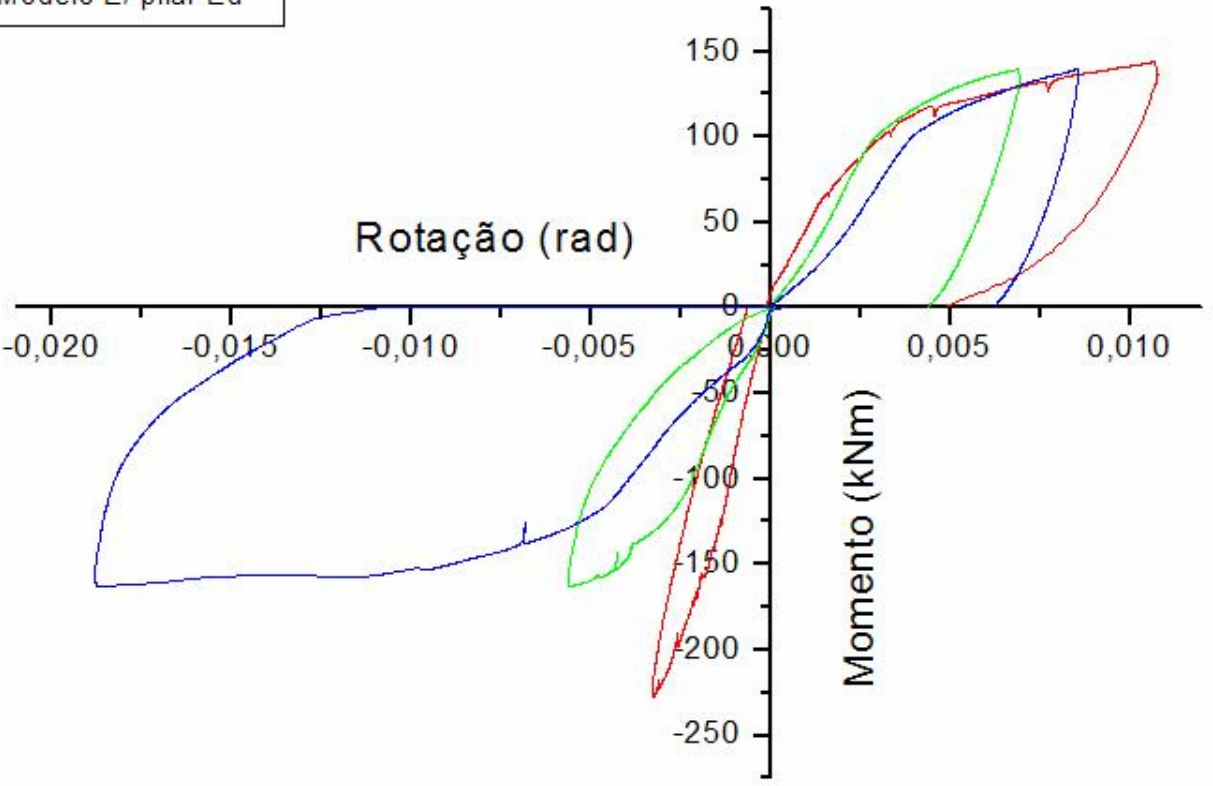

Figura 4.40- Curva momento-rotação dos últimos ciclos dos modelos I e E

Com base nestas figuras percebe-se que para momento fletor negativo a ligação do modelo I é capaz de suportar momentos 30\% maiores que a do modelo E enquanto que para o momento positivo a ligação possui praticamente o mesmo momento 
resistente. Isso se deve ao fato da armadura da capa não ser continua no $\mathrm{E}$ e na região do chumbador não ter sido feita nenhuma modificação.

Quanto às rigidezes a o momento fletor negativo nota-se que há uma variação bastante grande entre o pilar $E_{\mathrm{e}}$ e o pilar $\mathrm{E}_{\mathrm{d}}$ do modelo $\mathrm{E}$ e que ambas são inferiores a do modelo I. Devido à modificação da armação mencionada acima era esperado que o modelo E tivesse uma menor rigidez, porém acredita-se devido ao desprendimento da capa em relação ao pilar o modelo tenha rotacionado mais diminuindo sua rigidez, em especial para o pilar $\mathrm{E}_{\mathrm{d}}$ do modelo $\mathrm{E}$.

Para o momento fletor positivo as rigidezes do modelo I e E são próximas tendo inclusive pequena variação entre os pilares $E_{e}$ e $E_{d}$ do modelo E. Verifica-se que o modelo I apresenta-se com um comportamento mais dúctil, rotacionando-se mais para momentos da ordem de $120 \mathrm{kNm}$.

A Tabela 4.8 apresenta o resumo das rigidezes obtidos para ambos os modelo e sentido de momento.

Tabela 4.8 - Resumo das rigidezes dos modelos I e E

\begin{tabular}{|c|c|c|c|c|}
\hline & \multirow{2}{*}{$\begin{array}{c}\text { Modelo I } \\
\text { Rigidez } \\
(\mathrm{MNm} / \mathrm{rad})\end{array}$} & \multicolumn{2}{|c|}{$\begin{array}{c}\text { Modelo E } \\
\text { Rigidez (MNm/rad) }\end{array}$} \\
\hline & & & Pilar $E_{e}$ & Pilar $E_{d}$ \\
\hline \multirow{2}{*}{ Momento negativo } & Envoltória & 84,0 & 54,3 & 25,1 \\
\hline & Último ciclo & 79,6 & 40,7 & 20,4 \\
\hline \multirow{2}{*}{ Momento positivo } & Envoltória & 33,3 & 47,4 & 42,1 \\
\hline & Último ciclo & 28,8 & 28,0 & 22,8 \\
\hline
\end{tabular}

Outra forma de se obter a rigidez da ligação é através da comparação dos deslocamentos medidos pelos transdutores posicionados sobre os pilares com os deslocamentos destes obtidos através de simulação numérica.

A simulação numérica foi feita no programa ANSYS 8.0 que utiliza o método dos elementos finitos (MEF). Foi escolhido o elemento BEAM 23, descrito mais adiante na seção 4.4 deste capítulo, para simulação dos pilares e vigas. No caso das vigas foi feita uma simplificação considerando-a retangular e com um só módulo de elasticidade (da viga). Os módulos de elasticidades usados foram iguais aos obtidos experimentalmente e para considerar a fissuração na capa a momento negativo a rigidez 
das vigas foi de 0,6 EI. Para momento fletor positivo considerou-se o próprio EI por não haver fissuração no elemento

Para o modelo I, os deslocamentos que serviram para definição da rigidez foram dados pela média dos transdutores TD 47 e TD 48 e para o modelo E os transdutores TD 47 e TD 48 para o pilar $\mathrm{E}_{\mathrm{e}}$ e pilar $\mathrm{E}_{\mathrm{d}}$ respectivamente.

A Figura 4.41 mostra o esquema estrutural utilizado para cada modelo. Cabe mencionar apesar dos pilares do modelo $\mathrm{E}$ terem sofrido uma pequena rotação o esquema estrutural com 2 apoios restringindo o deslocamento horizontal é representativo. Isso foi comprovado comparando os resultados da simulação da estrutura com 1 apoio na base do pilar (caso extremo) e os 2 apoios. A variação dos valores de rigidezes foi inferior a $5 \%$.

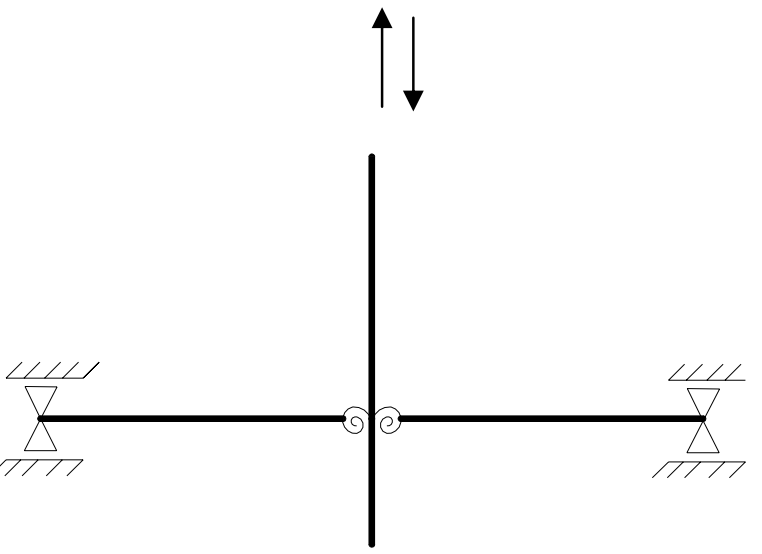

Modelo I

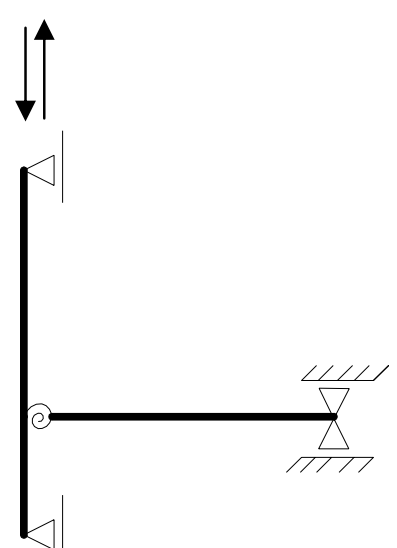

Modelo E

Figura 4.41 - Esquema estrutural da simulação numérica

Os resultados observados são mostrados na Tabela 4.9.

Tabela 4.9 - Rigidezes obtidas através da simulação numérica

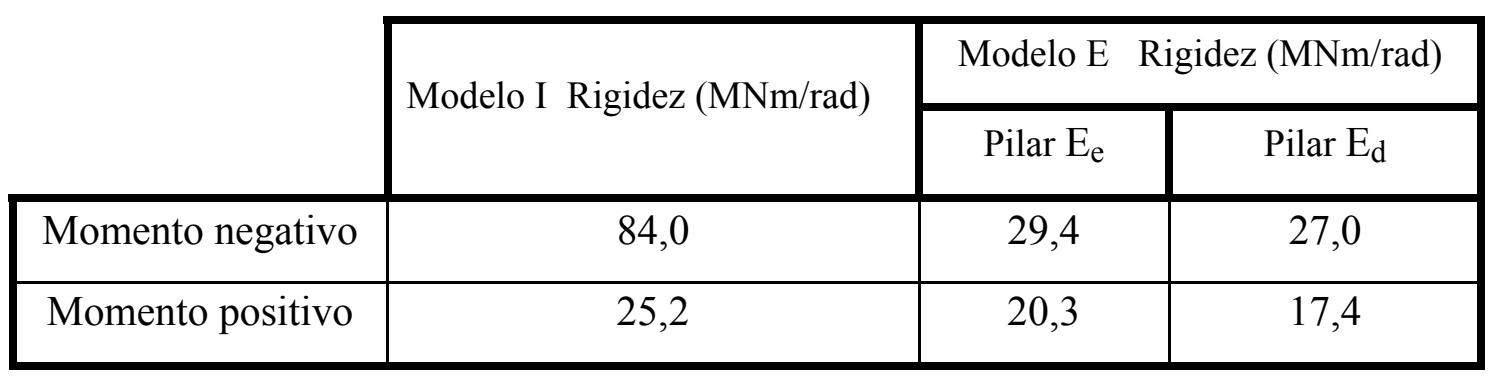


Comparando-se os resultados das rigidezes obtidos através das leituras dos relógios comparadores (para o último ciclo) com a simulação numérica calibrada pelas leituras dos transdutores dos pilares percebe-se que para o modelo I os valores estão bem próximos. No sentido de momento fletor negativo houve uma variação de $5,5 \%$ a mais para o modelo numérico a um momento de $90 \%$ do de plastificação. Para o momento positivo, para os mesmos $90 \%$ do momento de plastificação, esta variação foi de $10 \%$ só que a menos para o modelo numérico.

Para o pilar $\mathrm{E}_{\mathrm{e}}$ do modelo $\mathrm{E}$ os valores das rigidezes obtidos pela simulação numérica a um momento de $80 \%$ do momento de plastificação do último ciclo foram de 73 e $72 \%$ para o momento fletor negativo e positivo respectivamente. Para o pilar $E_{d}$ os valores foram de $32 \%$ a mais para o momento negativo e $76 \%$ a menos para o momento fletor positivo.

\subsection{MODELO ANALÍTICO}

Nesta seção propõem-se um modelo analítico para o cálculo dos momentos de plastificação da ligação, separando-o para o caso de momento fletor negativo e positivo.

\subsubsection{Momento fletor negativo}

A ligação ao ser submetida a momento fletor negativo tem o seguinte esquema de forças em equilíbrio mostrado na Figura 4.42.

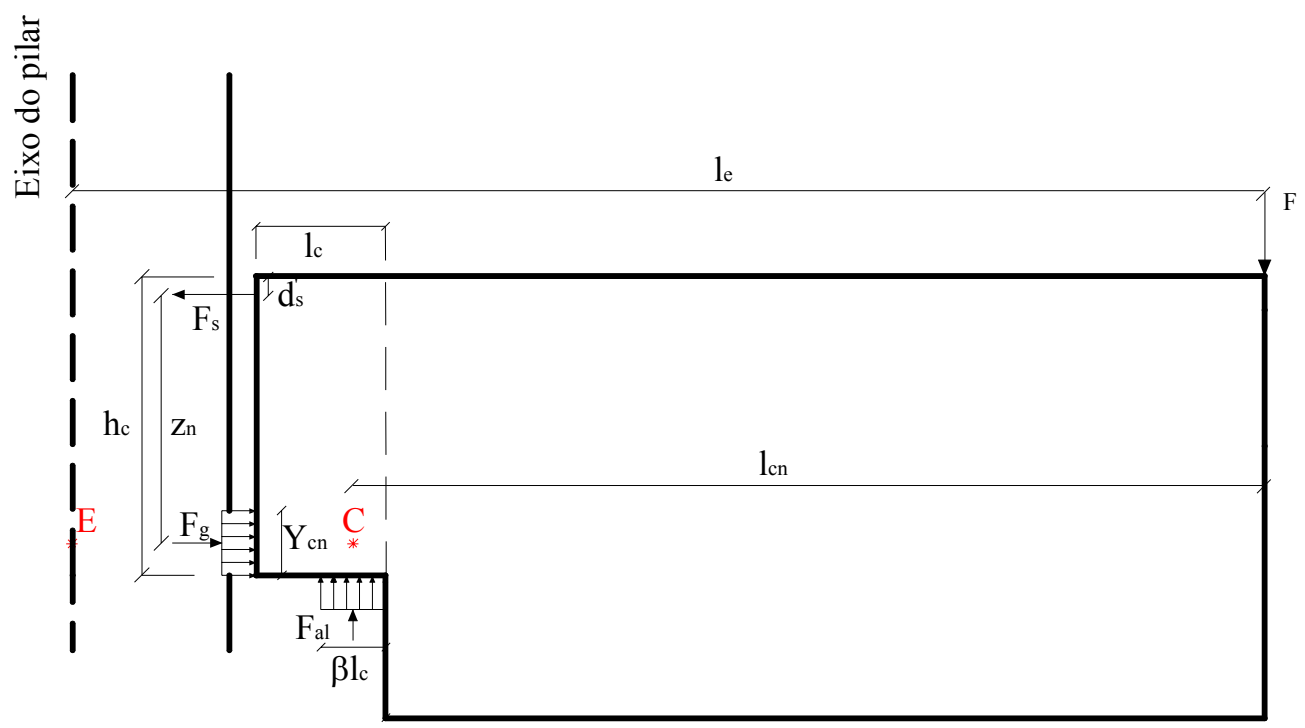


Nota-se que o esforço de compressão sobre o chumbador foi desprezado. Através do equilíbrio de forças temos:

$$
\begin{array}{ll}
\sum F_{x}=0 \quad F_{s}=F_{g}, \text { sendo } F_{g}=f_{c g} \cdot Y_{c n} \cdot b \text { e } F_{s}=f_{y} \cdot A_{s n} \\
\sum F_{y}=0 \quad F=F_{a l}, \text { sendo } F_{a l}=f_{c, a l} \cdot \beta \cdot l_{c} \cdot b \\
\sum M_{c}=0 \quad F_{s} \cdot z_{n}-F \cdot l_{c n}=0
\end{array}
$$

Onde:

$$
\begin{aligned}
& F=\text { Força aplicada na viga } \\
& F_{a l} \quad=\text { Força de compressão na almofada de apoio } \\
& F_{s} \quad=\text { Força de tração na armadura da capa de concreto } \\
& F_{g} \quad=\text { Força de compressão do graute entre a viga e o pilar } \\
& f_{c, a l} \quad=\text { Resistência à compressão da almofada de apoio } \\
& l_{c} \quad=\text { Comprimento do consolo } \\
& b \\
& f_{c g} \quad=\text { Largura do consolo } \\
& f_{y} \quad=\text { Tensão de escoamento do aço } \\
& A_{s n} \quad=\text { Área da armadura da capa de concreto } \\
& z_{n} \quad=\text { Braço de alavanca para momento fletor negativo }
\end{aligned}
$$

Através das eq. (4.11) e (4.12) respectivamente obtemos:

$Y_{c n}=\frac{f_{y} \cdot A_{s n}}{f_{c g} \cdot b}$

$$
\beta=\frac{F}{f_{c, a l} \cdot l_{c} \cdot b}
$$

Com base na Figura 4.42 verifica-se que o máximo momento fletor da ligação ocorre no ponto $\mathrm{C}$, onde a força de compressão na almofada equilibra a força externa 
aplicada. Porém para modelagem de pórticos esta configuração, com o posicionamento da mola representante da semi-rigidez no ponto $C$, não é a mais adequada sendo preferível posiciona lá no eixo do pilar (ponto E). A Figura 4.43 demonstra a forma de idealização da ligação para ambas às situações de modelagem.

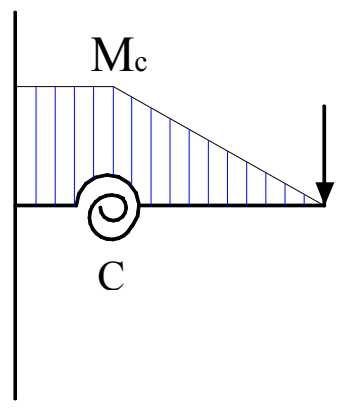

Mola no ponto $\mathrm{C}$

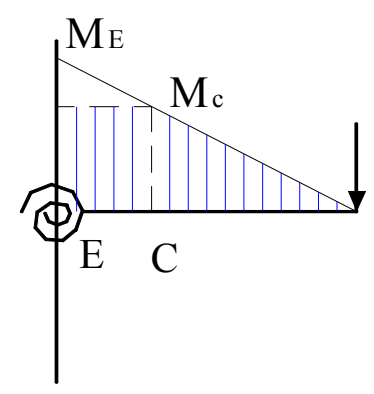

Mola no ponto $\mathrm{E}$

Figura 4.43- Diagrama para modelagem do momento negativo

O valor do momento no eixo do pilar foi obtido através da relação entre os braços de alavanca do ponto $\mathrm{C}$ e $\mathrm{E}$ como mostram a eq. (4.16) e a eq. (4.17).

$$
\begin{aligned}
& M_{E}=\frac{M_{c} \cdot l_{e}}{l_{c n}} \\
& M_{E}=f_{y} \cdot A_{s n} \cdot z_{n} \cdot \frac{l_{e}}{l_{c n}}
\end{aligned}
$$

Sendo:

$$
\begin{aligned}
& z_{n}=h_{c}-d_{s}^{\prime}-\frac{Y_{c n}}{2} \\
& l_{c n}=\left(l_{e}-\frac{b_{\text {pilar }}}{2}\right)-l_{c}+\frac{\beta \cdot l_{c}}{2}
\end{aligned}
$$

Onde:

$$
\begin{aligned}
& l_{c n} \quad=\text { Comprimento entre o ponto de aplicação da carga ao ponto C } \\
& l_{e} \quad=\text { Comprimento entre o ponto de aplicação da carga e o eixo do pilar } \\
& h_{c} \quad=\text { Altura da seção }
\end{aligned}
$$


$d_{s}^{\prime} \quad=$ Centro de gravidade da armadura da capa de concreto

$b_{\text {pilar }}=$ Largura do pilar

$M_{c} \quad=$ Momento no ponto $\mathrm{C}$

$M_{E} \quad=$ Momento no ponto $\mathrm{E}$

\subsubsection{Momento fletor positivo}

Para o cálculo do momento de plastificação da ligação sob a ação de momentos positivos, o chumbador foi considerado submetido a duas forças: a de tração e a uma parcela do efeito de pino, uma vez que o este não esta na posição vertical.

A escolha do percentual a ser considerado do efeito de pino foi baseada em resultados experimentais. Foram calculados, separadamente, os momentos devido à tração e ao efeito de pino caso o chumbador tivesse na posição vertical e subtraído do valor experimental o momento devido apenas à tração. A diferença corresponde parcela do efeito de pino. Os valores dos momentos para cada efeito separadamente foram feitos através de simplificações da eq. (4.24) apresentada logo abaixo.

O sistema de equilíbrio da ligação é mostrado na Figura 4.44.

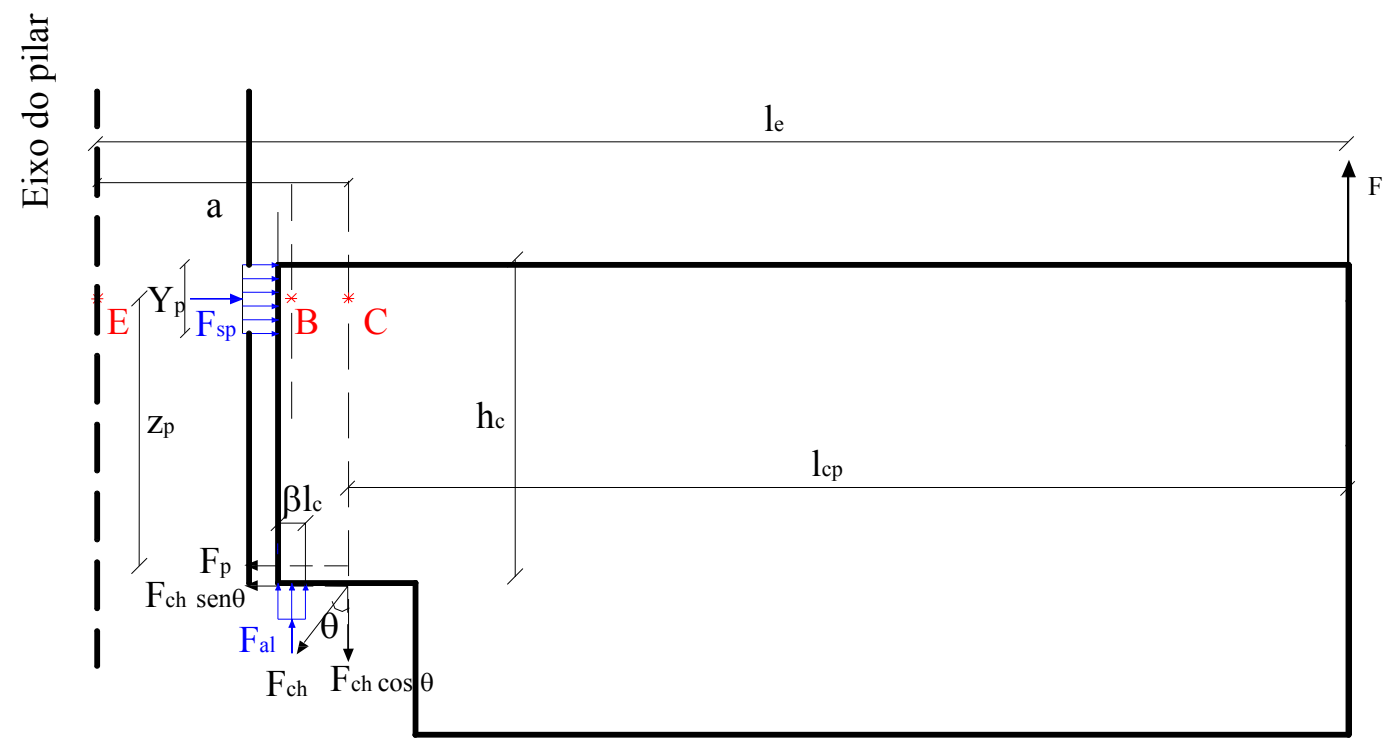

Figura 4.44 - Sistema de forças em equilíbrio para momento positivo 


$$
\begin{gathered}
\sum F_{x}=0, \quad F_{s p}=F_{c h} \cdot \operatorname{sen}(\theta)+F_{p}, \text { sendo } F_{s p}=f_{c c} \cdot b \cdot Y_{p} \\
\sum F_{y}=0 \quad F=F_{c h} \cdot \cos (\theta)-F_{a l}, \text { sendo } F_{c h}=f_{y} \cdot A_{s c h} \\
F_{a l}=f_{c, a l} \cdot b \cdot \beta \cdot l_{c} \\
\sum M_{c}=0 \quad F \cdot l_{c p}-F_{c h} \cdot \operatorname{sen}(\theta) \cdot z_{p}-F_{p} \cdot z_{p}=0
\end{gathered}
$$

Através da eq. (4.18) e eq. (4.19) podemos determinar:

$$
\begin{gathered}
Y_{p}=\frac{f_{y} \cdot A_{s c h} \cdot \operatorname{sen}(\theta)+F_{p}}{f_{c c} \cdot b} \\
\beta=\frac{f_{y} \cdot A_{s c h} \cdot \cos (\theta)-F}{f_{c, a l} \cdot b \cdot l_{c}}
\end{gathered}
$$

Onde:

$F_{s p} \quad=$ Força de compressão do concreto entre o pilar e a laje pré-moldada

$F_{c h} \quad=$ Força dos 2 chumbadores

$F_{p} \quad=$ Força responsável pela formação da segunda rótula plástica no chumbador

$f_{c c} \quad=$ Resistência do concreto entre as lajes pré-moldadas

$A_{\text {sch }}=$ Área dos 2 chumbadores

$l_{e} \quad=$ Comprimento da força aplicada até o eixo do pilar

$l_{c p} \quad=$ Comprimento entre o ponto de aplicação da carga e o chumbador

$\theta \quad=$ Inclinação do chumbador

$z_{p} \quad=$ Braço de alavanca para momento fletor positivo

$a \quad=$ Distância entre o eixo do pilar e o chumbador

Observa-se que com a contribuição da almofada de apoio o diagrama de momentos difere do apresentado na Figura 4.43 para momento fletor negativo. Há agora um trecho decrescente entre os pontos C e B como mostra a Figura 4.45. 


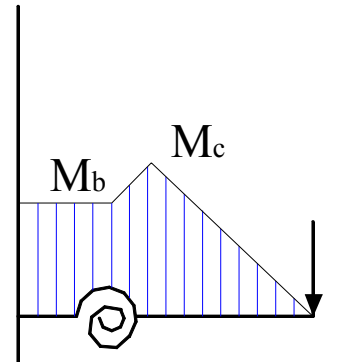

B C

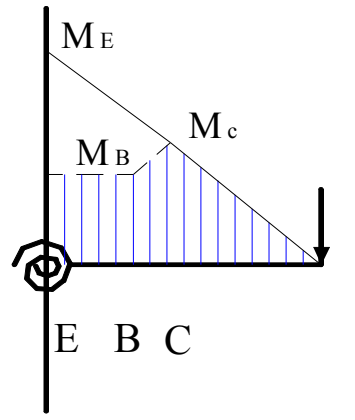

Mola no ponto E

Mola no ponto B

Figura 4.45- Diagrama de momentos para modelagem do momento positivo

Seguindo o mesmo raciocínio para modelagem da ligação que feito anteriormente o momento de plastificação será dado no ponto E através de uma relação entre os braços de alavanca do ponto $\mathrm{C}$ e E. Preferiu-se o usar o ponto C ao invés do $\mathrm{B}$ por ser este um ponto de máximo.

A equação do momento $M_{E}$ é apresentada abaixo

$$
\begin{aligned}
& M_{E}=\frac{M_{c} \cdot l_{e}}{l_{c p}} \\
& M_{E}=\left(F_{p} \cdot z_{p} \cdot \eta_{p}+F_{c h} \cdot \operatorname{sen}(\theta) \cdot z_{p}\right) \cdot \frac{l_{e}}{l_{c p}}
\end{aligned}
$$

sendo:

$$
\begin{aligned}
& F_{p}=2 \cdot c \cdot \phi_{c h}^{2} \cdot \sqrt{f_{y} \cdot f_{c c, \max }} \\
& c=c_{1} \cdot c_{r} \\
& z_{p}=h_{c}-\frac{Y_{p}}{2} \\
& l_{c p}=l_{e}-a
\end{aligned}
$$

$\eta_{p} \quad=$ Parcela do efeito de pino

$c_{1}=1,03$ [ausência de atrito na interface almofada de apoio/viga conforme ENGSTROM (1992)]

$c_{r}=1,21 \quad$ [caso de restrição parcial ao giro do chumbador conforme 


\section{ENGSTROM (1992)]}

$\phi_{c h} \quad=$ Diâmetro do chumbador

$f_{c c \text {, max }}=$ Maior valor de resistência do concreto/graute entre os elementos nos qual o chumbador está inserido (corpos de prova cúbicos)

A Tabela 4.10 mostra as equações dos momentos últimos para momento fletor negativo e positivo.

Tabela 4.10- Resumo das equações dos momentos de plastificação

\begin{tabular}{|c|c|}
\cline { 2 - 2 } \multicolumn{1}{c|}{} & Momento de plastificação \\
\hline Momento negativo & $M_{E}=f_{y} \cdot A_{s n} \cdot z_{n} \cdot \frac{l_{e}}{l_{c n}}$ \\
\hline Momento positivo & $M_{E}=\left(F_{p} \cdot z_{p} \cdot \eta_{p}+F_{c h} \cdot \operatorname{sen}(\theta) \cdot z_{p}\right) \cdot \frac{l_{e}}{l_{c p}}$ \\
\hline
\end{tabular}

\subsubsection{Comparação do modelo analítico com os resultados experimentais}

Utilizando os dados de entrada reunidos nas Tabelas 4.11 e 4.12 e de posse das equações apresentadas na Tabela 4.10 calculou-se os momentos de plastificação teóricos da ligação.

Tabela 4.11 - Dados de entrada para obtenção do momento de plastificação negativo

\begin{tabular}{|c|c|c|}
\hline & \multicolumn{2}{|c|}{ Momento Negativo } \\
\hline Parâmetro & Modelo I & Modelo E \\
\hline$f_{c, a l}$ & $28 \mathrm{MPa}$ & $30,55 \mathrm{MPa}$ \\
\hline$l_{c}$ & $19 \mathrm{~cm}$ & $19 \mathrm{~cm}$ \\
\hline$b$ & $30 \mathrm{~cm}$ & $30 \mathrm{~cm}$ \\
\hline$f_{c g}$ & $37,15 \mathrm{MPa}$ & $45,51 \mathrm{MPa}$ \\
\hline$f_{y}$ & $593 \mathrm{MPa}$ & $593 \mathrm{MPa}$ \\
\hline$A_{s n}$ & $9,62 \mathrm{~cm}^{2}$ & $6,48 \mathrm{~cm}^{2}$ \\
\hline$l_{b}$ & $157,50 \mathrm{~cm}$ & $157,50 \mathrm{~cm}$ \\
\hline$h_{c}$ & $45 \mathrm{~cm}$ & $45 \mathrm{~cm}$ \\
\hline$d_{s}^{\prime}$ & $4,47 \mathrm{~cm}$ & $5,09 \mathrm{~cm}$ \\
\hline
\end{tabular}


Tabela 4.12 - Dados de entrada para obtenção do momento de plastificação positivo

\begin{tabular}{|c|c|c|}
\cline { 2 - 3 } \multicolumn{1}{c|}{} & \multicolumn{2}{c|}{ Momento Positivo } \\
\hline Parâmetro & Modelo I & Modelo E \\
\hline$f_{c c, \max }$ & $50,90 \mathrm{MPa}$ & $53,14 \mathrm{MPa}$ \\
\hline$f_{c c}$ & $33,40 \mathrm{MPa}$ & $40,74 \mathrm{MPa}$ \\
\hline$A_{s c h}$ & $6,28 \mathrm{~cm}^{2}$ & $6,28 \mathrm{~cm}^{2}$ \\
\hline$l_{p}$ & $157,50 \mathrm{~cm}$ & $157,50 \mathrm{~cm}$ \\
\hline$\phi_{c h}$ & $2 \mathrm{~cm}$ & $2 \mathrm{~cm}$ \\
\hline$a$ & $26 \mathrm{~cm}$ & $26 \mathrm{~cm}$ \\
\hline $\mathrm{b}$ & $16 \mathrm{~cm}$ & $16 \mathrm{~cm}$ \\
\hline
\end{tabular}

Vale salientar foi utilizado $f_{y}$ na comparação com os dados experimentais por, em ambos os sentidos de momentos, as armaduras terem escoado.

Para momento fletor negativo os valores teóricos de plastificação foram de -285 kNm para o modelo I e $-195,7 \mathrm{kNm}$ para o modelo E. Comparando com os dados experimentais estes valores equivalem $125 \%$ e $120 \%$ dos valores experimentais observados. Cabe mencionar que os momentos teóricos de plastificação encontrado foram para o ponto E. Se comparados ao ponto C estes valores são de -216 e -148 kNm (modelo I e E respectivamente) o que corresponde a 95 e $91 \%$ dos momentos experimentais obtidos.

Para o momento fletor positivo os dados experimentais serviram para determinação da parcela do efeito de pino em chumbadores inclinados, uma vez que não foi encontrada na literatura uma forma para sua obtenção.

Para o modelo I o momento de plastificação devido apenas à tração no chumbador foi de $129,1 \mathrm{kNm}$ enquanto que o momento experimental foi de $144,1 \mathrm{kNm}$. Esta diferença representa a parcela do efeito de pino e equivale a $17 \%$ do valor calculado estando o chumbador submetido apenas ao efeito de pino.

Já para o modelo E o momento de plastificação devido apenas à tração no chumbador foi de $131,3 \mathrm{kNm}$ enquanto que o momento experimental foi de $139,3 \mathrm{kNm}$. A diferença representante da parcela do efeito de pino equivale a $9 \%$ do valor calculado caso ocorresse só o efeito de pino.

As Tabelas 4.13 e 4.14 resumem os resultados obtidos analítica e experimentalmente para o caso do momento fletor negativo e os cálculos dos 
percentuais do efeito de pino em cada modelo para o momento fletor positivo respectivamente.

Tabela 4.13 - Resumo da comparação entre valores analíticos e experimentais para momento negativo

\begin{tabular}{|c|c|c|c|c|c|c|}
\cline { 2 - 6 } \multicolumn{1}{c|}{} & \multicolumn{3}{c|}{ Modelo I } & \multicolumn{3}{c|}{ Modelo E } \\
\cline { 2 - 6 } & Analítico & Experimental & $\begin{array}{c}\text { Diferença } \\
(\%)\end{array}$ & Analítico & Experimental & $\begin{array}{c}\text { Diferença } \\
(\%)\end{array}$ \\
\hline $\begin{array}{c}\text { Momento } \\
\text { negativo } \\
(\mathrm{kNm})\end{array}$ & -285 & -227 & 25 & $-195,7$ & $-162,2$ & 20 \\
\hline
\end{tabular}

Tabela 4.14 - Resumo dos valores analíticos para momento fletor positivo

\begin{tabular}{|c|c|c|c|c|c|c|c|c|}
\cline { 2 - 8 } \multicolumn{1}{c|}{} & \multicolumn{4}{c|}{ Modelo I } & \multicolumn{4}{c|}{ Modelo E } \\
\cline { 2 - 8 } & Tração & E. Pino & Exper. & $\begin{array}{c}\% \\
\text { Pino }\end{array}$ & Tração & E.Pino & Exper. & $\begin{array}{c}\% \\
\text { Pino }\end{array}$ \\
\hline $\begin{array}{c}\text { Momento } \\
\text { positivo }(\mathrm{kNm})\end{array}$ & 129,1 & 89,9 & 144,1 & 17 & 131,3 & 92,5 & 139,3 & 9 \\
\hline
\end{tabular}

De posse destas informações podemos determinar, através da média dos modelos I e E, que a parcela atuante do efeito de pino na ligação estudada é de $13 \%$.

\subsection{SIMULAÇÃO NUMÉRICA DE UMA ESTRUTURA TÍPICA DE CONCRETO PRÉ-MOLDADO}

Com o objetivo de avaliar a influência da semi-rigidez da ligação viga-pilar estudada no comportamento da estrutura foi realizada uma simulação numérica, via ANSYS, de uma estrutura típica de concreto pré-moldado.

A análise promovida na estrutura foi limitada à estabilidade global, inicialmente verificando os momentos atuantes e os deslocamentos ao se considerar a ligação como articulada, semi-rígida ou rígida e posteriormente verificando quantos pavimentos poderiam ser acrescidos na estrutura até atingir os momentos de plastificação da ligação. 
A Figura 4.46 mostra o pórtico de referência definido composto por três vãos de 6 metros e dois pavimentos com 4 metros de altura cada. Sobre a estrutura foram definidos dois tipos diferentes de carregamento. No primeiro atuam um carregamento vertical referente ao peso ao peso próprio $(\mathrm{G})$ e sobrecarga de utilização $(\mathrm{Q})$ e um carregamento horizontal para simulação de vento (W) e no segundo apenas o peso próprio da estrutura e o vento.

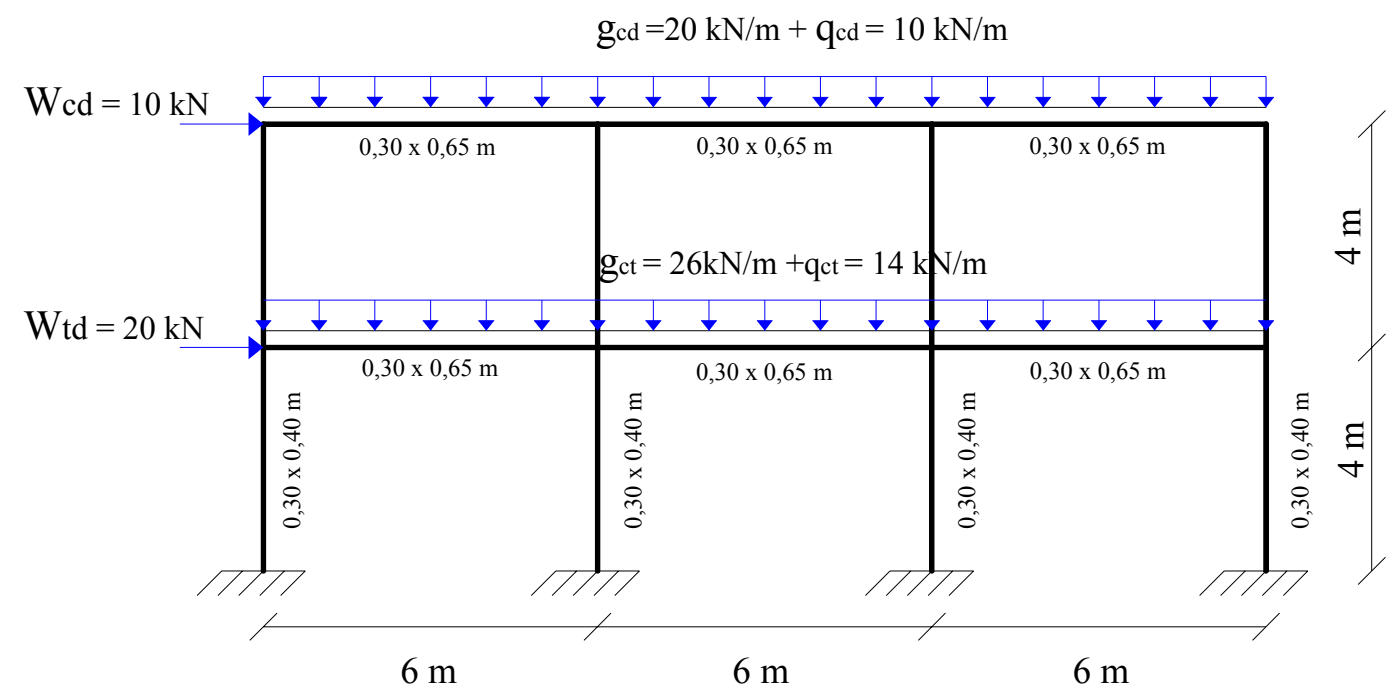

Figura 4.46 - Pórtico de referência para simulação

Com o intuito de simular as etapas construtivas, a estrutura foi considerada articulada quando atuante o peso próprio e semi-rígida depois de feita às ligações entre os elementos e atuando as cargas de vento e sobrecarga de utilização. A Figura 4.47 apresenta o esquema estático do pórtico para os dois casos.

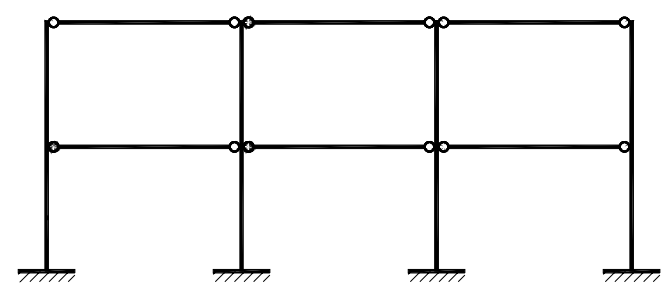

Ligação articulada $(\mathrm{G})$

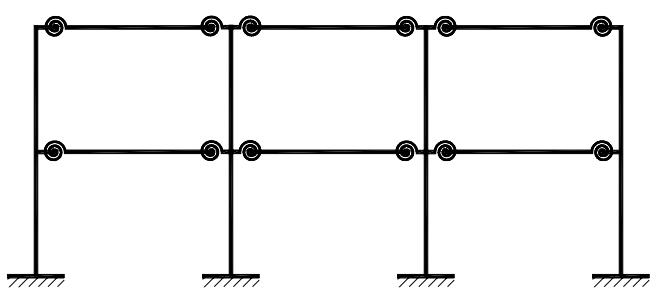

Ligação semi-rígida $(\mathrm{Q}+\mathrm{W})$

Figura 4.47 - Esquema estático da estrutura 
Para a verificação da necessidade de consideração dos efeitos de $2^{\circ}$ ordem foi utilizado o processo do coeficiente $\gamma_{z}$ definido por:

$$
\gamma_{z}=\frac{1}{1-\frac{\Delta M_{d}}{M_{1 d}}}
$$

$\Delta M_{d}=$ Soma dos produtos de todas as forças verticais atuantes na estrutura pelos seus deslocamentos horizontais de seus respectivos pontos de aplicação

$M_{1 d} \quad=$ Momento de tombamento dado pela soma dos momentos de todas as forças horizontais em relação à base da estrutura

Para o cálculo do $\Delta M_{d}$ e $M_{1 d}$ as forças foram majoradas em 1,4.

Segundo a norma NBR 6118:2003 pode-se considerar a estrutura de nós fixos, ou seja, os efeitos globais de segunda ordem desprezíveis, para $\gamma_{z}<1,1$. Para valores de $\gamma_{z}$ entre 1,1 e 1,3 os esforços de $1^{\circ}$ ordem devem ser multiplicados por $0,95 \cdot \gamma_{z}$.

A simulação numérica foi realizada no programa ANSYS 8.0 disponível na Escola de Engenharia de São Carlos (EESC-USP) considerando os pilares e vigas representadas pelo elemento BEAM 23 e a ligação viga-pilar pelo elemento COMBIN 39.

O elemento BEAM 23 possui três graus de liberdade por nó e resiste a ações de compressão, tração e momento fletor. Já o elemento COMBIN 39 é um elemento não linear com três graus de liberdade por nó e que além de resistir às ações do BEAM 23 também permite a análise da torção. Seus dados de entrada são os pontos de uma curva força - deslocamento ou momento - rotação.

Os dados de entrada das características geométricas e dos materiais utilizados encontram-se na Tabela 4.15. Vale a pena ressaltar que apesar da viga ser de seção T e apresentar materiais com módulo de elasticidades diferentes, para efeito de simplificação as seções das vigas foram consideradas retangulares e com um só módulo de elasticidade. 
Tabela 4.15 - Características geométricas e dos materiais dos elementos

\begin{tabular}{|l|c|c|}
\hline Elemento & Pilar & Viga \\
\hline Seção Transversal $\left(\mathrm{m}^{2}\right)$ & $0,30 \times 0,40$ & $0,30 \times 0,65$ \\
\hline Altura $(\mathrm{m})$ & 0,4 & 0,65 \\
\hline Área $\left(\mathrm{m}^{2}\right)$ & 0,12 & 0,195 \\
\hline Momento de inércia I $\left(\mathrm{m}^{4}\right)$ & 0,0016 & 0,00687 \\
\hline Material & concreto & concreto \\
\hline Módulo de elasticidade E $(\mathrm{GPa})$ & 33 & 33 \\
\hline Coeficiente de Poisson $v$ & 0,2 & 0,2 \\
\hline
\end{tabular}

Para levar em consideração a não linearidade física foi feita uma redução nos módulos de elasticidade dos elementos segundo a Tabela 4.16 .

Tabela 4.16 - Fator de redução do módulo de elasticidade para consideração da não linearidade física

\begin{tabular}{|c|c|c|}
\hline \multirow{2}{*}{ Tipo de ligação viga-pilar } & \multicolumn{2}{|c|}{ Fator de redução } \\
\cline { 2 - 3 } & Vigas & Pilares \\
\hline Articulada & 1 & 0,4 \\
\hline Semi-rígida & 0,6 & 0,6 \\
\hline Rígida & 0,4 & 0,8 \\
\hline
\end{tabular}

Os valores de rigidez e momento de plastificação da ligação usados na simulação são apresentados na Tabela 4.17. Os momentos de plastificação foram obtidos através do modelo analítico apresentado na seção 4.3 deste capítulo considerando os elementos pré-moldados com resistência à compressão de $35 \mathrm{MPa}$, os elementos moldados em loco com resistência de $25 \mathrm{MPa}$ e os aços com resistência a tração de $500 \mathrm{MPa}$ e módulo de elasticidade de $210 \mathrm{GPa}$. Para o concreto foi introduzido o coeficiente de ponderação de 1,4 e para o aço de 1,15.

Os valores de rigidez foram obtidos dividindo os momentos de plastificação descritos acima pelas rotações experimentais máximas do último ciclo. Para o momento fletor positivo foi feita uma média entre as rotações do modelo I e E. 
Tabela 4.17 - Rigidezes e momentos de plastificação utilizados na simulação numérica

\begin{tabular}{|c|c|c|c|c|}
\hline \multirow{2}{*}{} & \multicolumn{2}{|c|}{ Modelo I } & \multicolumn{2}{c|}{ Modelo E } \\
\cline { 2 - 5 } & M. negativo & M. positivo & M. negativo & M. positivo \\
\hline $\mathrm{Ko}(\mathrm{MNm} / \mathrm{rad})$ & 70,6 & 18,17 & 34,6 & 18,17 \\
\hline $\mathrm{M}_{\mathrm{y}}(\mathrm{kNm})$ & 201 & 99,1 & 138,5 & 99,1 \\
\hline
\end{tabular}

Nas Figuras 4.48, 4.49 e 4.50 são apresentados os diagramas de momento fletor do pórtico de referência para as situações de ligações articuladas, semi-rígidas e rígidas. Para a ligação rígida foram feitas duas considerações: $\mathrm{G}$ articulado e $\mathrm{W}+\mathrm{Q}$ rígido e $\mathrm{G}$ $+\mathrm{Q}+\mathrm{W}$ rígido (monolítico).

A obtenção do diagrama de momentos da ligação semi-rígida foi composta pela soma dos momentos devido ao peso próprio (articulado) e a sobrecarga e vento (semirígido). As Figuras 4.51 e 4.52 mostram os diagramas individualmente e sua soma.

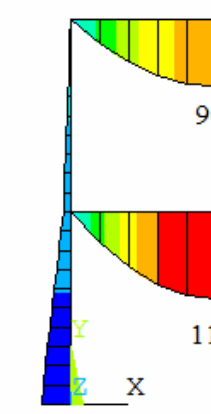

$-40,101$

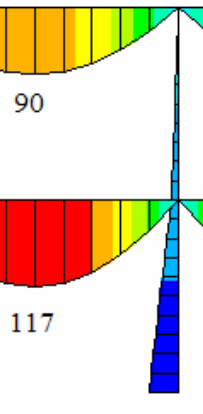

$-40,101$

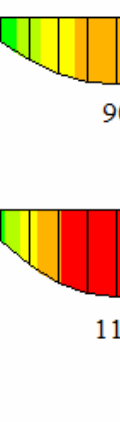

117
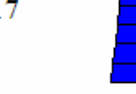

$-40,101$

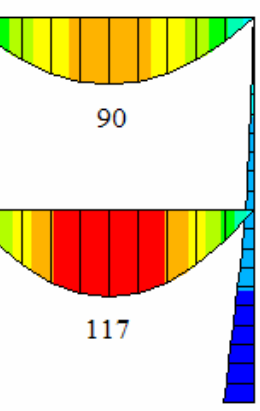

$-40,101$
Legenda $(\mathrm{kNm})$

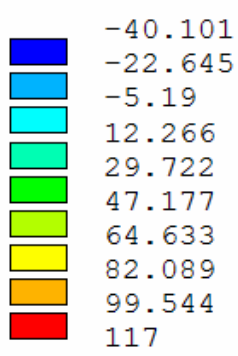

Carregamento $\mathrm{G}+\mathrm{W}$

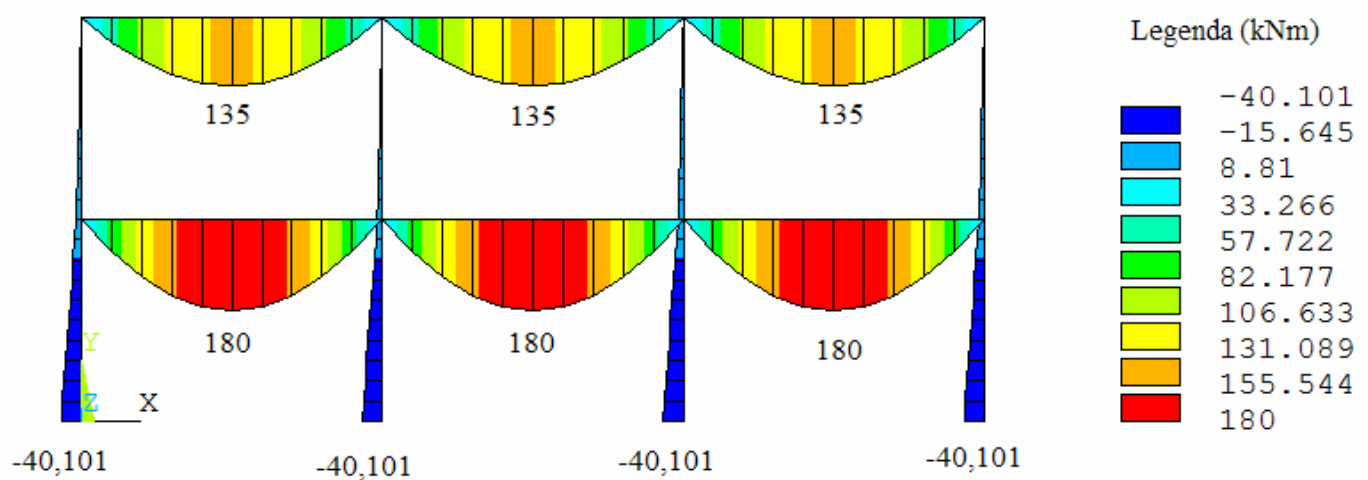

Carregamento $\mathrm{G}+\mathrm{W}+\mathrm{Q}$

Figura 4.48 - Ligação articulada 


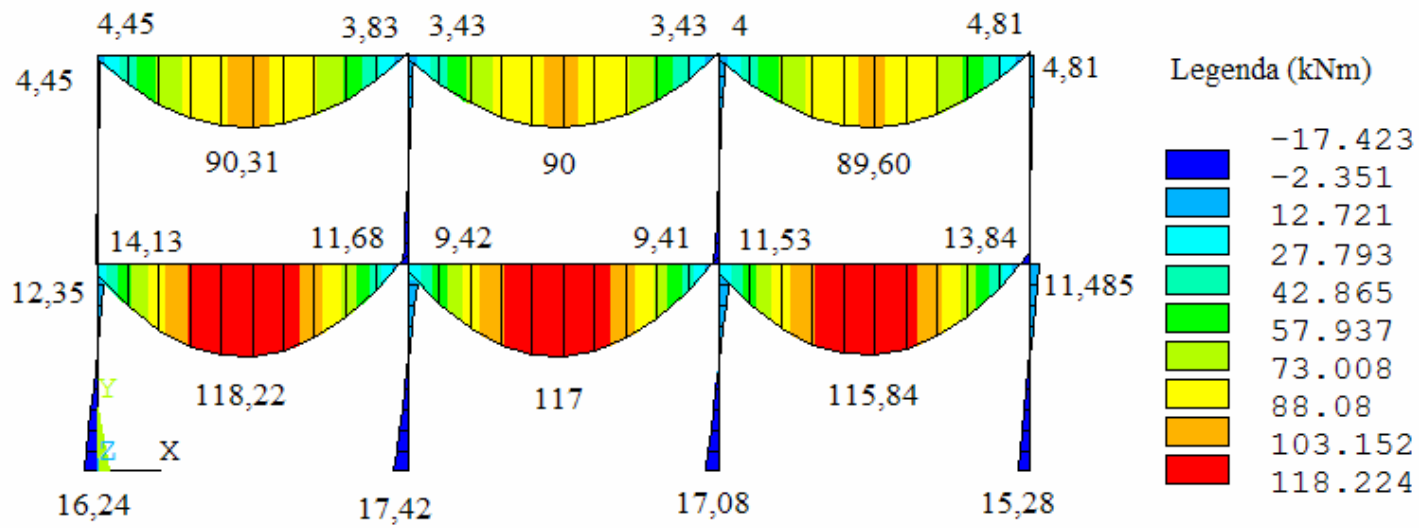

Carregamento G (articulado) $+\mathrm{W}$

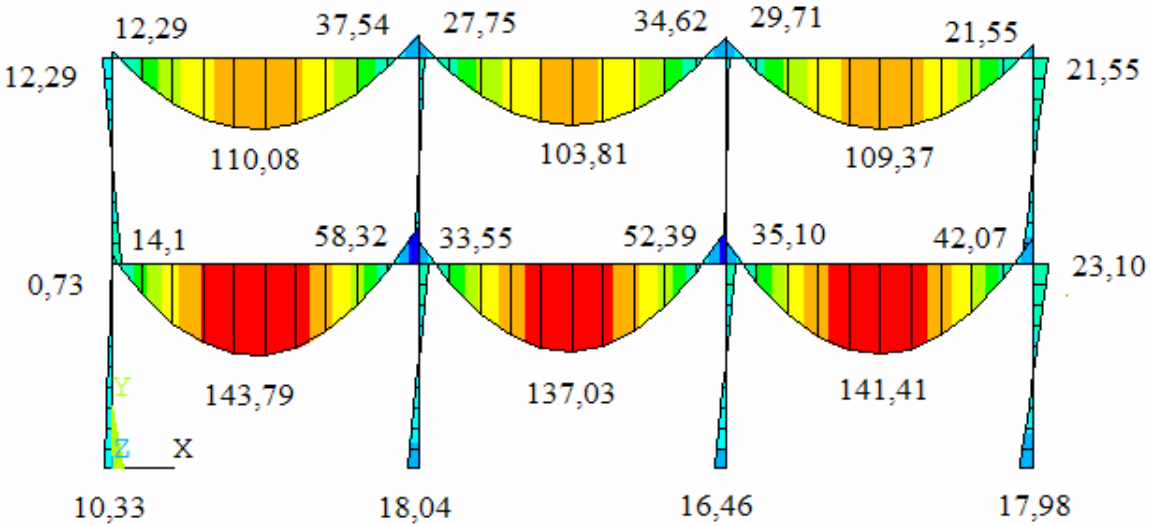

Legenda $(\mathrm{kNm})$

$-58.32$

$-35.863$

$-13.406$

9.051

31.508

53.965

76.422

98.879

121.336

143.793

Carregamento G (articulado) + W $+\mathrm{Q}$

Figura 4.49 - Ligação rígida com $\mathrm{G}$ articulado

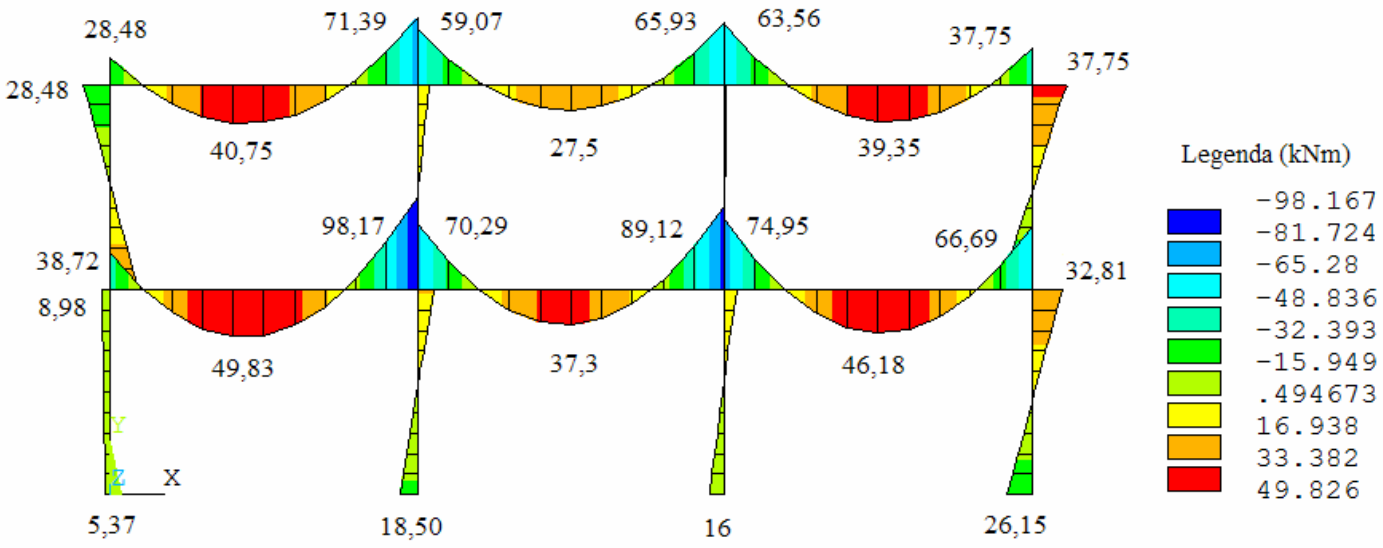

Carregamento $\mathrm{G}+\mathrm{W}$

Figura 4.50 - Ligação monolítica 


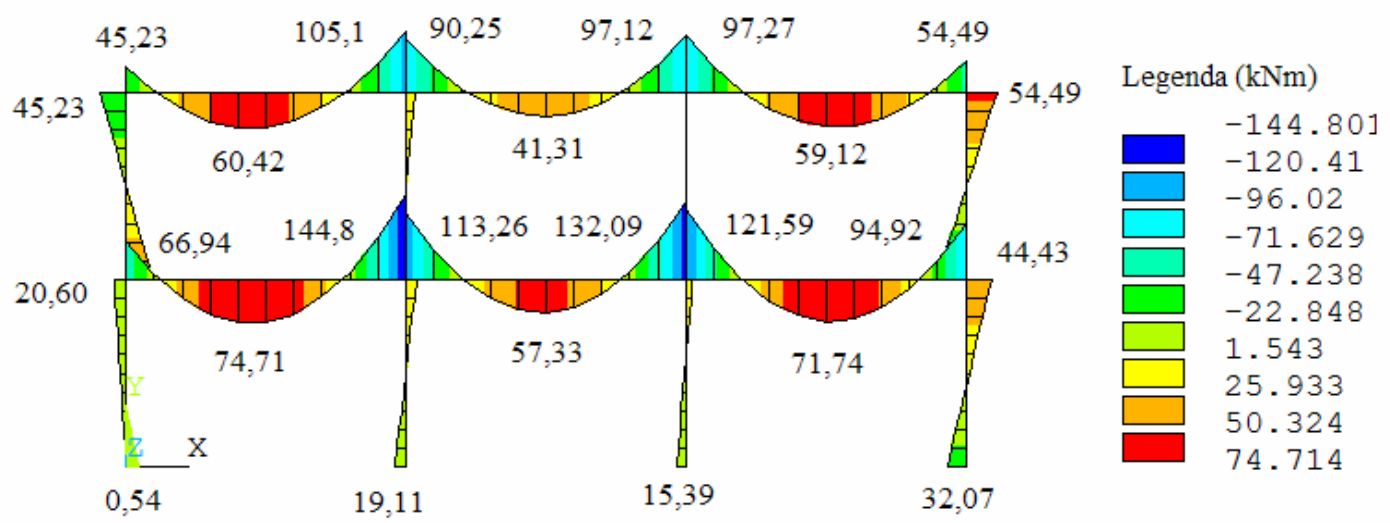

Carregamento $\mathrm{G}+\mathrm{W}+\mathrm{Q}$

Figura 4.50 - Ligação monolítica (continuação)

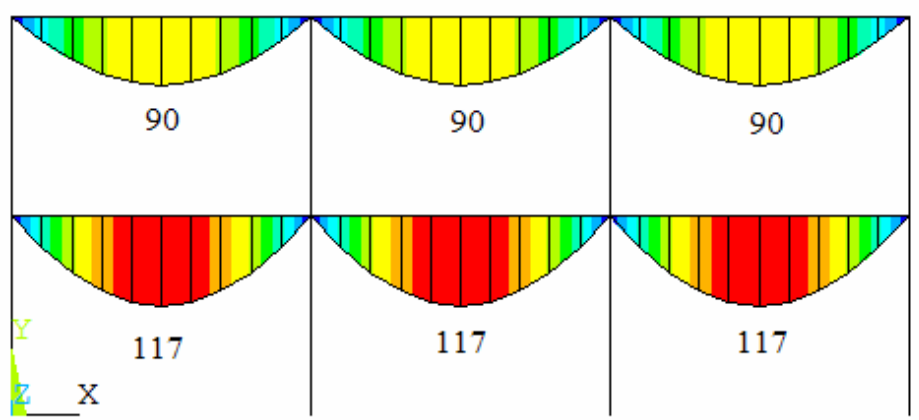

Legenda $(\mathrm{kNm})$

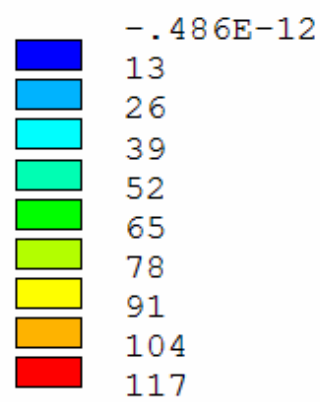

Carregamento $\mathrm{G}$ articulado

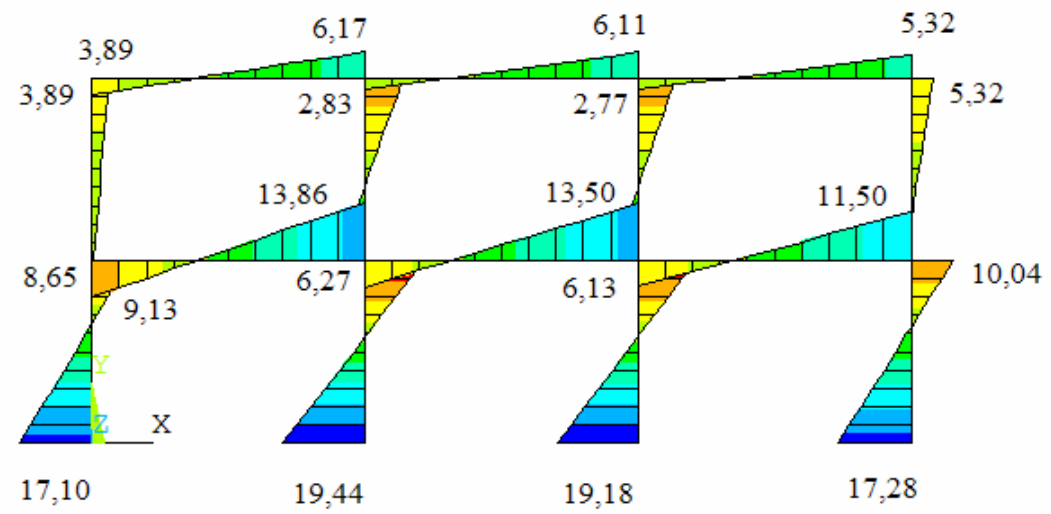

Legenda (kNm)

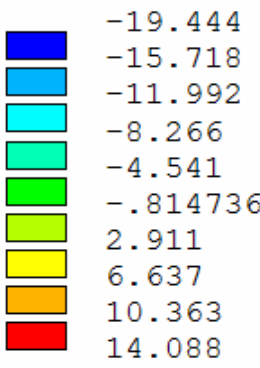

Carregamento W

Figura 4.51 - Ligação semi-rígida $G+W$ 


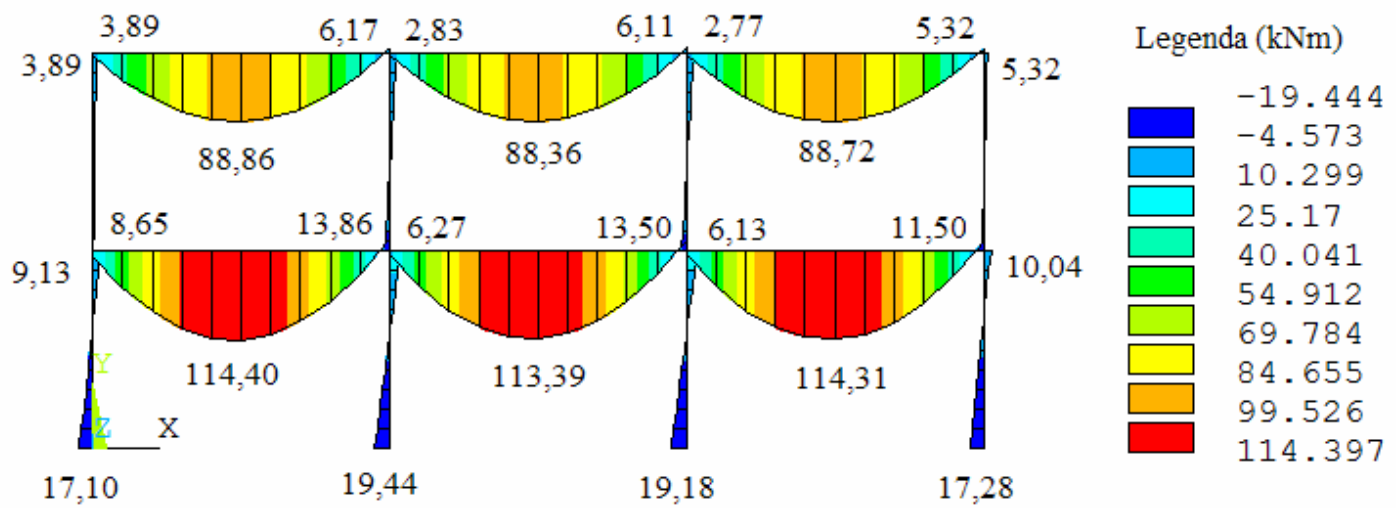

Soma dos diagramas $\mathrm{G}+\mathrm{W}$

Figura 4.51- Ligação semi-rígida $\mathbf{G}+\mathbf{W}$ (continuação)
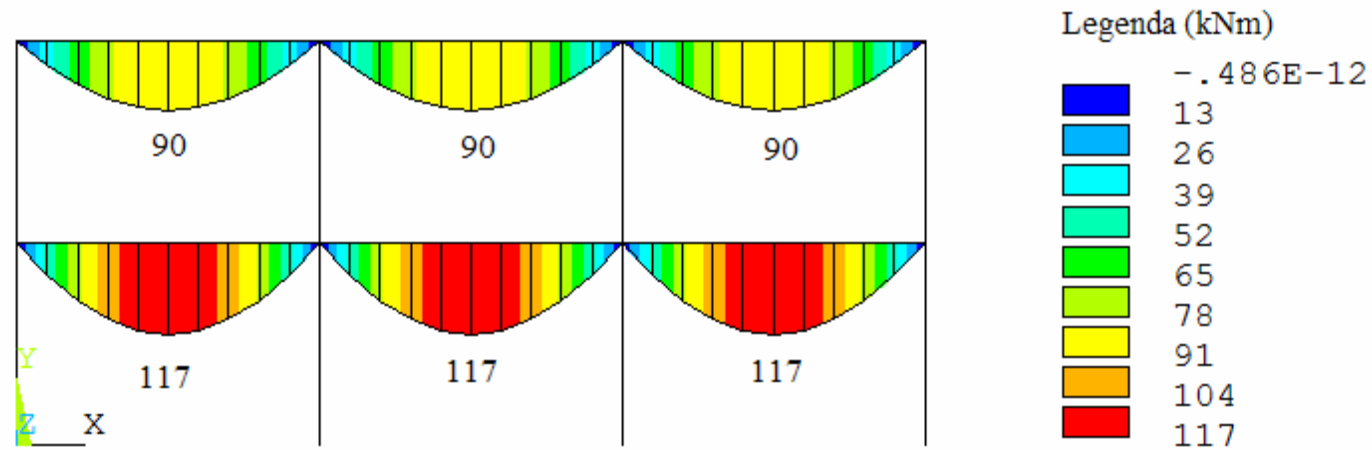

Carregamento $\mathrm{G}$

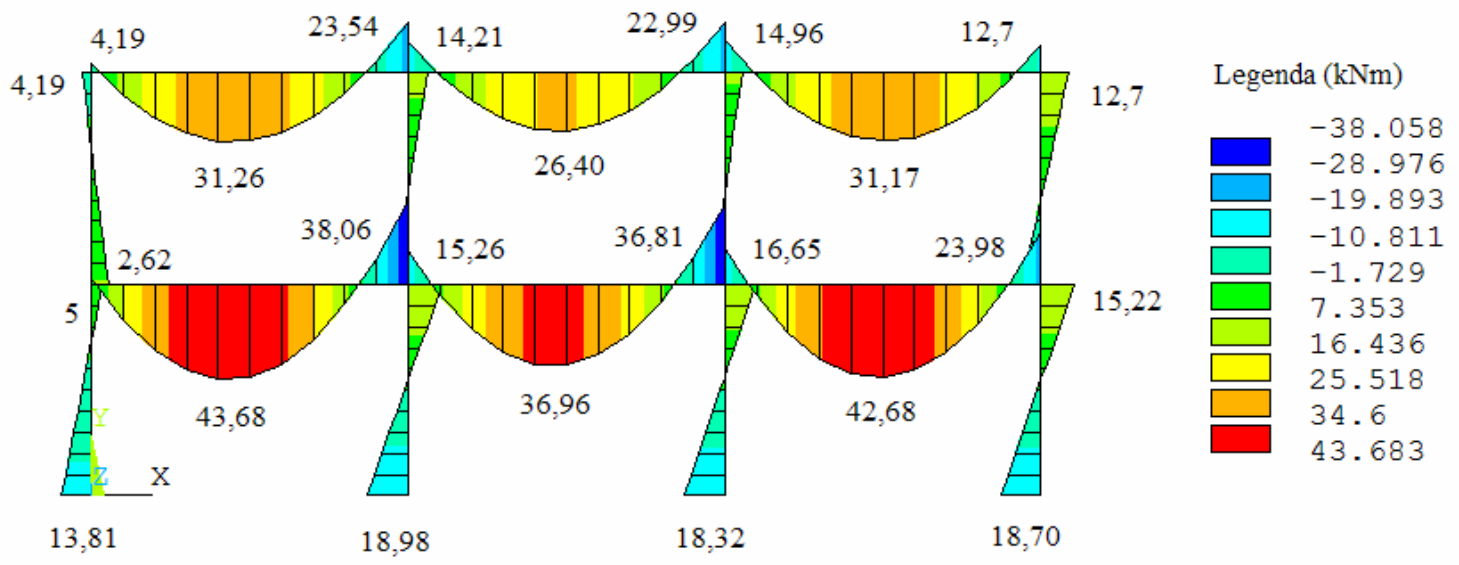

Carregamento $\mathrm{W}+\mathrm{Q}$

Figura 4.52 - Ligação semi-rígida $G+W+Q$ 


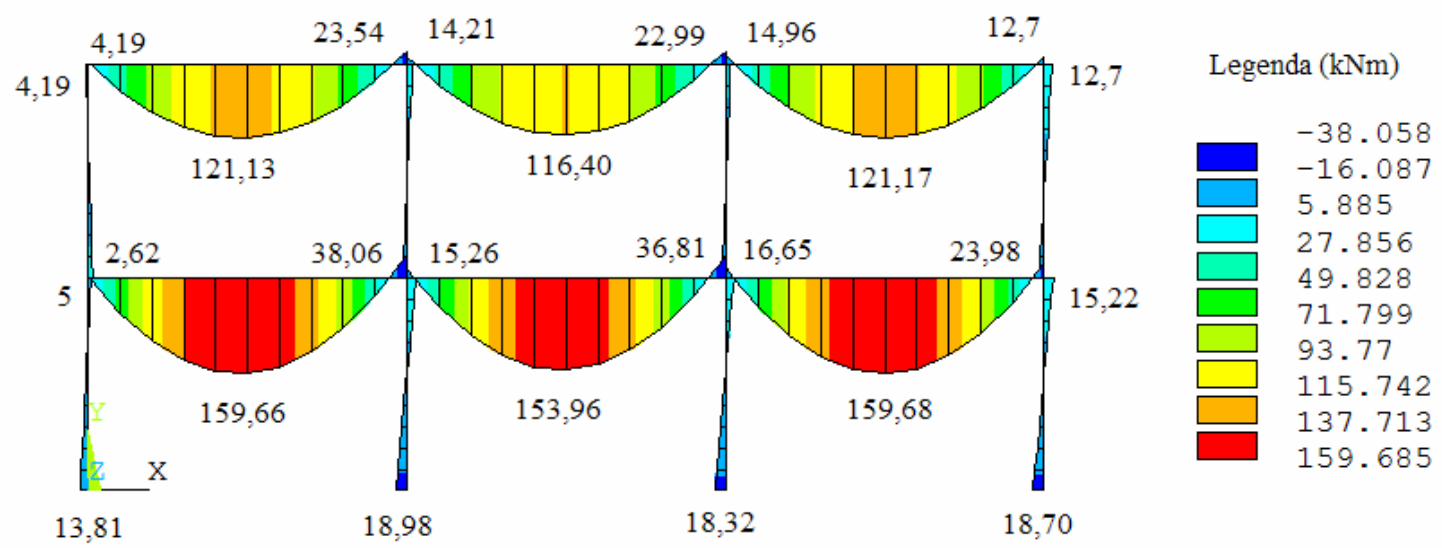

Soma dos diagramas $\mathrm{G}+\mathrm{W}+\mathrm{Q}$

Figura 4.52 - Ligação semi-rígida $G+W+Q$ (continuação)

O resumo dos principais resultados da simulação do pórtico de referência encontra-se na Tabela 4.18. Cabe mencionar que os momentos $M_{b}$ e $M_{v}$ não foram multiplicados por $0,95 \cdot \gamma_{z}$ para o caso de articulação.

Tabela 4.18 - Resumo dos resultados do pórtico de referência

\begin{tabular}{|l|c|c|c|c|c|c|}
\cline { 3 - 7 } \multicolumn{1}{c|}{} & \multicolumn{6}{c|}{ Carregamento $\mathrm{G}+\mathrm{W}+\mathrm{Q}$} \\
\hline \multirow{2}{*}{$\begin{array}{l}\text { Tipo de } \\
\text { ligação }\end{array}$} & $\mathrm{a}(\mathrm{mm})$ & $\gamma_{z}$ & $\mathrm{M}_{\mathrm{b}}(\mathrm{kNm})$ & $(+)$ & $\begin{array}{c}\text { (-) pilar de } \\
\text { extremidade }\end{array}$ & $\begin{array}{c}\mathrm{M}_{\mathrm{v}}(\mathrm{kNm}) \\
\text { intermediário }\end{array}$ \\
\cline { 5 - 8 } & & & & - pilar & 0 \\
\hline Articulado & 32,83 & 1,19 & $-40,10$ & 0 & 0 & $-38,06$ \\
\hline Semi-rígido & 3,20 & 1,02 & $-18,98$ & --- & $-23,98$ & $-144,8$ \\
\hline Rígido (1) & 2,09 & 1,01 & $-32,06$ & --- & $-94,92$ & $-58,32$ \\
\hline Rígido (2) & 1,98 & 1,01 & $-18,04$ & --- & $-42,07$ & \\
\hline
\end{tabular}

\begin{tabular}{|l|c|c|c|c|c|c|}
\cline { 5 - 7 } \multicolumn{1}{c|}{} & \multicolumn{5}{c|}{ Carregamento $\mathrm{G}+\mathrm{W}$} \\
\hline \multirow{2}{*}{$\begin{array}{l}\text { Tipo de } \\
\text { ligação }\end{array}$} & $\mathrm{a}(\mathrm{mm})$ & $\gamma_{z}$ & $\mathrm{M}_{\mathrm{b}}(\mathrm{kNm})$ & $(+)$ & $\begin{array}{c}\text { (-) pilar de } \\
\text { extremidade }\end{array}$ & $\begin{array}{c}\mathrm{M}_{\mathrm{v}}(\mathrm{kNm}) \\
\text { intermediário }\end{array}$ \\
\hline Articulado & 32,83 & 1,12 & $-40,10$ & 0 & 0 & 0 \\
\hline Semi-rígido & 3,71 & 1,01 & $-19,44$ & 8,65 & $-11,50$ & $-13,86$ \\
\hline Rígido (1) & 2,01 & 1,01 & $-26,15$ & --- & $-66,69$ & $-98,17$ \\
\hline Rígido (2) & 1,95 & 1,01 & $-17,42$ & 14,13 & $-13,84$ & $-11,69$ \\
\hline
\end{tabular}

Rígido (1) - estrutura monolítica, Rígido (2) - estrutura com G articulado.

a - deslocamento no topo da estrutura, $\mathrm{M}_{\mathrm{b}}$ - momento na base do pilar, $\mathrm{M}_{\mathrm{v}}$ - momento nas vigas junto ao apoio. 
Percebe-se que a ligação semi-rígida estudada apresenta se mais próxima de uma ligação rígida do que de uma ligação articulada e que os momentos próximos aos apoios estão distantes dos momentos de plastificação definidos na Tabela 4.17.

Com a intenção de saber quantos pavimentos poderiam ser acrescidos para que a ligação atingisse o momento de plastificação foi feita uma nova simulação cujos resultados estão na Tabela 4.19 e Figuras 4.53 e 4.54.

Tabela 4.19- Resumo dos resultados para acréscimo de pavimentos

\begin{tabular}{|c|c|c|c|c|c|c|c|}
\hline \multirow{3}{*}{$\begin{array}{l}\text { Tipo de } \\
\text { ligação }\end{array}$} & \multicolumn{7}{|c|}{ Carregamento $\mathrm{G}+\mathrm{W}+\mathrm{Q}$} \\
\hline & \multirow[b]{2}{*}{$\mathrm{N}$} & \multirow[b]{2}{*}{$\begin{array}{c}\mathrm{a} \\
(\mathrm{mm})\end{array}$} & \multirow[b]{2}{*}{$\gamma_{z}$} & \multirow{2}{*}{$\begin{array}{c}\mathrm{M}_{\mathrm{b}} \\
(\mathrm{kNm})\end{array}$} & \multicolumn{3}{|c|}{$\mathrm{M}_{\mathrm{v}}(\mathrm{kNm})$} \\
\hline & & & & & $(+)$ & $\begin{array}{l}\text { (-) pilar de } \\
\text { extremidade }\end{array}$ & $\begin{array}{c}\text { (-) pilar } \\
\text { intermediário }\end{array}$ \\
\hline Articulado & 2 & 32,83 & 1,19 & $-40,10$ & 0 & 0 & 0 \\
\hline \multirow{9}{*}{$\begin{array}{l}\text { Semi- } \\
\text { rígido }\end{array}$} & 2 & 3,20 & 1,02 & $-18,98$ & --- & $-23,98$ & $-38,06$ \\
\hline & 3 & 8,23 & 1,03 & $-33,11$ & 6,05 & $-35,47$ & $-48,72$ \\
\hline & 4 & 16,09 & 1,05 & $-47,51$ & 14,64 & $-48,00$ & $-62,49$ \\
\hline & 5 & 27,18 & 1,07 & $-62,31$ & 23,99 & $-61,03$ & $-77,72$ \\
\hline & 6 & 41,43 & 1,09 & $-77,13$ & 33,36 & $-74,19$ & $-93,05$ \\
\hline & 7 & 58,88 & 1,11 & $-91,95$ & 42,73 & $-87,20$ & $-108,5$ \\
\hline & 8 & 79,60 & 1,13 & $-106,8$ & 52,11 & $-100,3$ & $-123,9$ \\
\hline & 9 & 103,7 & 1,16 & $-121,6$ & 61,48 & $-113,3$ & $-139,4$ \\
\hline & 10 & 131,2 & 1,18 & $-136,5$ & 70,86 & $-126,4$ & $-154,8$ \\
\hline
\end{tabular}

\begin{tabular}{|c|c|c|c|c|c|c|c|}
\hline & \multicolumn{7}{|c|}{ Carregamento $\mathrm{G}+\mathrm{W}$} \\
\hline \multirow{2}{*}{$\begin{array}{l}\text { Tipo de } \\
\text { ligação }\end{array}$} & \multirow[b]{2}{*}{$\mathrm{N}$} & \multirow[b]{2}{*}{$\mathrm{a}(\mathrm{mm})$} & \multirow[b]{2}{*}{$\gamma_{z}$} & \multirow{2}{*}{$\begin{array}{c}\mathrm{M}_{\mathrm{b}} \\
(\mathrm{kNm})\end{array}$} & \multicolumn{3}{|c|}{$\mathrm{M}_{\mathrm{v}}(\mathrm{kNm})$} \\
\hline & & & & & $(+)$ & $\begin{array}{l}\text { (-) pilar de } \\
\text { extremidade }\end{array}$ & $\begin{array}{c}\text { (-) pilar } \\
\text { intermediário }\end{array}$ \\
\hline Articulado & 2 & 32,83 & 1,12 & $-40,10$ & 0 & 0 & 0 \\
\hline \multirow{9}{*}{$\begin{array}{l}\text { Semi- } \\
\text { rígido }\end{array}$} & 2 & 3,71 & 1,01 & $-19,44$ & 8,65 & $-11,50$ & $-13,86$ \\
\hline & 3 & 9,75 & 1,03 & $-34,11$ & 17,81 & $-23,68$ & $-28,51$ \\
\hline & 4 & 18,84 & 1,04 & $-48,91$ & 27,25 & $-36,43$ & $-44,05$ \\
\hline & 5 & 31,01 & 1,05 & $-63,75$ & 36,77 & $-49,27$ & $-59,67$ \\
\hline & 6 & 46,30 & 1,06 & $-78,60$ & 46,29 & $-62,12$ & $-75,29$ \\
\hline & 7 & 64,76 & 1,08 & $-93,46$ & 55,81 & $-74,97$ & $-90,89$ \\
\hline & 8 & 86,45 & 1,09 & $-108,3$ & 65,32 & $-87,82$ & $-106,5$ \\
\hline & 9 & 111,4 & 1,10 & $-123,2$ & 74,82 & $-100,7$ & $-122,1$ \\
\hline & 10 & 139,8 & 1,12 & $-138,1$ & 84,31 & $-113,5$ & $-137,6$ \\
\hline
\end{tabular}




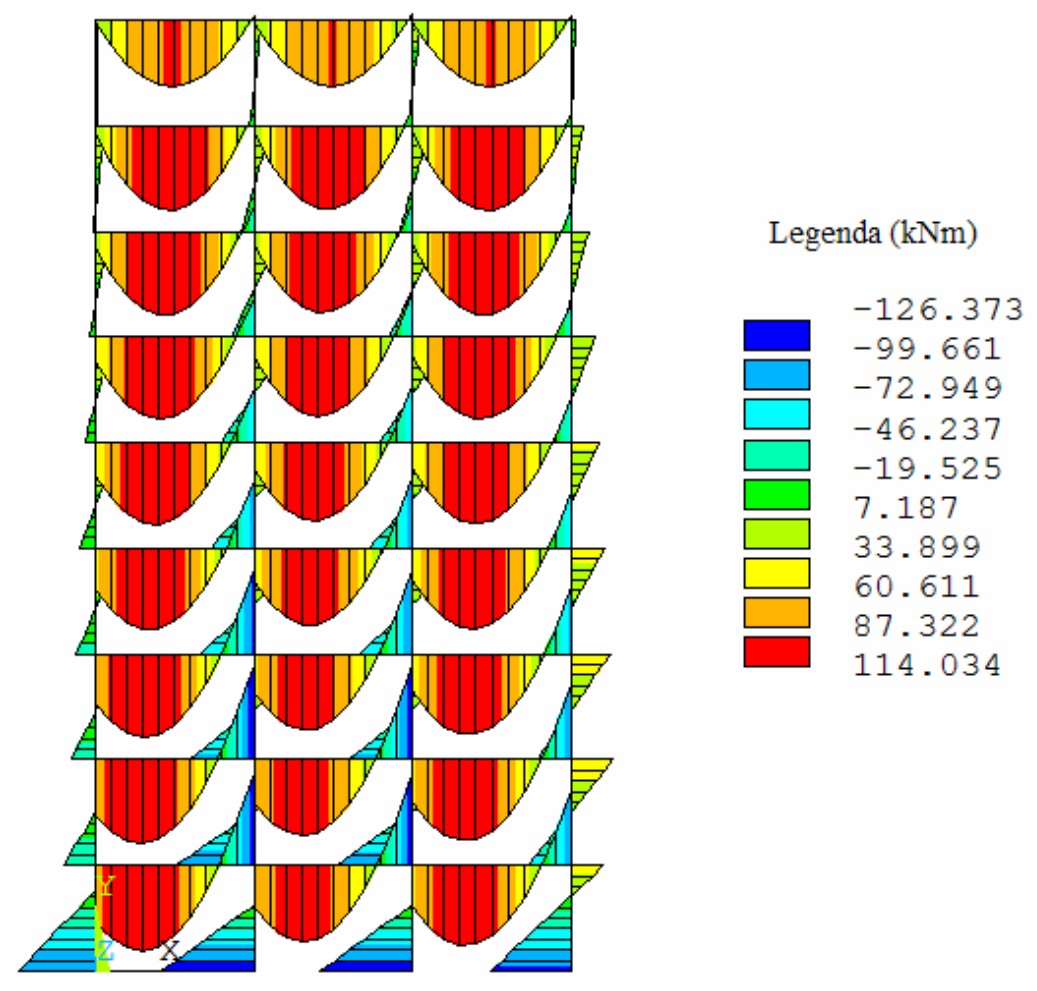

Figura 4.53 - Estrutura com 9 pavimentos - carregamento G+W

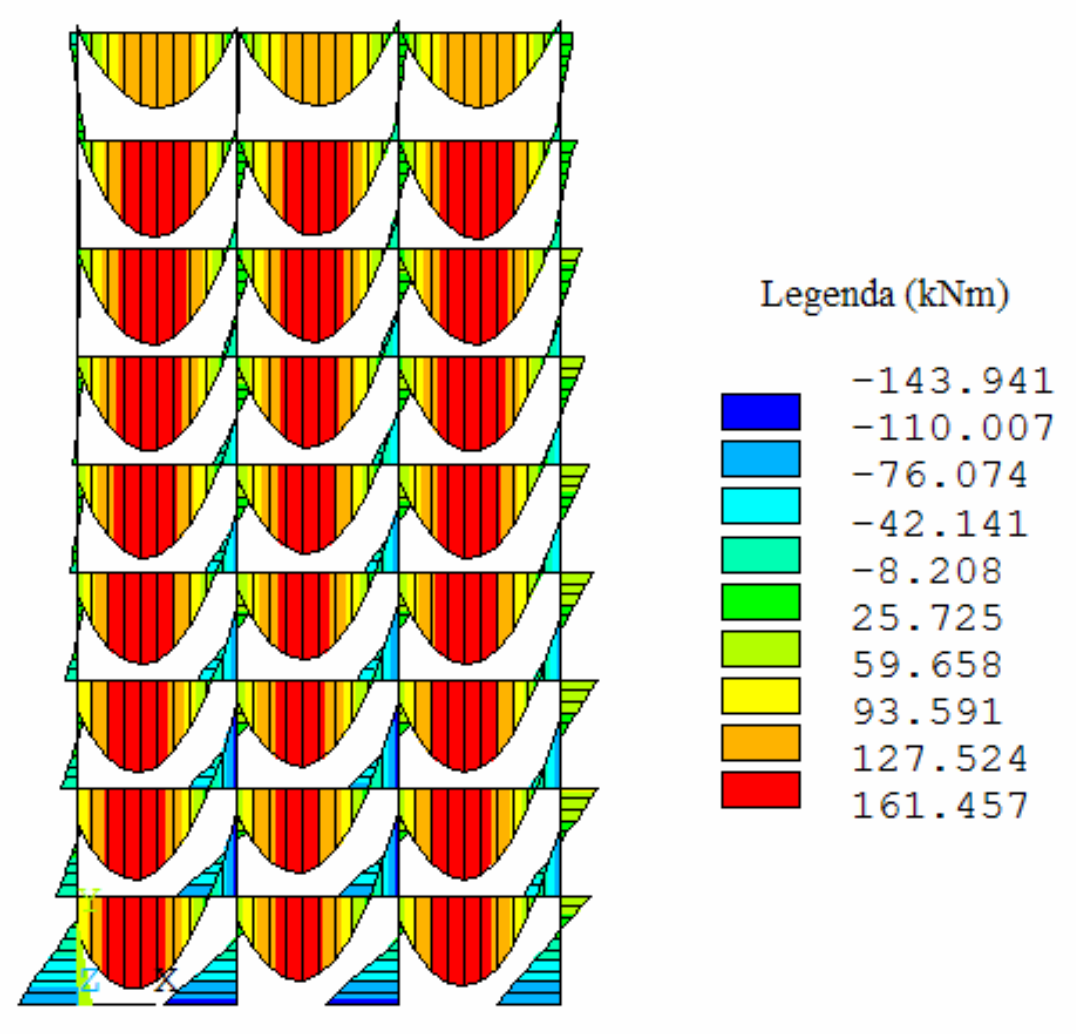

Figura 4.54- Estrutura com 9 pavimentos - carregamento $G+W+Q$ 
Pensando no regime elástico a ligação estudada é compatível com as solicitações para estruturas equivalentes a 9 pavimentos, pois apesar de no $10^{\circ}$ pavimento o momento fletor negativo do pilar intermediário $\left(182,6<\mathrm{M}_{\mathrm{y}}=201 \mathrm{kNm}\right)$ e o momento fletor positivo na viga $\left(94,4<\mathrm{M}_{\mathrm{y}}=99,1 \mathrm{kNm}\right)$ serem inferiores aos limites de plastificação, para o pilar de extremidade os momentos negativos são superiores $(149,1$ $\left.>\mathrm{M}_{\mathrm{y}}=138,5 \mathrm{kNm}\right)$.

As rotações máximas verificadas na estrutura com 9 pavimentos foram de:

$\checkmark$ Pilar intermediário - momento negativo $0,20.10^{-2} \mathrm{rad}$ momento positivo $0,31 \cdot 10^{-2} \mathrm{rad}$

$\checkmark$ Pilar de extremidade - momento negativo $0,33 \cdot 10^{-2} \mathrm{rad}$ momento positivo $0,41 \cdot 10^{-2} \mathrm{rad}$

Ainda com base na Tabela 4.19 observa-se que o máximo momento na base dos pilares para a situação articulada com 2 pavimentos é bastante próxima a estruturas de 4 pavimentos com ligações semi-rígidas. Ou seja, a estrutura poderia passar para 4 pavimentos com um acréscimo muito pequeno nos custos dos pilares e da fundação.

Com o intuito de verificar como a mudança nos valores de rigidezes influi no diagrama de momentos na estrutura, mantendo se o momento de plastificação, foi feita uma nova simulação para os 4 pavimentos com 0,5 Ko e 2 Ko (Ko da Tabela 4.17). As seções e os módulos de elasticidade permaneceram os mesmos. As Tabelas 4.20 e 4.21 apresentam os novos valores de rigidezes.

Tabela 4.20- Novo valor de rigidez - 0,5 Ko

\begin{tabular}{|c|c|c|c|c|}
\cline { 2 - 5 } & \multicolumn{2}{|c|}{ Modelo I } & \multicolumn{2}{c|}{ Modelo E } \\
\cline { 2 - 5 } & M. negativo & M. positivo & M. negativo & M. positivo \\
\hline $\mathrm{K} 1(\mathrm{MNm} / \mathrm{rad})$ & 35,3 & 9,08 & 17,3 & 9,08 \\
\hline $\mathrm{M}_{\mathrm{y}}(\mathrm{kNm})$ & 201 & 99,1 & 138,5 & 99,1 \\
\hline
\end{tabular}


Tabela 4.21 - Novo valor de rigidez - 2 Ko

\begin{tabular}{|c|c|c|c|c|}
\hline \multirow{2}{*}{} & \multicolumn{2}{|c|}{ Modelo I } & \multicolumn{2}{c|}{ Modelo E } \\
\cline { 2 - 5 } & M. negativo & M. positivo & M. negativo & M. positivo \\
\hline $\mathrm{K} 2(\mathrm{MNm} / \mathrm{rad})$ & 141,2 & 36,3 & 69,2 & 36,3 \\
\hline $\mathrm{M}_{\mathrm{y}}(\mathrm{kNm})$ & 201 & 99,1 & 138,5 & 99,1 \\
\hline
\end{tabular}

As Tabelas 4.22 e 4.23 mostram os resultados dos momentos na base do pilar, o máximo momento positivo nas vigas junto ao apoio e os deslocamentos no topo do pórtico.

Tabela 4.22 - Resumo dos resultados para rigidez $0,5 \mathrm{Ko}$

\begin{tabular}{|c|c|c|c|c|c|c|c|}
\cline { 5 - 8 } \multicolumn{1}{c|}{} & \multicolumn{9}{c|}{ Carregamento $\mathrm{G}+\mathrm{W}+\mathrm{Q}$} \\
\hline \multirow{2}{*}{$\begin{array}{c}\text { Tipo de } \\
\text { ligação }\end{array}$} & $\mathrm{N}$ & $\begin{array}{c}\mathrm{a} \\
(\mathrm{mm})\end{array}$ & $\gamma_{z}$ & $\begin{array}{c}\mathrm{M}_{\mathrm{b}} \\
(\mathrm{kNm})\end{array}$ & \multicolumn{3}{c|}{$\mathrm{M}_{\mathrm{v}}(\mathrm{kNm})$} \\
\hline Articulado & 2 & 32,83 & 1,19 & $-40,10$ & 0 & $\begin{array}{c}(-) \text { pilar de } \\
\text { extremidade }\end{array}$ & $\begin{array}{c}(-) \text { pilar } \\
\text { intermediário }\end{array}$ \\
\hline \multirow{2}{*}{$\begin{array}{l}\text { Semi- } \\
\text { rígido }\end{array}$} & 2 & 3,98 & 1,02 & $-20,12$ & --- & $-17,98$ & 0 \\
\cline { 2 - 8 } & 3 & 10,78 & 1,04 & $-35,81$ & 5,36 & $-27,40$ & $-40,30$ \\
\cline { 2 - 8 } & 4 & 22,21 & 1,07 & $-52,42$ & 12,38 & $-38,31$ & $-56,02$ \\
\hline
\end{tabular}

\begin{tabular}{|c|c|c|c|c|c|c|c|}
\cline { 5 - 8 } \multicolumn{1}{c|}{} & \multicolumn{9}{c|}{ Carregamento $\mathrm{G}+\mathrm{W}$} \\
\hline \multirow{2}{*}{$\begin{array}{c}\text { Tipo de } \\
\text { ligação }\end{array}$} & $\mathrm{N}$ & $\mathrm{a}(\mathrm{mm})$ & $\gamma_{z}$ & $\begin{array}{c}\mathrm{M}_{\mathrm{b}} \\
(\mathrm{kNm})\end{array}$ & \multicolumn{4}{c|}{$\mathrm{M}_{\mathrm{v}}(\mathrm{kNm})$} \\
\cline { 5 - 8 } & & & & & $\begin{array}{c}(-) \text { pilar de } \\
\text { extremidade }\end{array}$ & $\begin{array}{c}(-) \text { pilar } \\
\text { intermediário }\end{array}$ \\
\hline Articulado & 2 & 32,83 & 1,12 & $-40,10$ & 0 & 0 & 0 \\
\hline \multirow{2}{*}{$\begin{array}{c}\text { Semi- } \\
\text { rígido }\end{array}$} & 2 & 4,78 & 1,02 & $-20,95$ & 6,37 & $-9,45$ & $-13,41$ \\
\cline { 2 - 8 } & 3 & 13,14 & 1,03 & $-37,40$ & 13,25 & $-19,64$ & $-27,69$ \\
\cline { 2 - 8 } & 4 & 26,03 & 1,05 & $-54,17$ & 20,53 & $-30,58$ & $-43,31$ \\
\hline
\end{tabular}


Tabela 4.23 - Resumo dos resultados para rigidez 2 Ko

\begin{tabular}{|c|c|c|c|c|c|c|c|}
\cline { 5 - 8 } \multicolumn{1}{c|}{} & \multicolumn{9}{c|}{ Carregamento $\mathrm{G}+\mathrm{W}+\mathrm{Q}$} \\
\hline \multirow{2}{*}{$\begin{array}{c}\text { Tipo de } \\
\text { ligação }\end{array}$} & $\mathrm{N}$ & $\begin{array}{c}\mathrm{a} \\
(\mathrm{mm})\end{array}$ & $\gamma_{z}$ & $\begin{array}{c}\mathrm{M}_{\mathrm{b}} \\
(\mathrm{kNm})\end{array}$ & $(+)$ & $\begin{array}{c}(-) \text { pilar de } \\
\text { extremidade }\end{array}$ & $\begin{array}{c}(-) \text { pilar } \\
\text { intermediário }\end{array}$ \\
\hline Articulado & 2 & 32,83 & 1,19 & $-40,10$ & 0 & 0 & 0 \\
\hline \multirow{2}{*}{$\begin{array}{l}\text { Semi- } \\
\text { rígido }\end{array}$} & 2 & 2,74 & 1,02 & $-18,86$ & --- & $-29,15$ & $-45,85$ \\
\cline { 2 - 8 } & 3 & 6,84 & 1,03 & $-31,27$ & 6,94 & $-42,54$ & $-56,66$ \\
\cline { 2 - 8 } & 4 & 12,92 & 1,04 & $-44,39$ & 17,06 & $-56,57$ & $-68,16$ \\
\hline
\end{tabular}

\begin{tabular}{|c|c|c|c|c|c|c|c|}
\cline { 5 - 8 } \multicolumn{1}{c|}{} & \multicolumn{9}{c|}{ Carregamento $\mathrm{G}+\mathrm{W}$} \\
\hline \multirow{2}{*}{$\begin{array}{c}\text { Tipo de } \\
\text { ligação }\end{array}$} & $\mathrm{N}$ & $\mathrm{a}(\mathrm{mm})$ & $\gamma_{z}$ & $\begin{array}{c}\mathrm{M}_{\mathrm{b}} \\
(\mathrm{kNm})\end{array}$ & \multicolumn{3}{|c|}{$\mathrm{M}_{\mathrm{v}}(\mathrm{kNm})$} \\
\hline Articulado & 2 & 32,83 & 1,12 & $-40,10$ & 0 & $\begin{array}{c}(-) \text { pilar de } \\
\text { extremidade }\end{array}$ & $\begin{array}{c}(-) \text { pilar } \\
\text { intermediário }\end{array}$ \\
\hline \multirow{2}{*}{$\begin{array}{c}\text { Semi- } \\
\text { rígido }\end{array}$} & 2 & 3,06 & 1,01 & $-18,35$ & 10,97 & $-13,14$ & $-13,61$ \\
\cline { 2 - 8 } & 3 & 7,74 & 1,02 & $-31,78$ & 22,37 & $-26,83$ & $-27,84$ \\
\cline { 2 - 8 } & 4 & 14,68 & 1,03 & $-45,25$ & 33,93 & $-40,92$ & $-42,61$ \\
\hline
\end{tabular}

Comparando as tabelas para as várias rigidezes calculadas percebe-se que uma variação de metade, ou dobro, da rigidez não gera mudanças da mesma proporção nos momentos na estrutura. Para o caso dos momentos na base dos pilares esta variação é, em média, de $6 \%$. Já para os momentos nas vigas esse percentual atinge $29 \%$ para o momento positivo, $23 \%$ para momento negativo nos pilares de extremidade e $16 \%$ para os pilares intermediários.

Este resultado mostra que apesar de haver certa imprecisão na determinação da rigidez, seja esta devido à leitura dos relógios ou uso de uma curva bi-linear simplificada, ela serve como um bom parâmetro e os esforços na estrutura não variaram muito.

Com a finalidade de comparar o comportamento da ligação estudada com uma ligação similar, porém com o chumbador retilíneo foi feita outra simulação numérica para uma estrutura de 4 pavimentos. A ligação avaliada é composta por $4 \phi 12,5 \mathrm{~mm}$ transpassando o pilar e $2 \phi 20 \mathrm{~mm}$ do chumbador. Os valores das rigidezes e momentos de plastificação para o momento negativo foram iguais aos mencionados na Tabela 4.17 (calculada pelo modelo analítico apresentado neste capítulo). Para os momentos 
positivos foi utilizada uma formulação baseada em Miotto (2002). Os valores de resistências e tensão de escoamento do aço foram iguais às usadas no modelo analítico da seção 4.3 deste capítulo.

A Figura 4.55 apresenta o sistema de forças em equilíbrio para o momento fletor positivo.

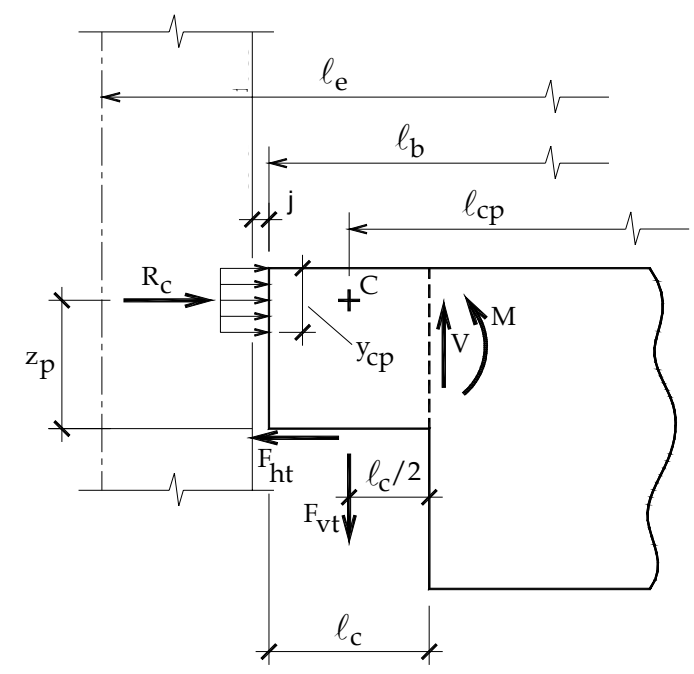

Figura 4.55 - Sistema de forças em equilíbrio para momento fletor positivo

O momento no ponto $\mathrm{C}$ é dado pela eq. (4.26)

$$
M_{y p}=F_{h t} \cdot z_{p}
$$

O momento na face do pilar e dado pela eq. (4.27)

$$
M_{E}=F_{h t} \cdot z_{p} \cdot \frac{l_{e}}{l_{c p}}
$$

Onde:

$$
\begin{aligned}
& z_{p}=h_{c}-\frac{y_{c p}}{2} \\
& F_{h t}=c \cdot \phi_{b}^{2} \cdot \sqrt{f_{y b} \cdot f_{c c, \text { max }}}
\end{aligned}
$$




$$
l_{p n}=\left(l_{e}-\frac{b_{p i l a r}}{2}\right)-j-l_{c} / 2
$$

Sendo:

$$
\begin{array}{ll}
F_{h t} & =\text { força de horizontal (cisalhamento) no chumbador } \\
z_{p} & =\text { braço de alavanca } \\
l_{e} & =\text { comprimento entre a carga aplicada e o eixo do pilar } \\
l_{c p} & =\text { comprimento entre a carga aplicada e o ponto C } \\
h_{c} & =\text { altura da seção } \\
y_{c p} & =\text { altura do bloco de compressão na parte superior do dente gerber } \\
c & =\text { coeficiente para levar em consideração a ausência de atrito e restrição } \\
& \quad \text { parcial de giro } \\
\phi_{b} & =\text { diâmetro do chumbador } \\
f_{y b} & =\text { resistência ao escoamento do aço do chumbador } \\
f_{c c, \text { max }} & =\text { máximo valor de resistência do concreto/graute entre os elementos } \\
b_{p i l a r} & =\text { nos qual o chumbador esta inserido } \\
j & =\text { espessura do junta } \\
l_{c} & =\text { dimensão do consolo }
\end{array}
$$

O cálculo da rigidez da ligação foi feito baseado no método dos componentes. A Figura 4.56 mostra o posicionamento das molas de cada componente ativo.

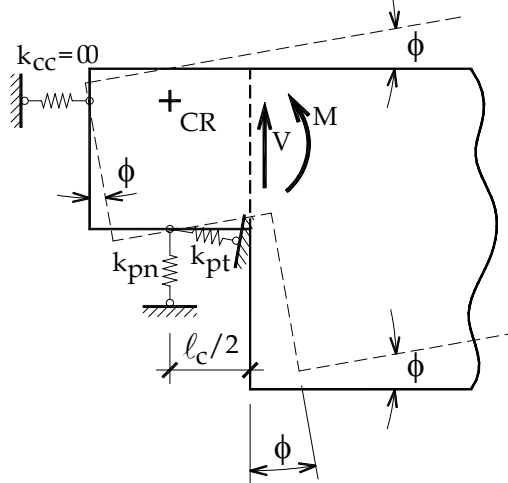


Fazendo o equilíbrio de momentos em relação ao centro de rotação, pode calcular a rigidez da ligação, com a eq. (4.28)

$$
k_{\phi p}=k_{p t}\left(h_{c}-\frac{y_{c p}}{2}\right)^{2}
$$

Para a rigidez no eixo do pilar deve-se multiplicar a eq. (4.28) pela razão do comprimento entre o ponto CR e o eixo do pilar.

O valor da rigidez corresponde à deformação de cisalhamento do chumbador é dado pela eq. (4.29)

$$
\begin{aligned}
& k_{p t}=\frac{F_{h t}}{a_{v y}} \\
& a_{v y}=0,1 \cdot \phi_{b}
\end{aligned}
$$

Onde:

$$
\begin{aligned}
& a_{v y}=\text { deslocamento transversal do chumbador quando a sua força máxima é } \\
& \text { atingida. }
\end{aligned}
$$

A Tabela 4.24 apresenta as rigidezes e momento de plastificação usados na simulação.

Tabela 4.24 - Rigidezes e momentos de plastificação da ligação com chumbador $2 \phi 20$ mm retilíneo

\begin{tabular}{|c|c|c|c|c|}
\hline & \multicolumn{2}{|c|}{ Pilar intermediário } & \multicolumn{2}{c|}{ Pilar de extremidade } \\
\hline & M. negativo & M. positivo & M. negativo & M. positivo \\
\hline $\mathrm{K} 2(\mathrm{MNm} / \mathrm{rad})$ & 70,6 & 8,7 & 34,6 & 8,7 \\
\hline $\mathrm{M}_{\mathrm{y}}(\mathrm{kNm})$ & 201 & 39,2 & 138,5 & 39,2 \\
\hline
\end{tabular}

A Tabela 4.25 apresenta os resultados obtidos. 
Tabela 4.25 - Resultado obtido da simulação numérica

\begin{tabular}{|c|c|c|c|c|c|c|c|}
\cline { 5 - 8 } \multicolumn{1}{c|}{} & \multicolumn{9}{c|}{ Carregamento $\mathrm{G}+\mathrm{W}+\mathrm{Q}$} \\
\hline \multirow{2}{*}{$\begin{array}{c}\text { Tipo de } \\
\text { ligação }\end{array}$} & $\mathrm{N}$ & $\begin{array}{c}\mathrm{a} \\
(\mathrm{mm})\end{array}$ & $\gamma_{z}$ & \multirow{2}{*}{$\begin{array}{c}\mathrm{M}_{\mathrm{b}} \\
(\mathrm{kNm})\end{array}$} & $(+)$ & $\begin{array}{c}(-) \text { pilar de } \\
\text { extremidade }\end{array}$ & $\begin{array}{c}(-) \text { pilar } \\
\text { intermediário }\end{array}$ \\
\hline Articulado & 2 & 32,83 & 1,19 & $-40,10$ & 0 & 0 & 0 \\
\hline \multirow{2}{*}{$\begin{array}{c}\text { Semi- } \\
\text { rígido }\end{array}$} & 2 & 3,20 & 1,02 & $-18,98$ & --- & $-23,98$ & $-36,06$ \\
\cline { 2 - 8 } & 3 & 8,31 & 1,03 & $-33,42$ & 3,67 & $-35,75$ & $-48,72$ \\
\cline { 2 - 8 } & 4 & 16,67 & 1,05 & $-48,39$ & 9,16 & $-49,08$ & $-64,29$ \\
\hline
\end{tabular}

\begin{tabular}{|c|c|c|c|c|c|c|c|}
\cline { 5 - 8 } \multicolumn{1}{c|}{} & \multicolumn{9}{c|}{ Carregamento $\mathrm{G}+\mathrm{W}$} \\
\hline \multirow{2}{*}{$\begin{array}{c}\text { Tipo de } \\
\text { ligação }\end{array}$} & $\mathrm{N}$ & $\mathrm{a}(\mathrm{mm})$ & $\gamma_{z}$ & \multirow{2}{*}{$\begin{array}{c}\mathrm{M}_{\mathrm{b}} \\
(\mathrm{kNm})\end{array}$} & \multicolumn{3}{|c|}{$\mathrm{M}_{\mathrm{v}}(\mathrm{kNm})$} \\
\cline { 6 - 9 } & & & & $\begin{array}{c}(-) \text { pilar de } \\
\text { extremidade }\end{array}$ & $\begin{array}{c}(-) \text { pilar } \\
\text { intermediário }\end{array}$ \\
\hline Articulado & 2 & 32,83 & 1,12 & $-40,10$ & 0 & 0 & 0 \\
\hline \multirow{2}{*}{$\begin{array}{c}\text { Semi- } \\
\text { rígido }\end{array}$} & 2 & 4,12 & 1,02 & $-20,08$ & 5,58 & $-12,33$ & $-15,60$ \\
\cline { 2 - 8 } & 3 & 11,03 & 1,03 & $-35,50$ & 11,55 & $-25,46$ & $-32,15$ \\
\cline { 2 - 8 } & 4 & 21,51 & 1,04 & $-51,08$ & 17,72 & $-39,41$ & $-49,92$ \\
\hline
\end{tabular}

Nota-se que ao se posicionar os chumbadores inclinados na ligação viga-pilar há um aumento de aproximadamente 2,5 vezes no momento de plastificação e de 2 vezes na rigidez no sentido do momento fletor positivo. Quando aos esforços ao qual a estrutura esta submetida, para 4 pavimentos, verifica-se que os momentos na base dos pilares são próximos enquanto que para os momentos positivos da viga há um acréscimo de $50 \%$. Para os deslocamentos no topo da estrutura nota-se que há uma redução de $15 \%$ quando comparado à ligação com o chumbador na posição vertical.

Tendo em vista os resultados apresentados podemos concluir que a ligação vigapilar estudada possui uma boa capacidade de transmissão a momento fletor negativo, devido à presença de armaduras de continuidade, e a momento fletor positivo com um comportamento bastante dúctil.

Sem a necessidade grandes alterações de custos e de execução a ligação proposta promoveu uma redução significativa dos momentos na base dos pilares (aproximadamente 50\%) quando comparado à ligação articulada. Quando comparada à ligação similar, porém com os chumbadores retilíneos, há um aumento superior a 2,5 vezes nos momentos de plastificação e de 2 vezes na rigidez a momento fletor positivo. Quanto aos esforços na estrutura não há redução significativa dos momentos na base 
dos pilares, porém para 4 pavimentos os momentos máximos positivos junto ao apoio são $50 \%$ maiores que os com ligação com chumbador retilíneo.

Através da simulação numérica em estruturas típicas de concreto pré-moldado constatou-se que para o regime elástico a ligação viga-pilar estudada é compatível com solicitações em estruturas equivalentes a 9 pavimentos. 


\section{G๐ms}

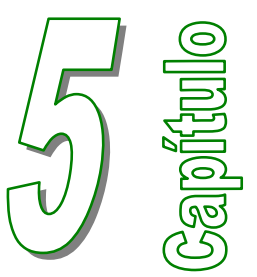

\subsection{CONSIDERAÇÕES INICIAIS}

O presente trabalho teve por objetivo compreender o comportamento de uma ligação viga-pilar ao ser submetida a momentos fletores negativos e positivos através de ensaios físicos, definir um modelo analítico para os momentos resistentes e promover uma simulação numérica em estruturas típicas de concreto pré-moldado para avaliar seus benefícios.

Com a finalidade de melhorar os momentos de plastificação e rigidez no sentido de momento fletor positivo obtidos em Miotto (2002) a ligação estudada foi composta por 2 chumbadores inclinados presos à viga através de chapas metálicas, porcas e arruelas ao invés de um chumbador retilíneo. No sentido de momento fletor negativo foi colocada uma armadura de continuidade transpassando o pilar, assim como em Miotto (2002).

Para o ensaio físico foram definidos dois modelos, modelo I para representar o pilar intermediário e modelo E para o pilar de extremidade, sobre os quais foram aplicados carregamentos alternados, em ciclos, de curta duração. Ambos os modelos foram levados à ruptura tanto a momento fletor negativo como positivo.

Através das leituras da instrumentação foram definidos os momentos de plastificação e rigidez de cada modelo e sentido de momento. De posse destes resultados foi possível calibrar o modelo analítico e promover a simulação numérica. 


\subsection{CONCLUSÕES}

Tendo em vista os resultados obtidos neste trabalho podemos delinear as seguintes conclusões:

A ligação viga-pilar estudada possui uma boa capacidade de transmissão a momento fletor negativo, devido à presença de armaduras de continuidade, e a momento fletor positivo com um comportamento bastante dúctil, sendo o momento resistente positivo da ordem de $60 \%$ do momento negativo para o pilar intermediário e $85 \%$ para o pilar de extremidade.

Quando comparando os momentos de plastificação de ambos os modelos percebe-se que para momento fletor negativo a ligação do modelo I é capaz de suportar momentos 30\% maiores que a do modelo E enquanto que para o momento positivo a ligação possui praticamente o mesmo momento resistente. Isso se deve ao fato da armadura da capa não ser continua no modelo E e na região do chumbador não ter sido feita nenhuma modificação.

Por meio dos resultados experimentais e o modelo analítico notou-se que para a ligação estudada, sobre o chumbador além do efeito de tração há uma parcela do efeito de pino de $13 \%$.

Através da simulação numérica observou-se que a ligação com as configurações geométricas adotadas no ensaio pode ser executada na prática, pois atingiu valores de resistência e rigidez adequadas ao sistema estrutura a que fazem parte.

Sem a necessidade grandes alterações de custos e de execução a ligação proposta promoveu uma redução significativa dos momentos na base dos pilares (aproximadamente 50\%) quando comparado à ligação articulada. Quando comparada à ligação similar, porém com os chumbadores retilíneos, há um acréscimo superior a 2,5 vezes nos momentos de plastificação e de 2 vezes na rigidez a momento fletor positivo. Quanto aos esforços na estrutura não há redução significativa dos momentos na base dos pilares, porém quando comparado os momentos máximos positivos junto ao apoio para a estrutura com 4 pavimentos nota-se um aumento de $50 \%$.

Observou-se que a ligação, pensando apenas no regime elástico, é compatível com as solicitações para estrutura equivalente a 9 pavimentos. 
Por fim a análise da influência da variação das rigidezes, sem, contudo modificar os momentos de plastificação, mostrou que uma variação de metade, ou dobro, da rigidez não gera mudanças da mesma proporção nos momentos na estrutura. Para o caso dos momentos na base dos pilares esta variação é, em média, de $6 \%$. Já para os momentos nas vigas esse percentual atinge $29 \%$ para momento positivo, $23 \%$ para o momento negativo nos pilares de extremidade e 16\% para os pilares intermediários.

Este resultado mostra que apesar de haver certa imprecisão na determinação da rigidez, seja esta devido à leitura dos relógios ou uso de uma curva bi-linear simplificada, ela serve como um bom parâmetro e os esforços na estrutura não variaram muito.

\subsection{SUGESTÕES PARA PESQUISAS FUTURAS}

Devido ao tema desenvolvido neste trabalho ser bastante amplo e a ligação vigapilar ser nova há a necessidade de uma maior investigação. Como sugestões para trabalhos futuros temos:

$\checkmark$ Estudo mais aprofundado do comportamento do chumbador inclinado na ligação, verificando os parâmetros que interferem no efeito de pino e seus percentuais.

$\checkmark$ Promover formulações analíticas das rigidezes e momentos de plastificação para as diversas ligações estudadas de forma a auxiliar os projetistas na consideração da semi-rigidez das ligações 


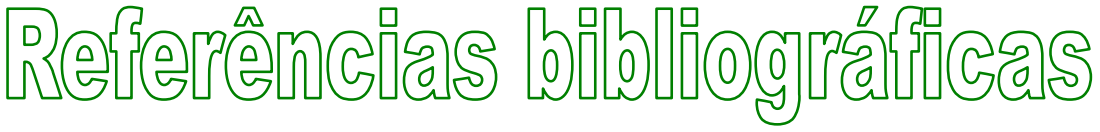

ALZAMEL, H.S; ELGHAZALY, H.A (1991). An innovative detail for precast concrete beam-column moment connections. Canadian Journal of Civil Engineering, V 18, n 4, p 690-710.

ASSOSIAÇÃO BRASILEIRA DE NORMAS TÉCNICAS (1984). NBR 8522: Concreto -Determinação do módulo de deformação estática e diagrama - Tensãodeformação - Procedimento.Rio de Janeiro.

ASSOSIAÇÃO BRASILEIRA DE NORMAS TÉCNICAS (1985). NBR 9062: Projeto e Execução de Estruturas de Concreto Pré-Moldado - Procedimento.Rio de Janeiro.

ASSOSIAÇÃO BRASILEIRA DE NORMAS TÉCNICAS (2001).NBR 6118: Projeto de estruturas de concreto - Procedimento.Rio de Janeiro.

ASSOSIAÇÃO BRASILEIRA DE NORMAS TÉCNICAS (2003). Texto base para revisão da NBR 8800: Projeto e execução de estruturas de aço de edifícios. Rio de janeiro.

BALLARIN, A.W. (1993). Desempenho das ligações de elementos estruturais prémoldados de concreto. 255p. Dissertação (Mestrado) - Escola de engenharia de São Carlos, Universidade de São Paulo, São Carlos. 1993. 
BARBOZA, A.S.R (2001). Comportamento de juntas de argamassa solicitadas à compressão na ligação entre elementos pré-moldados. 143p. Tese (Doutorado) - Escola de engenharia de São Carlos, Universidade de São Paulo, São Carlos. 2001.

BJLUGER, F.E. (1988). Design of precast concrete structures. New York, John Wiley \& sons.297p.

CANADIAN PORTLAND CEMENT ASSOCIATION (1994). A23.3: Concrete design handbook. Canadá.

CHEFDEBIEN, A. (1998). Precast concrete beam to column head connections. In: CONTROL OF THE SEMI-RIGID BEHAVIOUR OF CIVIL ENGINEERING STRUCTURAL CONNECTIONS, COST C1 INTERNATIONAL CONFERENCE, 1998. Cost C1: Proceedings. Liege, Belgium. p. 35-43.

CHEOK, G.S.; LEW, H.S. (1991). Performance of precast concrete beam-to-column connections subject to cyclic loading. PCI journal precast/prestressed concrete institute, v.36, n. 3, p. 56-67, May-June.

COMITE EURO-INTERNATIONAL DU BETON (1990). CEB-FIP Model Code for Concrete Structures. Paris: CEB, 1991. Bulletin d'Information 203.

CONNECTIONS, COST C1 INTERNATIONAL CONFERENCE, 1994. Cost C1: Proceedings. Prague. p. 31-40.

COST C1 (1996). Composite steel concrete joints in braced frames for building. Brussels, Luxembourg.

DOLAN, C.W.; STANTON, J.F.; ANDERSON, R.G. (1987). Moment resistant connections and simple connections. PCI journal precast/prestressed concrete institute, v.32, n 2, p 62-74, March-April.

EL DEBS, M.K. (2000). Concreto pré-moldado: Fundamentos e aplicações. 1.ed. São Carlos, EESC-USP, 441p. 
ELLIOT, K.S.; DAVIES, G.; GORGUN, H. (1994). The determination of momentrotation in semi-rigid precast concrete connections using the component method. In: SEMI-RIGID BEHAVIOUR OF CIVIL ENGINEERING STRUCTURAL

ELLIOT, K.S. (1998). Semi-rigid connections in precast concrete structures and bridges. In: CONTROL OF THE SEMI-RÍGID BEHAVIOUR OF CIVIL ENGINEERING STRUCTURAL CONNECTIONS, COST C1 INTERNATIONAL CONFERENCE, 1998. Cost C1: Proceedings. Liege, Belgium. p. 3-12.

ELLIOT, K.S et al (1998). Precast concrete semi-rigid beam-to-column connections in skeletal frames. In: CONTROL OF THE SEMI-RÍGID BEHAVIOUR OF CIVIL ENGINEERING STRUCTURAL CONNECTIONS, COST C1 INTERNATIONAL CONFERENCE, 1998. Cost C1: Proceedings. Liege, Belgium. p. 45-54.

ELLIOTT, K.S. et al. (2003). Can precast concrete structures be designed as semi-rigid frames?. Structural engineer, v.81, n.16, p. 14-37, August.

EL SHEIKH, M. et al (2000). Moment rotation behavior of unbounded post-tensioned concrete beam-column connections. ACI Structural journal, v 97. n 1, p 122-131.

ENGLEKIRK, R. E. (1995). Development and testing of a ductile connector for assembling precast concrete beams and columns. PCI journal precast/prestressed concrete institute, v.40. n 2.p 36-51.

ENGSTROM, B. (1992). Combined effects of dowel action and friction in bolted connections. In: WORKSHOP ON SEMI-RIGID BEHAVIOUR OF CIVIL ENGINEERING STRUCTURAL CONNECTIONS, 1992. Cost C1: Proceedings. Strasbourg, France.p.77-98.

EUROCODE 3 (2003). Design of steel structures, part 1.8: design of joints. European committee for standardization, CEN, Brussels.

EUROCODE 2 (2002). Design of concrete structures, part 1: general rules and rules for buildings. European committee for standardization, CEN, Brussels. 
FERREIRA, M.A. (1993). Estudo de deformabilidade de ligações para análise linear em pórticos planos de elementos pré-moldados de concreto. 166p. Dissertação (Mestrado) -Escola de engenharia de São Carlos, Universidade de São Paulo, São Carlos. 1993.

FERREIRA, M.A. (1999). Deformabilidade de ligações viga pilar de concerto prémoldado. 232p. Tese (Doutorado) - Escola de engenharia de São Carlos, Universidade de São Paulo, São Carlos. 1999.

FÉDÉRATION INTERNATIONALE DU BÉTON - FIB (2003). Structural connections for precast concrete buildings. Lausanne, Suíça.

GOMES, F.C.T. et al. (1998). Recent developments on classification of joint. In: CONTROL OF THE SEMI-RÍGID BEHAVIOUR OF CIVIL ENGINEERING STRUCTURAL CONNECTIONS, COST C1 INTERNATIONAL CONFERENCE, 1998. Cost C1: Proceedings. Liege, Belgium. p. 187-198.

GONZALES, F. (2002). Research on precast beam-to-column connections. PCI journal precast/prestressed concrete institute, v.47, n 4, p 149.

GORGUN, H. (1998). Semi-rigid behavior of connections in precast concrete structures. Nottingham. PhD Thesis - University of Nottingham, United Kingdom.

KERONEN, A. (1996). Effect of semi-rigid connections in rc portal frame: Load tests. Report of Tampare University of Technology, Finlândia. p 95.

LEON, R.T. (1998) Developments in the use of partial restraint frames in the United States. In: CONTROL OF THE SEMI-RÍGID BEHAVIOUR OF CIVIL ENGINEERING STRUCTURAL CONNECTIONS, COST C1 INTERNATIONAL CONFERENCE, 1998. Cost C1: Proceedings. Liege, Belgium. p. 95-104.

MALITE, M. (2003). Ligações mistas e vigas mistas aço-concreto com continuidade nos apoios. p 49. Notas de aula disciplina ES 021-projeto de estruturas mistas.PECEEPUSP. 
MIOTTO, A.M. (2002). Ligações viga-pilar de estruturas de concreto pré-moldado: Análise com ênfase na deformabilidade ao momento fletor. 234p. Tese (Doutorado) Escola de engenharia de São Carlos, Universidade de São Paulo, São Carlos. 2002.

MONTEDOR, L.C. (2004). Desenvolvimento de compósito a ser utilizado como almofada de apoio nas ligações entre elementos pré-moldados. 144p. Dissertação (Mestrado) - Escola de engenharia de São Carlos, Universidade de São Paulo, São Carlos. 2004

PFEIFER, D.W.; IVERSON, J.K. (1985). Bearing pads for precast concrete buildings. PCI journal precast/prestressed concrete institute, v.30. n 5, p 128-154.

PRESTRESSED CONCRETE INSTITUTE (1988). Design and typical detail of connections for precast and prestressed concrete. 2 ed.Chicago, PCI.

SCOTT, N.L. (2004). Reflections on the early precast/prestressed concrete industry in America. PCI journal precast/prestressed concrete institute, v.49. n 2, p 20-33.

SECKIN, M.; FU, H.C (1990). Beam-column connections in precast reinforced concrete construction-discussion. ACI Structural journal, v 87. n 3, p 252-261.

SOARES, A.M.M. (1998). Análise estrutural de pórticos planos de elementos préfabricados de concreto considerando a deformabilidade das ligações. 178p. Dissertação (Mestrado) - Escola de engenharia de São Carlos, Universidade de São Paulo, São Carlos. 1998.

TSCHEMMERNEGG, F.; HUBER, G. (1998). Classification and assessment of joints. In: CONTROL OF THE SEMI-RÍGID BEHAVIOUR OF CIVIL ENGINEERING STRUCTURAL CONNECTIONS, COST C1, 1998. Innsbruck, april 1998.

VIRDI, K.S. et al. (1998). Semi-rigid frame analysis using rigorous and simplified methods. In: CONTROL OF THE SEMI-RÍGID BEHAVIOUR OF CIVIL ENGINEERING STRUCTURAL CONNECTIONS, COST C1 INTERNATIONAL CONFERENCE, 1998. Cost C1: Proceedings. Liege, Belgium. p. 75-84. 